CLOTILDE ASSIS OLIVEIRA

\title{
CARGA DE TRABALHO DO NUTRICIONISTA CLÍNICO: ESTUDO DE TEMPO E MOVIMENTO CONTÍNUO EM UNIDADES DE INTERNAÇÃO HOSPITALAR
}

Tese apresentada ao Programa de Pós-Graduação em Gerenciamento em Enfermagem da Escola de Enfermagem da Universidade de São Paulo para obtenção do título de Doutor em Ciências

Área de concentração: Fundamentos e Práticas de Gerenciamento em Enfermagem e em Saúde

Orientadora: Prof. ${ }^{a}$ Dr. ${ }^{a}$ Raquel Rapone Gaidzinski

\section{VERSÃO CORRIGIDA}

A versão original encontra-se disponível na Biblioteca da Escola de Enfermagem da Universidade de São Paulo e na Biblioteca Digital de Teses e Dissertações da Universidade de São Paulo.

\section{São Paulo}


AUTORIZO A REPRODUÇÃO E DIVULGAÇÃO TOTAL OU PARCIAL DESTE TRABALHO, POR QUALQUER MEIO CONVENCIONAL OU ELETRÔNICO, PARA FINS DE ESTUDO E PESQUISA, DESDE QUE CITADA A FONTE.

Assinatura: Data:

\section{Catalogação na Publicação (CIP)}

Biblioteca "Wanda de Aguiar Horta"

Escola de Enfermagem da Universidade de São Paulo

Oliveira, Clotilde Assis

Carga de trabalho do nutricionista clínico: estudo de tempo e movimento contínuo em unidades de internação hospitalar / Clotilde Assis Oliveira. São Paulo, 2016.

$274 \mathrm{p}$.

Tese (Doutorado) - Escola de Enfermagem da Universidade de São Paulo.

Orientadora: Prof. ${ }^{\text {a }}$ Dr. ${ }^{\text {a }}$ Raquel Rapone Gaidzinski

Área de concentração: Fundamentos e Práticas de Gerenciamento em Enfermagem e em Saúde

1. Carga de trabalho. 2. Recursos humanos. 3. Nutrição. 4. Serviço hospitalar de nutrição. I. Título. 
Nome: Clotilde Assis Oliveira

Título: Carga de trabalho do nutricionista clínico: estudo de tempo e movimento contínuo em unidade de internação hospitalar.

Tese apresentada ao Programa de Pós-Graduação em Gerenciamento em Enfermagem da Escola de Enfermagem da Universidade de São Paulo para obtenção do título de Doutor e Ciências.

Aprovado em:

Banca examinadora

Prof. Dr. Instituição:

Julgamento: Assinatura:

Prof. Dr. Instituição:

Julgamento:

Assinatura:

Prof. Dr. Instituição:

Julgamento: Assinatura:

Prof. Dr. Instituição:

Julgamento: Assinatura:

Prof. Dr. Instituição:

Julgamento: Assinatura: 



\section{DEDICATÓRIA}

Dedico esta tese aos nutricionistas que, de maneira corajosa e descontraída, aceitaram participar desta pesquisa e a todos aqueles que buscam incessantemente um novo jeito de pensar e agir com qualidade no trabalho. 



\section{AGRADECIMENTOS}

É com muita alegria que expresso aqui meu sincero agradecimento a todos aqueles que me acompanharam durante essa jornada e, de alguma forma, contribuíram neste trabalho.

Como em toda caminhada, há sempre desafios, surpresas, tristezas e alegrias. Comigo não foi diferente. Mas, se eu pudesse resumir em uma frase todo o trabalho desenvolvimento nesta tese, diria: uma combinação linda de experiências e emoções vividas, informações adquiridas, leituras e imaginações.

Este trabalho não teria se tornado realidade sem a colaboração de muitas pessoas, as quais agradeço neste momento.

À querida Prof. ${ }^{a}$ Dr. ${ }^{a}$ Raquel Rapone Gaidzinski, que me aceitou sem restrições e conduziu a orientação com muito amor, carinho, alegria, sabedoria e perspicácia. Não tenho palavras para agradecer o tempo dedicado, o conhecimento compartilhado $\mathrm{e}$ as boas risadas que sempre estiveram presentes em nossos encontros. Agradeço a oportunidade de vivenciar a interdisciplinaridade, de forma natural e estimulante, em todas as etapas do desenvolvimento deste trabalho.

Às professoras, Dr. ${ }^{\text {a }}$ Fernanda Fugulin e Dr. ${ }^{a}$ Rosa Wanda Diez-Garcia, pelas considerações e sugestões feitas no exame de qualificação.

Às colegas, enfermeiras e nutricionistas, que participaram na condição de juízas e muito contribuíram na etapa de validação do instrumento. Pelos resultados do estudo piloto e da pesquisa propriamente dita dá para imaginar o quanto vocês contribuíram!

Às chefias dos Serviços de Nutrição e aos nutricionistas dos hospitais estudados. Sem a anuência e o consentimento de vocês não seria possível executar o projeto.

Agradeço à Fundação de Amparo à Pesquisa do Estado de São Paulo (FAPESP) pelo auxílio financeiro (Processo n.ำ 2014/13150-3). Partes dos 
resultados obtidos nesta tese foram decorrentes da minha participação no projeto "Dimensionamento de recursos humanos em assistência nutricional hospitalar"

.Ao Sr. Raul Gaidzinski, Ricardo Góes e Bernardo Santos pelas contribuições no tratamento e análise dos dados.

Às colegas que conheci nas disciplinas, aos professores e funcionários do Programa de Pós-Graduação em Gerenciamento em Enfermagem da Escola de Enfermagem da USP. Agradeço a cordialidade e acolhida recebidas. Vocês merecem meus parabéns!

Aos servidores técnicos e docentes do Centro de Ciências da Saúde e da Pró-Reitoria de Pós-Graduação da Universidade Federal do Recôncavo da Bahia, que autorizaram o horário especial para servidor estudante e o afastamento integral para qualificação profissional.

Às colegas da área de Práticas de Cuidado em Saúde, que continuam comigo na UFRB e àqueles que seguiram para outras universidades, mas que não serão esquecidos.

À eterna coordenadora, Márcia Oliseski, que acompanhou meus primeiros passos enquanto profissional e me apresentou a Resolução CFN n. 380/2005 no ano da sua publicação.

A todos os meus amigos e parentes, por entenderem a minha ausência nesses últimos anos, especialmente, nos últimos meses.

À Julieta, vizinha "uspiana" e amiga, com quem me afeiçoei e vivi momentos intensos e inesquecíveis. Espero poder encontrá-la outras vezes, na Bahia, em São Paulo ou na Colômbia.

Ao meu cunhado querido, Nimish, que mesmo à distância torce pelo sucesso do trabalho e me presenteou com o livro, Achieving Excellence: Cinical Staffing for Today and Tomorrow, importante referência que tive que buscar fora do Brasil, porque não encontrei no acervo das bibliotecas brasileiras. 
À querida Marisa, meu anjo da guarda, por compartilhar comigo os momentos felizes e os mais difíceis, pela acolhida calorosa e por tudo o que tenho aprendido ao longo desses dez anos de convivência.

Aos meus sogros, pelo amor, carinho e amizade. Mesmo que estejamos distantes, estaremos sempre perto.

Ao meu esposo pela compreensão, paciência, companheirismo e verdadeiro amor.

Aos meus irmãos, pela amizade, confiança e bom humor. Adoro vocês do jeito diferente que cada um é!

Aos meus pais, pelo amor, carinho e suporte que me deram nessa jornada e durante a vida.

À energia do "universo que conspira a nosso favor"! 

O homem é a medida de todas as coisas, das coisas que são, enquanto são, das coisas que não são, enquanto não são.

(Protágoras) 

Oliveira CA. Carga de trabalho do nutricionista clínico: estudo de tempo e movimento contínuo em unidades de internação hospitalar [tese]. São Paulo: Escola de Enfermagem, Universidade de São Paulo; 2016.

\section{RESUMO}

Introdução: O planejamento da força de trabalho em saúde tem sido referido como um dos principais instrumentos para a efetividade do cuidado. Entretanto, na área de nutrição clínica, os estudos ainda são escassos. Diante dessa constatação, surge a necessidade de pesquisas que possam trazer contribuições científicas, no sentido de preencher as lacunas existentes. Objetivo: Propor parâmetros de referência para o dimensionamento dos nutricionistas clínicos em unidades de internação hospitalar e compará-los com os parâmetros estabelecidos pela Resolução Conselho Federal de Nutricionistas ํo. 380 de 2005. Método: Pesquisa aplicada, de campo, metodológica, descritiva, com abordagem quantitativa, realizada em três instituições hospitalares públicas de boas práticas em nutrição, localizadas no município de São Paulo. Para a identificação da carga de trabalho foi empregado o estudo de tempo movimento contínuo, com observação de 19 nutricionistas clínicos, durante a jornada de trabalho. Selecionaram-se 24 dias típicos de trabalho para observação sistemática dos profissionais. $O$ instrumento de medida da carga de trabalho foi construído especificamente para o estudo, validado e verificada a sua aplicabilidade na população-alvo. A análise dos dados envolveu medidas de tendência central e de variabilidade. Para comparação entre as médias, aplicou-se o teste $t$-Student, ao nível de significância de 5\%. Resultados: Foram realizadas 3931 observações. Os nutricionistas despenderam durante a jornada de trabalho: $72,8 \%$ em intervenções (9,5\% em cuidado direto e $63,3 \%$ em cuidado indireto), $0,6 \%$ em atividades associadas, $9,1 \%$ em atividades pessoais, $0,6 \%$ em ausências, $11,8 \%$ em deslocamento, $2,6 \%$ em espera, $0,6 \%$ em reuniões administrativa e em $1,9 \%$ do tempo não houve observação. O tempo médio de assistência utilizado para atender os pacientes, nas seis horas, correspondeu a 7,6 minutos, no nível de atendimento primário, 16,1 minutos no secundário e 28,6 minutos no terciário, que equivale a uma proporção de pacientes por nutricionista de 48:1, 22:1 e 13:1, respectivamente. A carga média de trabalho, 360 minutos, correspondeu a 17,4 minutos. As proporções de pacientes por nutricionistas obtidas nesta investigação foram inferiores às preconizadas e estatisticamente significantes. Conclusão: Os resultados apresentados neste estudo avançam o conhecimento na área de nutrição clínica em dois aspectos. Primeiro, ao fornecer dados sobre o processo de trabalho dos nutricionistas clínicos, as intervenções/atividades mais representativas realizadas pelos nutricionistas clínicos em unidades de internação hospitalar e o tempo médio despendido por estes profissionais. $O$ segundo aspecto refere-se à obtenção da carga média de trabalho, parâmetro importante para o cálculo do quadro de nutricionistas clínicos, em unidades de internação hospitalar.

PALAVRAS-CHAVE: Carga de trabalho. Estudos de tempo e movimento. Recursos humanos em Nutrição. Serviço hospitalar de nutrição. 

Oliveira CA. Workload of clinical dietitian: continuous observation time motion study in inpatient care services [thesis]. São Paulo: Escola de Enfermagem, Universidade de São Paulo; 2016.

\begin{abstract}
Introduction: Health workforce planning is considered as a main tool for health care effectiveness. In spite of this, studies applying planning in the Clinical Nutrition area are still scarce. This fact demands for research that may fill the knowledge vacuum through scientific contributions. Objective: To propose reference parameters for measuring staffing needs of clinical dietitians in hospital units, in comparison to the established parameters stated by Resolution CFN 380 from 2005. Methods: Descriptive applied field research, using a quantitative approach, in three public hospitals considered as sites of good practices in nutrition in Sao Paulo city. A continuous time and motion study was used to measure the workload, through observation of the daily work of 19 clinical dietitians. This systematic observation was performed through 24 typical working days. The workload measurement tool was purposefully designed for this study and its validity and appropriateness to the specific target population was verified beforehand. Data analysis used central tendency and variance measurements, applying t-Student tests at the $5 \%$ significance level. Results: A total of 3931 observations were performed. During the workday the dietitians spent: $72.8 \%$ in interventions $(9.5 \%$ in direct care and $63.3 \%$ in indirect care), $0.6 \%$ in unit-related activity, $9.1 \%$ in personal activities, $0.6 \%$ in absence, $11.8 \%$ in displacement, $2.6 \%$ in standby time, $0.6 \%$ in administrative meetings and in $1.9 \%$ was not observed. The mean care time used to assist patients in six hours corresponded to 7.6 minutes in the primary care level, 16.1 minutes in the secondary and the tertiary 28.6 minutes, which is equivalent to dietitian-to-patient ratio of 48: 1, 22: 1 and 13: 1, respectively. The mean workload of the dietitian staff corresponded,to 17.4 minutes, in 360 minutes. The dietitian-to-patient ratio was lower than recommended and statistically significant.. The parameters obtained in this research showed are lower than recommended, with statistically significant differences. Conclusion: The study results are useful to enhance knowledge in two areas: firstly, it provides data about the dietitian work process, most significant interventions performed in inpatient care and the mean time spent by these professionals. The second aspect refers to the workload identification of dietitian staff, an important parameter for the calculation the dietitian staff, in inpatient care services.
\end{abstract}

KEYWORDS: Food nutrition, hospital. Nutrition personnel. Time and motion studies. Workload. 



\section{LISTA DE ILUSTRAÇÕES}

Figura 1 - Procedimentos metodológicos realizados para o alcance dos objetivos da pesquisa. .63

Figura 2 - Taxonomia das intervenções propostas pelos juízes em junho de 2014 .96

Figura 3 - Taxonomia das atividades propostas pelos juízes em junho de 2014......97

Figura 4 - Página inicial da folha de registro (frente) 104

Figura 5 - Página inicial da folha de registro (verso) 105

Figura 6 - Tela inicial do aplicativo cronômetro 260

Figura 7 - Processo de Mensuração do tempo 261

Figura 8 - Processo de anotação da folha de registro (frente) 262

Figura 9 - Processo de transmissão dos dados. 263

Figura 10 - Processo de anotação da folha de registro (verso) 264 



\section{LISTA DE GRÁFICOS}

Gráfico 1 - Intervalos de confiança de 95\% dos tempos médios, por turno no estudo piloto, em agosto de 2014 109

Gráfico 2 - Tamanho da amostra $\mathrm{N}$ para $\mathrm{k}$ atividades/intervenções de uma distribuição multinomial com intervalo de confiança de $95 \%$ e erro $=5 \%$ 110

Gráfico 3 - Distribuição percentual do tempo despendido pelos nutricionistas em intervenções de cuidado direto e de cuidado indireto, atividades associadas, atividades pessoais, tempo de espera, deslocamento, ausência e participar de reunião administrativa, de acordo com o turno, entre setembro e dezembro de 2014 126

Gráfico 4 - Distribuição percentual do tempo despendido em intervenções de cuidado direto e cuidado indireto, atividades associadas, atividades pessoais, reunião administrativa, espera, deslocamento, ausência e sem observação, segundo a unidade hospitalar, entre setembro e dezembro de 2014

Gráfico 5 - Distribuição percentual do tempo despendido em cada intervenção, com representatividade $\geq 1 \%$, no total dos três hospitais, entre setembro e dezembro de 2014 131

Gráfico 6 - Distribuição percentual do tempo despendido em cada atividade, com representatividade $\geq 1 \%$, no total dos três hospitais, entre setembro e dezembro de 2014 132

Gráfico 7 - Distribuição percentual das intervenções e atividades realizadas pelos nutricionistas clínicos em São Paulo, entre setembro e dezembro de 2014 133 



\section{LISTA DE QUADROS}

Quadro 1 - Publicações sobre dimensionamento do quadro de nutricionistas clínicos em hospitais, de acordo com o ano, título e tipo, selecionadas em março de 2014..50

Quadro 2 - Características dos hospitais estudados nos meses de setembro a dezembro de 2014

Quadro 3 - Critérios para classificação dos níveis de assistência de nutrição .76

Quadro 4 - Critérios para classificação dos níveis de assistência de nutrição segundo o resultado do diagnóstico educacional.

Quadro 5 - Taxonomia das intervenções de nutrição clínica e atividades validadas pelos juízes em junho de 2014 .98

Quadro 6 - Intervenções de nutrição clínica que ocorreram durante o estudo piloto em junho de 2014

Quadro 7 - Distribuição das atividades relacionadas a cada intervenção, de acordo com o tipo de cuidado, entre setembro e dezembro de 2014 113

Quadro 8 - Comparação dos tempos médios observados com os tempos médios preconizados pela Resolução CFN no 380 de 2005, segundo o nível de atendimento nutricional, entre setembro e dezembro de 2014 142

Quadro 9 - Comparação entre o tempo requerido por paciente e o quantitativo de pacientes por nutricionista, conforme o nível de atendimento de nutrição, obtido na pesquisa e o preconizado pela resolução CFN no. 380/2005 



\section{LISTA DE TABELAS}

Tabela 1 - Caracterização dos juízes participantes da oficina de trabalho realizada em junho de 2014

Tabela 2 - Análise da distribuição das frequências e do tempo médio das intervenções/atividades observadas no estudo piloto

Tabela 3 - Quantidade das amostras previstas por turno observado nas instituições hospitalares entre setembro e dezembro de 2014

Tabela 4 - Caracterização dos nutricionistas observados entre setembro e dezembro de 2014

Tabela 5 - Distribuição do quantitativo de nutricionistas clínicos observados por turno e hospital, no período entre setembro e dezembro de 2014 120

Tabela 6 - Características das UAN observadas nos meses de setembro 121

Tabela 7 - Quantidade de pacientes submetidos a intervenções de cuidado direto, segundo o nível de atendimento de nutrição, o turno e o hospital, entre setembro e dezembro de 2014 1222

Tabela 8 - Distribuição do quantitativo de pacientes atendidos pelos nutricionistas, segundo o grupo etário, entre setembro e dezembro de 2014

Tabela 9- Distribuição das amostradas coletadas e do tempo total observado no período de setembro a dezembro de 2014 123

Tabela 10 - Distribuição do tempo médio despendido em intervenções/atividades realizadas pelos nutricionistas clínicos, no período matutino, entre setembro e dezembro de 2014 124

Tabela 11 - Distribuição do tempo médio despendido nas intervenções/atividades realizadas pelos nutricionistas clínicos, no período vespertino, entre setembro e dezembro de 2014

Tabela 12 - Distribuição da frequência e do tempo despendido nas intervenções/atividades realizadas pelos nutricionistas clínicos, nas três unidades hospitalares 
Tabela 13 - Distribuição do tempo despendido nas intervenções, atividades associadas, atividades pessoais e outras realizadas pelos nutricionistas clínicos, segundo a instituição hospitalar, entre setembro e dezembro de 2014 129

Tabela 14 - Distribuição percentual do tempo observado em intervenções de cuidados diretos de nutricionistas em três hospitais, segundo a intervenção realizada e a classificação do nível de atendimento, entre setembro e dezembro de 2014... 134 Tabela 15 - Distribuição do tempo observado em intevenções de cuidados indiretos de nutricionistas em três unidades hospitalares, segundo hospital e intervenção realizada, entre sembro e dezembro de 2014 136

Tabela 16 - Tempo produtivo dos nutricionistas clínicos, nos três hospitais, entre setembro e dezembro de 2014 138

Tabela 17 - Demonstrativo do tempo despendido pelos nutricionistas clínicos em intervenções de cuidados diretos, segundo o nível de atendimento nutricional, nas três unidades hospitalares, entre setembro e dezembro de 2014 139

Tabela 18 - Demonstrativo do tempo despendido pelos nutricionistas clínicos em intervenções de cuidados diretos, com acréscimo do valor rateado dos tempos referentes às atividades pessoais, deslocamento e espera, segundo o nível de atendimento nutricional, nas três unidades hospitalares 140

Tabela 19 - Demonstrativo do tempo despendido pelos nutricionistas clínicos em intervenções de cuidados diretos, com acréscimo dos tempos referentes às atividades associadas e valor proporcional de cuidados indiretos, segundo o nível de atendimento nutricional, $\mathrm{n}$ nas três unidades hospitalares, entre setembro e dezembro de 2014 


\section{LISTA DE SIGLAS E ABREVIATURAS}

ADA

AHP/HCS

AND

ASBRAN

CFN

EMTN

ESPEN

FTE

FELANPE

ICDA

IDNT

NCM

NCPM

NIC

NKF KDOQI Initiative

SND

SUS

UAN
National Kidney

American Dietetic Association

Allied Health Care Professionals/Healthcare Services

Academy of Nutrition and Dietetics

Associação Brasileira de Nutricionistas

Conselho Federal de Nutricionistas

Equipe Multiprofissional de Terapia Nutricional

European Society for Clinical Nutrition and Metabolism

Full-time equivalente

Federação Latino-americana de Terapia Nutricional, Nutrição Clínica e Metabolismo

International Confederation of Dietetic Associations

International Dietetics \& Nutrition Terminology

Nutrition Care Model

Nutrition Care Process and Model

Nursing Intervention Classification

Serviço de Nutrição e Dietética

Sistema Único de Saúde

Unidade de Alimentação e Nutrição 



\section{SUMÁRIO}

1 INTRODUÇÃO

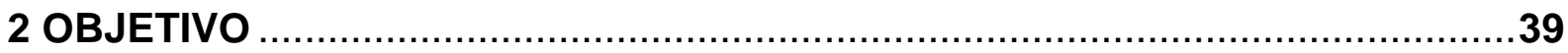

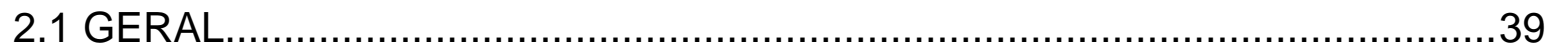

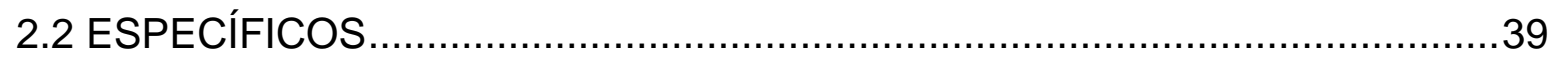

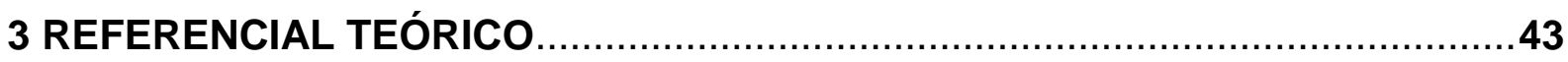

3.1 O CUIDADO ALIMENTAR E NUTRICIONAL NO AMBIENTE HOSPITALAR .43

3.2 A SISTEMATIZAÇÃO DO CUIDADO ALIMENTAR E NUTRICIONAL ............45

3.3 MÉTODOS DE DIMENSIONAMENTO DE NUTRICIONISTAS ......................48

3.4 MÉTODOS PARA MENSURAÇÃO DA CARGA DE TRABALHO ..................56

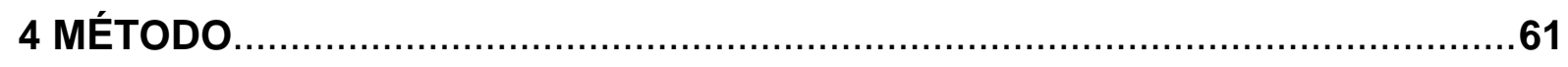

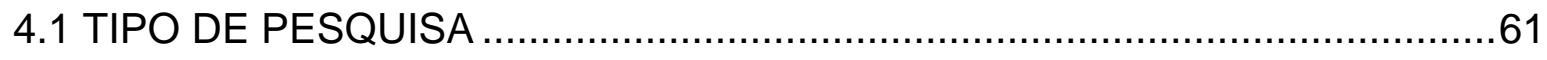

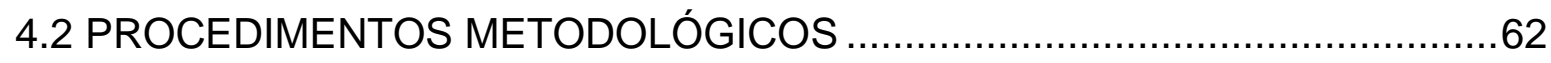

4.2.1 Primeira Etapa: identificação, classificação e validação das intervenções e atividades desenvolvidas pelos nutricionistas clínicos..............................63

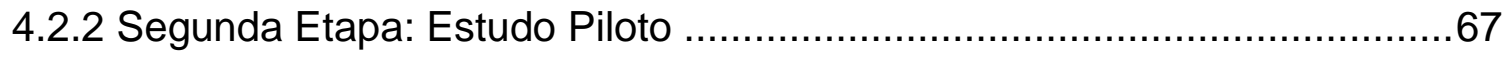

4.2.3.Terceira Etapa: Pesquisa de Campo......................................................68

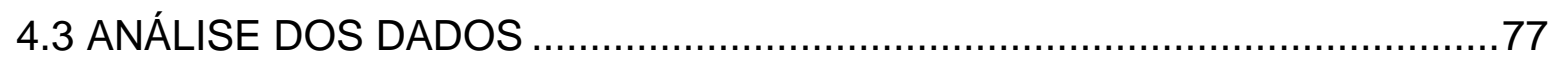

4.3.1 Organização dos dados coletados ……………..................................77

4.3.2 Obtenção dos padrões de referência para o cálculo da carga de trabalho

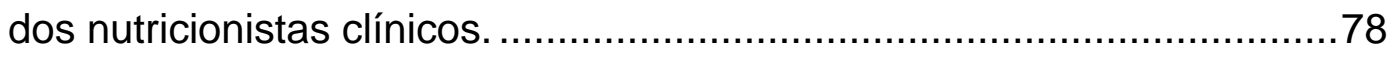

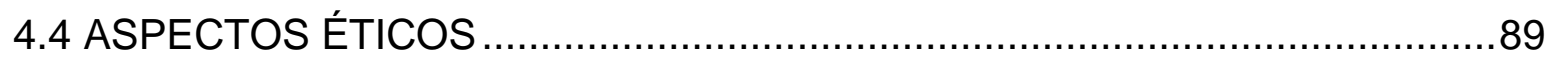

5 RESULTADOS

5.1 INSTRUMENTO DE MEDIDA DA CARGA DE TRABALHO .........................93

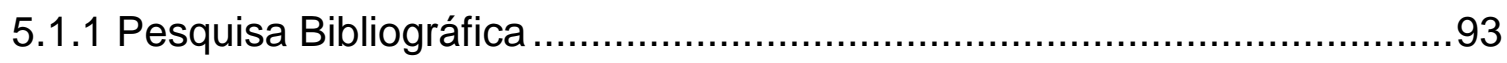


5.1.2 Classificação e mapeamento das intervenções e atividades 94

5.1.3 Oficina de trabalho 94

5.1.4 Construção do instrumento de medida da carga de trabalho 103

5.2 ESTUDO PILOTO . 105

5.2.1 Tempo médio das intervenções/atividades e tamanho da amostra ......... 106

5.2.2 Verificação da aplicabilidade do documento 111

5.3 MENSURAÇÃO DO TEMPO DESPENDIDO NAS INTERVENÇÕES E ATIVIDADES. 118

5.3.1 Caracterização dos participantes. 118

5.3.2 Caracterização das unidades de internação estudadas 120

5.4 DISTRIBUIÇÃO DAS FREQUÊNCIAS E O CÁLCULO DO TEMPO DAS INTERVENÇÕES/ATIVIDADES, SEGUNDO O NÍVEL DE ATENDIMENTO DE NUTRIÇÃO 123

5.5. COMPARAÇÃO DOS PARÂMETROS OBTIDOS NA PESQUISA COM OS PRECONIZADOS PELA RESOLUÇÃO CFN №. 280/2005 ${ }^{(7)}$. 142

6. DISCUSSÃO 147

6.1 VALIDAÇÃO DAS INTERVENÇÕES E ATIVIDADES 148

6.2 CONSTRUÇÃO DO INSTRUMENTO 149

6.3 CARACTERIZAÇÃO DOS PARTICIPANTES 154

6.4 CARACTERIZAÇÃO DAS UNIDADES 155

6.5. FREQUÊNCIAS DAS INTERVENÇÕES 156

6. 5.1 Cuidado direto 156

6.5.2 Cuidado indireto 163

6.5.3 Atividades associadas ao trabalho 166

6.5.4 Atividades pessoais 167

6.5.5 Outras atividades: Espera, Ausência, Deslocamento e Participação em reunião administrativa 167

6.6 DISTRIBUIÇÃO DAS INTERVENÇÕES 169 
6.7 PRODUtIVIDADE, TEMPO EFETIVO DE TRABALHO E CARGA DE

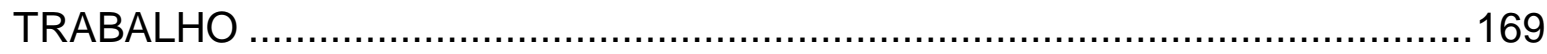

6.8 COMPARAÇÃO COM OS PARÂMETROS NUMÉRICOS ESTABELECIDOS

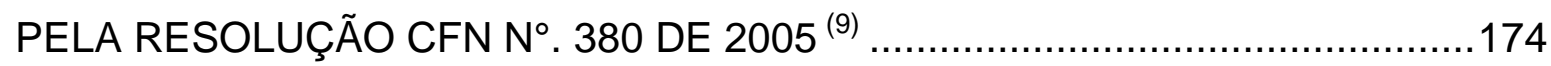

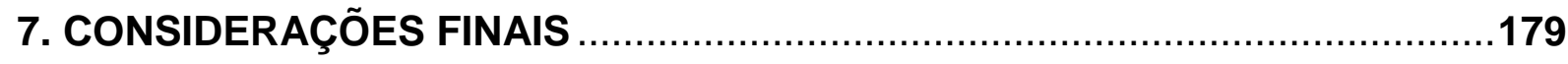

7.1 PERSPECTIVAS E LIMITES DA PESQUISA …....................................179

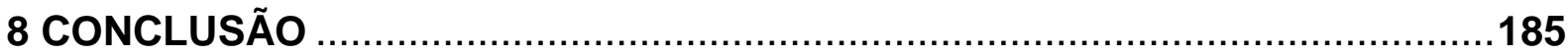

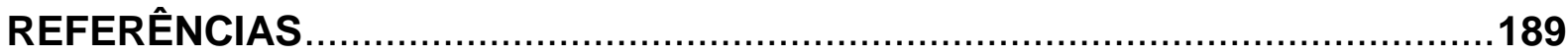

APÊNDICE A - INSTRUMENTO DE CARACTERIZAÇÃO DOS JUÍZES ..............203 APÊNDICE B - LISTA DE INTERVENÇÕES DE NUTRIÇÃO CLÍNICA E ATIVIDADES, SEGUNDO A CLASSIFICAÇÃO DA NIC …............................205 APÊNDICE C - CARTA AOS JUÍZES PARA ORIENTAR A AVALIAÇÃO DAS

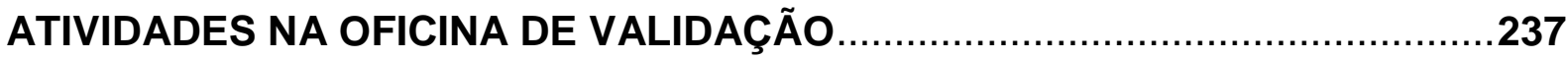
APÊNDICE D - INSTRUMENTO DE CARACTERIZAÇÃO DOS NUTRICIONISTAS

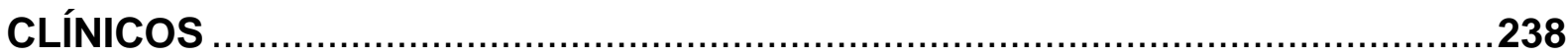

APÊNDICE E - INSTRUMENTO DE CARACTERIZAÇÃO DOS HOSPITAIS.......239 APÊNDICE F - TERMO DE CONSENTIMENTO LIVRE E ESCLARECIDO_..........241 APÊNDICE G - QUADRO COMPARATIVO DA TAXONOMIA …......................244 APÊNDICE H - INSTRUÇÃO PARA O USO DO CRONÔMETRO ………….........260 ANEXO 1 - PARECER DO CÔMITE DE ÉTICA EM PESQUISA ….......................267 

1 INTRODUÇÃO 



\section{INTRODUÇÃO}

As instituições hospitalares são unidades de produção de cuidado de saúde ${ }^{(1)}$, "responsáveis pela assistência aos usuários com condições agudas ou crônicas, que apresentem potencial de instabilização e de complicações de seu estado de saúde" (2).

Para conseguir cumprir com a sua finalidade essencial e desenvolver condições favoráveis à prestação de serviços de saúde, as instituições hospitalares utilizam-se de uma diversidade de profissionais e de recursos tecnológicos específicos ${ }^{(1,2)}$.

Na prática, entretanto, um grande desafio enfrentado pelo segmento hospitalar, em todo o mundo, é equacionar os custos, identificados como o maior componente do aumento global dos gastos em saúde ${ }^{(3,4)}$. No Brasil, esse problema ganha maior dimensão devido à transição demográfica, epidemiológica e nutricional mais acelerada ${ }^{(5-7)}$.

Em outra perspectiva, o tema tem sido objeto de preocupação por parte dos profissionais de saúde, visto que, os efeitos do controle e redução de custos pode afetar a qualidade na prestação dos serviços de saúde, especialmente, no que se refere à saúde do trabalhador e segurança do paciente ${ }^{(8)}$.

Vale salientar, entretanto, que a reflexão crítica acerca dos fatores responsáveis pelos desperdícios e ineficiências no processo de produção dos serviços de saúde, se constitui o primeiro passo em direção à utilização de um sistema de controle gerencial eficaz de garantia da qualidade ${ }^{(8)}$.

Nesse sentido, o desafio posto pela realidade é o de compatibilizar a demanda com a disponibilidade dos serviços, de maneira que possibilitem atender as necessidades dos usuários, a incorporação tecnológica e os objetivos das instituições hospitalares.

Para atingir a meta de redução de custos hospitalares, o Serviço de Nutrição e Dietética (SND), também denominado Unidade de Alimentação e Nutrição (UAN) ${ }^{(9)}$, 
tem sido frequentemente visto como um setor onde os cortes orçamentais terão um impacto mínimo ${ }^{(10)}$.

Essa tendência ganha mais força porque a prestação de serviços de fornecimento de refeições hospitalares não se constitui atividade-fim. Ou seja, a UAN hospitalar se caracteriza como um serviço especializado cujas atividades dão suporte à atividade-fim ${ }^{(10)}$.

Contudo, é importante destacar uma particularidade das UAN hospitalares. Embora seu enfoque esteja centrado na produção de refeições, uma parcela do quadro de trabalhadores, representada pelos nutricionistas clínicos, está envolvida na consecução do objetivo final das instituições hospitalares.

Diante desse cenário, merece destaque as ações desenvolvidas pelo nutricionista clínico. Elas abrangem um conjunto integrado de intervenções e/ou atividades executadas conforme os níveis de complexidade do cuidado e os problemas de saúde apresentados por cada indivíduo ${ }^{(11)}$.

Com relação à prática profissional do nutricionista clínico em hospitais, dados oriundos de estudos nacionais sugerem que apesar dos avanços científicos na área de nutrição clínica, ainda há desafios ${ }^{(12-15)}$.

As dificuldades enfrentadas pelos profissionais relacionam-se, principalmente, à execução de ações de cuidado nutricional e envolvem a inclusão de atividades ligadas à produção de refeições e/ou administrativas da UAN, resultando na sobreposição de funções ${ }^{(12,13)}$; a falta de recursos materiais que dão suporte ao desenvolvimento das atividades assistenciais básicas ${ }^{(13,14)}$; e a falta de autonomia técnica ${ }^{(14,15)}$. Esses problemas tendem a repercutir de maneira desfavorável na qualidade da assistência nutricional.

Além disso, há evidências que corroboram a existência de um quantitativo insuficiente de nutricionistas clínicos em hospitais brasileiros. Quatro estudos $(12,14,17,18)$ fizeram menção a aspectos dessa natureza.

Os resultados obtidos por Carmo et al. ${ }^{(12)}$ mostraram uma média de 109 leitos por nutricionista. $O$ estudo foi realizado em dez hospitais da grande Florianópolis, dos quais foram entrevistados 20 nutricionistas. 
Em outro estudo, realizado em hospitais públicos de quatro estados brasileiros, Pernambuco, Rio de Janeiro, Rio Grande do Sul e Sergipe, a menor proporção encontrada entre o número de pacientes por nutricionista clínico foi de 50:1 e a maior alcançou 150:1. Outro aspecto importante a ser destacado é o fato de que todos os hospitais participantes desse estudo integravam o QualiSUS, programa do Ministério da Saúde que busca a qualificação do Sistema Único de Saúde ${ }^{(14)}$.

Almeida et al. ${ }^{(17)}$, ao realizar um comparativo entre o quadro de pessoal existente e o levantamento da necessidade por categoria profissional nas unidades hospitalares do Instituto Nacional de Câncer, evidenciaram um déficit de 56 nutricionistas clínicos nas unidades de internação e ambulatoriais.

Em outro estudo, realizado em 27 hospitais localizados em dois municípios do estado de São Paulo, verificou-se que a média de leitos por nutricionista foi de 38,2 (hospitais públicos) e 94,6 (hospitais privados), sendo esta diferença significativa. Já os resultados obtidos em cada uma dessas cidades, Campinas e Ribeirão Preto, a média encontrada foi de 82,4 e 87,1 leitos por nutricionista, respectivamente ${ }^{(18)}$.

Embora não haja menção explícita dos autores ${ }^{(14,17,18)}$ quanto aos parâmetros utilizados para avaliar o déficit de nutricionistas, acredita-se que o levantamento considerou os parâmetros numéricos de referência para o dimensionamento de nutricionistas em hospitais, preconizados pela Resolução do Conselho Federal de Nutricionistas (CFN), no. 380 de 2005, que estabelece a proporção de pacientes por nutricionista, sendo 60:1 (nível primário), 30:1 (nível secundário) e 15:1 (nível terciário) ${ }^{(9)}$.

No entanto, convém destacar que não foram encontrados estudos que avaliassem a relação causal entre uma maior proporção de nutricionistas e a efetividade das práticas de cuidado nutricional no Brasil. Consequentemente, isso faz com que os parâmetros numéricos estabelecidos ${ }^{(9)}$ não ofereçam dados suficientes para que seja possível avaliar sua adequação.

Face ao exposto, quaisquer conclusões sobre o quantitativo de nutricionistas clínicos, necessário para a prestação da assistência nutricional hospitalar, são limitadas pela escassez de estudos. 
É nesse contexto que se inicia a discussão acerca do dimensionamento de nutricionistas clínicos no âmbito hospitalar. De acordo com Biesemeier ${ }^{(19)}$, as dificuldades para predizer a necessidade de pessoal são conhecidas e estão relacionadas à complexidade crescente dos hospitais e à ausência de definições objetivas daquilo que se espera em termos de pessoal de nutrição clínica. Enquanto os administradores tendem a focar o impacto financeiro do excesso de pessoal, falta às chefias das UAN justificar a necessidade de pessoal, tomando como referência o impacto financeiro dos resultados do cuidado.

Segundo essa mesma autora ${ }^{(19)}$, é imprescindível identificar e analisar as características e diversidades das atividades desenvolvidas pelos nutricionistas clínicos e especialistas que atuam junto às Equipes Multiprofissionais de Terapia Nutricional (EMTN). A partir dessas informações, poderá ser possível propor um método adequado ao dimensionamento dessa força de trabalho.

Diante da falta de estudos sobre a carga de trabalho do nutricionista clínico, fator crítico para o dimensionamento de recursos humanos, o problema que motivou o presente estudo pode ser resumido em quatro questões:

1) Quais são as intervenções/atividades prestadas pelos nutricionistas clínicos aos pacientes hospitalizados, de acordo com o nível de assistência nutricional?

2) Qual o tempo padrão médio despendido nessas intervenções/atividades, de acordo com o nível de assistência nutricional?

3) Qual o tempo efetivo de dedicação ao trabalho dos nutricionistas clínicos?

4) Os parâmetros estabelecidos pela Resolução CFN ${ }^{(9)}$, que servem de orientação para quantificar o quadro de nutricionistas clínicos, estão adequados à prestação de cuidado aos pacientes internados? 


\section{OBJETIVO}

\subsection{GERAL}

- Propor parâmetros de referência para o dimensionamento da carga de trabalho dos nutricionistas clínicos em unidades de internação hospitalar.

\subsection{ESPECÍFICO}

- Comparar os parâmetros numéricos encontrados neste estudo, segundo o nível de atendimento nutricional, com os estabelecidos na Resolução CFN no. 380 de 2005. 


\section{REFERENCIAL TEÓRICO}

\subsection{O CUIDADO ALIMENTAR E NUTRICIONAL NO AMBIENTE HOSPITALAR}

Diversas pesquisas científicas apontam que a evolução clínica dos pacientes internados depende da adequada ingestão de água, energia e nutrientes (20-29). Apesar disso, um número expressivo de pacientes está em situação de risco nutricional ou mesmo mal nutrido no momento da admissão hospitalar, enquanto outros desenvolvem a malnutrição durante a internação ${ }^{(30-39)}$.

Embora o termo malnutrição não tenha uma definição universalmente aceita, é considerado pela European Society for Clinical Nutrition and Metabolism (ESPEN) "um estado de nutrição em que existe deficiência ou excesso (desequilíbrio) entre a oferta de nutrientes e de energia e a exigência do corpo para garantir a manutenção, crescimento e funções específicas das células" ${ }^{40)}$.

De acordo com Stratton, Green e Elia ${ }^{(41)}$, o estado de malnutrição pode variar em termos de gravidade, causa e tipo de nutriente, logo, pode estar relacionado tanto à subnutrição quanto à supernutrição.

No ambiente hospitalar, particularmente, o termo malnutrição é frequentemente usado como sinônimo de subnutrição ou desnutrição e tem sido objeto de vários estudos ${ }^{(30-37,42)}$. A desnutrição pode ocorrer como consequência da deficiência na ingestão dietética, má absorção, aumento das necessidades ou de excessiva perda de nutrientes associadas à doença ou a partir de uma combinação destes fatores (43).

De acordo com Jackson ${ }^{(44)}$, provavelmente, o fator etiológico mais importante da desnutrição relacionada à doença é o reduzido consumo alimentar, resultante de alterações nas citocinas, glicocorticoides e fatores de crescimento semelhantes à insulina (somatomedinas). 
Por outro lado, deve-se considerar que a inapetência pode ser agravada por fatores circunstanciais como alterações psicológicas e comportamentais, novo ambiente e intervenções medicamentosas ${ }^{(45)}$. Além disso, a desnutrição também pode estar relacionada a fatores iatrogênicos, isto é, "precipitada e/ou perpetuada pelas ações (ou omissões) da equipe de saúde" (45).

A iatrogenia do cuidado da equipe de saúde pode envolver desde situações de omissão (massa corporal e estatura não aferidos, consumo alimentar não avaliado) $(34,38-40,46,47)$ e imperícia (uso prolongado de soros) ${ }^{(33,45)}$ até situações de negligências ou abusos por parte da gestão de pessoas (divisão de responsabilidades e elevada rotatividade de pessoal) ${ }^{(45)}$. Todavia, esses fatores que podem ser facilmente detectados e corrigidos se atenção especial for dada ao cuidado nutricional.

Em todas essas as situações, a desnutrição é reconhecida como fator de risco para a morbimortalidade e está associada a complicações clínicas ${ }^{(47-55)}$, além de contribuir para o aumento do tempo de internação hospitalar ${ }^{(45,48,50)}$, maior incidência de complicações ${ }^{(49,52,53,55)}$, readmissão hospitalar ${ }^{(51)}$ e elevação dos custos envolvidos com o tratamento ${ }^{(51,56-58)}$.

Vale lembrar que a desnutrição não é a única desordem nutricional que afeta os pacientes internados. Outro motivo de preocupação consiste no aumento do número de internações hospitalares para o tratamento das doenças crônicas não transmissíveis, entre as quais se destaca a obesidade e suas comorbidades. Assim como a desnutrição, os desdobramentos das doenças crônicas se dão nos planos social e econômico ${ }^{(59)}$.

Entendendo que a alimentação hospitalar pode exercer um papel importante no tratamento das doenças (transmissíveis ou não) e agravos à saúde, é desnecessário destacar a importância do cuidado nutricional aos pacientes internados.

Baseado na definição de Brylinski ${ }^{(60)}$, o cuidado nutricional consiste em uma relação participativa entre o profissional e o paciente, que se desenvolve por meio da "avaliação do estado nutricional, identificação das necessidades ou problemas nutricionais, planejamento de objetivos de cuidado nutricional que preencham essas necessidades e implementação de atividades nutricionais". 
Contudo, esse termo não tem sido aceito por alguns autores porque remete a ideia de uma relação quase exclusiva entre a condição clínica e as necessidades nutricionais dos pacientes, o que pode gerar uma interpretação simplista da prática profissional.

De acordo com Parisenti, Copetti e Espínola ${ }^{(61)}$, o cuidado de nutrição envolve também os aspectos relacionados à alimentação, que podem favorecer o consumo alimentar e, ao mesmo tempo, reduzir o desperdício. A adequação dos utensílios e das características sensoriais das preparações servidas aliada à apresentação da refeição e cortesia do atendimento, por exemplo, devem ser consideradas como parte do cuidado.

Nessa perspectiva, Pedroso, Sousa e Salles ${ }^{(62)}$ chamam atenção para o uso da expressão cuidado alimentar e nutricional, que pode ser mais apropriado, uma vez que amplia a abrangência do cuidado para os aspectos relacionados à alimentação.

Portanto, embora a expressão "cuidado alimentar e nutricional" não seja reconhecida pela legislação que rege a profissão no Brasil, as autoras ${ }^{(62)}$ acreditam que ele poderá contribuir como estratégia para auxiliar a prática profissional do nutricionista que atua no contexto hospitalar. Neste sentido, por ser considerada tecnicamente mais adequada, será adotada no presente estudo a expressão "cuidado alimentar e nutricional".

\subsection{A SISTEMATIZAÇÃO DO CUIDADO ALIMENTAR E NUTRICIONAL}

De acordo com Merhy ${ }^{(63)}$, a organização do processo de trabalho oferece aos profissionais ferramentas tecnológicas que auxiliam o exercício da profissão, ao mesmo tempo em que criam um ambiente propício para o alcance de resultados.

Assim como ocorreu em outras disciplinas na área da saúde, incluindo a enfermagem ${ }^{(64)}$, fisioterapia ${ }^{(65)}$ e terapia ocupacional ${ }^{(66)}$, o reconhecimento da necessidade de adotar processos de cuidado foi identificado pela American Dietetic 
Association $(A D A)^{(67)}$, atualmente reconhecida como Academy of Nutrition and Dietetics (AND).

Nutrition Care Process and Model (NCPM) surgiu em 2003 como ação prioritária para a profissão cumprir com os objetivos do plano estratégico da $A N D$, os quais se destacam: aumentar a demanda e utilização dos serviços prestados pelos membros e capacitá-los para competir com sucesso em um ambiente de rápidas mudanças ${ }^{(67)}$. Desde então, os nutricionistas têm sido incentivados a incorporar o processo e o modelo de cuidado nutricional.

A AND define o Nutrition Care Process (NCP) como um método sistemático para resolução de problemas que os nutricionistas usam para pensar criticamente e tomar decisões frente aos problemas relatados e fornecer o cuidado nutricional seguro e eficaz ${ }^{(67)}$.

Já o Nutrition Care Model (NCM) é uma representação visual que reflete conceitos chave de cada etapa do processo do cuidado nutricional e ilustra o contexto em que o processo do cuidado nutricional é conduzido ${ }^{(67)}$.

As etapas para aplicação do NCP abrangem a avaliação do estado nutricional, o diagnóstico nutricional, a intervenção nutricional e o monitoramento e avaliação dos resultados. Embora haja interdependência entre essas quatro etapas não se trata de um processo linear ${ }^{(67)}$.

De acordo com a $A N D$, a triagem não se constitui uma etapa do processo de cuidado nutricional, por não se tratar de uma intervenção privativa do nutricionista. Contudo, apesar de não fazer parte do cuidado real, a triagem nutricional é reconhecida como um sistema de suporte extremamente importante para a identificação do risco nutricional, que permite o acesso ao processo de cuidado nutricional $^{(67,68)}$.

Usando uma estrutura centrada no paciente/cliente, o NCP torna claro o papel do nutricionista, os elementos da prática de nutrição e habilidades no ambiente em que elas ocorrem ${ }^{(68)}$.

O NCP utiliza uma estrutura de avaliação, que inclui metas e acompanhamento de resultados clínicos e comportamentais específicos, para melhorar a qualidade e 
eficácia dos cuidados de nutrição, utilizando as melhores evidências disponíveis para tomar decisões ${ }^{(69)}$.

Em 2008 a AND desenvolveu uma International Dietetics \& Nutrition Terminology (IDNT) que descreve as atribuições exclusivas do nutricionista em cada etapa do NCP. Essa iniciativa contribuiu para garantir uma articulação entre os nutricionistas com a natureza exata do problema de nutrição e, especificamente, descrever qual intervenção foi realizada, bem como as metas e abordagens, tendo como vantagens a melhoria da assistência ao paciente e a comunicação interdisciplinar ${ }^{(70)}$.

Várias edições têm sido publicadas com informações adicionais e atualizações de conteúdo referente a cada etapa do cuidado de nutrição. Cada termo tem um identificador único contendo cinco dígitos após o código alfanumérico da IDNT ${ }^{(71)}$.

O grupo da $A D N$ vem apoiando e incentivando a tradução e aplicação do $N C P$ e da IDNT em outros países, além de aceitar comentários de nutricionistas que estão usando estas ferramentas. Atualmente, os nutricionistas em muitos países têm mostrado grande interesse no NCP e estão buscando implementá-lo ${ }^{(71-77)}$.

Sobre a temática do processo de cuidado do paciente no Brasil, os resultados de uma pesquisa que avaliou a opinião da comunidade científica brasileira acerca de critérios para avaliar e monitorar o estado nutricional de pacientes hospitalizados, já sinalizavam para a necessidade de estabelecer protocolos para o cuidado nutricional e difundir sua utilização ${ }^{(78)}$, como elemento chave do processo de atenção nutricional em instituições hospitalares.

Baseados em procedimentos aceitos pela comunidade científica brasileira, Duchini, Jordão e Diez-Garcia ${ }^{(78)}$ propuseram um modelo de triagem para definição da complexidade do atendimento nutricional.

Com relação à disseminação de uma linguagem padronizada internacionalmente, entre os nutricionistas brasileiros, a que se destacar a participação da Associação Brasileira de Nutricionistas (ASBRAN), que publicou um "Manual Orientativo de Sistematização do Cuidado de Nutrição" ${ }^{(79)}$, em formato digital, disponível em seu sítio desde dezembro de 2014. 
Esse manual propõe orientar os profissionais para a prestação do cuidado alimentar e nutricional com foco no paciente e nos resultados, aproximando o NPC e a IDNT da realidade brasileira.

O esquema conceitual proposto pelos organizadores do manual inclui a triagem nutricional, os níveis de atendimento de nutrição, a avaliação do estado nutricional e metabólico, os diagnósticos de nutrição, a intervenção nutricional, o acompanhamento de nutrição, além da comunicação e gestão ${ }^{(79)}$.

Nesse contexto, merece destaque o tópico referente aos diagnósticos de nutrição. A padronização internacional de diagnósticos de nutrição, proposta pela $A N D$, está presente no "Manual Orientativo de Sistematização do Cuidado de Nutrição", sendo publicada na língua portuguesa ${ }^{(79)}$. Entretanto, não há informações sobre o procedimento de tradução, ou seja, se foi baseado em métodos padronizados.

Apesar do avanço, há aspectos que se colocam de forma prioritária e constituem desafios para os nutricionistas brasileiros e suas entidades de classe federal e regionais. O primeiro está relacionado à tradução e adaptação das terminologias internacionais, propostas pela $A N D$, para o idioma português. $O$ segundo se refere ao processo de institucionalização.

No entanto, o êxito dessa iniciativa da ASBRAN dependerá da vontade dos profissionais em incorporar uma linguagem padronizada internacionalmente e da existência de obrigatoriedade legal.

\subsection{MÉTODOS DE DIMENSIONAMENTO DE NUTRICIONISTAS}

Como definido pela International Confederation of Dietetic Associations $(I C D A)^{(80)}$, o nutricionista é a pessoa com qualificação em nutrição e dietética, reconhecida por autoridade (s) nacional (ais).

De acordo com a $I C D A^{(80)}$, o nutricionista aplica a ciência da nutrição para a alimentação e educação de indivíduos ou grupos na saúde e na doença. Para tanto, 
torna-se necessário também o desenvolvimento de habilidades administrativas e gerenciais.

Assim, pode-se dizer que, a profissão de nutricionista, como é conhecida hoje, tem crescido e diversificado as formas de atuação que abrange a ciência da nutrição e a arte da gestão ${ }^{(81)}$.

A pressão crescente pelo aumento da produtividade e a redução nos custos, tem afetado dramaticamente os nutricionistas. Devido ao maior quantitativo de profissionais se concentrarem na área de Nutrição Clínica $(41,7 \%){ }^{(82)}$, o impacto da redução arbitrária do número de funcionários reflete e altera, especialmente, o setor hospitalar.

No estudo de temas sobre planejamento de recursos humanos, dimensionamento de pessoal e carga de trabalho na área de Nutrição Clínica, identificou-se que o número de pacientes por nutricionista como parâmetro para o cálculo do quantitativo necessário na prestação do cuidado vem sendo usado há algum tempo.

O Quadro 1 apresenta resumidamente as informações recolhidas em cada uma das fontes de dados. Em termos de evolução temporal, o maior número de publicações ocorreu a partir de 2000 e na língua inglesa. 


\section{Quadro 1 - Publicações sobre dimensionamento do quadro de nutricionistas clínicos em hospitais, de acordo com o ano, título e tipo, selecionadas em março de 2014}

\begin{tabular}{|c|c|c|c|}
\hline $\mathrm{N}^{0}$. & ANO & TÍTULO & $\begin{array}{c}\text { TIPO DE } \\
\text { MATERIAL }\end{array}$ \\
\hline$[01]$ & 1974 & $\begin{array}{l}\text { Organización Mundial de la Salud (OMS): 10.a Asamblea Mundial de la Salud } \\
\text { 1974; } 29 . \text { a Asamblea Mundial de la Salud 1976, resolución WHA29.72; } 35 \\
\text { Asamblea Mundial de la Salud 1982, resolución WHA35.25. 1982(83). }\end{array}$ & $\begin{array}{l}\text { Norma, regra, } \\
\text { resolução, } \\
\text { diretriz }\end{array}$ \\
\hline [02] & 1983 & $\begin{array}{l}\text { Workload measurement study to develop staffing guidelines for the clinical } \\
\text { inpatient dietitian }{ }^{(84)} \text {. }\end{array}$ & Artigo \\
\hline [03] & 1997 & $\begin{array}{l}\text { Normas de organización y funcinamento de las areas de alimentación y } \\
\text { dietoterapia de los estabelecimientos asistenciales. Resolución } 168^{(85)} \text {. }\end{array}$ & $\begin{array}{l}\text { Norma, regra, } \\
\text { resolução, } \\
\text { diretriz }\end{array}$ \\
\hline [04] & 1999 & $\begin{array}{l}\text { Patient nutrition acuity as a predictor of the time required to perform medical } \\
\text { nutrition therapy }{ }^{(86)} \text {. }\end{array}$ & Artigo \\
\hline [05] & 2001 & NKF-KJDOQI Clinical practice guidelines for nutrition in chronic renal failure ${ }^{(87)}$. & $\begin{array}{l}\text { Norma, regra, } \\
\text { resolução, } \\
\text { diretriz }\end{array}$ \\
\hline [06] & 2002 & $\begin{array}{l}\text { The renal team a multi-orofessional renal workforce plan for ddults and children } \\
\text { with renal disease }{ }^{(88)} \text {. }\end{array}$ & $\begin{array}{l}\text { Norma, regra, } \\
\text { resolução, } \\
\text { diretriz }\end{array}$ \\
\hline [07] & 2003 & A Guideline for AHP and HCS staffing levels ${ }^{(89)}$. & $\begin{array}{l}\text { Norma, regra, } \\
\text { resolução, } \\
\text { diretriz }\end{array}$ \\
\hline [08] & 2005 & Resolução do Conselho Federal de Nutricionistas $n^{\circ} .380^{(9)}$. & $\begin{array}{l}\text { Norma, regra, } \\
\text { resolução, } \\
\text { diretriz }\end{array}$ \\
\hline [09] & 2006 & Quality requirements for adult critical care in Wales ${ }^{(90)}$. & $\begin{array}{l}\text { Norma, regra, } \\
\text { resolução, } \\
\text { diretriz }\end{array}$ \\
\hline [10] & 2010 & Service standards for hospitals providing neonatal care ${ }^{(91)}$. & $\begin{array}{l}\text { Norma, regra, } \\
\text { resolução, } \\
\text { diretriz }\end{array}$ \\
\hline [11] & 2010 & End stage renal dialysis facilities licensing rules ${ }^{(92)}$. & $\begin{array}{c}\text { Norma, regra, } \\
\text { resolução, } \\
\text { diretriz }\end{array}$ \\
\hline [12] & 2011 & $\begin{array}{l}\text { Standards for the provision of inpatient adult rehabilitation medicine services in } \\
\text { public and private hospitals }{ }^{(93)} \text {. }\end{array}$ & $\begin{array}{c}\text { Norma, regra, } \\
\text { resolução, } \\
\text { Diretriz }\end{array}$ \\
\hline [13] & 2012 & Funciones y competencias del nutricionista clinico ${ }^{(94)}$. & $\begin{array}{c}\text { Norma, regra, } \\
\text { resolução, } \\
\text { diretriz }\end{array}$ \\
\hline
\end{tabular}

Fonte: Arquivos da pesquisadora. São Paulo, 2016 
A proposta apresentada pela Organização Mundial de Saúde $(\mathrm{OMS})^{(83)}$, estabelece que todos os hospitais com capacidade superior a 70 leitos devem ter nutricionista na proporção de um para cada 50 pacientes. Se for considerada jornada de trabalho diária de oito horas, o tempo despendido para cada paciente será de 9,6 minutos.

Somers e Mulroney ${ }^{(84)}$ realizaram um estudo com o objetivo de desenvolver diretrizes para o dimensionamento de nutricionistas clínicos em um hospital no Canadá. Os autores consideram quatro variáveis interferentes: o número de pacientes em risco nutricional e que necessitam de dieta modificada, o tempo médio requerido por paciente, o tempo médio de internação e as horas de cuidado disponíveis por nutricionista (jornada de trabalho).

De acordo com esses autores ${ }^{(84)}$, o quantitativo necessário de nutricionistas clínicos pode ser obtido mediante a identificação das atividades e do tempo despendido no seu desenvolvimento, o que requer realização de um estudo da assistência nutricional prestada aos pacientes.

O Ministério da Saúde e Ação Social da Nação Argentina ${ }^{\left({ }^{85}\right)}$ estabelece a necessidade de trabalhadores por meio da relação entre o tempo de cuidado requerido por paciente (estimado em 10 minutos) e a jornada de trabalho do nutricionista clínico (420 minutos por dia e 111.300 minutos por ano). Para tanto, considera-se jornada de trabalho diária de sete horas durante 265 dias por ano.

A estimativa do tempo de cuidado requerido por paciente representa um importante passo para garantir a implementação desse parâmetro nas instituições hospitalares da Argentina. Porém, é importante destacar que não há referência quanto ao nível de complexidade do cuidado de nutrição, admitindo-se, portanto, que todos os pacientes requerem o mesmo tempo de cuidado ${ }^{(85)}$.

O método proposto por Simmons e Vaughan ${ }^{(86)}$, baseia-se na classificação da gravidade do paciente, obtido mediante equação logarítmica com 22 variáveis preditoras, classificadas em sete categorias (gênero, idade, status neurológico, alimentar e bioquímico, alterações sistêmicas, aconselhamento e educação nutricional), que mostrou associação significativa em relação ao tempo requerido ao 
cuidado nutricional. O tempo requerido ao cuidado dos pacientes foi obtido pela razão entre o tempo total despendido ao cuidado dos pacientes e o número de pacientes atendidos. Participaram deste estudo 92 hospitais dos Estados Unidos e 3321 pacientes foram incluídos na análise. Simmons e Vaughan destacam que a equação proposta é válida, apenas, para cálculo do tempo necessário ao cuidado dos pacientes assistidos pelas Equipes Multiprofissionais de Terapia Nutricional (EMTN) e que não foi incluído na equação proposta o tempo despendido em atividades não relacionadas ao paciente ${ }^{(86)}$.

De acordo com National Kidney Foundation - A Kidney Disease Outcomes Quality Initiative $^{(87)}$, NKF- KDOITM , a proporção de um nutricionista em tempo integral (jornada de trabalho de 40 horas por semana) para cada 100 ou no máximo 150 pacientes com doença renal crônica em diálise de manutenção (4,8 min ou 3,6 $\mathrm{mim} /$ paciente) é considerada adequada para os Serviços de Nutrição. Essa recomendação foi obtida a partir de consenso geral de especialistas, com base na experiência prática, e se limita aos pacientes com falência renal permanente, que realizam tratamento de hemodiálise ou diálise peritoneal periodicamente em centros de referência (clínicas ou hospitais) ou em domicílio ${ }^{(87)}$.

Já no estado do Texas, Estados Unidos ${ }^{(92)}$, a proporção de pacientes por nutricionista estabelecida pelo Departamento de Serviços Saúde é de um nutricionista em tempo integral para cada 100 ou no máximo 125 pacientes na fase final de doença renal ( 4,8 ou $3,8 \mathrm{~min} /$ paciente).

Em relação aos pacientes hospitalizados, que necessitam se submeter a tratamento dialítico durante o período de internação, as recomendações da The British Renal Society ${ }^{(86)}$, estabelecem que, anualmente, para cada leito de uma unidade especializada em doenças renais devem ser destinadas 78 horas de acompanhamento por nutricionista especialista em doenças renais.

Quatro referências propõem parâmetros específicos para as unidades de cuidados intensivos e unidades de alta dependência, cuja recomendação estabelecida para pacientes críticos, é de 0,05 a 0,1 nutricionistas em tempo integral por leito por ano. Considera-se jornada integral sempre que o trabalhador é 
contratado para trabalhar 40 horas por semana, sendo 37,5 horas destinadas ao trabalho e 2,5 horas referentes às pausas intercaladas ${ }^{(88-91)}$.

Em relação aos serviços de reabilitação, em regime de internação, os parâmetros numéricos recomendados, podem variar de acordo com a especialidade. Recomenda-se 0,5 nutricionistas em tempo integral para cada 10 pacientes em tratamento de reabilitação devido a problemas neurológicos, tuberculose ou queimaduras (24 min/paciente). Para pacientes em fase de reabilitação após amputação, trauma ortopédico ou medular a recomendação é de 0,4 nutricionistas em tempo integral (carga horária diária de 8 horas) para cada 10 pacientes $(19,2$ $\min /$ paciente) ${ }^{(93)}$.

Em 2012, o Comitê de Nutricionistas da Federação Latino-americana de Terapia Nutricional, Nutrição Clínica e Metabolismo (FELANPE) ${ }^{(94)}$, elaborou um documento de consenso das funções e competências do Nutricionista Clínico, onde está definido o quantitativo de nutricionistas por leito.

A proporção de nutricionistas clínicos por leito, estabelecida pela FELANPE, é de 1:20 e 1:41, a depender da especialidade médica, e o tempo estimado para o desenvolvimento das intervenções nas unidades de internação de cuidados agudos e crônicos é de 10 e dois minutos por paciente, respectivamente ${ }^{(94)}$.

Para obter o quantitativo de nutricionistas clínicos necessários, consideram-se os dias efetivos de trabalho pela subtração do total de dias do ano (365 dias) pelos dias não trabalhados (142 dias), relativos aos finais de semana e feriados (112 dias), as férias anuais (20 dias) e a estimativa das ausências não previstas (10 dias) o que perfaz 223 dias de trabalho ${ }^{(94)}$. Porém, não foi estabelecida nesse consenso, a jornada de trabalho dos nutricionistas.

No Brasil, a fundamentação legal para o dimensionamento de nutricionistas clínicos, em unidades de internação hospitalares, está respaldada pela Resolução CFN n‥ 380/2005 ${ }^{(9)}$, que estabelece os parâmetros numéricos de referência para unidades de internação hospitalar, de acordo com o nível de atendimento de nutrição. 
Os parâmetros numéricos de referência, previstos nessa Resolução ${ }^{(9)}$, preconizam a proporção de um nutricionista para cada 60 pacientes de nível primário ou 30 pacientes de nível secundário ou 15 pacientes de nível terciário.

Além disso, está estabelecido o tempo de cobertura do setor de nutrição clínica, que deve ser de pelo menos 12 horas por dia, ininterruptas, inclusive nos finais de semana e feriados ${ }^{(9)}$.

Ao converter esse quantitativo em horas de cuidado, pode-se considerar que cada paciente requer cerca de 6, 12 e 24 minutos para os níveis primário, secundário e terciário, respectivamente, considerando jornada semanal de 30 horas diária de trabalho e seis horas de jornada diária $e^{(9)}$.

Sobre a classificação dos níveis de atendimento, a Resolução CFN $\mathrm{n}^{\circ}$. 380/2005 (2005, p. 36) define como:

\begin{abstract}
"Nível de Atendimento Primário - assistência nutricional aos pacientes cuja doença de base ou problema apresentado não implica em fatores de risco nutricional. Nível de Atendimento Secundário - assistência nutricional aos pacientes cuja doença de base ou problema apresentado pode acarretar fatores de risco nutricional associados, ou ainda assistência nutricional aos pacientes cuja patologia de base exige cuidados dietéticos mais específicos e não acarretam fatores de risco nutricional associados. Nível de Atendimento Terciário - assistência nutricional aos pacientes cuja patologia de base exige cuidados dietéticos mais específicos e apresenta fatores de risco nutricional associados".
\end{abstract}

Ao analisar a Resolução CFN nำ. 380/2005 ${ }^{(9)}$ percebe-se que os critérios para classificação do nível de atendimento não se mostram claramente delineados, especialmente, quando comparado ao instrumento validado por Simmons \& Vaughan ${ }^{(86)}$, além de não estarem definidas as intervenções/atividades padrão para cada nível de atendimento de nutrição.

A delimitação das intervenções/atividades de acordo com o nível de atendimento de nutrição visa, basicamente, estabelecer regras comuns e a ausência delas prejudica tanto a sua aplicação pelas UAN hospitalares quanto à avaliação da adequação dos parâmetros estabelecidos pelo órgão fiscalizador.

O levantamento da produção científica apresentado nesta seção revelou que existe uma diversidade de métodos, modelos, normas e diretrizes sobre o dimensionamento da força de trabalho em nutrição clínica. Provavelmente eles não 
representam a totalidade, visto que não foi objetivo esgotar todas as fontes sobre esse assunto.

Contudo, é possível observar um grande esforço por parte das entidades de representação da categoria profissional de nutricionista e dos órgãos governamentais e não governamentais, no sentido de melhorar ou garantir a adequação do quadro de pessoal.

A revisão bibliográfica mostrou que é predominante o uso de parâmetros baseados no número de pacientes por nutricionista. Essas publicações, em sua maioria, estão apoiadas no julgamento de profissionais, com base em suas experiências e intuições ${ }^{(9,83,87-94)}$.

Porém, é importante destacar que, se por um lado a proporção paciente por nutricionista pode facilitar o entendimento sobre a sua aplicação, por outro lado, a prática clínica sem a fundamentação da evidência científica pode dificultar as negociações com os gestores hospitalares quando o assunto é contratação de profissionais.

Outro aspecto a ser considerado é que somente a referência brasileira ${ }^{(9)}$ faz menção ao período de assistência nutricional em hospitais e clínicas, que deve ser de no mínimo 12 horas por dia, inclusive nos finais de semana e feriados, além de recomendar que a jornada de trabalho seja de 30 horas semanais.

$\mathrm{Na}$ prática, isso significa dizer que a prestação de cuidado deve seguir um padrão e tomar como base o atendimento das necessidades dos pacientes. Ou seja, o dimensionamento quantitativo dos nutricionistas clínicos deve seguir essa mesma lógica, independente do dia da semana.

Em síntese, é possível perceber que além do nível de cuidado do paciente, as condições e a organização do trabalho são fatores que devem ser considerados para 0 adequado dimensionamento de nutricionistas. A identificação e o acompanhamento das atividades desenvolvidas por esses profissionais, por sua vez, se constituem procedimentos de gestão que orientam o dimensionamento.

Destaca-se, também, a importância de se obter estimativas do tempo médio necessário à prestação do cuidado, por meio de métodos de mensuração do 
trabalho, visto que esta variável tem se mostrado a mais crítica no planejamento da força de trabalho.

\subsection{MÉTODOS PARA MENSURAÇÃO DA CARGA DE TRABALHO}

O funcionamento eficaz e eficiente de qualquer sistema de saúde é dependente do desempenho da força de trabalho. E a melhor forma de medir o desempenho do trabalhador é realizar um estudo em seu contexto específico.

Segundo Gaidzinski ${ }^{(95)}$, considera-se carga de trabalho o produto entre o tempo de cuidado e o número médio de pacientes atendidos. Essa definição, adotada pelas enfermeiras, abrange aspectos referentes à dimensão física da carga de trabalho e pode se aplicar às diversas áreas profissionais inseridas no contexto da saúde.

Partindo-se da análise dos dados obtidos da observação e mensuração do trabalho, é possível aperfeiçoar os processos de trabalho, como também, melhorar a confiabilidade, flexibilidade, custo, saúde, segurança e qualidade de vida do trabalhador ${ }^{(96)}$.

Os estudos de tempo e movimento, utilizados para reunir informação detalhada sobre os processos de trabalho e muito difundidos na engenharia industrial, também tem sido foco de interesse de gestores e pesquisadores da área de saúde. Recentemente foi publicada uma revisão sistemática da literatura sobre a aplicação dos métodos de tempo e movimento na área de saúde para mensuração do trabalho (97).

De acordo com os resultados apresentados pelos autores, destacam-se os métodos que requerem um observador externo, meticulosamente treinado, para verificar e registrar dados detalhados sobre a duração e os movimentos necessários para a execução de uma tarefa ou operação específica. Uma desvantagem frente aos outros métodos são os custos envolvidos no processo de obtenção e análise de dados $^{(97)}$. 
Nesse conjunto, encontram-se descritos na literatura o método de observação contínua, a amostragem do trabalho e a filmagem. Os dois primeiros métodos são realizados por meio da observação direta, seguindo o trabalhador em tempo real. Já o último, pode ser realizado de forma assíncrona, em que o observador analisa as gravações do comportamento do trabalhador no ambiente de trabalha (observação indireta) ${ }^{(97)}$.

No método de observação contínua, o observador externo mantém sua atenção sobre 0 trabalhador e registra continuamente o tempo despendido na execução das atividades, na sequência em que elas ocorrem. Essa abordagem é útil para coletar dados de atividades não-centralizadas e sensível para atividades de curta duração, pois fornece dados detalhados sobre o processo de trabalho. Porém, o custo envolvido neste tipo de estudo é elevado, pois a relação trabalhador observador requerida é de 1:1 ${ }^{(97)}$.

O método de amostragem do trabalho caracteriza-se pela identificação das atividades executadas instantaneamente, em intervalos aleatórios de tempo, permitindo que o observador se concentre em mais de um trabalhador durante $o$ mesmo período de tempo. Não é possível obter o tempo real, mas uma estimativa, por meio de um intervalo fixo de tempo ${ }^{(97-100)}$.

Nos estudos que utilizam métodos de observação direta do trabalho, devido à presença de um observador externo, é possível ocorrer uma mudança positiva no desempenho do trabalhador, conhecido como "Efeito de Hawthorne" (97).

Outro método utilizado é o auto-relato, onde os próprios trabalhadores fornecem os dados relacionados ao tempo. Estão descritas na literatura, em estudos de tempo que utilizam o auto-relato, técnicas de grupos focais, investigação por inquérito ou survey amostragem do trabalho e rastreamento ativo ${ }^{(97)}$.

Embora o auto-relato seja um método de baixo custo para a mensuração das atividades de trabalho, diferenças na percepção dos trabalhadores podem levar a discrepâncias, devido à avaliação subjetiva, podendo resultar em estimativas pobres sobre a duração das atividades ${ }^{\left({ }^{(9)}\right.}$. 
Além disso, os trabalhadores podem superestimar o tempo de cuidado direto aos pacientes, subestimar o tempo não produtivo ou mudar a rotina normal, a fim de apresentar dados que na concepção deles são desejáveis ${ }^{(97)}$.

Dados de tempo e movimento também podem ser produzidos automaticamente por sistemas informatizados. A duração das atividades é gerada por sistemas computadorizados quando os trabalhadores realizam atividades pré-definidas. Tratase de um método de controle passivo, capaz de registrar o tempo automaticamente durante a execução da atividade, sendo considerada uma medida precisa, desde que a variável de interesse seja a duração das interações do trabalhador com 0 sistema ${ }^{(97)}$. 


\section{MÉTODO}

\subsection{TIPO DE PESQUISA}

Para atingir o objetivo proposto, a estratégia de pesquisa adotada caracterizouse quanto à natureza como pesquisa aplicada, quanto à abordagem do problema como pesquisa quantitativa, quanto à finalidade como pesquisa descritiva e metodológica e quanto aos meios de investigação como pesquisa de campo ${ }^{(101-103)}$.

Como pesquisa aplicada, o objetivo foi levantar dados reais sobre a carga de trabalho dos nutricionistas clínicos, mediante observação sistemática do trabalho, para aplicação direta dos resultados obtidos, comparando-os com os parâmetros numéricos estabelecidos na Resolução CFN no. 380/2005 ${ }^{(9)}$.

A abordagem quantitativa baseou-se no emprego da quantificação na coleta de informações para caracterização das unidades hospitalares e dos sujeitos que participaram da pesquisa, na obtenção da amostra e no tratamento dos dados, por meio de técnicas estatísticas descritivas e analíticas.

Para alcançar o objetivo, foi necessário construir um instrumento específico para medir o tempo e a frequência das atividades desenvolvidas pelos nutricionistas clínicos, visto que, era desconhecida a existência de um instrumento para medir o tempo de trabalho dos nutricionistas no contexto hospitalar brasileiro. Por isso, a pesquisa caracterizou-se como metodológica.

Com o intuito de descrever a distribuição do tempo de trabalho dos nutricionistas clínicos em cada intervenção/atividade durante a jornada de trabalho e obter dados referentes ao tempo efetivo de trabalho, realizou-se uma pesquisa caráter descritivo. 


\subsection{PROCEDIMENTOS METODOLÓGICOS}

Os procedimentos metodológicos adotados na coleta de dados compreenderam três etapas.

A primeira etapa envolveu a identificação, classificação e validação das intervenções e atividades realizadas pelos nutricionistas, bem como a construção de um instrumento de medida da frequência do tempo despendido pelos nutricionistas clínicos em hospitais.

Na segunda etapa realizou-se um estudo piloto para avaliação do instrumento mediante observação contínua dos nutricionistas clínicos in loco e mensuração do tempo despendido nas intervenções e atividades desenvolvidas junto aos pacientes internados, durante a jornada de trabalho.

A terceira etapa constituiu-se pelos procedimentos de coleta de dados em campo. Após a coleta de dados, procedeu-se à análise dos indicadores de produção e desempenho dos nutricionistas clínicos, obtidos a partir da pesquisa de campo realizada em três hospitais, que serviram para o estabelecimento de parâmetros quantitativos para o cálculo do efetivo de nutricionistas clínicos para cada nível de atendimento nutricional. Os parâmetros obtidos neste estudo foram analisados e comparados com a Resolução CFN n‥ 380 de $2005^{\text {(9). }}$.

A Figura 1 resume o plano de coleta de dados, os objetivos de cada etapa para o alcance dos objetivos da pesquisa, técnica utilizada, localização (anexo e apêndices) e responsável.

Todas as etapas foram estruturadas metodologicamente, conforme descrição a seguir. 


\section{Figura 1 - Procedimentos metodológicos realizados para o alcance dos objetivos da pesquisa}

\begin{tabular}{|c|c|c|c|c|}
\hline Etapa & Objetivo & Técnica & Instrumento & Responsável \\
\hline (2) & $\begin{array}{l}\text { Avaliar a aplicabilidade do } \\
\text { instrumento de medida de } \\
\text { carga de trabalho }\end{array}$ & $\begin{array}{l}\text { Observação sistemática } \\
\text { "in loco" do trabalhador, } \\
\text { preenchimento de } \\
\text { questionários, formulários e } \\
\text { análise de dados }\end{array}$ & $\begin{array}{c}\text { Anexo } 1 \\
\text { Apêndices } \mathrm{D}, \mathrm{E}, \mathrm{Fe} \mathrm{H}\end{array}$ & Pesquisadora \\
\hline (3) & $\begin{array}{l}\text { executadas pelos nutricionistas } \\
\text { clínicos, estabelecer parâmetros } \\
\text { quantitativos para o cálculo do } \\
\text { número de nutricionistas necessário } \\
\text { para cada nível de atendimento } \\
\text { de nutrição e compará-los } \\
\text { com a legislação vigente }\end{array}$ & $\begin{array}{c}\text { Estatística descritiva e } \\
\text { analítica }\end{array}$ & $\begin{array}{l}\text { Apêndices D, E, F e H } \\
\text { Microsoft Excel } 2010 @\end{array}$ & Pesquisadora \\
\hline
\end{tabular}

Fonte: arquivos da pesquisadora. São Paulo, 2016

\subsubsection{Primeira Etapa: identificação, classificação e validação das intervenções e atividades desenvolvidas pelos nutricionistas clínicos}

\subsubsection{Identificação e classificação das intervenções/atividades}

Foram identificadas as atividades que representam a assistência prestada pelos nutricionistas clínicos aos pacientes internados em instituições hospitalares, mediante revisão da literatura e vivência da pesquisadora.

Para seleção das referências realizou-se busca eletrônica na base de dados Medline/PubMed no período entre janeiro e março de 2014. Como estratégia de 
busca, utilizou-se a associação de termos do vocabulário MeSH com operadores booleanos. Durante a busca, foram utilizados os seguintes termos compostos: "dietary services AND food service, hospital AND dietetics" e "personnel management".

Critérios de inclusão adotados: apresentar as atividades e/ou atribuições do nutricionista clínico na assistência hospitalar no título, resumo e/ou assunto; ser escrito nos idiomas português, espanhol ou inglês; e ter sido publicado no período entre 1970 e 2013. Foram exluídos os estudos que não estavam disponíveis na íntegra.

A opção de iniciar o recorte temporal no ano de 1970 se justifica, uma vez que, os avanços na gestão da saúde em hospitais brasileiros tiveram início a partir desta década.

Para evitar a não inclusão de estudos importantes, foi realizada consulta manual ao Acervo das Bibliotecas da Universidade de São Paulo, em sites institucionais e referências citadas nas fontes primárias.

As atividades de nutrição clínica foram analisadas e classificadas em intervenções, em linguagem padronizada proposta pela Classificação das Intervenções de Enfermagem - Nursing Intervention Classification $\left(\right.$ NIC ${ }^{(104)}$, pela técnica de mapeamento cruzado ${ }^{(105)}$.

A NIC define intervenção como "qualquer tratamento, baseado no julgamento clínico e no conhecimento, realizado por uma enfermeira para aumentar os resultados obtidos pelo paciente/cliente" e atividade como "comportamento ou ações específicos realizados por enfermeiros para implementar uma intervenção e que auxiliam pacientes/clientes a obterem o resultado desejado" (104).

A escolha dessa linguagem partiu dos achados preliminares da pesquisa bibliográfica, os quais permitiram constatar a estreita relação existente entre as intervenções/atividades de enfermagem e de nutrição clínica.

Tendo em vista as atribuições privativas dos nutricionistas não contempladas na NIC ${ }^{(104)}$, sempre que necessário, foram acrescentadas intervenções, conceitos e 
um conjunto de atividades que representam o trabalho dos nutricionistas clínicos nas unidades de internação hospitalares.

Para tanto, recorreu-se a instrumentos utilizados em pesquisas no campo da enfermagem relacionadas com o tema ${ }^{(106-108)}$, no intuito de adaptá-los. Logo, alguns títulos e definições foram modificados integralmente ou adaptados.

As atividades mapeadas/classificadas, não contempladas nas intervenções de nutrição clínica, foram categorizadas como atividades pessoais e associadas. Para Fugulin, Gadzinski e Castilho ${ }^{(95)}$, as atividades associadas ao trabalho, dizem respeito às atividades que poderiam ser executadas por outros profissionais ou categorias, embora sejam realizadas pelos profissionais de enfermagem. Para as autoras, as atividades pessoais estão relacionadas ao atendimento das necessidades fisiológicas e de comunicação pessoal dos trabalhadores.

De acordo com o sugerido pela literatura ${ }^{(109)}$, a lista contendo as intervenções/atividades realizadas pelos nutricionistas e os aspectos conceituais foi submetida ao processo de validação de conteúdo.

Uma comissão de profissionais com expertise nas áreas de nutrição e enfermagem foi convidada para avaliar o conteúdo do instrumento. Utilizou-se um subtipo da validação de conteúdo, denominado validação de rosto, que consiste em um tipo intuitivo de validade ${ }^{(109)}$.

O perfil dos juízes convidados contemplou os critérios de inclusão descritos a seguir. Critérios de seleção para os juízes da área de nutrição: ser nutricionista; ter experiência na área de nutrição clínica hospitalar, no mínimo quatro anos; pósgraduação stricto-sensu na área de Nutrição Clínica; ter produção científica na área de nutrição clínica; ter experiência como tutor ou supervisor de estagiários, residentes ou aprimorandos em Nutrição Clínica.

Já os critérios de seleção para os juízes da área de enfermagem foram: ser enfermeiro; ter experiência no uso da técnica de tempos e movimentos; ter experiência e conhecimento na utilização da Classificação em Intervenções em Enfermagem; ter especialização em Enfermagem; ter pós-graduação stricto-sensu em Enfermagem. 
A partir desses critérios, foram convidados dois docentes de nutrição, duas enfermeiras e três nutricionistas assistenciais (um representante de cada hospital), totalizando sete juízes.

A operacionalização do processo de validação do instrumento ocorreu por meio da técnica de Oficina de Trabalho, realizada em dois momentos distintos. Como instrumento quantitativo da coleta de dados, foi elaborado um formulário buscando traçar o perfil dos juízes (Apêndice A).

No primeiro momento, os juízes receberam uma lista contendo as intervenções/atividades de nutrição clínica (Apêndice B) e uma carta orientando a avaliação (Apêndice C). A referida lista foi entregue para avaliação dos juízes com trinta dias de antecedência da oficina de trabalho.

Em cada intervenção/atividade foi avaliada a clareza e a objetividade na definição, na descrição das atividades indicadas e na classificação, bem como se as atividades/intervenções apontadas representavam o trabalho do nutricionista clínico nas unidades de internação hospitalares e se havia necessidade de inclusão ou exclusão de alguma intervenção/atividade.

No segundo momento realizou-se a oficina de validação de conteúdo, nos dias 11 e 26 de junho de 2014, que totalizou carga horária de oito horas. Para coordenar a oficina de validação e prestar esclarecimentos aos juízes, estiveram presentes as pesquisadoras responsáveis pelo projeto.

Durante a oficina, utilizaram-se os seguintes procedimentos:

1) Leitura de cada item ou subitem presente na lista, de acordo com a sequência apresentada no texto;

2) Manifestação individual dos juízes;

3) Discussão de cada item ou subitem até consenso (concordância superior a $80 \%)$;

4) Apresentação das alterações incorporadas. 
4.2.1.2 Construção do instrumento de medida do tempo e da frequência das intervenções e atividades desenvolvidas pelos nutricionistas clínicos

O instrumento de medida da carga de trabalho foi construído a partir das atividades e intervenções validadas pelos juízes e baseou-se em modelos publicados por outros autores ${ }^{(105-107,110)}$.

\subsubsection{Segunda Etapa: Estudo Piloto}

\subsubsection{Teste do instrumento}

Para verificar a aplicabilidade do instrumento na população-alvo, realizou-se um estudo piloto. Antes de iniciar o estudo piloto, foram apresentados aos participantes os formulários com as informações que seriam levantadas, bem como esclarecidas as dúvidas. Além disso, foi disponibilizado pela gerência da UAN um cronograma com os nomes dos participantes, datas e horários das observações.

Selecionaram-se quatro dias consecutivos para observação sistemática dos trabalhadores, sendo dois dias no turno matutino (das $7 \mathrm{~h}$ às $16 \mathrm{~h}$ ) e dois dias no turno vespertino (das $11 \mathrm{~h}$ às $19 \mathrm{~h}$ ). As observações foram feitas pela pesquisadora em um dos hospitais que aceitaram participar da pesquisa, durante uma semana típica, no mês de agosto de 2014.

Todos os procedimentos adotados na coleta de dados do estudo piloto foram reproduzidos na pesquisa de campo propriamente dita e seguem descritos na terceira etapa. 


\subsubsection{Terceira Etapa: Pesquisa de Campo}

\subsubsection{Local do Estudo}

O estudo foi desenvolvido nas unidades de internação: clínica médica, clínica cirúrgica, unidade de terapia intensiva e emergência, de instituições hospitalares que atenderam aos seguintes critérios de escolha:

a) Instituição hospitalar pública considerada de boas práticas de nutrição;

b) Instituição hospitalar com papel relevante no sistema de saúde do estado de São Paulo e também do Brasil, qualidade de prestação de assistência aos pacientes, no desenvolvimento de atividades de ensino e pesquisa e como referência em atendimento de média e alta complexidade;

c) Instituição hospitalar cuja localização não implicasse elevação dos custos acarretados pela necessidade de grandes deslocamentos da pesquisadora.

d) Instituição hospitalar cujo tempo de assistência nutricional ao paciente hospitalizado atendesse às exigências da Resolução CFN №. 380/2005 ${ }^{(9)}$, ou seja, de pelo menos, 12 (doze) horas/dia ininterruptas, inclusive nos finais de semana e feriados.

Dentre as instituições hospitalares que atenderam aos critérios de participação, foram escolhidas três, localizadas na cidade de São Paulo, que foram convidadas e aceitaram participar do presente estudo.

Para preservar o sigilo e a confidencialidade das informações obtidas, os hospitais participantes foram identificados por letras do alfabeto, por meio das siglas HSPA, HSPB e HSPC (Quadro 2). 


\section{Quadro 2 - Características dos hospitais estudados nos meses de setembro a dezembro de 2014}

\begin{tabular}{|c|c|c|c|}
\hline Descrição & HSPA & HSPB & HSPC \\
\hline Tipo de estabelecimento & Especializado & Geral & Geral \\
\hline Fonte de financiamento ${ }^{1}$ & SUS & $\begin{array}{c}\text { SUS, convênio e } \\
\text { particular }\end{array}$ & SUS \\
\hline Complexidade da atenção & Alta & Alta & Média \\
\hline Número de leitos operacionais & 512 & 919 & 236 \\
\hline $\begin{array}{l}\text { Número de nutricionistas } \\
\text { clínicos }\end{array}$ & 44 & 19 & 6 \\
\hline $\begin{array}{l}\text { Número de nutricionistas } \\
\text { especialistas da EMTN }{ }^{2}\end{array}$ & 2 & 2 & 1 \\
\hline Relação nutricionista/leito & $1 / 11$ & $1 / 44$ & $1 / 34$ \\
\hline \multicolumn{4}{|c|}{$\begin{array}{l}\text { 1Atendimento financiado por três fontes: Sistema Único de Saúde (SUS), empresas de } \\
\text { saúde suplementar (convênio) e particular. } \\
{ }^{2} \text { Membros da Equipe Multiprofissional de Terapia Nutricional responsáveis pela } \\
\text { assistência nas unidades de internação. }\end{array}$} \\
\hline
\end{tabular}

Fonte: Instituições hospitalares participantes do estudo. São Paulo, 2016

A escolha de três instituições hospitalares, com diferentes perfis, teve como justificativa a necessidade de tornar as amostras mais independentes das características dos pacientes internados e da própria instituição, no que se refere à obtenção de valores de tempos médios das instervenções/atividades, além de servir de modelo de referência, com possibilidade de aplicação generalizada.

Uma vez definidos os hospitais, partiu-se para a seleção das unidades de internação a observadas. Os critérios adotados para delimitação das unidades de internação consideraram o perfil etário dos pacientes atendidos (preferencialmente adultos e idosos), o desenvolvimento do plano de cuidados que envolvesse as 
etapas de avaliação, diagnóstico, monitoramento, orientação e documentação e o interesse do nutricionista lotado na unidade em participar do estudo.

O HSPA é um hospital público vinculado à Secretaria do Estado da Saúde de São Paulo e, no período da pesquisa, era administrado por uma Organização Social de Saúde (OSS). As OSS são pessoas jurídicas privadas, sem fins lucrativos, e colaboram por meio de parceria formal com o Estado para consolidação do Sistema Único de Saúde, conforme previsto na Lei Orgânica da Saúde no. 8.080/90 (111),

A distribuição do quantitativo de nutricionistas clínicos no HSPA é fixa e contínua, abrangendo os turnos matutino, vespertino e noturno. Os nutricionistas clínicos cumprem jornada de trabalho semanal de 40 horas, distribuídas em turnos de oito horas (diurno) e $12 \times 36$ horas (noturno). O turno matutino compreende 0 horário das $7 \mathrm{~h}$ às $16 \mathrm{~h}$, o vespertino das $11 \mathrm{~h}$ às $20 \mathrm{~h}$ e o período noturno das $19 \mathrm{~h}$ às $7 \mathrm{~h}$.

O HSPB é uma autarquia de regime especial do governo do estado de São Paulo, vinculado à Secretaria de Estado da Saúde, responsável pela coordenação administrativa, e associado a uma instituição estadual de ensino superior para fins de ensino, pesquisa e prestação de ações e serviços de saúde.

Os nutricionistas que prestam assistência aos pacientes nas unidades de internação do HSPB cumprem jornada de trabalho semanal de 40 horas, distribuídas em turnos de seis horas de segunda a sexta-feira e doze horas nos finais de semana e feriados. $O$ atendimento dos nutricionistas clínicos nas unidades de internação compreende o período entre $7 \mathrm{~h}$ e $20 \mathrm{~h}$, sendo que o turno matutino das $7 \mathrm{~h}$ às $13 \mathrm{~h}$ e 0 vespertino das $14 \mathrm{~h}$ às $20 \mathrm{~h}$. O período entre $13 \mathrm{~h}$ e $14 \mathrm{~h}$ é coberto pelos nutricionistas clínicos com jornada de trabalho diária de oito horas.

O HPSC é um hospital público que faz parte do Sistema Integrado de Saúde de uma instituição estadual de ensino superior. Os nutricionistas que prestam assistência aos pacientes nas unidades de internação cumprem jornada de trabalho semanal de 40 horas, distribuídas em turnos de seis horas (matutino e vespertino) de segunda a sexta-feira e de doze horas nos finais de semana e feriados. $O$ atendimento dos nutricionistas clínicos nas unidades de internação no matutino compreende o horário das $7 \mathrm{~h}$ às $13 \mathrm{~h}$ e vespertino das $13 \mathrm{~h}$ às $19 \mathrm{~h}$. 
Os nutricionistas clínicos dos três hospitais são alocados em unidades previamente definidas e prestam atendimento a todos os pacientes internados. A composição da equipe de nutrição clínica que atua nas unidades de internação dos três hospitais estudados inclui os atendentes ou auxiliares de nutrição hospitalar.

Os auxiliares de nutrição são responsáveis pela montagem das bandejas (conforme a prescrição dietética) e carros térmicos, monitoramento do estoque de gêneros alimentícios e materiais de cozinha nas copas localizadas nas unidades de internação, distribuição das refeições, além de apoiarem as atividades de monitoramento da aceitação das refeições pelos pacientes, realizadas pelos nutricionistas clínicos.

A distribuição dos nutricionistas nas unidades de internação estudadas considera o nível de complexidade do atendimento e número de leitos disponíveis nas unidades de internação.

No HSPA, cada unidade de internação de pacientes adulto possui um nutricionista clínico responsável, no turno matutino, enquanto que no HSPB e HSPC os nutricionistas são responsáveis por duas ou mais unidades. No turno vespertino, os nutricionistas são responsáveis por mais de uma unidade em todos os hospitais estudados.

\subsubsection{Participantes da pesquisa}

O critério para a escolha dos nutricionistas clínicos considerou a(s) unidade em que 0 trabalhador estava alocado e a disponibilidade para participar da pesquisa. Diante da necessidade de tornar as amostras mais independentes das características do participante, recomendou-se, sempre que possível, a participação de um nutricionista diferente por turno. 
A caracterização dos nutricionistas clínicos e das UAN das instituições participantes do estudo foi obtida mediante o preenchimento de dois formulários distintos (Apêndices $D$ e $E$ ).

É importante destacar que embora seja reconhecido o papel fundamental que desempenha o auxiliar de nutrição, nas unidades de internação, esta categoria profissional não foi incluída na presente investigação, devido à inexistência de parâmetros numéricos preconizados para o seu dimensionamento, aliada à variabilidade existente nas atividades estabelecidas para o cargo, de acordo com a instituição hospitalar.

4.2.3.3 Distribuição do período de coleta de dados

A distribuição da coleta de dados foi baseada na repartição equitativa de turnos em cada instituição hospitalar, de maneira a abranger uma quantidade igual de amostras nos dois turnos de observação. Com isso, se minimizou o viés, que por ventura poderia existir, entre os dados coletados no turno matutino e no turno vespertino.

Assim, a pesquisa foi realizada de forma independente nas três instituições hospitalares S (HSPA, HSPB e HSPC), onde cada ocorrência $i$ da mesma intervenção/atividade foi identificada e cronometrada, e o resultado do seu tempo de execução $t_{S /}$ foi sequencialmente anotado no instrumento de coleta de dados.

\subsubsection{Cálculo do tamanho da amostra}

O tamanho da amostra $\boldsymbol{N}$ necessária para a determinação da frequência de ocorrência $\boldsymbol{F}_{l}$, bem como o tempo médio de execução $\overline{T_{I}}$ com que cada intervenção/atividade foi realizada pelos nutricionistas clínicos, nos cuidados de 
nutrição aos pacientes internados nas instituições hospitalares foi predeterminado considerando-se os seguintes critérios:

1. Os dados coletados na pesquisa ocorrem ao acaso, pois a sequência das intervenções/atividades dos nutricionistas clínicos executadas na instituição hospitalar depende, principalmente, das necessidades dos pacientes internados, não sofrendo interferência da técnica de pesquisa adotada. Assim, os dados coletados permitiram a abordagem estatística convencional na sua análise.

2. Intervalo de confiança de $95 \%$, isto é, $\alpha=0,05$;

3. Erro de $5 \%$ entre o valor médio amostrado e o valor médio da população, isto é, $\boldsymbol{e}=0,05$;

4. $\mathrm{O}$ valor do tempo médio de execução das intervenções/atividades $\bar{\delta}$ foi obtido com base no estudo piloto;

5. Foi adotada a técnica de tempo e movimento contínuo, na qual um observador acompanha o nutricionista clínico durante toda sua jornada de trabalho, cuja praticidade foi justificada e testada no estudo piloto;

6. O valor do tamanho da amostra $\boldsymbol{N}_{\boldsymbol{I}}$ foi obtido por meio da aplicação da equação de regressão dos dados extrapolados para valores de $\boldsymbol{I}=33$ categorias (intervenções/atividades), do método proposto por Bromaghin (112) para a distribuição multinomial.

7. A jornada de trabalho $\boldsymbol{J}_{\boldsymbol{s}}$ dos nutricionistas clínicos foi de 6 ou 8 horas/dia (360 ou 480 minutos/dia), em função das características de cada instituição hospitalar $\boldsymbol{S}$.

8. A quantidade de turnos $\boldsymbol{U}$ amostrados na pesquisa foi calculada mediante a seguinte equação:

$$
U=\frac{N \cdot \bar{\delta}}{J}
$$


4.2.3.5 Operacionalização da coleta de dados

A aplicação do instrumento de coleta de dados foi realizada pela pesquisadora e ocorreu de forma direta, contínua e não participativa, na proporção de um observador para um nutricionista clínico ${ }^{(96)}$.

A leitura do cronômetro foi realizada ao final de cada intervenção/atividade executada pelo nutricionista, sendo registrado o tempo indicado no cronômetro, sem interrompê-lo ${ }^{(96)}$.

Para evitar qualquer tipo de alteração de ritmo ou hábitos do nutricionista clínico, o horário de chegada do observador obedeceu a uma antecedência mínima de 30 minutos, tempo este necessário para o observador guardar seus objetos de uso pessoal, se paramentar, preencher os dados iniciais da folha de registro e aguardar a chegada do nutricionista clínico, a ser acompanhado, na área próxima ao equipamento de registro de ponto.

A paramentação do observador seguiu as normas de saúde e segurança no trabalho e os instrumentos auxiliares utilizados foram caneta, dispositivo móvel, cronômetro (aplicativo), prancheta e folha de registro.

A prancheta foi necessária para segurar o papel e apoiar o dispositivo móvel, porque a rotina de trabalho dos nutricionistas clínicos implica deslocamento para a execução das intervenções que, em geral, se desenvolvem em pé.

A mensuração do tempo gasto nas intervenções/atividades foi obtida através de um aplicativo que simula, por software, um cronômetro, sendo capaz de medir tempos, além de outras funcionalidades auxiliares, tais como armazenar e transferir os dados, instalado em um dispositivo móvel. Assim, foi possível garantir segurança no armazenamento dos dados referentes ao tempo de cada intervenção/atividade.

Rotineiramente, ao término de cada período de observação, procedeu-se à revisão da folha de registro para verificar seu completo preenchimento. $O$ observador sempre se posicionava próximo ao nutricionista, a uma distância que 
permitisse vê-lo e ouvi-lo simultaneamente. No que se refere à folha de registro, as instruções para utilização do cronômetro estão descritas no apêndice H.

Segundo Dellefield e Harrington ${ }^{(113)}$, a postura adequada do observador tem como objetivo reduzir o risco de reatividade e desconforto do trabalhador durante a cronometragem.

As pausas relacionadas às atividades pessoais do observador (toalete, hidratação e ausência) foram cronometradas e apresentadas nos resultados desta pesquisa como tempo não observado.

Para maximizar o tempo de observação dos trabalhadores, o tempo destinado ao descanso e refeição do observador coincidia com o do nutricionista, em conformidade com a jornada de trabalho.

Quanto ao registro das intervenções/atividades de ocorrência simultânea, considerou-se a intervenção/atividade principal. Por exemplo, se a documentação foi realizada durante a triagem nutricional, considerou-se a última opção como intervenção principal. Quando a documentação ocorria de forma isolada, foi considerada como atividade-fim.

Outro exemplo de atividades/intervenções as quais podem ser executadas simultaneamente é a socialização com a equipe multidisciplinar (ou entre os pares profissionais), ocorrida durante o deslocamento. Nos casos em que o deslocamento tinha como atividade-fim os cuidados relacionados aos pacientes, considerou-se o deslocamento e não a socialização.

Apenas os pacientes atendidos diretamente pelos nutricionistas clínicos observados foram classificados, pela pesquisadora, quanto ao nível de assistência nutricional, segundo a recomendação da Resolução CFN no. 380/2005 ${ }^{(9)}$.

Para fins de comparação dos tempos obtidos na presente investigação com aqueles preconizados pela Resolução CFN n․ 380/2005 ${ }^{(9)}$ foi necessário converter a proporção de pacientes por nutricionistas, de acordo com o nível de atendimento de nutrição, em minutos, e obtiveram-se os seguintes tempos: 6, 12 e 24 minutos/paciente por turno de 360 minutos para os níveis primário, secundário e terciário, respectivamente. 
A fim de sumarizar e simplificar o processo de classificação do nível de atendimento de nutrição considerou-se o esquema apresentado no "Manual Orientativo para Sistematização do Cuidado de Nutrição"(79) organizado pela Associação Brasileira de Nutricionistas (Quadro 3).

Quadro 3 - Critérios para classificação dos níveis de assistência de nutrição

\begin{tabular}{|l|c|c|c|c|}
\hline \multicolumn{1}{|c|}{$\begin{array}{c}\text { Critérios relacionados ao } \\
\text { paciente }\end{array}$} & Primário & \multicolumn{2}{|c|}{ Secundário } & Terciário \\
\hline Risco Nutricional & Não & Sim & Não & Sim \\
\hline $\begin{array}{l}\text { Necessidade de dietoterapia } \\
\text { específica }\end{array}$ & Não & Não & Sim & Sim \\
\hline
\end{tabular}

Fonte: Associação Brasileira de Nutricionistas ${ }^{(79)}$. São Paulo, 2016

As informações referentes ao resultado da triagem de risco nutricional e à necessidade de dietoterapia específica foram disponibilizadas pelos nutricionistas clínicos ao final do período de acompanhamento.

Considerando que, em geral, o uso de instrumentos de triagem do risco nutricional é limitado ao tempo de internação, nos casos em que o tempo de permanência hospitalar do paciente excedeu a quatro semanas, utilizou-se como critério para classificação do nível de atendimento de nutrição, dados relativos ao diagnóstico nutricional, conforme descrito no Quadro 4. 
Quadro 4 - Critérios para classificação dos níveis de assistência de nutrição segundo o resultado do diagnóstico educacional

\begin{tabular}{|l|c|c|c|c|}
\hline \multicolumn{1}{|c|}{$\begin{array}{c}\text { Critérios relacionados ao } \\
\text { paciente }\end{array}$} & Primário & \multicolumn{2}{|c|}{ Secundário } & Terciário \\
\hline Má Nutrição & Não & Sim & Não & Sim \\
\hline $\begin{array}{l}\text { Necessidade de dietoterapia } \\
\text { específica }\end{array}$ & Não & Não & Sim & Sim \\
\hline
\end{tabular}

Fonte: Adaptado da Associação Brasileira de Nutricionistas ${ }^{(79)}$. São Paulo, 2016

\subsection{ANÁLISE DOS DADOS}

\subsubsection{Organização dos dados coletados}

As amostras coletadas foram armazenadas e organizadas em um banco de dados e transpostas para planilhas eletrônicas (Microsoft Exceß®, versão 2010), permitindo processar os cálculos referentes à quantidade de intervenções/atividades, ao tempo (em minutos) total e médio despendido em cada intervenção/atividade, ao desvio padrão, bem como calcular os valores dos limites superior e inferior para o intervalo de confiança de $95 \%$ e a distribuição proporcional do tempo de trabalho dos nutricionistas assistenciais, nas diferentes intervenções/atividades.

As planilhas eletrônicas permitiram extrair, também, os resultados das observações por turnos de trabalho, por instituição e no conjunto delas, evidenciando a distribuição da jornada de trabalho dos nutricionistas clínicos em: intervenções de cuidado direto, indireto, atividades associadas, atividades pessoais, espera, deslocamento, ausência, participação em reunião administrativa e tempo sem registro de observação. 


\subsubsection{Obtenção dos padrões de referência para o cálculo da carga de trabalho dos nutricionistas clínicos.}

a) Amostras de cada uma das instituições hospitalares

As $i_{S I}$ ocorrências de uma mesma intervenção/atividade I coletadas na mesma instituição hospitalar $\boldsymbol{S}$ foram agrupadas, numeradas e contadas, sendo que a quantidade dessas ocorrências em cada grupo representa a frequência $\boldsymbol{F}_{\boldsymbol{S I}}$ da intervenção I na instituição $S$.

$$
F_{S I}=\sum_{i_{S I}=1}^{n} i_{S I}
$$

Assim, a quantidade de grupos de intervenções/atividades $\boldsymbol{G}$ formados representa o total de intervenções/atividades $\boldsymbol{l}$.

Os tempos de execução $\left(t_{S I}\right)_{i}$ de cada intervenção ocorrida $\boldsymbol{i}_{S I}$ em cada grupo de intervenção/atividade foram somados, sendo $T_{s I}$ o tempo despendido em cada intervenção/atividade I da instituição hospitalar $\boldsymbol{S}$.

$$
T_{S I}=\sum_{i_{S I}=1}^{n}\left(t_{S I}\right)_{i_{S I}}
$$

b) Amostras das três instituições hospitalares

A frequência de ocorrência $\boldsymbol{F}_{\boldsymbol{I}}$ na mesma intervenção/atividade $\boldsymbol{I}$ coletadas nas três instituições hospitalares (HSPA, HSPB e HSPC) foi obtida pela soma das frequências de ocorrência dessa intervenção/atividade em cada instituição hospitalar:

$$
F_{I}=F_{A I}+F_{B I}+F_{C I}
$$


O tempo total de execução $T_{I}$ de cada intervenção/atividade $I$ coletado nas três instituições hospitalares (HSPA, HSPB, e HSPC) foi obtido pela soma do tempo $T_{\text {sI }}$ despendido na execução de cada intervenção/atividade de cada uma das instituições pesquisadas.

$$
T_{I}=T_{A I}+T_{B I}+T_{C I}
$$

c) Tempo médio de execução de cada intervenção/atividade

O tempo médio de execução $\bar{T}_{I}$ de cada intervenção/atividade I foi calculado com as amostras das três instituições hospitalares pela aplicação da seguinte equação:

$$
\bar{T}_{I}=\frac{T_{I}}{F_{I}}
$$

Onde:

$\boldsymbol{F}_{\boldsymbol{I}}=$ frequência das intervenções ocorridas numa mesma intervenção/atividade $I$ amostrada nas três instituições;

$\boldsymbol{T}_{\boldsymbol{I}}=$ tempo total de execução de cada intervenção/atividade $\boldsymbol{I}$ amostradas nas três instituições.

d) Tempo total amostrado

O tempo total amostrado $\boldsymbol{T}_{\text {amostra }}$ corresponde à soma do tempo de todas as intervenções/atividades ocorridas nas três instituições hospitalares: 


$$
\begin{gathered}
\boldsymbol{T}_{\text {amostra }}=\sum_{I=1}^{G} T_{I} \\
\text { Ou } \\
T_{\text {amostra }}=360 \times U_{6}+480 \times U_{8}=360 \times 16+480 \times 8=9600 \text { minuto }
\end{gathered}
$$

e) Percentual (probabilidade) de ocorrência de cada intervenção/atividade.

O percentual $\boldsymbol{P}_{\boldsymbol{I}} \%$ de ocorrência de cada uma das intervenções/atividades I nas três instituições hospitalares foi calculado pela aplicação da seguinte equação:

$$
P_{I} \%=100 \times \frac{T_{I}}{T_{\text {amostra }}}
$$

Sendo:

$T_{I}$ = a soma dos tempos de execução de cada ocorrência $\boldsymbol{i}$ da mesma intervenção/atividade amostrada nas três instituições;

$\boldsymbol{T}_{\text {amostra }}=$ a soma dos tempos de execução de todas as intervenções/atividades amostradas (isto é, tempo total amostrado nas três instituições).

f) Intervalo de confiança de cada intervenção/atividade.

O limite superior $L_{s}$ e o limite inferior $L_{i}$ do intervalo de confiança de $95 \%$ para a média dos tempos das intervenções/atividades foi obtido pela aplicação das seguintes equações:

$$
L_{\text {sup }}=\bar{T}_{I}+t_{9596, g l} \times\left(\frac{s}{\sqrt{F_{I}}}\right)
$$




$$
L_{\text {inf }}=\bar{T}_{I}-t_{959, g l} \times\left(\frac{s}{\sqrt{F_{I}}}\right)
$$

Onde:

$\bar{T}_{I}=$ tempo médio da intervenção/atividade $\boldsymbol{I}$;

$t_{59, g l}=$ valor da distribuição t-Student para o nível de confiança $a=5 \%$, bi caudal e grau de liberdade $\mathrm{gl}=\left(F_{s_{I}}-1\right)$;

$s=$ desvio padrão dos tempos $\left(\boldsymbol{t}_{\boldsymbol{l}}\right)$ da mesma intervenção/atividade $\boldsymbol{I}$;

$F_{I}=$ frequência de cada intervenção/atividade $I$.

$t_{95 \%, g l} \times\left(\frac{s}{\sqrt{F_{I}}}\right)=$ erro de estimação para pequenas amostras.

g) Tempo total de execução de cada o tipo de intervenções/atividades.

As intervenções/atividades I foram classificadas e agrupadas conforme seu tipo em:

- Intervenções de cuidado direto ao paciente (designadas por $\boldsymbol{I}_{D I}$ ), conforme a classificação do nível de atendimento de nutrição foram subagrupadas em:

$>\quad$ Intervenções de cuidado direto em pacientes primários $\boldsymbol{I}_{\left(\mathbf{D} 11^{2}\right) ;}$

$>\quad$ Intervenções de cuidado direto em pacientes secundários $\boldsymbol{I}_{\left(\mathbf{D} \mathbf{2}^{2}\right)}$;

$>\quad$ Intervenções de cuidado direto em pacientes terciários $\boldsymbol{I}_{\left(D / 3^{3}\right)}$.

- Intervenções de cuidado indireto ao paciente (designadas por $I_{\mathbb{I N}}$ );

- Atividades Associadas (designadas por $\boldsymbol{I}_{\boldsymbol{A S}}$ ); 
- Outras atividades (designada por lout), que englobaram as seguintes atividades:

$>\quad$ Atividades Pessoais (designadas por $I_{P E}$ );

$>\quad$ Atividades Administrativas (designadas por $I_{A D}$ );

$>\quad$ Atividades de Deslocamento (designadas por $I_{D E}$ );

$>\quad$ Atividades de Espera (designada por $I_{E S}$ ).

Para cada uma das intervenções/atividades pertencentes a estes agrupamentos foram somados:

- O tempo de execução de cada ocorrência, sendo que o resultado constitui-se o tempo total de execução das intervenções/atividades conforme seu tipo;

- A quantidade de intervenções/atividades ocorridas, sendo que o resultado constitui-se o total de intervenções realizadas por tipo de intervenção/atividade.

h) Percentual de cada grupo de tipo de intervenção/atividade

A proporção de cada grupo de tipo de intervenção/atividade foi obtida pela razão entre o tempo total de execução das intervenções/atividades agrupadas conforme seu tipo e o tempo total amostrado. Como exemplo, calculou-se o percentual para o grupo de intervenções de cuidado direto em paciente primário conforme segue:

$$
P_{I(D I 1 z)} \%=100 \times \frac{T_{I(D I 13)}}{T_{\text {amostra }}}
$$

i) Quantidade de pacientes sob os cuidados diretos, segundo o nível de atendimento nutricional. 
Os pacientes que receberam cuidados diretos foram identificados, classificados e agrupados pela pesquisadora, segundo o nível de atendimento de nutrição, como primário $\left(1^{\mathrm{a}}\right)$, secundário $\left(2^{\mathrm{a}}\right)$ e terciário $\left(3^{\mathrm{a}}\right)$.

A quantidade de pacientes $\boldsymbol{k}$ com a mesma classificação de nível de atendimento foi contada e os resultados foram designados por $\boldsymbol{k}_{\left(\boldsymbol{D} / 1^{a}\right)}, \boldsymbol{k}_{\left(\boldsymbol{D} \mid \mathbf{2}^{\mathrm{a}}\right)}$ e $\boldsymbol{k}_{\left(\boldsymbol{D} / \mathbf{3}^{\mathrm{a}}\right)}$ e o total de pacientes que receberam cuidados diretos $\boldsymbol{K}_{(D I)}$ foi obtido pela soma da quantidade de pacientes dos três grupos classificados.

$$
K_{(D I)}=k_{(D I 1 z)}+k_{(D I 2 z)}+k_{(D I 3 z)}
$$

j) Tempo total das intervenções de cuidado direto ao paciente

O Tempo total para cada Intervenção direta $T_{(D I)}$ foi determinado pela soma de todos os tempos das intervenções diretas executadas nos pacientes conforme 0 nível de atendimento em cada instituição hospitalar:

$$
\begin{gathered}
T_{A(D I)}=T_{A(D I 1 z)}+T_{A(D I 2 z)}+T_{A(D I 3 z)} \\
T_{B(D I)}=T_{B(D I 1 z)}+T_{B(D I 2 z)}+T_{B(D I 3 z)} \\
T_{C(D I)}=T_{C(D I 1 z)}+T_{C(D I 2 z)}+T_{C(D I 3 z)} \\
T_{(D I)}=T_{A(D I)}+T_{B(D I)}+T_{C(D I)}
\end{gathered}
$$

k) Tempo total das intervenções de cuidado indireto ao paciente

O Tempo total das Intervenções de Cuidados Indiretos $T_{(I N)}$ foi determinado pela soma de todos os tempos das intervenções indiretas ocorridas durante 0 período da pesquisa em cada uma das instituições hospitalares:

$$
T_{(I N)}=T_{A(I N)}+T_{B(I N)}+T_{C(I N)}
$$

I) Tempo total das atividades associadas 
O tempo total das Atividades Associadas $T_{(A S)}$ foi determinado pela soma de todos os tempos das atividades associadas ocorridas durante o período da pesquisa em cada uma das instituições hospitalares:

$$
T_{(A S)}=T_{A(A S)}+T_{B(A S)}+T_{C(A S)}
$$

m) Tempo total de outras atividades

O tempo total das outras atividades $\boldsymbol{T}_{(\text {(out) }}$ foi determinado pela soma dos tempos das atividades pessoais $T_{(P E)}$, atividades administrativas $T_{(A D)}$, atividades de deslocamento $\boldsymbol{T}_{(D E)}$, e atividade de espera $\boldsymbol{T}_{(E S)}$ em cada instituição hospitalar:

$$
\begin{gathered}
T_{(P E)}=T_{A(P E)}+T_{B(P E)}+T_{C(P E)} \\
T_{(A D)}=T_{A(A D)}+T_{B(A D)}+T_{C(A D)} \\
T_{(D E)}=T_{A(D E)}+T_{B(D E)}+T_{C(D E)} \\
T_{(E S)}=T_{A(E S)}+T_{B(E S)}+T_{C(E S)} \\
\boldsymbol{T}_{(O U T)}=\boldsymbol{T}_{(P E)}+\boldsymbol{T}_{(A D)}+\boldsymbol{T}_{(D E)}+\boldsymbol{T}_{(E S)}
\end{gathered}
$$

n) Carga total de trabalho dos nutricionistas clínicos no atendimento de todos os pacientes internados nas três instituições hospitalares

A carga total de trabalho $\boldsymbol{C} \boldsymbol{T}_{\boldsymbol{S}}$, a ser executada, pelos nutricionistas clínicos no cuidado de todos os pacientes internados nas três instituições hospitalares, durante o período da pesquisa, foi calculada pela soma do tempo despendido em todas as intervenções/atividades ocorridas durante o período da pesquisa. 


$$
C T=T_{(D I)}+T_{(I N)}+T_{(A S)}+T_{(O U T)}
$$

Como somente os pacientes que receberam intervenções de cuidado direto foram classificados e computados, conforme as suas necessidades de cuidados de nutrição, os tempos despendidos nas demais intervenções/atividades, cuja execução foi realizada genericamente para todos os pacientes, tiveram que ser adicionados proporcionalmente aos tempos das Intervenções de Cuidado Indireto. Esta adição foi calculada em duas etapas:

$\mathrm{Na}$ primeira etapa foram distribuídos, proporcionalmente, os tempos despendidos com outras atividades (pessoais, deslocamento e espera) aos tempos das intervenções diretas, ao tempo das intervenções indiretas e ao tempo das atividades associadas.

Obtendo-se, assim novos tempos despendidos com intervenções diretas, intervenções indiretas e atividades associadas.

$$
\begin{aligned}
& T_{2(D I 13)}=T_{(D I 13)} \times\left[1+\frac{T_{(O U T)}}{T_{(D I)}+T_{(I N)}+T_{(A S)}}\right] \\
& T_{2(D I 2 z)}=T_{(D I 23)} \times\left[1+\frac{T_{(O U T)}}{T_{(D I)}+T_{(I N)}+T_{(A S)}}\right] \\
& T_{2(D I 3 z)}=T_{(D I 3 !)} \times\left[1+\frac{T_{(O U T)}}{T_{(D I)}+T_{(I N)}+T_{(A S)}}\right] \\
& T_{2(I N)}=T_{(I N)} \times\left[1+\frac{T_{(O U T)}}{T_{(D I)}+T_{(I N)}+T_{(A S)}}\right] \\
& T_{2(A S)}=T_{(A S)} \times\left[1+\frac{T_{(O U T)}}{T_{(D I)}+T_{(I N)}+T_{(A S)}}\right]
\end{aligned}
$$


Na segunda etapa foram distribuídos, proporcionalmente, os novos tempos despendidos com as atividades associadas e intervenções indiretas, em cada grupo de tempos das intervenções diretas (conforme o nível de atendimento de nutrição), obtidos após a aplicação da distribuição da primeira etapa.

$$
\begin{aligned}
& T_{3(D I 13)}=T_{2(D I 1 z)} \times\left[1+\frac{T_{2(I N)}+T_{2(A S)}}{T_{2(D I)}+T_{2(I N)}+T_{2(A S)}}\right] \\
& T_{3(D I 2 z)}=T_{2(D I 2 z)} \times\left[1+\frac{T_{2(I N)}+T_{2(A S)}}{T_{2(D I)}+T_{2(I N)}+T_{2(A S)}}\right] \\
& T_{3(D I 3:)}=T_{2(D I 3:)} \times\left[1+\frac{T_{2(I N)}+T_{2(A S)}}{T_{2(D I)}+T_{2(I N)}+T_{2(A S)}}\right]
\end{aligned}
$$

Carga de trabalho de cuidado despendido pelos nutricionistas clínicos, segundo o nível de atendimento nutricional, após o rateio foi então:

$$
C T=T_{3(D I 13)}+T_{3(D I 2 z)}+T_{3(D I 3 z)}
$$

o) Tempo de cuidado despendido pelos nutricionistas clínicos por paciente internado.

Tempo de cuidado, despendido pelos nutricionistas clínicos, por paciente classificado nas três instituições hospitalares foi calculado por: 


$$
\begin{gathered}
H_{(D I 1)}=\frac{T_{3(D I 1)}}{k_{(D I 12)}} \\
H_{(D I 2 z)}=\frac{T_{3(D I 2 z)}}{k_{(D I 2)}} \\
H_{(D I 3:)}=\frac{T_{3(D I 3)}}{k_{(D I 3 !)}}
\end{gathered}
$$

p) Comparação entre a carga de trabalho obtida pela pesquisa e a carga de trabalho esperada pela aplicação dos valores recomendados pela Resolução CFN $n^{\circ} .380$ de $2005^{(9)}$

Os valores dos tempos de cuidado por paciente primário, secundário e terciário, recomendados pela Resolução CFN o․ 380 de $2005{ }^{(9)}$, por nutricionista, em turnos de 360 minutos foram representados por:

$$
\begin{gathered}
H_{6(\text { CFN 13 })}=6 \text { minutos } / \text { paciente } \\
H_{6(\text { CFN 23) }}=12 \text { minutos } / \text { paciente } \\
H_{6(\text { CFN 33 })}=24 \text { minutos } / \text { paciente }
\end{gathered}
$$

Os tempos médios de cuidado por paciente se referem a um turno médio de 400 minutos, pois o tempo $\boldsymbol{T}_{A U}$ do turno de trabalho da instituição HSPA foi de 480 minutos e os tempos $T_{B U}$ e $T_{C U}$ dos turnos de trabalho das instituições HSPB e HSPC foram de 360 minutos, sendo que o tempo do turno médio da pesquisa foi obtido pela ponderação da quantidade de turnos observados por instituição:

$$
\overline{T_{U}}=\frac{360 \times U_{6}+480 \times U_{8}}{U_{6}+U_{8}}
$$




$$
\overline{T_{U}}=\frac{360 \times 16+480 \times 8}{24}=400 \mathrm{~min}
$$

Para possibilitar a comparação dos resultados do tempo de cuidado preconizado pela Resolução CFN no. 380/2005 com o tempo de cuidado obtido na pesquisa foram necessários transformar os resultados obtidos nesta pesquisa em turnos de 360 minutos.

$$
\begin{aligned}
& H_{6(D I 1 z)}=\frac{T_{3(D I 1 z)}}{k_{(D I 13)}} \times \frac{360}{400} \\
& H_{6(D I 2 z)}=\frac{T_{3(D I 2 z)}}{k_{(D I 2 z)}} \times \frac{360}{400} \\
& H_{6(D I 3 z)}=\frac{T_{3(D I 3 z)}}{k_{(D I 3 z)}} \times \frac{360}{400}
\end{aligned}
$$

Os tempos de cuidado despendido pelos nutricionistas clínicos, segundo o nível de atendimento de cada paciente, obtidos pela transformação para turnos de 360 minutos puderam ser comparados com os tempos de cuidado preconizados pela Resolução CFN n‥ 380/2005 ${ }^{(9)}$, mediante a aplicação do teste $t$-Student, com nível de significância de $\alpha=5 \%$.

É importante destacar que não foram considerados os tempos despendidos pelos nutricionistas relacionados à participação em reuniões administrativas e o tempo não observado pela cronoanalista (a pesquisadora). 


\subsection{ASPECTOS ÉTICOS}

O projeto deste estudo foi aprovado pelo Comitê de Ética em Pesquisa da Escola de Enfermagem da USP, parecer no. 561.818 e CAAE ํo. 26889914.9.0000.5392 (Anexo 1).

Após aprovação do centro coordenador do projeto, a Escola de Enfermagem da USP, e a anuência das chefias dos Serviços de Nutrição e Dietética, a pesquisa foi replicada, automaticamente, para os Comitês de Ética do HSPA, HSPB e HSPC.

Todos os nutricionistas que aceitaram participar da pesquisa assinaram o Termo de Consentimento Livre e Esclarecido (TCLE), em duas cópias, de igual conteúdo, ficando uma com a pesquisadora e outra com os nutricionistas (Apêndice F).

Partiu-se do princípio que, o critério estabelecido, durante o processo de seleção das instituições hospitalares, considerou que a UAN atendia aos padrões mínimos de qualidade exigidos. Assim, tanto as chefias dos serviços quanto os nutricionistas clínicos foram informados que não seria realizada avaliação da qualidade da UAN, do setor de nutrição clínica nem das intervenções executadas pelos participantes. 


\section{RESULTADOS}

Neste capítulo estão apresentados os resultados referentes ao desenvolvimento metodológico do instrumento de medida da carga de trabalho dos nutricionistas e à identificação da carga de trabalho dos nutricionistas clínicos, obtida por meio do estudo de campo propriamente dito, conforme ordem demonstrada a seguir: 1) instrumento de medida da carga de trabalho; 2) estudo piloto; 3) mensuração do tempo despendido em intervenções e atividades; 4) distribuição das frequências; 5) cálculo do tempo das intervenções e atividades para cada nível de atendimento de nutrição; 6) comparação dos parâmetros obtidos no estudo de campo com a Resolução CFN n‥ 380 de $2005^{(9)}$.

\subsection{INSTRUMENTO DE MEDIDA DA CARGA DE TRABALHO}

\subsubsection{Pesquisa Bibliográfica}

Foram encontradas na busca eletrônica 555 publicações e 30 na consulta manual, totalizando 585 produções. Após aplicação dos critérios de inclusão e exclusão, passou-se à fase do processo de revisão.

Um total de 11 produções foi submetido à leitura na íntegra e avaliação ${ }^{(9,29,84,}$ 86, 103, 114-120), sendo identificadas 85 atividades desenvolvidas pelos nutricionistas clínicos. Além dessas atividades, o levantamento bibliográfico também identificou ações que apesar de representarem o cotidiano dos nutricionistas clínicos nos hospitais, não se aplicam às classificações anteriormente citadas, tais como: 
a) Ausência: quando o nutricionista, durante a jornada de trabalho, ausenta-se para realizar atividade não relacionada à UAN, como atrasos e saídas antecipadas (adaptado de Bonfim) ${ }^{(110)}$;

b) Deslocamento: todo deslocamento ocorrido dentro do hospital relacionado ao trabalho, inclusive para realizar as atividades pessoais;

c) Espera: quando o nutricionista está em seu local de trabalho, disponível para o atendimento, mas aguarda o paciente e/ou profissional, seja por ausência de demanda ou porque o paciente e/ou profissional está ocupado em outra atividade (adaptado de Bonfim) (110).

d) Participação em reunião administrativa: quando a chefia e/ou coordenação reúne o (s) nutricionista (s) para tratar de questões eminentemente administrativas que envolvem a UAN, como por exemplo, a remanejamento de folga ou férias e alteração da escala (adaptado de Cruz) $^{(106)}$.

\subsubsection{Classificação e mapeamento das intervenções e atividades}

Como produto final das atividades levantadas durante a revisão bibliográfica, elaborou-se uma lista estruturada com a descrição das atividades de nutrição clínica, mapeadas conforme os domínios, classes e intervenções de enfermagem, acrescidas de uma relação de atividades pessoais, associadas e outras (Apêndice B).

\subsubsection{Oficina de trabalho}

Participaram da oficina quatro juízas, sendo duas nutricionistas e duas enfermeiras. As outras três convidadas não puderam comparecer. A tabela 1 apresenta a caracterização dos juízes. 
Tabela 1 - Caracterização dos juízes participantes da oficina de trabalho realizada em junho de 2014

\begin{tabular}{|c|c|c|}
\hline Variáveis & $N$ & $\%$ \\
\hline \multicolumn{3}{|l|}{ Gênero } \\
\hline Feminino & 4 & 100 \\
\hline \multicolumn{3}{|l|}{ Idade } \\
\hline 35 anos (média) & - & - \\
\hline \multicolumn{3}{|l|}{ Graduação } \\
\hline Universidade Pública & 3 & 75 \\
\hline Universidade Privada & 1 & 25 \\
\hline \multicolumn{3}{|l|}{ Área de graduação } \\
\hline Enfermagem & 2 & 50 \\
\hline Nutrição & 2 & 50 \\
\hline \multicolumn{3}{|l|}{ Tempo de formação } \\
\hline Entre 8 a 10 anos & 2 & 50 \\
\hline Entre 16 a 18 anos & 2 & 50 \\
\hline \multicolumn{3}{|l|}{ Maior titulação } \\
\hline Mestrado & 3 & 75 \\
\hline Doutorado & 1 & 25 \\
\hline \multicolumn{3}{|c|}{ Experiência em Nutrição Clínica } \\
\hline Não & 2 & 50 \\
\hline de 16 a 18 anos & 2 & 50 \\
\hline \multicolumn{3}{|c|}{ Experiência em estudos do tempo e movimento } \\
\hline Não & 2 & 50 \\
\hline 4 anos & 1 & 25 \\
\hline 10 anos & 1 & 25 \\
\hline \multicolumn{3}{|c|}{ Experiência no uso da $N I C$} \\
\hline Não & 2 & 50 \\
\hline Entre 4 e 5 anos & 2 & 50 \\
\hline
\end{tabular}

Fonte: Dados da pesquisa. São Paulo, 2016

O quadro comparativo com a descrição pormenorizada da taxonomia das intervenções de nutrição clínica, antes e após a validação de conteúdo, está apresentado no Apêndice $G$.

A estrutura taxonômica das intervenções de nutrição clínica validadas pelas juízas resultou em quatro domínios, seis classes e 16 intervenções (Figuras 2 e 3). 
Figura 2 - Taxonomia das intervenções propostas pelos juízes em junho de 2014

Domínio

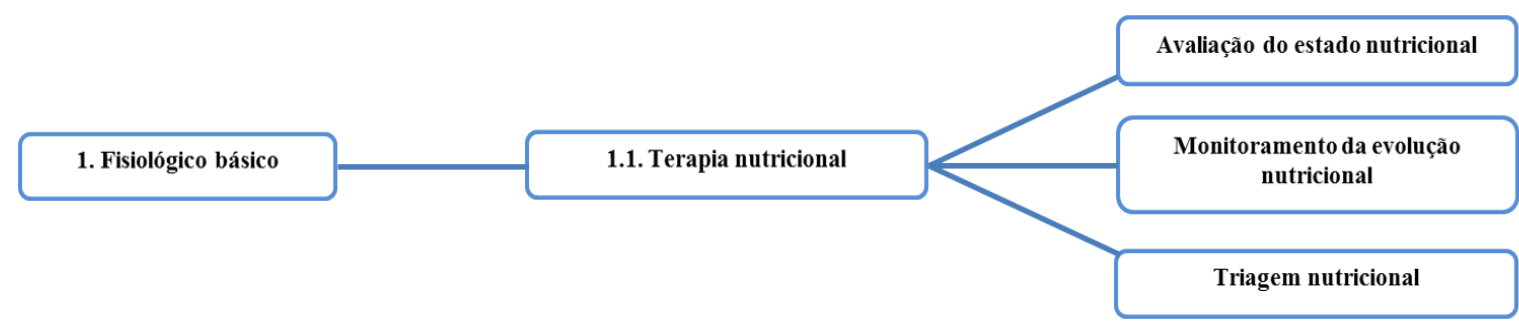

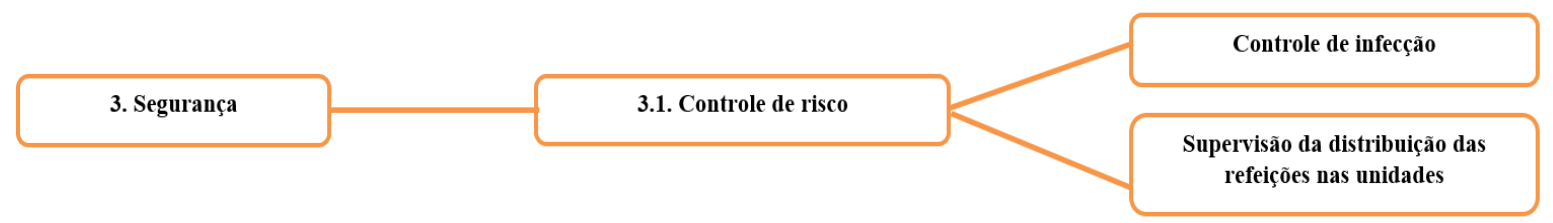

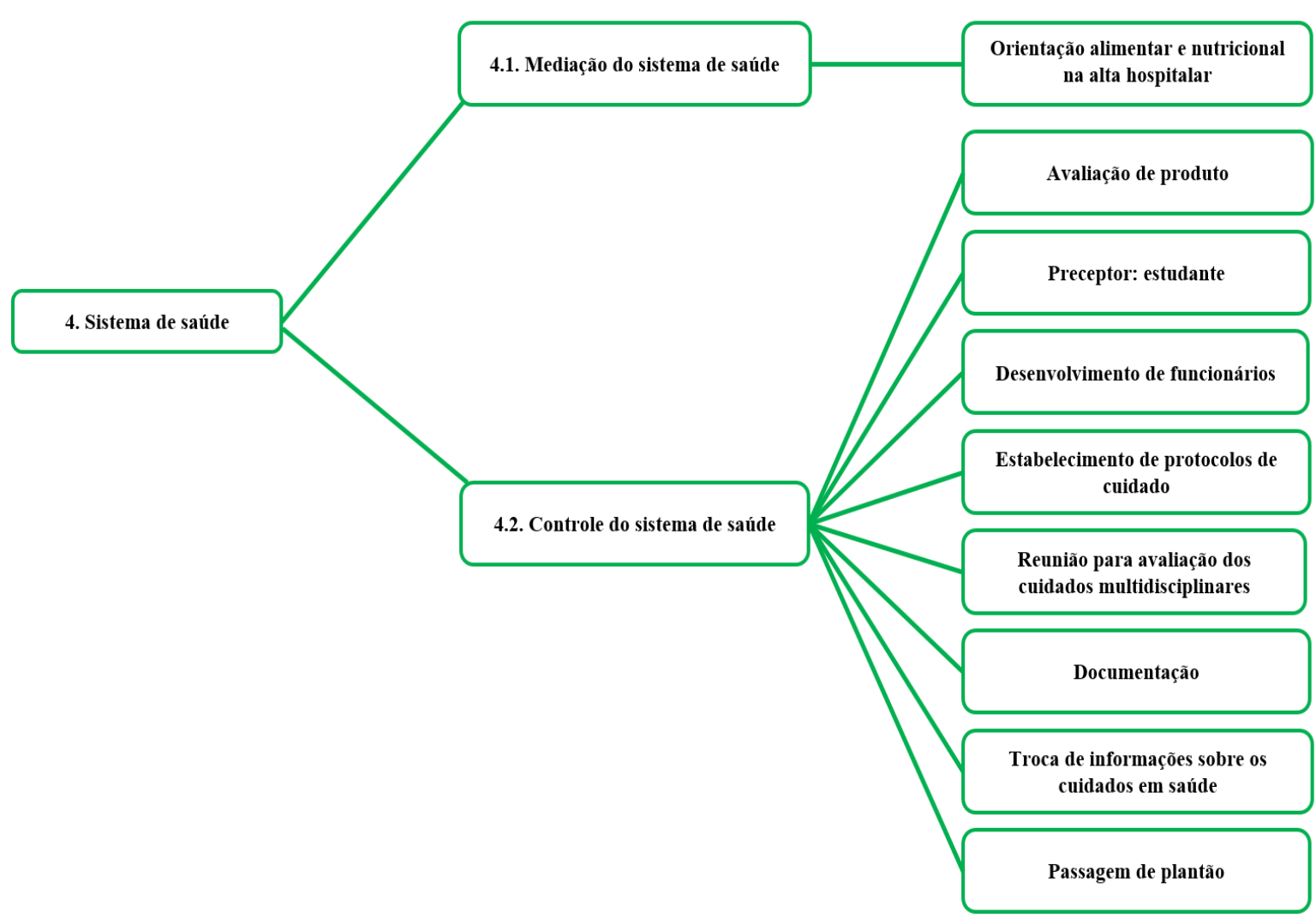

Fonte: Arquivo da pesquisadora. São Paulo, 2016 
Figura 3 - Taxonomia das atividades propostas pelos juízes em junho de 2014

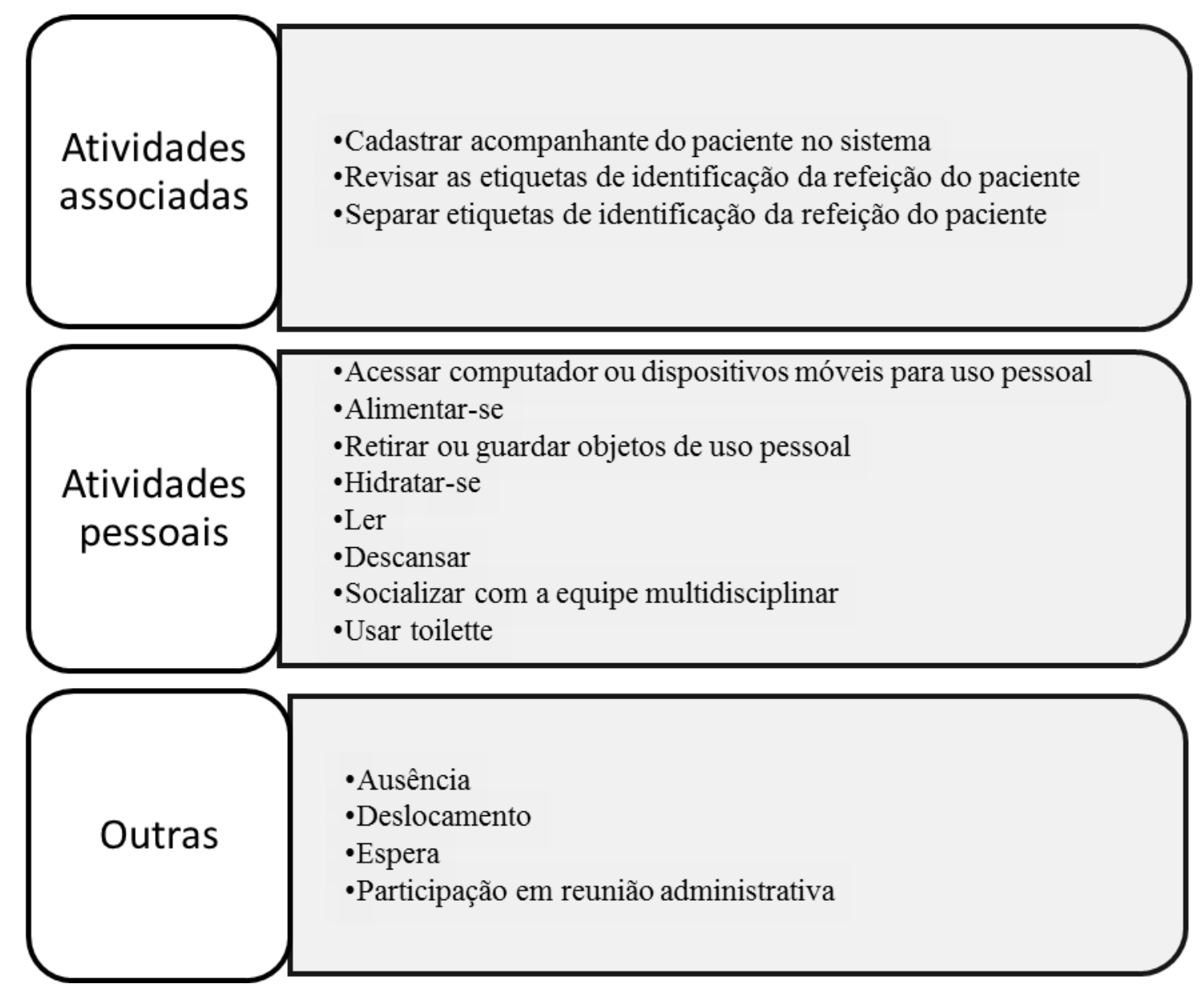

Fonte: Arquivo da pesquisadora. São Paulo, 2016

O Quadro 5 apresenta a taxonomia das intervenções e atividades validadas pelas juízas. 
Quadro 5 - Taxonomia das intervenções de nutrição clínica e atividades validadas pelos juízes em junho de 2014

Domínio 1 - Fisiológico básico: cuidados que dão suporte ao funcionamento físico.

Classe 1.1 - Terapia nutricional: conjunto de procedimentos terapêuticos para manutenção e/ou recuperação do estado nutricional.

Intervenção 1.1.1 - Avaliação do estado nutricional: obtenção e análise de indicadores (clínicos, bioquímicos, antropométricos, consumo alimentar e sociodemográficos) que tem como conclusão o (s) diagnóstico (s) nutricional (ais) inicial (ais).

\section{Atividades}

Levantar dados do prontuário do paciente, tais como: doença/diagnóstico, dieta prescrita, idade, sexo, peso e estatura, medicamentos em uso e exames laboratoriais.

Realizar anamnese: preferências e aversões, intolerâncias, alergias, apetite, problemas alimentares, mudança de peso recente, ingestão alimentar habitual, frequência alimentar, medicamentos, suplementos nutricionais, habilidade para ler e escrever, nível de atividade física, condição socioeconômica e conhecimento prévio acerca das restrições alimentares.

Avaliar a composição corporal através de medidas antropométricas, bioimpedância ou calorimetria.

Analisar a composição corporal através de medidas antropométricas, bioimpedância ou calorimetria.

Cálculo do gasto energético basal e das necessidades energéticas e nutricionais.

Retirar/devolver materiais/equipamentos para avaliação do estado nutricional.

Intervenção 1.1.2 Monitoramento da evolução nutricional: o acompanhamento da evolução nutricional para prevenir ou minimizar desnutrição, favorecendo a recuperação clínica.

\section{Atividades}

Monitorar a ingestão calórica e de nutrientes, os dados dos exames laboratoriais, medicações em uso, medidas antropométricas e/ou composição corporal.

Observar a ocorrência de mudanças importantes no estado nutricional e iniciar tratamentos, conforme apropriado.

Escolher os indicadores nutricionais adequados ao paciente para monitoramento contínuo com base na condição do paciente.

Estabelecer frequência da coleta e interpretação dos dados conforme protocolo. 
Comparar o estado nutricional atual com o anterior para detectar melhorias e pioras na condição do paciente.

Instituir o tratamento adequado, usando protocolos válidos.

Identificar os fatores fisiológicos capazes de afetar os valores laboratoriais.

Verificar o efeito dos medicamentos sobre a interação droga-nutriente.

Verificar o efeito da ingestão alimentar sobre os valores laboratoriais.

Avaliar e analisar a composição corporal por bioimpedância.

Retirar/devolver materiais/equipamentos para avaliação nutricional.

Intervenção 1.1.3 - Triagem nutricional: o processo de identificação das características que se sabe estarem associadas a problemas dietéticos ou nutricionais. Busca identificar indivíduos em risco de desnutrição, com o propósito de verificar se uma avaliação nutricional adicional é necessária.

\section{Atividades}

Apresentar-se e informar seu papel na prestação dos cuidados.

Realizar o exame físico da admissão, conforme apropriado.

Realizar anamnese nutricional: preferências e aversões, intolerâncias, alergias, apetite, problemas alimentares, mudança de peso recente.

Identificar nível de assistência nutricional do paciente.

Classificar o paciente quanto ao risco nutricional.

Domínio 2 - Comportamental: cuidados que dão suporte ao funcionamento psicossocial e facilitam mudanças no estilo de vida.

Classe 2.1 - Educação do paciente: intervenções para facilitar a aprendizagem.

Intervenção 2.1.1 - Ensino: orientação da dieta prescrita: preparação do paciente para seguir a dieta prescrita.

\section{Atividades}

Avaliar o nível atual de conhecimentos do paciente sobre a dieta prescrita.

Explicar a finalidade da dieta e/ou esclarecer dúvidas relacionadas à dieta ou ao tratamento nutricional.

Reforçar informações oferecidas por outros membros da equipe de saúde, conforme apropriado.

Incluir familiares/pessoas importantes, conforme apropriado.

Orientar o paciente/família/pessoas importantes sobre a dieta prescrita.

Intervenção 2.1.2 - Terapia recreacional: uso proposital da recreação para promover relaxamento e melhorar habilidades sociais.

\section{Atividades}

Socializar com acompanhantes. 
Participar de confraternização com os pacientes.

Domínio 3 - Segurança: cuidados que dão suporte à proteção contra danos.

Classe 3.1 - Controle de risco: intervenções para iniciar atividades de redução de risco e manter o monitoramento de risco durante certo tempo.

Intervenção 3.1.1 - Controle de infecção: minimizar a aquisição e a transmissão de agentes infecciosos.

\section{Atividades}

Lavar as mãos.

Descartar roupa de precaução de contato.

Paramentar-se.

Higienizar as mãos com álcool gel.

Desprezar materiais descartáveis.

Realizar desinfecção de materiais e equipamentos.

Intervenção 3.1.2 - Supervisão da distribuição das refeições na enfermaria: avalia o consumo alimentar do paciente, distribuição da dieta e adequação entre a dieta prescrita e a oferecida e também a adequação dos porcionamentos.

\section{Atividades}

Avaliar a distribuição da dieta e adequação entre a dieta prescrita e ofertada e também a adequação dos porcionamentos.

Identificar os problemas nos alimentos/preparações que antecede sua distribuição aos pacientes, tais como temperatura e apresentação.

Realizar degustação das preparações.

Verificar se o cardápio servido está em concordância com o planejado.

Domínio 4 - Sistema de saúde: cuidados que dão suporte ao uso eficaz do sistema de atendimento à saúde.

Classe 4.1 - Mediação do sistema de saúde: intervenções para facilitar a interface entre paciente /família e o sistema de atendimento de saúde.

Intervenção 4.1.1 - Orientação alimentar e nutricional na alta hospitalar: orientação para segmento domiciliar ao paciente/família/responsável, relativa à alimentação e nutrição do paciente.

Atividade - Orientação alimentar e nutricional na alta hospitalar

Orientar o paciente/família/responsável quanto aos cuidados nutricionais em domicílio.

Realizar grupos educativos com pacientes no pós-alta hospitalar.

Classe 4.2 - Controle do sistema de saúde: intervenções para oferecer e melhorar os serviços de apoio para prestação de cuidados. 
Intervenção 4.2.1 - Preceptor-estudante: assistência e apoio a experiência de aprendizagem de um estudante.

\section{Atividades}

Facilitar a interação entre estudantes e pacientes.

Apresentar os alunos aos membros da equipe e aos pacientes.

Acompanhar estagiário de nutrição na realização das atividades.

Orientação aos internos e residentes.

Avaliar evoluções e prescrições de nutrição realizadas por estagiários.

Tirar dúvidas de estagiários de nutrição.

Discutir o plano de cuidados nutricionais com os estudantes.

Envolver os estudantes em atividades de pesquisa, conforme apropriado.

Participar em apresentação de estudantes.

Intervenção 4.2.3 - Avaliação de produto: determinação da eficácia de novos produtos ou equipamento.

\section{Atividades}

Identificar a necessidade de um novo produto ou uma mudança de produto atualmente usado.

Preencher formulários da experiência da avaliação.

Obter a avaliação do paciente sobre o produto (ex. suplemento nutricional).

Assistir a apresentação de representante de produto.

Intervenção 4.2.4 - Desenvolvimento de funcionários: desenvolvimento, manutenção e monitoração da competência de funcionários.

\section{Atividades}

Encorajar a participação em atividades dentro e fora do Serviço de Nutrição e Dietética (organizações profissionais, eventos científicos).

Preparar e/ou apresentar palestras e treinamentos.

Consultar bibliografia adequada em busca de implicação clínica.

Intervenção 4.2.5 - Desenvolvimento de protocolos de cuidado: elaboração e uso de uma sequência programada de atividades de cuidado para melhorar os resultados desejados para o paciente a um custo-efetivo.

\section{Atividades}

Elaborar/revisar os padrões atuais de prática relacionados à população de pacientes.

Elaborar/revisar impressos próprios para o atendimento nutricional.

Colaborar com outros profissionais de saúde para elaborar protocolos de cuidado multidisciplinar. 
Classe 4.3 - Controle das informações: intervenções para facilitar a comunicação sobre cuidados de saúde.

Intervenção 4.3.1 - Reunião para avaliação dos cuidados multidisciplinares: planejamento e avaliação dos cuidados do paciente em conjunto com profissionais de outras disciplinas.

\section{Atividades}

Resumir os dados sobre o estado nutricional do paciente pertinentes ao planejamento dos cuidados.

Identificar os diagnósticos nutricionais.

Descrever as intervenções nutricionais implementadas.

Discutir o progresso na direção das metas e a necessidade de outras intervenções multiprofissionais.

Revisar o plano de cuidados nutricionais, se necessário.

Recomendar mudanças no plano de cuidados nutricionais, conforme necessário.

Intervenção 4.3.2 - Documentação: registro de dados pertinentes ao paciente em prontuário clínico ou formulários específicos do Serviço de Nutrição e Dietética.

\section{Atividades}

Redigir ou digitar ou ticar dados relacionados ao cuidado nutricional do paciente.

Intervenção 4.3.3 - Troca de informações: oferecimento de informações de cuidados do paciente a outros profissionais da saúde.

\section{Atividades}

Acessar e-mail institucional.

Discutir as preocupações com os cuidados ao paciente, ou assuntos relativos à prática, diretamente com os profissionais envolvidos.

Intervenção 4.3.4 - Passagem de plantão: troca de informações essenciais sobre cuidados do paciente entre nutricionistas na mudança do turno.

\section{Atividade}

Passar plantão para o nutricionista.

\section{Atividades associadas}

5.0 - Cadastrar acompanhante do paciente no sistema.

5.1 - Revisar as etiquetas da refeição do paciente

5.2 - Separar as etiquetas de identificação da refeição do paciente

\section{Atividades pessoais}

6.0 - Acessar computador ou dispositivos móveis para uso pessoal

6.1 - Alimentar-se

6.2 - Descansar

6.3 - Hidratar-se

6.4 - Ler 
6.5 - Retirar ou guardar objetos de uso pessoal

6.6 - Socializar com a equipe multidisciplinar

6.7 - Usar toalete

\section{Outras}

8.1 - Ausência

8.2 - Deslocamento

8.3 - Espera

8.4 - Participação em reunião administrativa

8.5 - Outra (especificar):

Fonte: Arquivo da pesquisadora. São Paulo, 2016

\subsubsection{Construção do instrumento de medida da carga de trabalho}

Após a validação das intervenções/atividades pelas juízas, procedeu-se a elaboração do instrumento para mensuração do tempo e da frequência das intervenções e atividades desenvolvidas pelos nutricionistas clínicos (Figuras 4 e 5).

O campo superior direito do instrumento destinou-se à identificação do observador, unidade, trabalhador e período observado. Abaixo da identificação foram inseridas informações referentes ao tempo requerido em cada intervenção/atividade, além dos resultados da triagem nutricional, prescrição dietética e diagnóstico médico, imprescindíveis para classificar os pacientes quanto ao nível de atendimento de nutrição ${ }^{(9)}$. Na coluna à direita constam os códigos das intervenções e atividades (Figuras 4 e 5).

Todas as páginas do instrumento foram numeradas previamente em ordem crescente e divididas em duas partes, frente e verso, além de apresentarem a mesma sequência numérica. Para evitar erros no preenchimento do campo "tempo" do instrumento, decorrentes do deslocamento e do ritmo acelerado do profissional, foi fixada uma numeração em ordem crescente no campo denominado "lap" da folha de registro. 
Figura 4 - Página inicial da folha de registro (frente)

\begin{tabular}{|c|c|c|c|c|c|}
\hline \multirow{3}{*}{$\begin{array}{l}\text { Hospital:( )1 } \\
\text { Nutricionista: } \\
\text { Observador: } \\
\text { Obaciente }\end{array}$} & FOLHA DE REC & \multirow{2}{*}{\multicolumn{3}{|c|}{ 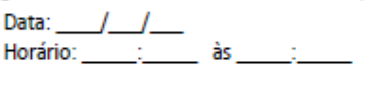 }} & $\begin{array}{l}\text { 1. Avaliação de produto } \\
\text { 2. Avaliação do estado nutricional } \\
\text { 3. Controle de infecção }\end{array}$ \\
\hline & & & & & 4. Desenvolvimento de funcionários \\
\hline & Unidade & Lap & Intervençăo & Tempo & 5. Documentação \\
\hline 1. & & 1 & & & 6. Ensino: orientação da dieta prescrita \\
\hline 2. & & 2 & & & 7. Estabelecimento de protocolos de cuidado \\
\hline 3. & & 3 & & & 8. Monitoramento da evolução nutricional \\
\hline 4. & & 4 & & & 9. Orientação alimentar e nutric na alta hospitalar \\
\hline 5. & & 5 & & & 10. Passagem de plantão \\
\hline 6. & & 6 & & & 11. Preceptor: estudante \\
\hline 7. & & 7 & & & |12. Reunião p/ avaliação do cuid. multidisciplinar \\
\hline 8. & & 8 & & & 13. Supervisão da distrib. nas refeic. nas unidades \\
\hline 9. & & 9 & & & 14. Terapia recreacional \\
\hline 10. & & 10 & & & |15. Triagem nutricional \\
\hline 11. & & 11 & & & 16. Troca de informaçōes sobre cuidad. de saúde \\
\hline 12. & & 12 & & & 17. Cadastrar acompanhante do paciente no sistema \\
\hline 13. & & 13 & & & 18. Separar etiquetas de identif. refeição do paciente \\
\hline 14. & & 14 & & & 19. Revisar etiquetas de identif. refeição do paciente \\
\hline 15. & & 15 & & & 20. Acessar comp./dispositivos p/ interesse próprio \\
\hline 16. & & 16 & & & 21. Alimentar-se \\
\hline 17. & & 17 & & & 22. Descansar \\
\hline 18. & & 18 & & & 23. Fumar \\
\hline 19. & & 19 & & & |24. Guardar/retirar objetos de uso pessoal \\
\hline 20. & & 20 & & & 25. Hidratar-se \\
\hline 21. & & 21 & & & 26. Leitura pessoal \\
\hline 22. & & 22 & & & ||27. Socializar com a equipe multidisciplinar \\
\hline 23. & & 23 & & & 28. Usar toilette \\
\hline 24. & & 24 & & & 29. Tempo de espera \\
\hline 25. & & 25 & & & 30. Ausente \\
\hline 26. & & 26 & & & |31. Deslocamento \\
\hline 27. & & 27 & & & 32. Participar de reunião administrativa \\
\hline 28. & & 28 & & & 33. Outra: especificar \\
\hline
\end{tabular}

Projeto: Dimensionamento de recursos humanos em assistência nutricional hospitalar. 
Figura 5 - Página inicial da folha de registro (verso)

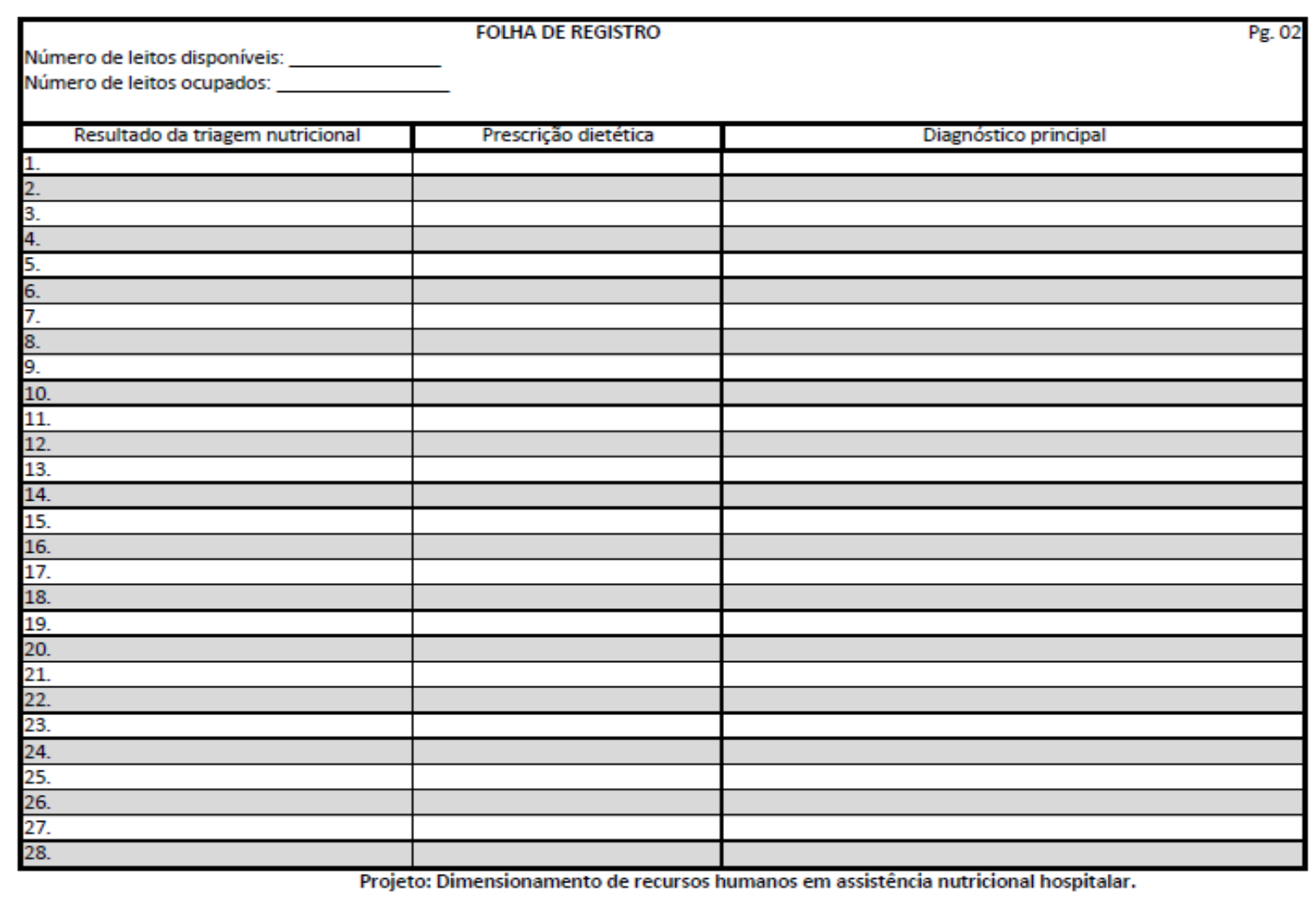

Fonte: Arquivo da pesquisadora. São Paulo, 2014

\subsection{ESTUDO PILOTO}

Participaram do estudo piloto dois nutricionistas clínicos, indicados pela gerência da UAN. Os nutricionistas eram do sexo feminino, média de idade de 26 anos, ambos especialistas em nutrição clínica, com experiência média de três anos na área hospitalar. 
106

5.2.1 Tempo médio das intervenções/atividades e tamanho da amostra

O tempo total observado foi de 1920 minutos, distribuídos em quatro turnos, sendo dois turnos matutinos e dois vespertinos (Tabela 2). Um total de 35 pacientes foi atendido durante o período de observação e a média por turno foi de 8,8 pacientes. 
Tabela 2 - Análise da distribuição das frequências e do tempo médio das intervenções/atividades observadas no estudo piloto

(continua)

\begin{tabular}{|c|c|c|c|c|c|c|c|c|c|c|c|c|c|c|c|}
\hline \multirow{3}{*}{ Intervenções e atividades } & \multicolumn{3}{|c|}{$1^{\circ}$ dia - matutino } & \multicolumn{3}{|c|}{$2^{\circ}$ dia - matutino } & \multicolumn{3}{|c|}{$3^{\circ}$ dia - vespertino } & \multicolumn{3}{|c|}{$4^{\circ}$ dia - vespertino } & \multicolumn{3}{|c|}{ Total geral } \\
\hline & \multirow{2}{*}{$\mathbf{F}_{\mathbf{I}}^{*}$} & \multicolumn{2}{|c|}{ tempo (minutos) } & \multirow{2}{*}{$\mathbf{F}^{*}$} & \multicolumn{2}{|c|}{ tempo (minutos) } & \multirow{2}{*}{$\mathbf{F}_{1}^{*}$} & \multicolumn{2}{|c|}{ tempo (minutos) } & \multirow{2}{*}{$\mathbf{F}_{1}^{*}$} & \multicolumn{2}{|c|}{ tempo (minutos) } & \multirow{2}{*}{$\mathbf{F}_{1}^{*}$} & \multicolumn{2}{|c|}{ tempo (minutos) } \\
\hline & & Total & médio & & Total & Médio & & Total & médio & & total & médio & & total & médio \\
\hline \multicolumn{16}{|l|}{ Intervenções de cuidado direto } \\
\hline 02 - Avaliação nutricional (N1) & 0 & 0,0 & - & 0 & 0,0 & - & 0 & 0,0 & - & 0 & 0,0 & - & 0 & 0,0 & - \\
\hline 02 - Avaliação nutricional (N2) & 0 & 0,0 & - & 0 & 0,0 & - & 0 & 0,0 & - & 3 & 17,8 & 5,9 & 3 & 17,8 & 5,9 \\
\hline 02 - Avaliação estado nutricional (N3) & 0 & 0,0 & - & 0 & 0,0 & - & 0 & 0,0 & - & 0 & 0,0 & - & 0 & 0,0 & - \\
\hline 06 - Ensino: dieta prescrita (N1) & 2 & 1,0 & 0,5 & 1 & 0,5 & 0,5 & 0 & 0,0 & - & 0 & 0,0 & - & 3 & 1,5 & 0,5 \\
\hline 06 - Ensino: dieta prescrita (N2) & 0 & 0,0 & - & 3 & 8,0 & 2,7 & 0 & 0,0 & - & 1 & 6,4 & 6,4 & 4 & 14,4 & 3,6 \\
\hline 06 - Ensino: dieta prescrita (N3) & 0 & 0,0 & - & 0 & 0,0 & - & 0 & 0,0 & - & 0 & 0,0 & - & 0 & 0,0 & - \\
\hline 08 - Monitoramento nutricional (N1) & 2 & 5,0 & 2,5 & 0 & 0,0 & - & 0 & 0,0 & - & 4 & 11,2 & 2,8 & 6 & 16,2 & 2,7 \\
\hline 08 - Monitoramento nutricional (N2) & 1 & 2,8 & 2,8 & 0 & 0,0 & - & 0 & 0,0 & - & 0 & 0,0 & - & 1 & 2,8 & 2,8 \\
\hline 08 - Monitoramento nutricional (N3) & 0 & 0,0 & - & 0 & 0,0 & - & 1 & 5,5 & 5,5 & 1 & 8,3 & 8,3 & 2 & 13,8 & 6,9 \\
\hline 15. Triagem nutricional (N1) & 0 & 0,0 & - & 5 & 10,7 & 2,1 & 4 & 25,2 & 6,3 & 2 & 3,0 & 1,5 & 11 & 38,9 & 3,5 \\
\hline 15. Triagem nutricional (N2) & 3 & 9,2 & 3,1 & 1 & 8,1 & 8,1 & 1 & 8,1 & 8,1 & 0 & 0,0 & - & 5 & 25,4 & 5,1 \\
\hline 15. Triagem nutricional (N3) & 0 & 0,0 & - & 0 & 0,0 & - & 0 & 0,0 & - & 0 & 0,0 & - & 0 & 0,0 & - \\
\hline \multicolumn{16}{|l|}{ Intervenções de cuidado indireto } \\
\hline 02 - Avaliação do estado nutricional & 1 & 5,8 & 5,8 & 10 & 15,2 & 1,5 & 2 & 5,6 & 2,8 & 3 & 33,0 & 11,0 & 16 & 59,6 & 3,7 \\
\hline 03 - Controle de infecção & 2 & 1,7 & 0,9 & 2 & 1,0 & 0,5 & 6 & 4,2 & 0,7 & 2 & 2,4 & 1,2 & 12 & 9,3 & 0,8 \\
\hline 05 - Documentação & 22 & 133,1 & 6,1 & 33 & 118,1 & 3,6 & 26 & 154,5 & 5,9 & 26 & 178,8 & 6,9 & 107 & 584,5 & 5,5 \\
\hline 08 - Monitoramento da evolução nutricional & 10 & 36,0 & 3,6 & 2 & 3,7 & 1,9 & 7 & 31,4 & 4,5 & 0 & 0,0 & - & 19 & 71,1 & 3,7 \\
\hline 10 - Passagem de plantão & 2 & 2,7 & 1,4 & 2 & 0,9 & 0,5 & 5 & 17,1 & 3,4 & 6 & 21,6 & 3,6 & 15 & 42,3 & 2,8 \\
\hline 12 - Reunião para avaliação do cuidado multidisciplinar & 1 & 24,9 & 24,9 & 1 & 3,5 & 3,5 & 0 & 0,0 & - & 0 & 0,0 & - & 2 & 28,4 & 14,2 \\
\hline 16 - Troca de informações & 22 & 38,8 & 1,8 & 30 & 25,1 & 0,8 & 28 & 51,6 & 1,8 & 34 & 31,5 & 0,9 & 114 & 147,0 & 1,3 \\
\hline
\end{tabular}




\section{Atividades associadas}

\begin{tabular}{|c|c|c|c|c|c|c|c|c|c|c|c|c|c|c|c|}
\hline 17 - Cadastrar acompanhante & 1 & 0,3 & 0,3 & 0 & 0,0 & - & 0,0 & 0,0 & - & 0,0 & 0,0 & - & 1,0 & 0,3 & 0,3 \\
\hline \multicolumn{16}{|l|}{ Atividades pessoais } \\
\hline 20 - Acessar computador/dispositivos móveis & 0 & 0,0 & - & 3 & 10,3 & 3,4 & 0,0 & 0,0 & - & 0,0 & 0,0 & - & 3,0 & 10,3 & 3,4 \\
\hline 21 - Alimentar-se & 3 & 20,4 & 6,8 & 2 & 25,9 & 13,0 & 0,0 & 0,0 & - & 0,0 & 0,0 & - & 5,0 & 46,3 & 9,3 \\
\hline 24 - Guardar/retirar objetos pessoais & 4 & 4,4 & 1,1 & 3 & 5,2 & 1,7 & 1,0 & 2,6 & 2,6 & 1,0 & 2,6 & 2,6 & 9,0 & 14,8 & 1,6 \\
\hline 25 - Hidratar-se & 1 & 0,8 & 0,8 & 1 & 3,9 & 3,9 & 1,0 & 3,3 & 3,3 & 0,0 & 0,0 & - & 3,0 & 8,0 & 2,7 \\
\hline 27 - Socializar c/ equipe multidisciplinar & 6 & 6,2 & 1,0 & 8 & 28,1 & 3,5 & 8,0 & 12,4 & 1,6 & 7,0 & 39,2 & 5,6 & 29,0 & 85,9 & 3,0 \\
\hline 28 - Usar toalete & 3 & 14,2 & 4,7 & 4 & 13,4 & 3,4 & 2,0 & 7,2 & 3,6 & 2,0 & 6,3 & 3,2 & 11,0 & 41,1 & 3,7 \\
\hline \multicolumn{16}{|l|}{ Outras } \\
\hline 29 - Ausência & 0 & 0,0 & - & 1 & 22,0 & 22,0 & 0,0 & 0,0 & - & 0,0 & 0,0 & - & 1,0 & 22,0 & 22,0 \\
\hline 30 - Deslocamento & 24 & 50,8 & 2,1 & 18 & 24,9 & 1,4 & 22,0 & 53,1 & 2,4 & 35,0 & 76,6 & 2,2 & 99,0 & 205,4 & 2,1 \\
\hline 31 - Tempo de espera & 15 & 120,7 & 8,0 & 18 & 146,3 & 8,1 & 13,0 & 50,4 & 3,9 & 14,0 & 40,6 & 2,9 & 60,0 & 358,0 & 6,0 \\
\hline 32 - Participação em reunião administrativa & 0 & 0,0 & - & 0 & 0,0 & - & 1,0 & 37,8 & - & 0,0 & 0,0 & - & 1,0 & 37,8 & - \\
\hline 33 - Tempo não observado & - & 1,2 & - & - & 5,2 & - & - & 10,0 & - & - & 0,7 & - & - & 17,1 & - \\
\hline Total & 125 & 480 & - & 148 & 480 & - & 128 & 480 & - & 141 & 480 & - & 542 & 1920 & - \\
\hline Contagem & & & 19 & & & 20 & & & 15 & & & 15 & & & 25 \\
\hline Mediana do tempo média das intervenções/atividades & & & 2,5 & & & $\mathbf{3 , 0}$ & & & 3,4 & & & 3,2 & & & 3,5 \\
\hline Tempo médio das intervenções/atividades & & & 3,8 & & & 3,2 & & & 3,8 & & & $\mathbf{3 , 4}$ & & & 3,5 \\
\hline Desvio padrão & & & $\mathbf{5 , 5}$ & & & $\mathbf{5 , 2}$ & & & 2,0 & & & 2,9 & & & 4,7 \\
\hline \multirow{2}{*}{ Intervalo de confiança de $95 \%$} & $\mathbf{L i}$ & & 1,2 & & & $\mathbf{0 , 8}$ & & & 2,6 & & & 1,8 & & & 1,6 \\
\hline & Ls & & 6,5 & & & 5,7 & & & 4,9 & & & $\mathbf{5 , 0}$ & & & 5,5 \\
\hline
\end{tabular}

N1: nível de atendimento de nutrição primário; N2: nível de atendimento de nutrição secundário; N3: nível de atendimento de nutrição terciário. Li: limite inferior; Ls: limite superior 
Os valores médios e intervalos de confiança estão apresentados no Gráfico 1.
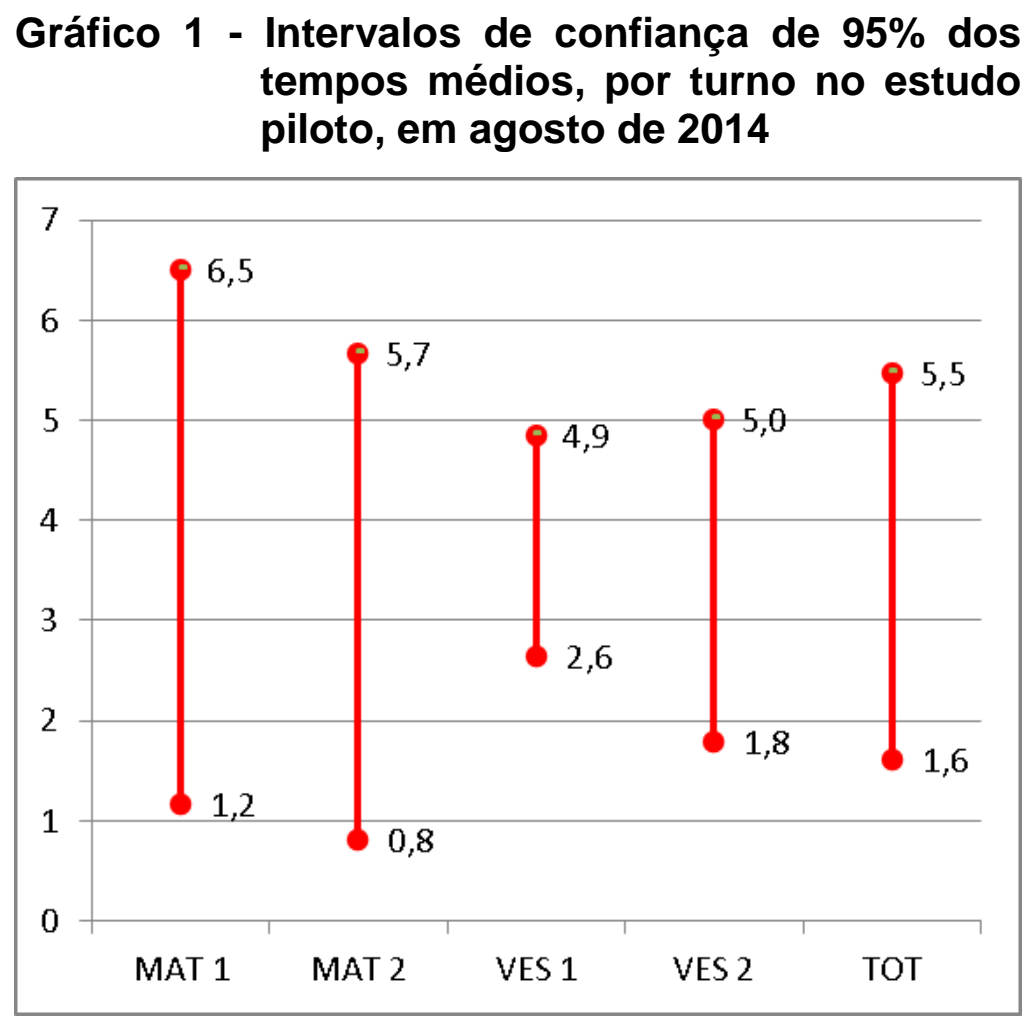

Fonte: Dados da pesquisa. São Paulo, 2016

O valor do tamanho da amostra $N_{I}=995$ observações foi obtido através da regressão dos dados, pela aplicação da equação (Gráfico 2):

$$
N_{I}=166,3[\ln (\mathrm{I}-1)+2,5]
$$


Gráfico 2 - Tamanho da amostra $\mathbf{N}$ para $\mathbf{k}$ atividades / intervenções de uma distribuição multinomial com intervalo de confiança de $95 \%$ e erro $=5 \%$

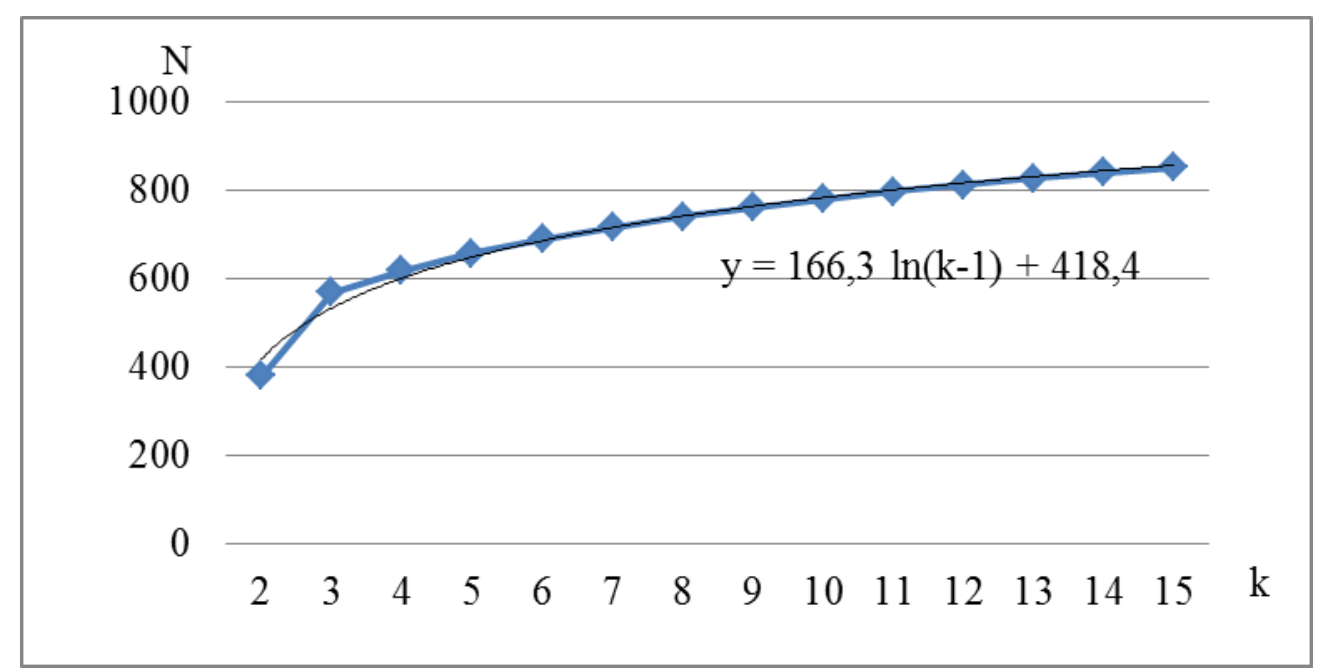

Fonte: Dados da pesquisa. São Paulo, 2016

A quantidade de turnos $\boldsymbol{U}$ amostrados na pesquisa foi calculada através da seguinte equação:

$$
U=\frac{N \cdot \bar{\delta}}{J}
$$

a) A quantidade de turnos $\boldsymbol{U}$ para jornadas de 6 horas foi:

$$
U_{6}=\frac{995 \times 3,5}{360}=9,7 \sim 10 \text { turnos }
$$

b) A quantidade de turnos $\boldsymbol{U}$ para jornadas de 8 horas foi:

$$
U_{8}=\frac{995 \times 3,5}{480}=7,3 \sim 8 \text { turnos }
$$


A quantidade de amostras estatísticas previstas nesta pesquisa foi de:

a) Para jornadas de 6 horas:

$$
N=U_{6} \frac{360}{\bar{\delta}_{i}}=10 \times \frac{360}{3,5}=1029
$$

b) Para jornadas de 8 horas:

$$
N=U_{8} \frac{480}{\delta_{i}}=8 \times \frac{480}{3,5}=1098
$$

A tabela 3 mostra a distribuição dos turnos e a quantidade de amostras das intervenções/atividades previstas para cada uma das instituições

Tabela 3 - Quantidade das amostras previstas por turno observado nas instituições hospitalares entre setembro e dezembro de 2014

\begin{tabular}{lc|c|c|c|c|c|c|c}
\hline \multirow{2}{*}{ Turnos } & \multicolumn{2}{c|}{ HSPA } & \multicolumn{2}{c|}{ HSPB } & \multicolumn{2}{c|}{ HSPC } & \multicolumn{2}{c}{3 HOSPITAIS } \\
\cline { 2 - 9 } & Turnos $^{1}$ & Amostras & Turnos $^{2}$ & Amostras & Turnos $^{2}$ & Amostras & Turnos $^{3}$ & Amostras \\
\hline Matutino & 4 & 549 & 4 & 412 & 4 & 412 & 12 & 1373 \\
Vespertino & 4 & 549 & 4 & 412 & 4 & 412 & 12 & 1373 \\
\hline TOTAL & 8 & 1098 & 8 & 824 & 8 & 824 & 24 & 2746 \\
\hline
\end{tabular}

${ }_{1}$ Turno de 480 minutos. ${ }^{2}$ Turno de 360 minutos. ${ }^{3}$ Turno médio de 400 minutos.

Fonte: Dados da pesquisa. São Paulo, 2016

\subsubsection{Verificação da aplicabilidade do documento}

Quanto ao desempenho, o instrumento para medida da frequência e do tempo despendido pelos nutricionistas clínicos na prestação do cuidado mostrou-se 
satisfatório. Das 16 intervenções de nutrição propostas no instrumento validado, nove (56\%) ocorreram durante o estudo piloto (Quadro 6).

\section{Quadro 6 - Intervenções de nutrição clínica que ocorreram durante o estudo piloto em junho de 2014}
2. Avaliação do estado nutricional
3. Controle de infecção
5. Documentação
6. Ensino: orientação da dieta prescrita
8. Monitoramento do estado nutricional
10. Passagem de plantão
12. Reunião para avaliação do cuidado multidisciplinar
15. Triagem nutricional
16. Troca de informações sobre cuidados de saúde

Fonte: Arquivo da pesquisadora. São Paulo, 2016

Além das intervenções de nutrição clínica, foi possível identificar as atividades associadas, atividades pessoais, deslocamento, espera e participação em reunião administrativa.

Percebeu-se, também, que uma mesma intervenção poderia abranger atividades relacionadas tanto ao cuidado direto quanto ao cuidado indireto. Assim sendo, procedeu-se a classificação de cada atividade contemplada nas intervenções de nutrição clínica.

O quadro 7 apresenta as intervenções, classificadas em ordem alfabética, as atividades relacionadas a cada intervenção e o tipo de cuidado. 
Quadro 7 - Distribuição das atividades relacionadas a cada intervenção, de acordo com o tipo de cuidado, entre setembro e dezembro de 2014

\begin{tabular}{|c|c|c|}
\hline Intervenção & Atividades & $\begin{array}{l}\text { Tipo de } \\
\text { cuidado }\end{array}$ \\
\hline $\begin{array}{l}\text { AVALIAÇÃO } \\
\text { DE PRODUTO }\end{array}$ & $\begin{array}{l}\text { - Identificar a necessidade de um novo } \\
\text { produto ou uma mudança de produto } \\
\text { atualmente usado. } \\
\text { - } \quad \text { Preencher formulários da experiência } \\
\text { da avaliação. } \\
\text { - Obter a avaliação do paciente sobre o } \\
\text { produto (ex. suplemento nutricional). } \\
\text { - Assistir à apresentação de } \\
\text { representante de produto. }\end{array}$ & Indireto \\
\hline \multirow[t]{2}{*}{$\begin{array}{l}\text { AVALIAÇÃO } \\
\text { DO ESTADO } \\
\text { NUTRICIONAL }\end{array}$} & $\begin{array}{l}\text { Realizar anamnese: preferências e } \\
\text { aversões, intolerâncias, alergias, } \\
\text { apetite, problemas alimentares, } \\
\text { mudança de peso recente, ingestão } \\
\text { alimentar habitual, frequência } \\
\text { alimentar, medicamentos, suplementos } \\
\text { nutricionais, habilidade para ler e } \\
\text { escrever, nível de atividade física, } \\
\text { condição socioeconômica e } \\
\text { conhecimento prévio acerca das } \\
\text { restrições alimentares. } \\
\text { Avaliar a composição corporal através } \\
\text { de medidas antropométricas. }\end{array}$ & Direto \\
\hline & $\begin{array}{l}\text { - Analisar a composição corporal através } \\
\text { de medidas antropométricas. } \\
\text { - Calcular o gasto energético basal e as } \\
\text { necessidades energéticas e } \\
\text { nutricionais. } \\
\text { - Retirar/devolver materiais para } \\
\text { avaliação do estado nutricional. }\end{array}$ & Indireto \\
\hline
\end{tabular}


(continuação)

\begin{tabular}{|c|c|c|}
\hline Intervenção & Atividades & $\begin{array}{l}\text { Tipo de } \\
\text { cuidado }\end{array}$ \\
\hline $\begin{array}{l}\text { Controle de } \\
\text { infecção }\end{array}$ & $\begin{array}{l}\text { - } \text { Lavar as mãos. } \\
\text { - } \text { Descartar roupa de precaução de } \\
\text { contato. } \\
\text { - } \text { Paramentar-se. } \\
\text { - Higienizar as mãos com álcool gel. } \\
\text { - Realizar desinfecção de materiais e } \\
\text { equipamentos }\end{array}$ & Indireto \\
\hline $\begin{array}{c}\text { Desenvolvimento } \\
\text { de funcionários }\end{array}$ & $\begin{array}{l}\text { Encorajar a participação em atividades } \\
\text { dentro e fora do Serviço de Nutrição e } \\
\text { Dietética (organizações profissionais, } \\
\text { eventos científicos). } \\
\text { - Preparar e/ou apresentar palestrar e } \\
\text { treinamentos. } \\
\text { - Consultar bibliografia adequada em } \\
\text { busca de implicação clínica. }\end{array}$ & Indireto \\
\hline Documentação & $\begin{array}{l}\text { - Redigir, digitar ou ticar dados } \\
\text { relacionados ao cuidado nutricional do } \\
\text { paciente. }\end{array}$ & Indireto \\
\hline $\begin{array}{l}\text { Ensino: } \\
\text { orientação da } \\
\text { dieta prescrita }\end{array}$ & $\begin{array}{l}\text { - Avaliar o nível de conhecimentos do } \\
\text { paciente sobre a dieta prescrita. } \\
\text { Explicar a finalidade da dieta e/ou } \\
\text { esclarecer dúvidas relacionadas à dieta } \\
\text { ou ao tratamento nutricional. } \\
\text { - Reforçar informações oferecidas por } \\
\text { outros membros da equipe de saúde, } \\
\text { conforme apropriado. } \\
\text { - Incluir familiares/pessoas importantes, } \\
\text { conforme apropriado. }\end{array}$ & Direto \\
\hline
\end{tabular}

(continua) 
(continuação)

\begin{tabular}{|c|c|c|}
\hline Intervenção & Atividades & $\begin{array}{l}\text { Tipo de } \\
\text { Cuidado }\end{array}$ \\
\hline $\begin{array}{c}\text { Ensino: } \\
\text { orientação da } \\
\text { dieta prescrita }\end{array}$ & $\begin{array}{l}\text { - Orientar o paciente/família/pessoas } \\
\text { importantes sobre a dieta prescrita. }\end{array}$ & Direto \\
\hline $\begin{array}{c}\text { Estabelecimento } \\
\text { de protocolos de } \\
\text { cuidado }\end{array}$ & $\begin{array}{l}\text { - Elaborar/revisar os padrões atuais de } \\
\text { prática relacionados à população de } \\
\text { pacientes. } \\
\text { - Elaborar/revisar impressos próprios } \\
\text { para o atendimento nutricional. } \\
\text { - Colaborar com outros profissionais de } \\
\text { saúde para elaborar protocolos de } \\
\text { cuidado multidisciplinar. }\end{array}$ & Indireto \\
\hline \multirow[b]{2}{*}{$\begin{array}{c}\text { Monitoramento } \\
\text { da evolução } \\
\text { nutricional }\end{array}$} & $\begin{array}{l}\text { Observar a ocorrência de mudanças } \\
\text { importantes no comportamento } \\
\text { alimentar ou no estado nutricional } \\
\text { durante a visita de acompanhamento, } \\
\text { conforme apropriado. }\end{array}$ & Direto \\
\hline & $\begin{array}{l}\text { - Monitorar a ingestão calórica e de } \\
\text { nutrientes, os dados dos exames } \\
\text { laboratoriais, medicações em uso. } \\
\text { - Monitorar e analisar medidas } \\
\text { antropométricas e/ou de composição } \\
\text { corporal. } \\
\text { - Escolher indicadores nutricionais } \\
\text { adequados aos pacientes para } \\
\text { monitoramento contínuo com base na } \\
\text { condição do paciente. } \\
\text { - Estabelecer frequência de coleta e } \\
\text { interpretação dos dados conforme } \\
\text { protocolo. } \\
\text { - Comparar o estado nutricional atual } \\
\text { com o anterior para detectar melhorias } \\
\text { e pioras na condição do paciente. } \\
\text { - Instituir tratamento adequado, usando } \\
\text { protocolos válidos. }\end{array}$ & Indireto \\
\hline
\end{tabular}


(continuação)

\begin{tabular}{|c|c|c|}
\hline Intervenção & Atividades & Tipo de cuidado \\
\hline $\begin{array}{c}\text { Monitoramento } \\
\text { da evolução } \\
\text { nutricional }\end{array}$ & $\begin{array}{l}\text { - Identificar os fatores capazes de afetar } \\
\text { os valores laboratoriais. } \\
\text { - Verificar o efeito dos medicamentos } \\
\text { sobre a interação droga-nutriente. } \\
\text { - Verificar o efeito da ingestão alimentar } \\
\text { sobre os valores laboratoriais. } \\
\text { - Retirar/devolver } \\
\text { materiais/equipamentos para avaliação } \\
\text { nutricional. }\end{array}$ & Indireto \\
\hline $\begin{array}{l}\text { Orientação } \\
\text { alimentar e } \\
\text { nutricional na } \\
\text { alta hospitalar }\end{array}$ & $\begin{array}{l}\text { - Orientar o paciente/família/responsável } \\
\text { quanto aos cuidados nutricionais em } \\
\text { domicílio. } \\
\text { - } \quad \text { Realizar grupos educativos com } \\
\text { pacientes no pós-alta hospitalar. }\end{array}$ & Direto \\
\hline $\begin{array}{l}\text { Passagem de } \\
\text { plantão }\end{array}$ & - Passar plantão para o nutricionista. & Indireto \\
\hline $\begin{array}{l}\text { Preceptor: } \\
\text { estudante }\end{array}$ & $\begin{array}{l}\text { - Apresentar os alunos aos membros da } \\
\text { equipe e os pacientes. } \\
\text { - } \quad \text { Facilitar a interação entre estudantes e } \\
\text { pacientes. } \\
\text { - } \text { Acompanhar estagiário de nutrição } \\
\text { clínica na realização das atividades. } \\
\text { - Prestar orientação aos internos e } \\
\text { residentes. } \\
\text { - Avaliar evoluções e prescrições de } \\
\text { nutrição realizadas por estagiários, } \\
\text { aprimorandos e residentes. } \\
\text { - Tirar dúvidas de estagiários, } \\
\text { aprimorandos e residentes de nutrição. } \\
\text { Discutir o plano de cuidados } \\
\text { nutricionais com os estudantes. }\end{array}$ & Indireto \\
\hline
\end{tabular}


(continuação)

\begin{tabular}{|c|c|c|}
\hline Intervenção & Atividades & Tipo de cuidado \\
\hline $\begin{array}{l}\text { Preceptor: } \\
\text { estudante }\end{array}$ & $\begin{array}{l}\text { Envolver os estudantes em atividades } \\
\text { de pesquisa, conforme apropriado. } \\
\text { - Participar em apresentação de } \\
\text { estudantes. }\end{array}$ & Indireto \\
\hline $\begin{array}{l}\text { Reunião para } \\
\text { avaliação do } \\
\text { cuidado } \\
\text { multidisciplinar }\end{array}$ & $\begin{array}{l}\text { - } \quad \text { Resumir os dados sobre o estado } \\
\text { nutricional do paciente, pertinentes ao } \\
\text { planejamento dos cuidados. } \\
\text { - } \quad \text { Identificar os diagnósticos nutricionais. } \\
\text { implementadas. } \\
\text { - } \quad \text { Discutir o progresso na direção das } \\
\text { metas e a necessidade de outras } \\
\text { intervenções multiprofissionais. } \\
\text { Revisar o plano de cuidados } \\
\text { nutricionais, se necessário. } \\
\text { Recomendar mudanças no plano de } \\
\text { cuidados nutricionais, conforme } \\
\text { necessário. }\end{array}$ & Indireto \\
\hline $\begin{array}{l}\text { Supervisão da } \\
\text { distribuição das } \\
\text { refeições nas } \\
\text { unidades }\end{array}$ & 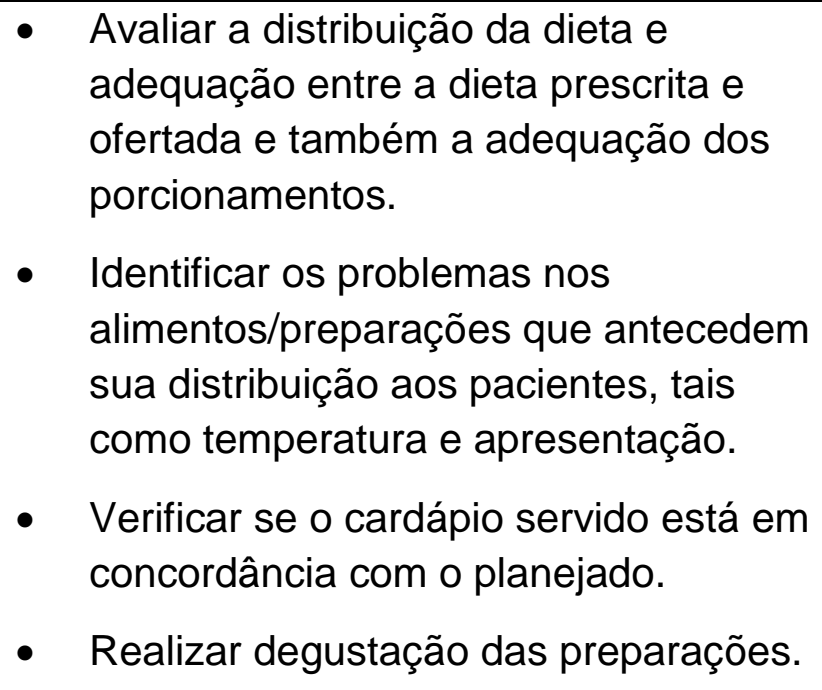 & Indireto \\
\hline $\begin{array}{c}\text { Terapia } \\
\text { recreacional }\end{array}$ & $\begin{array}{l}\text { - Socializar com acompanhantes. } \\
\text { - Participar de confraternização com os } \\
\text { pacientes }\end{array}$ & Direto \\
\hline
\end{tabular}


(continuação)

\begin{tabular}{|c|c|c|}
\hline Intervenção & Atividades & Tipo de cuidado \\
\hline $\begin{array}{l}\text { Triagem } \\
\text { nutricional }\end{array}$ & $\begin{array}{l}\text { - } \quad \text { Apresentar-se e informar seu papel na } \\
\text { prestação dos cuidados. } \\
\text { - } \quad \text { Realizar o exame físico da admissão, } \\
\text { conforme apropriado. } \\
\text { - Realizar anamnese nutricional: } \\
\text { preferências e aversões, intolerâncias, } \\
\text { alergias, apetite, problemas } \\
\text { alimentares e mudança de peso } \\
\text { recente. }\end{array}$ & Direto \\
\hline $\begin{array}{l}\text { Troca de } \\
\text { informações sobre } \\
\text { cuidados de saúde }\end{array}$ & $\begin{array}{l}\text { - } \quad \text { Discutir as preocupações com os } \\
\text { cuidados ao paciente, ou assuntos } \\
\text { relativos à prática, diretamente com os } \\
\text { profissionais envolvidos. } \\
\text { - } \quad \text { Acessar e-mail institucional. }\end{array}$ & Indireto \\
\hline
\end{tabular}

(conclusão)

Fonte: Arquivo da pesquisadora. São Paulo, 2016

\subsection{MENSURAÇÃO DO TEMPO DESPENDIDO NAS INTERVENÇÕES E ATIVIDADES}

\subsubsection{Caracterização dos participantes}

A tabela 4 apresenta o perfil dos nutricionistas observados. 
Tabela 4 - Caracterização dos nutricionistas observados entre setembro e dezembro de 2014

\begin{tabular}{|c|c|c|}
\hline & $\mathrm{n}$ & $\%$ \\
\hline \multicolumn{3}{|l|}{ Gênero } \\
\hline Feminino & 18 & 95 \\
\hline Masculino & 1 & 1 \\
\hline \multicolumn{3}{|l|}{ Idade } \\
\hline $20-30$ anos & 12 & 63 \\
\hline $31-40$ anos & 2 & 11 \\
\hline $41-50$ anos & 3 & 16 \\
\hline $50-55$ anos & 1 & 5 \\
\hline$>55$ anos & 1 & 5 \\
\hline \multicolumn{3}{|l|}{ Graduação } \\
\hline Universidade Pública & 15 & 79 \\
\hline Universidade Privada & 4 & 21 \\
\hline \multicolumn{3}{|l|}{ Tempo de graduação } \\
\hline de 1 a 5 anos & 9 & 48 \\
\hline de 6 a 10 anos & 5 & 26 \\
\hline de 11 a 15 anos & - & - \\
\hline acima de 15 anos & 5 & 26 \\
\hline \multicolumn{3}{|l|}{ Maior titulação } \\
\hline Graduação & 2 & 11 \\
\hline Aprimoramento & 2 & 11 \\
\hline Especialização & 13 & 67 \\
\hline Mestrado & 2 & 11 \\
\hline \multicolumn{3}{|c|}{ Tempo de experiência em Nutrição Clínica } \\
\hline de 1 a 5 anos & 11 & 58 \\
\hline de 6 a 10 anos & 3 & 16 \\
\hline de 11 a 15 anos & - & - \\
\hline acima de 15 anos & 5 & 26 \\
\hline \multicolumn{3}{|c|}{ Tempo de experiência na instituição } \\
\hline de 1 a 5 anos & 13 & 68 \\
\hline de 6 a 10 anos & 1 & 5 \\
\hline de 11 a 15 anos & 1 & 5 \\
\hline acima de 15 anos & 4 & 22 \\
\hline \multicolumn{3}{|c|}{ Tempo de experiência na unidade } \\
\hline de 1 a 5 anos & 13 & 68 \\
\hline de 6 a 10 anos & 2 & 10 \\
\hline de 11 a 15 anos & 2 & 11 \\
\hline acima de 15 anos & 2 & 11 \\
\hline \multicolumn{3}{|c|}{ Carga de trabalho semanal } \\
\hline 40 horas & 19 & 100 \\
\hline
\end{tabular}

Fonte: Dados da pesquisa. São Paulo, 2016 
A maioria dos nutricionistas foi observada durante um único dia de trabalho (Tabela 5).

Tabela 5 - Distribuição do quantitativo de nutricionistas clínicos observados por turno e hospital, no período entre setembro e dezembro de 2014

\begin{tabular}{lccccccccc}
\hline \multirow{2}{*}{ TURNO } & \multicolumn{2}{c}{ HSPA } & \multicolumn{2}{c}{ HSPB } & \multicolumn{2}{c}{ HSPC } & \multicolumn{2}{c}{ TOTAL } \\
\cline { 2 - 9 } & Nut & Turnos & Nut & Turnos & Nut & Turnos & Nut & Turnos \\
\hline Matutino & 4 & 4 & 4 & 4 & $3(1)$ & 4 & $11(1)$ & 12 \\
Vespertino & 4 & 4 & $2(2)$ & 4 & $2(2)$ & 4 & $8(4)$ & 12 \\
Total & 8 & 8 & $6(2)$ & 8 & $5(3)$ & 8 & $19(24)$ & 24 \\
\hline
\end{tabular}

O quantitativo entre parênteses representa os nutricionistas que foram observados repetidamente.

Nut: nutricionistas

Fonte: Dados da pesquisa. São Paulo, 2016

5.3.2 Caracterização das unidades de internação estudadas

A tabela 6 apresenta as características gerais das UAN. 
Tabela 6 - Características das UAN observadas nos meses de setembro

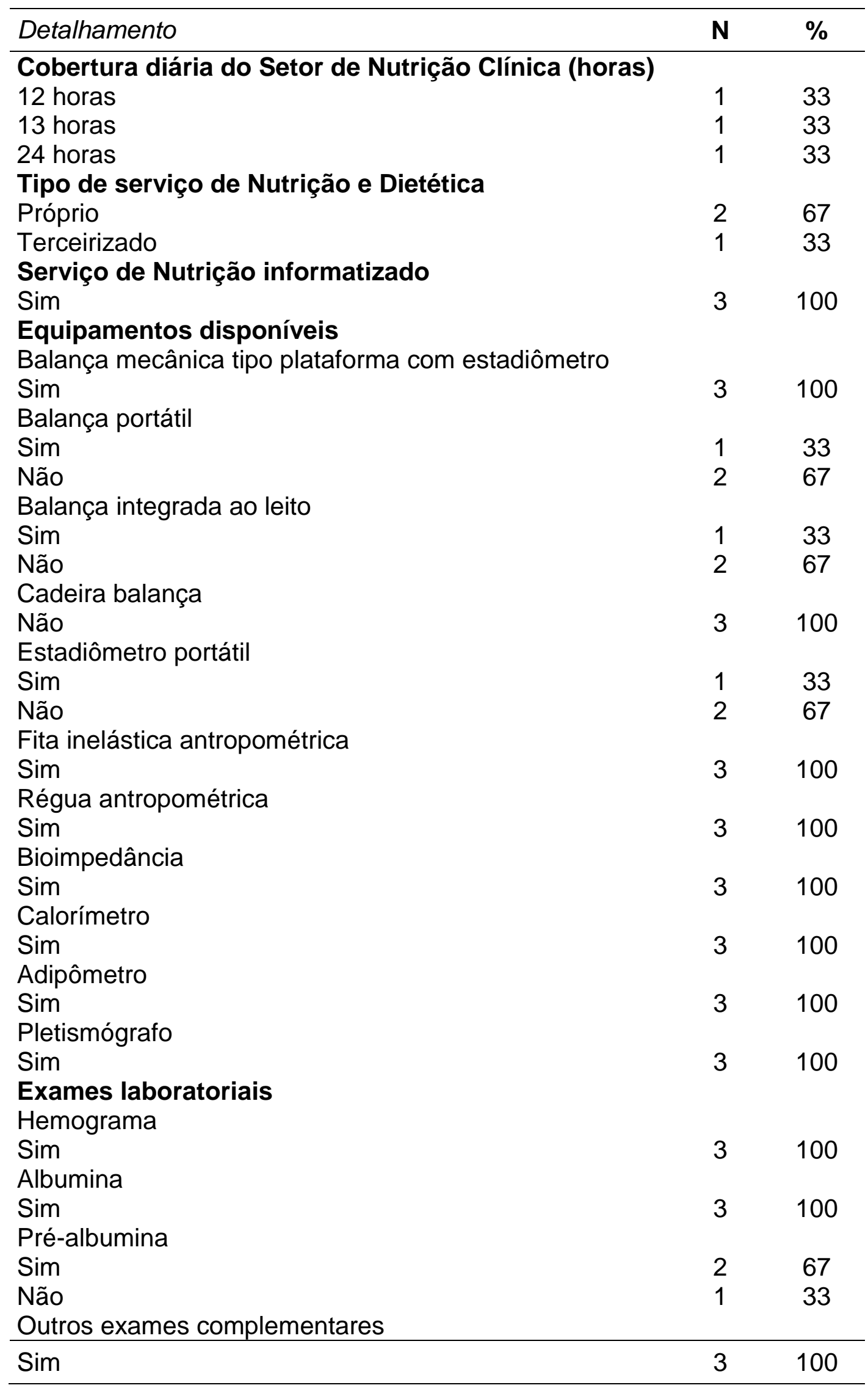


Um total de 205 pacientes foi atendido pelos nutricionistas clínicos ao longo dos 24 dias de acompanhamento da jornada de trabalho, totalizando uma média de nove pacientes por dia (Tabela 7).

Tabela 7 - Quantidade de pacientes submetidos a intervenções de cuidado direto, segundo o nível de atendimento de nutrição, o turno e o hospital, entre setembro e dezembro de 2014

\begin{tabular}{lccccccc}
\hline \multicolumn{1}{c}{$\begin{array}{c}\text { Nível de atendimento de } \\
\text { nutrição }\end{array}$} & \multicolumn{2}{c}{ HSPA } & \multicolumn{2}{c}{ HSPB } & \multicolumn{2}{c}{ HSPC } & Total \\
& $\mathrm{M}$ & $\mathrm{V}$ & $\mathrm{M}$ & $\mathrm{V}$ & $\mathrm{M}$ & $\mathrm{V}$ & $n(\%)$ \\
\hline Nível primário & 1 & 1 & 3 & 30 & 5 & 7 & $47(23)$ \\
Nível secundário & 21 & 16 & 16 & 15 & 9 & 13 & $90(44)$ \\
Nível terciário & 16 & 7 & 20 & 10 & 6 & 9 & $68(33)$ \\
\hline Total geral & $\mathbf{3 8}$ & $\mathbf{2 4}$ & $\mathbf{3 9}$ & $\mathbf{5 5}$ & $\mathbf{2 0}$ & $\mathbf{2 9}$ & $\mathbf{2 0 5}$ \\
\hline M = matutino; $\boldsymbol{V}=$ vespertino & & & & & & &
\end{tabular}

Fonte: Dados da pesquisa. São Paulo, 2016

A maioria dos pacientes atendidos pelos nutricionistas, ou seja, submetidos às intervenções de cuidado direto compreendeu o grupo etário adulto e idoso (Tabela 8). As unidades de internação observadas nos três hospitais compreenderam: clínica médica, clínica cirúrgica, unidade de terapia intensiva e emergência.

Tabela 8 - Distribuição do quantitativo de pacientes atendidos pelos nutricionistas, segundo o grupo etário, entre setembro e dezembro de 2014

\begin{tabular}{lccccc}
\hline Grupo etário dos pacientes & HSPA & HSPB & HSPC & Total & $\%$ \\
\hline Criança/adolescente & - & 8 & 10 & 18 & 9 \\
Adulto/idoso & 62 & 86 & 39 & 187 & 91 \\
Total geral & $\mathbf{6 2}$ & $\mathbf{9 4}$ & $\mathbf{4 9}$ & $\mathbf{2 0 5}$ & $\mathbf{1 0 0}$ \\
\hline
\end{tabular}

Fonte: Dados da pesquisa. São Paulo, 2016 


\subsection{DISTRIBUIÇÃO DAS FREQUÊNCIAS E O CÁLCULO DO TEMPO DAS INTERVENÇÕES/ATIVIDADES, SEGUNDO O NÍVEL DE ATENDIMENTO DE NUTRIÇÃO}

A distribuição total do tempo das intervenções/atividades realizadas pelos nutricionistas clínicos e do número de amostras de intervenções/atividades coletadas, durante a jornada de trabalho, por turno de trabalho e unidade hospitalar está apresentada na Tabela 9. O número de amostras coletadas (3931) superou em $43 \%$ o tamanho da amostra calculada (2746).

Tabela 9 - Distribuição das amostradas coletadas e do tempo total observado no período de setembro a dezembro de 2014

\begin{tabular}{cccccccccc}
\hline Unidade & \multicolumn{2}{c}{ HSPA } & \multicolumn{2}{c}{ HSPB } & \multicolumn{2}{c}{ HSPC } & \multicolumn{2}{c}{ Total geral } \\
\cline { 2 - 10 } hospitalar/turno & $\boldsymbol{N}$ & Minutos & $\boldsymbol{N}$ & Minutos & $\boldsymbol{N}$ & Minutos & $\boldsymbol{N}$ & Minutos \\
\hline Matutino & 502 & 1.920 & 693 & 1.440 & 633 & 1.440 & 1828 & 4.800 \\
Vespertino & 624 & 1.920 & 780 & 1.440 & 699 & 1.440 & 2073 & 4.800 \\
\hline Total geral & $\mathbf{1 . 1 2 6}$ & $\mathbf{3 . 8 4 0}$ & $\mathbf{1 . 4 7 3}$ & $\mathbf{2 . 8 8 0}$ & $\mathbf{1 . 3 3 2}$ & $\mathbf{2 . 8 8 0}$ & $\mathbf{3 . 9 3 1}$ & $\mathbf{9 . 6 0 0}$ \\
\hline
\end{tabular}

Fonte: Dados da pesquisa. São Paulo, 2016

A distribuição do tempo despendido nas intervenções, atividades associadas e pessoais, espera, deslocamento, ausência e participação em reunião administrativa, de acordo com o turno e o hospital, está apresentada nas tabelas 10 e 11. 
Tabela 10 - Distribuição do tempo médio despendido em intervenções/atividades realizadas pelos nutricionistas clínicos, no período matutino, entre setembro e dezembro de 2014

\begin{tabular}{|c|c|c|c|c|c|c|c|c|}
\hline \multirow[t]{2}{*}{ Intervenções/atividades } & \multicolumn{2}{|c|}{ HSPA } & \multicolumn{2}{|c|}{ HSPB } & \multicolumn{2}{|c|}{ HSPC } & \multicolumn{2}{|c|}{ NOS 3 HOSPITAIS } \\
\hline & $\begin{array}{c}\mathrm{T}_{\mathrm{A}} \\
\text { (min.) }\end{array}$ & $\mathbf{P} \%$ & $\begin{array}{c}T_{B} \\
\text { (min.) }\end{array}$ & $\mathbf{P} \%$ & $\begin{array}{c}T_{C} \\
\text { (min.) }\end{array}$ & $\mathbf{P} \%$ & $\begin{array}{c}\mathrm{T}_{\mathrm{T}} \\
(\min .)\end{array}$ & $\mathbf{P} \%$ \\
\hline Intervenções de cuidado direto & 312,7 & 16,3 & 133,0 & 9,2 & 74,5 & 5,2 & 520,2 & 10,8 \\
\hline Intervenções de cuidado indireto & 1268,8 & 66,1 & 945,3 & 65,6 & 993,2 & 68,9 & 3207,3 & 66,8 \\
\hline Atividades associadas & 3,3 & 0,2 & 2,5 & 0,2 & 17,0 & 1,2 & 22,8 & 0,5 \\
\hline Atividades pessoais & 166,5 & 8,7 & 95,2 & 6,6 & 110,0 & 7,6 & 371,7 & 7,7 \\
\hline Participar de reunião administrativa & 0,0 & 0,0 & 3,4 & 0,2 & 0,0 & 0,0 & 3,4 & 0,1 \\
\hline Ausência & 0,0 & 0,0 & 0,0 & 0,0 & 0,0 & 0,0 & 0,0 & 0,0 \\
\hline Deslocamento & 87,6 & 4,6 & 188,5 & 13,1 & 174,0 & 12,1 & 450,1 & 9,4 \\
\hline Espera & 43,6 & 2,3 & 32,4 & 2,3 & 33,3 & 2,3 & 109,3 & 2,3 \\
\hline Sem observação & 37,4 & 1,9 & 39,9 & 2,8 & 38,4 & 2,7 & 115,7 & 2,4 \\
\hline Total geral & 1920 & 100 & 1440 & 100 & 1440 & 100 & 4.800 & 100 \\
\hline
\end{tabular}

$\mathrm{T}_{\mathrm{A}}$ : tempo do HSPA; $\mathrm{T}_{\mathrm{B}}$ : tempo do HSPB; $\mathrm{T}_{\mathrm{C}}$ : tempo do HSPC.

$P$ : porcentagem do tempo em relação ao tempo total despendido nas intervenções/atividades.

Fonte: Dados da Pesquisa. São Paulo, 2016 
Tabela 11 - Distribuição do tempo médio despendido nas intervenções/atividades realizadas pelos nutricionistas clínicos, no período vespertino, entre setembro e dezembro de 2014

\begin{tabular}{|c|c|c|c|c|c|c|c|c|}
\hline \multirow[t]{2}{*}{ Intervenções/atividades } & \multicolumn{2}{|c|}{ HSPA } & \multicolumn{2}{|c|}{ HSPB } & \multicolumn{2}{|c|}{ HSPC } & \multicolumn{2}{|c|}{ TOTAL } \\
\hline & $\begin{array}{c}T_{A} \\
\text { (min.) }\end{array}$ & $\mathbf{P} \%$ & $\begin{array}{c}T_{A} \\
\text { (min.) }\end{array}$ & $\mathbf{P} \%$ & $\begin{array}{c}T_{A} \\
\text { (min.) }\end{array}$ & $\mathbf{P} \%$ & $\begin{array}{c}\mathrm{T}_{\mathrm{T}} \\
\text { (min.) }\end{array}$ & $\mathbf{P} \%$ \\
\hline Intervenções de cuidado direto & 147,2 & 7,7 & 153,6 & 10,7 & 91,3 & 6,3 & 392,1 & 8,2 \\
\hline Intervenções de cuidado indireto & 1283,0 & 66,8 & 720,0 & 50,0 & 865,1 & 60,1 & 2868,1 & 59,8 \\
\hline Atividades associadas & 0,0 & 0,0 & 3,8 & 0,3 & 31,7 & 2,2 & 35,5 & 0,7 \\
\hline Atividades pessoais & 182,5 & 9,5 & 171,1 & 11,9 & 146,8 & 10,2 & 500,4 & 10,4 \\
\hline Participar de reunião administrativa & 42,6 & 2,2 & 0,0 & 0,0 & 11,2 & 0,8 & 53,8 & 1,1 \\
\hline Ausência & 0,0 & 0,0 & 57,5 & 4,0 & 0,0 & 0,0 & 57,5 & 1,2 \\
\hline Deslocamento & 178,2 & 9,3 & 298,5 & 20,7 & 204,8 & 14,2 & 681,5 & 14,2 \\
\hline Tempo de espera & 77,3 & 4,0 & 10,2 & 0,7 & 56,6 & 3,9 & 144,1 & 3,0 \\
\hline Sem observação & 9,4 & 0,5 & 25,3 & 1,8 & 32,6 & 2,3 & 67,3 & 1,4 \\
\hline Total geral & 1920 & 100 & 1440 & 100 & 1440 & 100 & 4.800 & 100 \\
\hline
\end{tabular}

$\mathrm{T}_{\mathrm{A}}$ tempo do HSPA; $\mathrm{T}_{\mathrm{B}}$ tempo do HSPB; $\mathrm{T}_{\mathrm{C}}$ tempo do HSPC.

$\mathrm{P}$ : porcentagem do tempo em relação ao tempo total despendido nas intervenções/atividades.

Fonte: Dados da pesquisa. São Paulo, 2016 
O gráfico 3 mostra a distribuição percentual do tempo despendido pelos nutricionistas clínicos nas intervenções e atividades, durante a jornada de trabalho, nos três hospitais estudados.

Gráfico 3 - Distribuição percentual do tempo despendido pelos nutricionistas em intervenções de cuidado direto e de cuidado indireto, atividades associadas, atividades pessoais, tempo de espera, deslocamento, ausência e participar de reunião administrativa, de acordo com o turno, entre setembro e dezembro de 2014

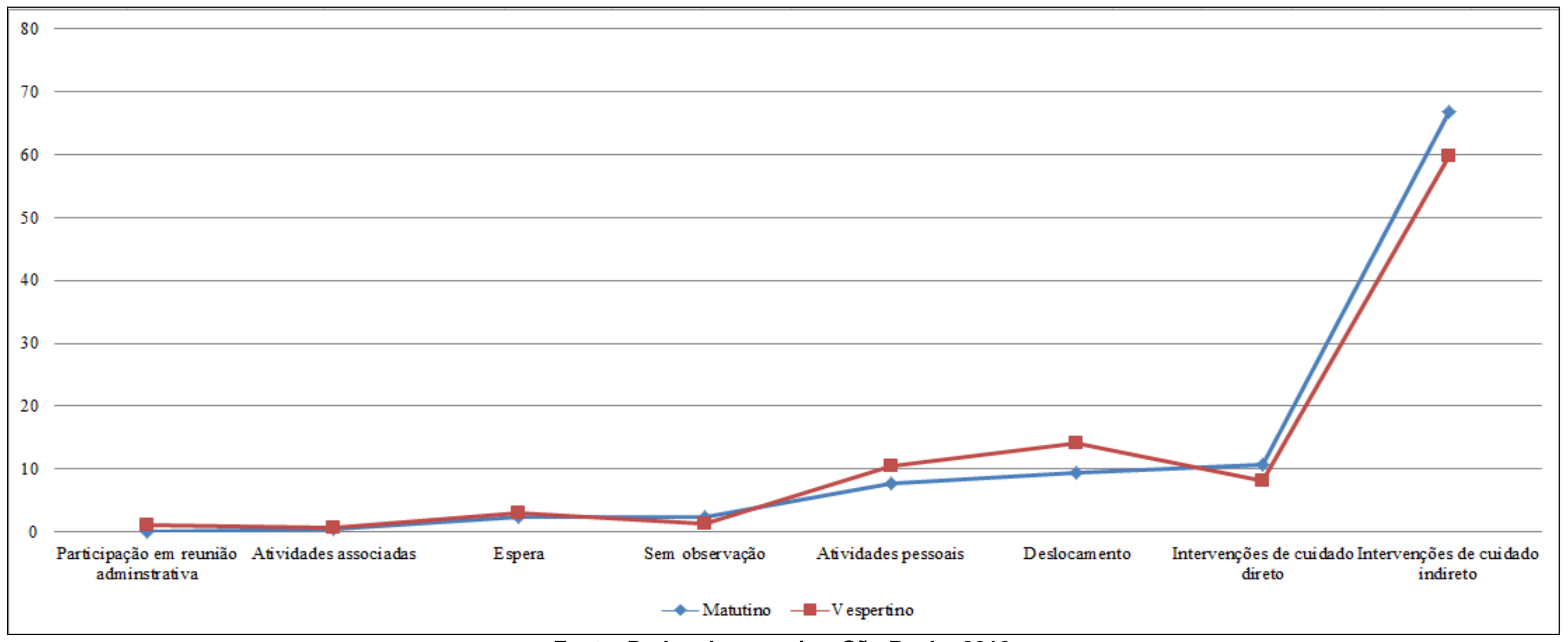

Fonte: Dados da pesquisa. São Paulo, 2016 
A tabela 12 mostra a distribuição geral da frequência das intervenções/atividades e do tempo de cuidado dos nutricionistas clínicos nos três hospitais estudados

Tabela 12 - Distribuição da frequência e do tempo despendido nas intervenções/atividades realizadas pelos nutricionistas clínicos, nas três unidades hospitalares

\begin{tabular}{|c|c|c|c|c|c|c|c|c|c|c|c|c|}
\hline \multirow{2}{*}{$\begin{array}{l}\text { Intervenções/ } \\
\text { atividades }\end{array}$} & \multicolumn{3}{|c|}{ HSPA } & \multicolumn{3}{|c|}{ HSPB } & \multicolumn{3}{|c|}{ HSPC } & \multicolumn{3}{|c|}{ TOTAL } \\
\hline & $F_{A}$ & $\begin{array}{c}T_{A} \\
\text { (min.) }\end{array}$ & $\mathbf{P} \%$ & $F_{B}$ & $\begin{array}{c}T_{B} \\
\text { (min.) }\end{array}$ & $\mathrm{P} \%$ & $\boldsymbol{F}_{C}$ & $\begin{array}{c}T_{C} \\
(\min .)\end{array}$ & $\mathbf{P} \%$ & $\boldsymbol{F}_{T}$ & $\begin{array}{c}\mathrm{T}_{\mathrm{T}} \\
\text { (min.) }\end{array}$ & $\mathrm{P} \%$ \\
\hline $\begin{array}{l}\text { Intervenções de } \\
\text { cuidado direto }\end{array}$ & 84 & 459,9 & 12,0 & 103 & 286,6 & 10,0 & 50 & 166,0 & 5,8 & 237 & 912,5 & 9,5 \\
\hline $\begin{array}{l}\text { Intervenções de } \\
\text { cuidado indireto }\end{array}$ & 668 & 2551,7 & 66,5 & 822 & 1665,0 & 57,8 & 750 & 1858,0 & 64,5 & 2240 & 6074,7 & 63,3 \\
\hline $\begin{array}{l}\text { Atividades } \\
\text { associadas }\end{array}$ & 1 & 3,3 & 0,1 & 11 & 6,3 & 0,2 & 26 & 48,5 & 1,7 & 38 & 58,1 & 0,6 \\
\hline $\begin{array}{l}\text { Atividades } \\
\text { pessoais }\end{array}$ & 116 & 349,0 & 9,1 & 65 & 266,8 & 9,3 & 62 & 256,5 & 8,9 & 243 & 872,3 & 9,1 \\
\hline $\begin{array}{l}\text { Participação em } \\
\text { reunião administrativa }\end{array}$ & 1 & 42,6 & 1,1 & 1 & 3,4 & 0,1 & 1 & 11,0 & 0,4 & 3 & 57,0 & 0,6 \\
\hline Ausência & 0 & 0,0 & 0,0 & 1 & 57,5 & 2,0 & 0 & 0,0 & 0,0 & 1 & 57,5 & 0,6 \\
\hline Deslocamento & 214 & 265,8 & 6,9 & 432 & 487,0 & 16,9 & 391 & 379,0 & 13,2 & 1037 & 1131,8 & 11,8 \\
\hline Espera & 35 & 120,9 & 3,1 & 30 & 42,6 & 1,5 & 44 & 90,0 & 3,1 & 109 & 253,5 & 2,6 \\
\hline Sem observação & 7 & 46,8 & 1,2 & 8 & 65,2 & 2,3 & 8 & 71,0 & 2,5 & 23 & 183,0 & 1,9 \\
\hline Total geral & 1126 & 3840 & 100 & 1473 & 2880 & 100 & 1332 & 2880 & 100 & 3931 & 9.600 & 100 \\
\hline
\end{tabular}

F: número de intervenções; P: porcentagem do tempo em relação ao tempo total despendido nas intervenções/atividades.

Fonte: Dados da pesquisa. São Paulo, 2016 
O gráfico 4 apresenta, por hospital, a distribuição do percentual do tempo despendido em intervenções de cuidado direto e

Gráfico 4 - Distribuição percentual do tempo despendido em intervenções de cuidado direto e cuidado indireto, atividades associadas, atividades pessoais, reunião administrativa, espera, deslocamento, ausência e sem observação, segundo a unidade hospitalar, entre setembro e dezembro de 2014

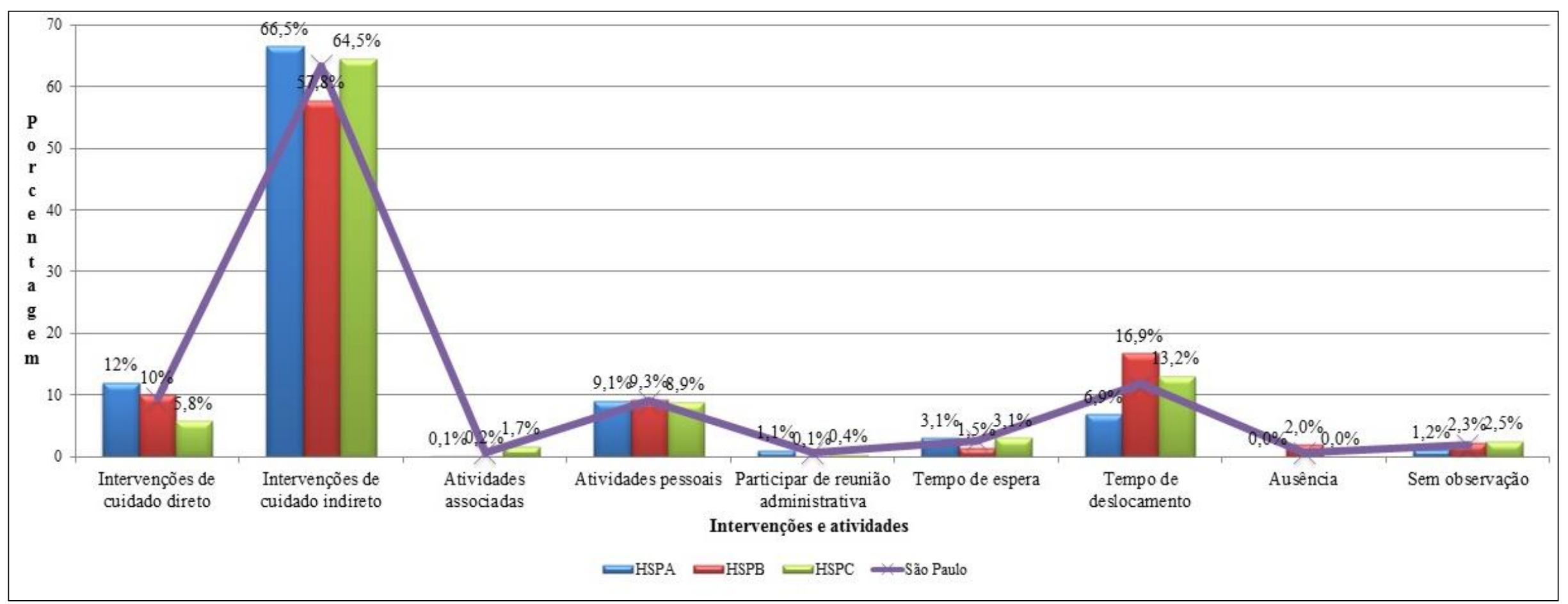

cuidado indireto, atividades associadas, atividades pessoais, tempo de espera, ausência, deslocamento e reunião administrativa.

Fonte: Dados da pesquisa. São Paulo, 2016 
Tabela 13 - Distribuição do tempo despendido nas intervenções, atividades associadas, atividades pessoais e outras realizadas pelos nutricionistas clínicos, segundo a instituição hospitalar, entre setembro e dezembro de 2014

(continua)

\begin{tabular}{|c|c|c|c|c|c|c|}
\hline \multirow[b]{2}{*}{ Intervenções/atividades } & \multicolumn{2}{|c|}{ Matutino } & \multicolumn{2}{|c|}{ Vespertino } & \multicolumn{2}{|c|}{ Total geral } \\
\hline & $\begin{array}{c}\text { Tempo } \\
\text { (min.) }\end{array}$ & $\%$ & $\begin{array}{c}\text { Tempo } \\
\text { (min.) }\end{array}$ & $\%$ & $\begin{array}{c}\text { Tempo } \\
\text { (min.) }\end{array}$ & $\%$ \\
\hline \multicolumn{7}{|l|}{ Intervenções } \\
\hline 01 - Avaliação de produto & 52 & 1,1 & 0,0 & 0,0 & 52 & 0,5 \\
\hline 02 - Avaliação do estado nutricional & 93,6 & 2,0 & 46 & 1 & 139,6 & 1,5 \\
\hline 03 - Controle de infecção & 59 & 1,2 & 27 & 0,6 & 86 & 0,9 \\
\hline 04 - Desenvolvimento de funcionários & 106 & 2,2 & 0,0 & 0,0 & 106 & 1,1 \\
\hline 05 - Documentação & $1.635,0$ & 34,1 & $1.389,0$ & 28,9 & 3024 & 31,5 \\
\hline 06 - Ensino: orientação da dieta prescrita & 4,9 & 0,1 & 4 & 0,1 & 8,9 & 0,1 \\
\hline 07 - Estabelecimento de protocolos de cuidado & 0,0 & 0,0 & 0,0 & 0,0 & 0,0 & 0,0 \\
\hline 08 - Monitoramento da evolução nutricional & 552 & 11,5 & 490 & 10,2 & 1042 & 10,9 \\
\hline 09 - Orientação alimentar e nutricional na alta hospitalar & 62 & 1,3 & 107 & 2,2 & 169 & 1,8 \\
\hline 10 - Passagem de plantão & 45,7 & 1 & 36 & 0,8 & 81,7 & 0,9 \\
\hline 11 - Preceptor: estudante & 299 & 6,2 & 77 & 1,6 & 376 & 3,9 \\
\hline 12 - Reunião para avaliação do cuidado multidisciplinar & 77 & 1,6 & 0,0 & 0,0 & 77 & 0,8 \\
\hline 13 - Supervisão da distribuição das refeições nas unidades & 44 & 0,9 & 57 & 1,2 & 101 & 1,1 \\
\hline 14 - Terapia recreacional & 0,0 & 0,0 & 0,0 & 0,0 & 0,0 & 0,0 \\
\hline 15 - Triagem nutricional & 149 & 3,1 & 101 & 2,1 & 250 & 2,6 \\
\hline 16 - Troca de informações sobre cuidados de saúde & 536 & 11,2 & 910 & 19 & 1446 & 15,1 \\
\hline Subtotal & $3.715,0$ & 77,4 & $3.271,9$ & 67,6 & 6986,9 & 72,8 \\
\hline
\end{tabular}


Tabela 13 - Distribuição do tempo despendido nas intervenções, atividades associadas, atividades pessoais e outras realizadas pelos nutricionistas clínicos, segundo a instituição hospitalar, entre setembro e dezembro de 2014

(continuação)

Atividades associadas

17 - Cadastrar acompanhante do paciente no sistema

18 - Revisar etiqueta de identificação da refeição do paciente

19 - Separar etiqueta de identificação da refeição do paciente

Subtotal

Atividades pessoais

20 - Acessar computador/dispositivos móveis

21 - Alimentar-se

22 - Descansar

23 - Fumar

24 - Guardar ou retirar refeição ou objetos pessoais

25 - Hidratar-se

26 - Leitura pessoal

27 - Socializar com a equipe multidisciplinar

28 - Usar toalete

Subtotal

Outras

29 - Ausência

30 - Deslocamento

31 - Espera

33 - Participação em reunião administrativa

34 - Sem observação

$\begin{array}{cccccc}0 & 0 & 1 & 0 & 1 & 0,0 \\ 14 & 0,3 & 30 & 0,6 & 44 & 0,5 \\ 8 & 0,2 & 3 & 0,1 & 11 & 0,1 \\ 22 & 0,5 & 36,1 & 0,7 & 58,1 & 0,6\end{array}$

Total geral

\begin{tabular}{cccccc}
6 & 0,1 & 2 & 0 & 8 & 0,1 \\
168 & 3,5 & 292 & 6,1 & 460 & 4,8 \\
0,0 & 0,0 & 0,0 & 0,0 & 0,0 & 0,0 \\
0,0 & 0,0 & 0,0 & 0,0 & 0,0 & 0,0 \\
13 & 0,3 & 18 & 0,4 & 31 & 0,3 \\
17 & 0,4 & 25 & 0,5 & 42 & 0,4 \\
0,0 & 0,0 & 0,0 & 0,0 & 0,0 & 0,0 \\
56 & 1,2 & 77 & 1,6 & 133 & 1,4 \\
108 & 2,3 & 81 & 1,7 & 189 & 2,0 \\
377,3 & 7,7 & 495 & 10,3 & 872,3 & 9,1 \\
& & & & & \\
0,0 & 0,0 & 57,5 & 1,2 & 57,5 & 0,6 \\
450,1 & 9,4 & 681,5 & 14,2 & 1131,6 & 11,8 \\
109,3 & 2,3 & 144,1 & 3,0 & 253 & 2,6 \\
3,4 & 0,1 & 53,8 & 1,1 & 57,2 & 0,6 \\
115,7 & 2,4 & 67,3 & 1,4 & 183 & 1,9 \\
\hline 4800 & 100 & 4800 & 100 & 9600 & 100,0
\end{tabular}

(conclusão)

Fonte: Dados da pesquisa. São Paulo, 2016 
Das 16 intervenções de nutrição clínica, 14 (87\%) foram executadas pelos nutricionistas clínicos. Apenas as intervenções "estabelecimento de protocolos de cuidado" e "terapia recreacional" não foram observadas durante o período estudado (Tabela 13).

Em relação às atividades, a maioria foi observada durante a pesquisa. Apenas as atividades "fumar", "descanso" e "leitura pessoal" não foram realizadas (Tabela 13).

A esse respeito cabe destacar que durante o período de coleta de dados todas as intervenções/atividades observadas foram contempladas na taxonomia de nutrição clínica validada pelos juízes.

O gráfico 5 mostra a distribuição percentual do tempo despendido pelos nutricionistas clínicos nas intervenções, com representatividade superior a 1\%, nos três hospitais.

Gráfico 5 - Distribuição percentual do tempo despendido em cada intervenção, com representatividade $\geq 1 \%$, no total dos três hospitais, entre setembro e dezembro de 2014

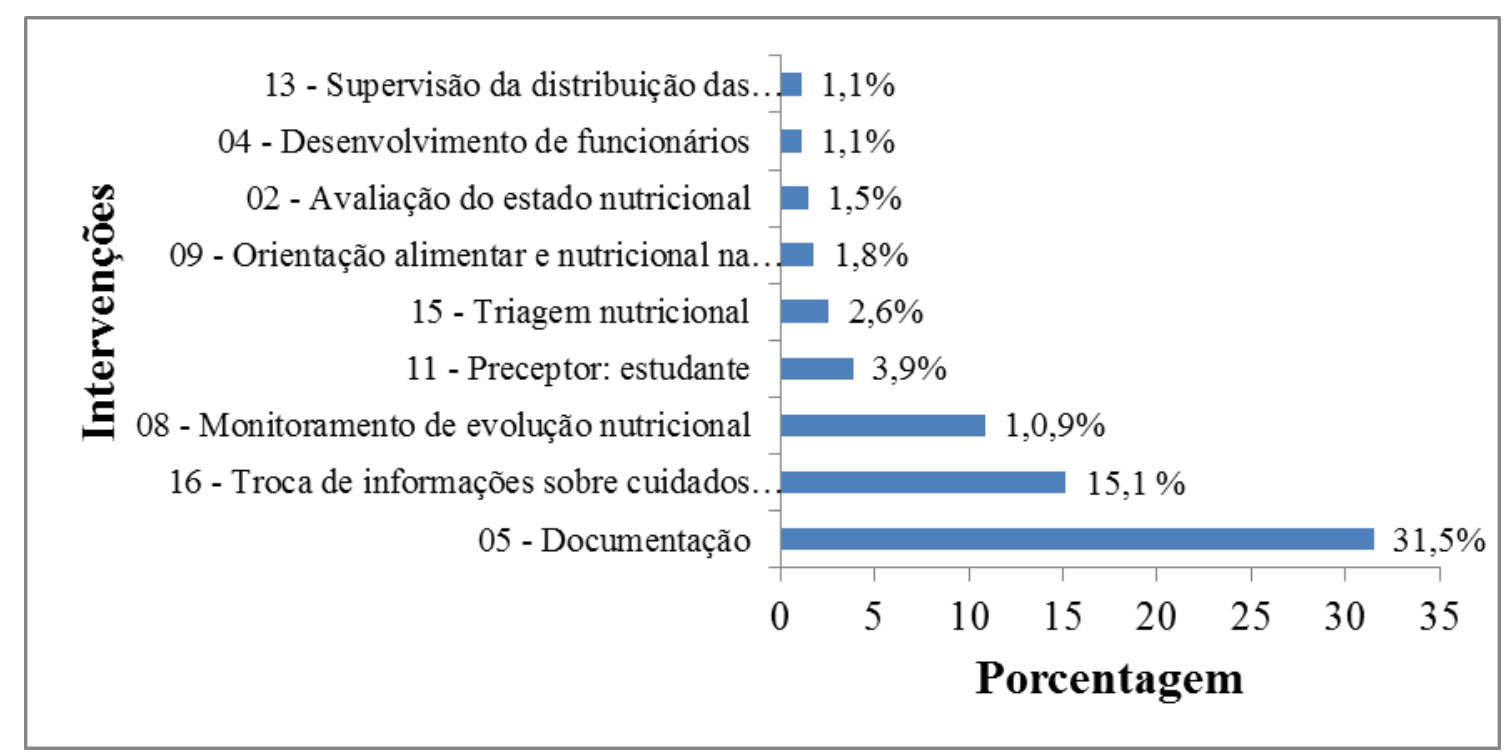

Fonte: Arquivo da pesquisadora. São Paulo, 2016 
Das 16 atividades observadas, apenas quarto (25\%) tiveram representatividade superior a $1 \%$ (Gráfico 6).

Gráfico 6 - Distribuição percentual do tempo despendido em cada atividade, com representatividade $\geq 1 \%$, no total dos três hospitais, entre setembro e dezembro de 2014

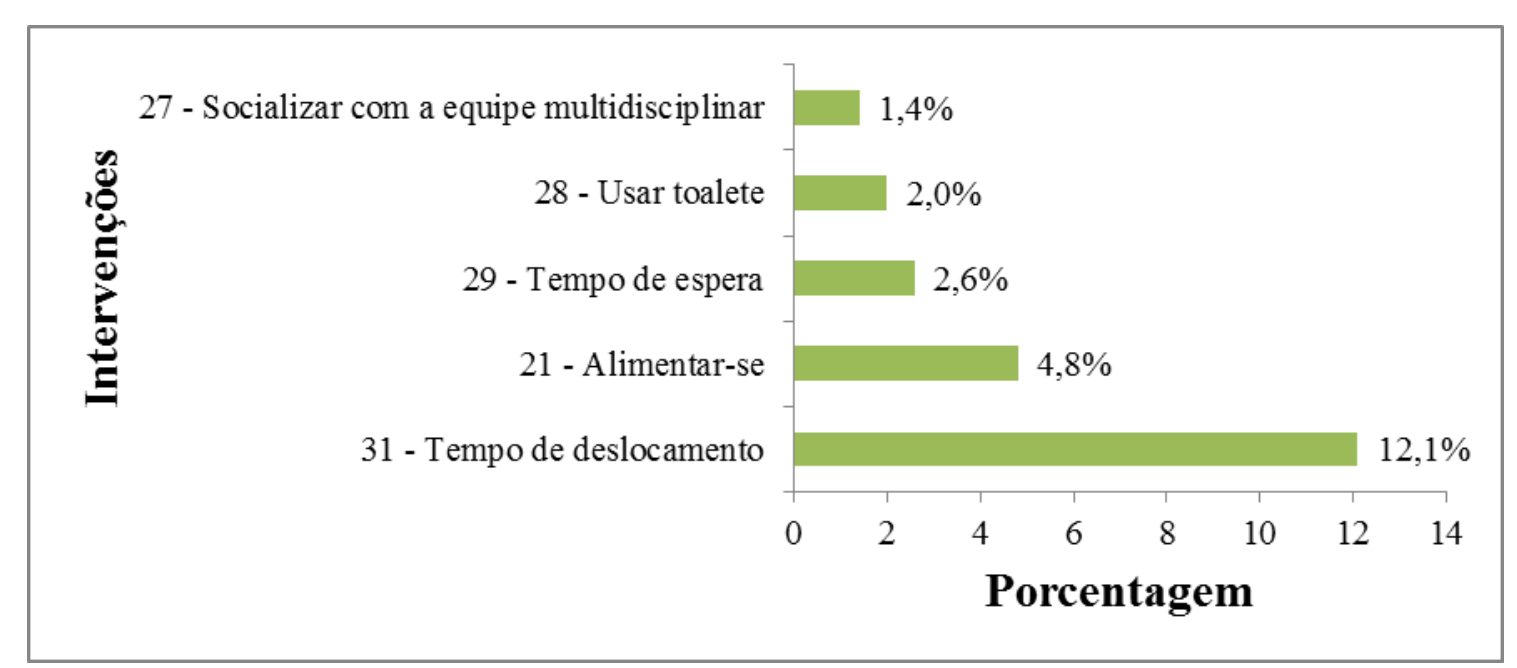

Fonte: Arquivo da pesquisadora. São Paulo, 2016 
Os dados do gráfico 7 mostram a distribuição percentual do tempo de trabalho dos nutricionistas clínicos, durante a jornada de trabalho, nos três hospitais.

\section{Gráfico 7 - Distribuição percentual das intervenções e atividades realizadas pelos nutricionistas clínicos em São Paulo, entre setembro e dezembro de 2014}

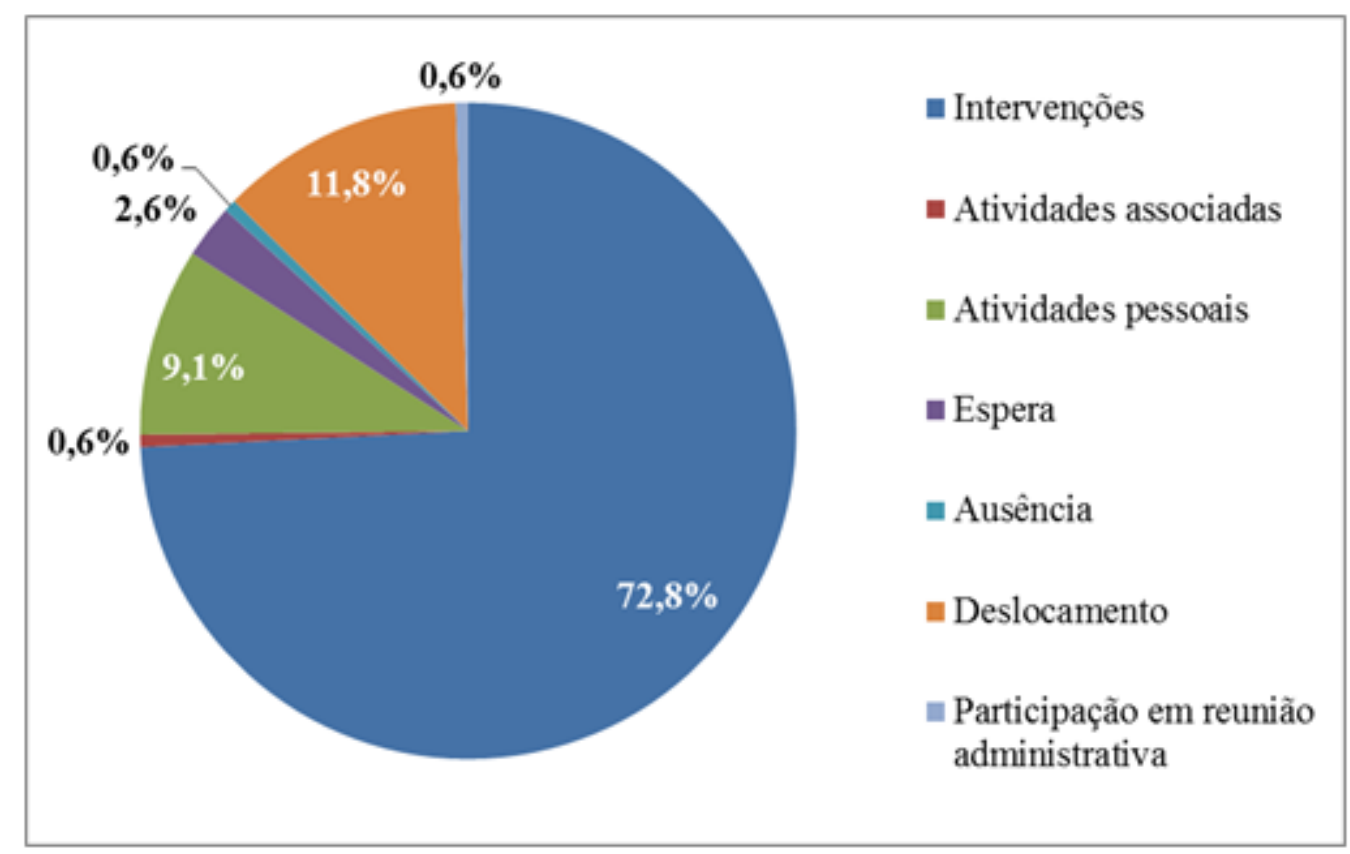

Fonte: Arquivo da pesquisadora. São Paulo, 2016

As tabelas 14 e 15 apresentam a frequência e o percentual do despendido pelos nutricionistas clínicos nas intervenções de cuidado direto e cuidado indireto realizadas nos três hospitais. 
Tabela 14 - Distribuição do tempo observado em intervenções de cuidados diretos de nutricionistas em três hospitais, segundo a intervenção realizada e a classificação do nível de atendimento, entre setembro e dezembro de 2014

\begin{tabular}{|c|c|c|c|c|c|c|c|c|c|c|c|c|c|}
\hline \multirow[b]{2}{*}{ Unidade } & \multirow[b]{2}{*}{ Intervenção de cuidado direto } & \multicolumn{3}{|c|}{ Nível primário } & \multicolumn{3}{|c|}{ Nível secundário } & \multicolumn{3}{|c|}{ Nível terciário } & \multicolumn{3}{|c|}{ Total } \\
\hline & & $\bar{F}$ & $\mathrm{~T} 1$ * & $\%$ & $\mathrm{~F}$ & $\mathrm{~T} 1^{*}$ & $\%$ & $\mathrm{~F}$ & $\mathrm{~T} 1^{*}$ & $\%$ & $\mathrm{~F}$ & $\mathrm{~T} 1^{*}$ & $\%$ \\
\hline & 02 - Avaliação do estado nutricional & 1 & 1,8 & 12,1 & - & - & - & - & - & - & 1 & 1,79 & 0,4 \\
\hline & 02 - Avaliação do estado nutricional & - & - & - & 21 & 72,58 & 31,7 & - & - & - & 21 & 72,58 & 15,8 \\
\hline & 02 - Avaliação do estado nutricional & - & - & - & - & - & - & 4 & 24,86 & 11,5 & 4 & 24,86 & 5,4 \\
\hline & 06 - Ensino: orientação da dieta prescrita & - & - & - & 1 & 1,7 & 0,7 & - & - & - & 1 & 1,7 & 0,4 \\
\hline & 08 - Monitoramento da evolução nutricional & - & - & - & 10 & 61,47 & 26,8 & - & - & - & 10 & 61,47 & 13,4 \\
\hline \multirow[t]{12}{*}{ HSPA } & 08 - Monitoramento da evolução nutricional & - & - & - & - & - & - & 17 & 124,91 & 57,9 & 17 & 124,91 & 27,2 \\
\hline & 09 - Orientação alimentar e nutricional na alta hospitalar & - & - & - & 2 & 9,42 & 4,1 & - & - & - & 2 & 9,42 & 2 \\
\hline & 09 - Orientação alimentar e nutricional na alta hospitalar & - & - & - & - & - & - & 4 & 46,02 & 21,3 & 4 & 46,02 & 10 \\
\hline & 15 - Triagem nutricional & 2 & 13 & 87,9 & - & - & - & - & - & - & 2 & 13 & 2,8 \\
\hline & 15 - Triagem nutricional & - & - & - & 17 & 84,15 & 36,7 & - & - & - & 17 & 84,15 & 18,3 \\
\hline & 15 - Triagem nutricional & - & - & - & & & - & 5 & 19,84 & 9,2 & 5 & 19,84 & 4,3 \\
\hline & Subtotal & 3 & 14,8 & 17,3 & 51 & 229 & 57,5 & 30 & 215,6 & 50,4 & 84 & 459,74 & 50,4 \\
\hline & 02 - Avaliação do estado nutricional & - & - & - & 1 & 0,8 & 0,8 & & & - & 1 & 0,8 & 0,3 \\
\hline & 02 - Avaliação do estado nutricional & - & - & - & - & - & - & 1 & 0,28 & 0,2 & 1 & 0,28 & 0,1 \\
\hline & 06 - Ensino: orientação da dieta prescrita & 1 & 0,7 & 1,3 & - & - & - & - & - & - & 1 & 0,68 & 0,2 \\
\hline & 08 - Monitoramento da evolução nutricional & 18 & 23,8 & 44,3 & - & - & - & - & - & - & 18 & 23,81 & 8,3 \\
\hline & 08 - Monitoramento da evolução nutricional & - & - & - & 18 & 53,11 & 55 & - & - & - & 18 & 53,11 & 18,5 \\
\hline \multirow[t]{7}{*}{ HSPB } & 08 - Monitoramento da evolução nutricional & - & - & - & & & - & 22 & 71,9 & 52,8 & 22 & 71,9 & 25,1 \\
\hline & 09 - Orientação alimentar e nutricional na alta hospitalar & - & - & - & 2 & 13,61 & 14,1 & - & - & - & 2 & 13,61 & 4,7 \\
\hline & 09 - Orientação alimentar e nutricional na alta hospitalar & - & - & - & - & - & - & 4 & 26,25 & 19,3 & 4 & 26,25 & 9,2 \\
\hline & 15 - Triagem nutricional & 14 & 29,2 & 54,4 & - & - & - & - & - & - & 14 & 29,23 & 10,2 \\
\hline & 15 - Triagem nutricional & - & - & - & 13 & 29 & 30 & - & - & - & 13 & 29 & 10,1 \\
\hline & 15 - Triagem nutricional & - & - & - & - & - & - & 9 & 37,86 & 27,8 & 9 & 37,86 & 13,2 \\
\hline & Subtotal & 33 & 53,7 & 63 & 34 & 96,5 & 24,2 & 36 & 136,3 & 31,8 & 103 & 286,53 & 31,4 \\
\hline
\end{tabular}


Tabela 14 - Distribuição do tempo observado em intervenções de cuidados diretos de nutricionistas em três hospitais segundo a intervenção realizada e a classificação do nível de atendimento, entre setembro e dezembro de 2014

(continuação)

\begin{tabular}{|c|c|c|c|c|c|c|c|c|c|c|c|c|c|}
\hline & 02 - Avaliação do estado nutricional & - & - & - & 1 & 7,92 & 10,8 & - & - & - & 1 & 7,92 & 4,8 \\
\hline & 06 - Ensino: orientação da dieta prescrita & - & - & - & 1 & 4,93 & 6,7 & - & - & - & 1 & 4,93 & 3 \\
\hline & 06 - Ensino: orientação da dieta prescrita & - & - & - & - & - & - & 1 & 2,25 & 3 & 1 & 2,25 & 1,4 \\
\hline & 08 - Monitoramento da evolução nutricional & 7 & 6,7 & 39,9 & - & - & - & - & - & - & 7 & 6,71 & 4 \\
\hline & 08 - Monitoramento da evolução nutricional & - & - & - & 7 & 11,11 & 15,2 & - & - & - & 7 & 11,11 & 6,7 \\
\hline \multirow[t]{8}{*}{ HSPC } & 08 - Monitoramento da evolução nutricional & - & - & - & & & - & 7 & 12,23 & 16,1 & 7 & 12,23 & 7,4 \\
\hline & 09 - Orientação alimentar e nutricional na alta hospitalar & - & - & - & 6 & 24,27 & 33,2 & & & - & 6 & 24,27 & 14,6 \\
\hline & 09 - Orientação alimentar e nutricional na alta hospitalar & - & - & - & - & - & - & 5 & 50,57 & 66,4 & 5 & 50,57 & 30,5 \\
\hline & 15 - Triagem nutricional & 5 & 10,1 & 60,1 & - & - & - & - & - & - & 5 & 10,11 & 6,1 \\
\hline & 15 - Triagem nutricional & - & - & - & 7 & 24,81 & 34 & - & - & - & 7 & 24,81 & 14,9 \\
\hline & 15 - Triagem nutricional & - & - & - & - & - & - & 3 & 11,08 & 14,6 & 3 & 11,08 & 6,7 \\
\hline & Subtotal & 12 & 16,8 & 19,7 & 22 & 73 & 18,3 & 16 & 76,13 & 17,8 & 50 & 165,99 & 18,2 \\
\hline & Total geral & 48 & 85,3 & 100 & 107 & 399 & 100 & 82 & 428,1 & 100 & 237 & 912,26 & 100 \\
\hline
\end{tabular}

T1: tempo observado.

(conclusão)

Fonte: Dados da pesquisa. São Paulo, 2016 
Tabela 15 - Distribuição do tempo observado em intervenções de cuidados indiretos de nutricionistas em três unidades hospitalares, segundo hospital e intervenção realizadas entre setembro e dezembro de 2014

(continua)

\begin{tabular}{|c|c|c|c|c|}
\hline Unidade & Intervenções de cuidado indireto & $\mathbf{F}$ & $\mathrm{T} 1^{*}$ & $\%$ \\
\hline \multirow{8}{*}{ HSPA } & 03 - Controle de infecção & 65 & 45,7 & 1,8 \\
\hline & 04 - Desenvolvimento de funcionários & 2 & 106,5 & 4,2 \\
\hline & 05 - Documentação & 243 & $1.635,0$ & 64,1 \\
\hline & 08 - Monitoramento da evolução nutricional & 44 & 138,7 & 5,4 \\
\hline & 10 - Passagem de plantão & 14 & 44,8 & 1,8 \\
\hline & 12 - Reunião para avaliação do cuidado multidisciplinar & 1 & 27,5 & 1,1 \\
\hline & 16 - Troca de informações sobre cuidados de saúde & 299 & 553,7 & 21,7 \\
\hline & Subtotal & 668 & $2.551,9$ & 42,0 \\
\hline \multirow{10}{*}{ HSPB } & 01 - Avaliação de produto & 1 & 53,6 & 3,2 \\
\hline & 02 - Avaliação do estado nutricional & 1 & 1,0 & 0,1 \\
\hline & 03 - Controle de infecção & 71 & 27,6 & 1,7 \\
\hline & 05 - Documentação & 258 & 811,2 & 48,7 \\
\hline & 08 - Monitoramento da evolução nutricional & 136 & 243,0 & 14,6 \\
\hline & 10 - Passagem de plantão & 7 & 37,4 & 2,2 \\
\hline & 11 - Preceptor: estudante & 1 & 26,5 & 1,6 \\
\hline & 13 - Supervisão da distribuição das refeições nas unidades & 11 & 33,1 & 2,0 \\
\hline & 16 - Troca de informações & 336 & 431,9 & 25,9 \\
\hline & Subtotal & 822 & $1.665,3$ & 27,4 \\
\hline
\end{tabular}


Tabela 15 - Distribuição do tempo observado em intervenções de cuidados indiretos de nutricionistas em três unidades hospitalares, segundo hospital e intervenção realizadas entre setembro e dezembro de 2014

(continuação)

\begin{tabular}{|c|c|c|c|c|}
\hline \multirow{10}{*}{ HSPC } & 02 - Avaliação do cuidado nutricional & 7 & 32,1 & 1,7 \\
\hline & 05 - Controle de infecção & 22 & 13,6 & 0,7 \\
\hline & 04 - Desenvolvimento de funcionários & 0 & 2,0 & 0,1 \\
\hline & 05 - Documentação & 207 & 578,3 & 31,1 \\
\hline & 08 - Monitoramento da evolução nutricional & 163 & 298,5 & 16,1 \\
\hline & 11 - Preceptor: estudante & 5 & 351,8 & 18,9 \\
\hline & 12 - Reunião para avaliação do cuidado multidisciplinar & 2 & 49,7 & 2,7 \\
\hline & 13 - Supervisão da distribuição das refeições nas unidades & 24 & 69,3 & 3,7 \\
\hline & 16 - Troca de informações & 320 & 463,4 & 24,9 \\
\hline & Subtotal & 750 & $1.858,6$ & 30,6 \\
\hline & Total geral & 2240 & $6.075,8$ & 100,0 \\
\hline
\end{tabular}

T1: tempo observado

(conclusão)

Fonte: Dados da pesquisa. São Paulo, 2016 
O tempo dedicado efetivamente ao trabalho, durante a jornada de trabalho, dos nutricionistas clínicos, pode ser verificado na tabela 16.

Tabela 16 - Tempo produtivo dos nutricionistas clínicos, nos três hospitais, entre setembro e dezembro de 2014

\begin{tabular}{|c|c|c|c|c|c|c|c|c|}
\hline \multirow{2}{*}{$\begin{array}{c}\text { Intervenções/ } \\
\text { atividades }\end{array}$} & \multicolumn{2}{|l|}{ HSPA } & \multicolumn{3}{|c|}{ HSPB } & \multirow{2}{*}{$\begin{array}{c}\text { HSPC } \\
\text { P\% }\end{array}$} & \multirow{2}{*}{$\begin{array}{c}\text { TOTAL } \\
\text { T1 }\end{array}$} & \multirow[b]{2}{*}{$\mathbf{P} \%$} \\
\hline & T1 & $\mathbf{P} \%$ & T1 & $\mathbf{P} \%$ & T1 & & & \\
\hline Intervenções & 3011,6 & 78,4 & 1951,6 & 67,8 & 2024 & 70,3 & 6987,2 & 72,8 \\
\hline $\begin{array}{l}\text { Atividades } \\
\text { associadas }\end{array}$ & 3,3 & 0,1 & 6,3 & 0,2 & 48,5 & 1,7 & 58,1 & 0,6 \\
\hline Deslocamento & 265,8 & 6,9 & 487 & 16,9 & 379 & 13,2 & 1131,8 & 11,8 \\
\hline Espera & 120,9 & 3,1 & 42,6 & 1,5 & 90 & 3,1 & 253,5 & 2,6 \\
\hline Total geral & 3401,6 & 89,0 & 2488 & 86,0 & 2541,5 & 88,0 & 8431 & 87,8 \\
\hline
\end{tabular}

T1: tempo observado

Fonte: Dados da pesquisa. São Paulo, 2016

As tabelas 17, 18 e 19 apresentam os tempos das intervenções de cuidado direto, segundo o nível de atendimento nutricional, no conjunto dos três hospitais estudados. 
Tabela 17 - Demonstrativo do tempo despendido pelos nutricionistas clínicos em intervenções de cuidados diretos, segundo o nível de atendimento nutricional, nas três unidades hospitalares, entre setembro e dezembro de 2014

\begin{tabular}{|c|c|c|c|c|c|c|c|}
\hline \multirow{2}{*}{$\begin{array}{l}\text { Nível de } \\
\text { Atendimento }\end{array}$} & \multirow[b]{2}{*}{ Intervenções de cuidados diretos } & \multirow[b]{2}{*}{$\boldsymbol{F}$} & \multicolumn{3}{|c|}{$\bar{T}$} & \multicolumn{2}{|c|}{ Intervalo de confiança $95 \%$} \\
\hline & & & T1 & Médio & DP & Limite inferior & Limite superior \\
\hline \multirow{5}{*}{ Primário } & 02 - Avaliação do estado nutricional & 1 & 1,8 & 1,8 & - & Dados insuficientes & Dados insuficientes \\
\hline & 06 - Ensino: dieta prescrita & 1 & 0,7 & 0,7 & - & Dados insuficientes & Dados insuficientes \\
\hline & 08 - Monitoramento da evolução nutricional & 25 & 30,5 & 1,2 & 8,0 & 0,0 & 4,5 \\
\hline & 15 - Triagem nutricional & 21 & 52,3 & 2,5 & 3,3 & 1,0 & 3,9 \\
\hline & Subtotal & 48 & 85,3 & 1,8 & 5,0 & 0,3 & 3,2 \\
\hline \multirow{5}{*}{ Secundário } & 02 - Avaliação do estado nutricional & 23 & 81,3 & 3,5 & 8,3 & 0,1 & 7,0 \\
\hline & 06 - Ensino: dieta prescrita & 2 & 6,6 & 3,3 & - & Dados insuficientes & Dados insuficientes \\
\hline & 08 - Monitoramento da evolução nutricional & 35 & 125,7 & 3,6 & 6,2 & 1,5 & 5,7 \\
\hline & 09 - Orientação alimentar e nutricional na alta hospitalar & 10 & 47,3 & 4,7 & 3,1 & 2,8 & 6,7 \\
\hline & 15 - Triagem nutricional & 37 & 138,0 & 3,7 & 11,8 & 0,0 & 7,6 \\
\hline \multirow{7}{*}{ Terciário } & Subtotal & 107 & 398,9 & 3,7 & 8,2 & 2,2 & 5,3 \\
\hline & 02 - Avaliação do estado nutricional & 5 & 25,1 & 5,0 & 6,7 & 0,0 & 11,2 \\
\hline & 06 - Ensino: dieta prescrita & 1 & 2,3 & 2,3 & - & Dados insuficientes & Dados insuficientes \\
\hline & 08 - Monitoramento da evolução nutricional & 46 & 209,0 & 4,5 & 19,7 & 0,0 & 10,3 \\
\hline & 09 - Orientação alimentar e nutricional na alta hospitalar & 13 & 122,8 & 9,4 & 8,2 & 5,0 & 13,9 \\
\hline & 15 - Triagem nutricional & 17 & 68,8 & 4,0 & 4,7 & 1,8 & 6,3 \\
\hline & Subtotal & 82 & 428,1 & 5,2 & 13,6 & 2,3 & 8,2 \\
\hline Total geral & & 237 & 912,3 & 3,8 & 10,5 & 2,5 & 5,2 \\
\hline
\end{tabular}

F: frequência; T1: tempo observado; $\bar{T}$ :tempo médio; DP: desvio padrão.

Fonte: Dados da pesquisa. São Paulo, 2016 
Tabela 18 - Demonstrativo do tempo despendido pelos nutricionistas clínicos em intervenções de cuidados diretos, com acréscimo do valor rateado dos tempos referentes às atividades pessoais, deslocamento e espera, segundo o nível de atendimento nutricional, nas três unidades hospitalares

\begin{tabular}{|c|c|c|c|c|c|c|c|}
\hline \multirow{2}{*}{$\begin{array}{l}\text { Nível de } \\
\text { Atendimento }\end{array}$} & \multirow[b]{2}{*}{ Intervenções de cuidados diretos } & \multirow[b]{2}{*}{$F$} & \multicolumn{3}{|c|}{$\bar{T} 2$} & \multicolumn{2}{|c|}{ Intervalo de confiança $95 \%$} \\
\hline & & & T2 & Médio & DP & Limite inferior & Limite superior \\
\hline \multirow{5}{*}{ Primário } & 02 - Avaliação do estado nutricional & 1 & 2,0 & 2,0 & - & Dados insuficientes & Dados insuficientes \\
\hline & 06 - Ensino: dieta prescrita & 1 & 0,9 & 0,9 & - & Dados insuficientes & Dados insuficientes \\
\hline & 08 - Monitoramento da evolução nutricional & 25 & 42,7 & 1,7 & 11,1 & 0,0 & 6,2 \\
\hline & 15 - Triagem nutricional & 21 & 73,0 & 3,5 & 5,0 & 1,3 & 5,7 \\
\hline & Subtotal & 48 & 118,6 & 2,5 & 7,1 & 0,4 & 4,5 \\
\hline \multirow{5}{*}{ Secundário } & 02 - Avaliação do estado nutricional & 23 & 99,5 & 4,3 & 9,6 & 0,3 & 8,3 \\
\hline & 06 - Ensino: dieta prescrita & 2 & 8,9 & 4,4 & - & Dados insuficientes & Dados insuficientes \\
\hline & 08 - Monitoramento da evolução nutricional & 35 & 166,2 & 4,7 & 8,6 & 1,9 & 7,6 \\
\hline & 09 - Orientação alimentar e nutricional na alta hospitalar & 10 & 63,7 & 6,4 & 3,8 & 4,0 & 8,8 \\
\hline & 15 - Triagem nutricional & 37 & 168,6 & 4,6 & 12,9 & 0,4 & 8,7 \\
\hline \multirow{7}{*}{ Terciário } & Subtotal & 107 & 506,9 & 4,7 & 9,5 & 2,9 & 6,6 \\
\hline & 02 - Avaliação do estado nutricional & 5 & 30,9 & 6,2 & 8,5 & 0,0 & 14,0 \\
\hline & 06 - Ensino: dieta prescrita & 1 & 3,2 & 3,2 & - & Dados insuficientes & Dados insuficientes \\
\hline & 08 - Monitoramento da evolução nutricional & 46 & 256,7 & 5,6 & 23,1 & 0,0 & 12,3 \\
\hline & 09 - Orientação alimentar e nutricional na alta hospitalar & 13 & 162,6 & 12,5 & 9,5 & 7,3 & 17,7 \\
\hline & 15 - Triagem nutricional & 17 & 83,6 & 4,9 & 5,6 & 2,2 & 7,6 \\
\hline & Subtotal & 82 & 537,0 & 6,5 & 16,1 & 3,1 & 10,0 \\
\hline Total geral & & 237 & $1.162,5$ & 4,9 & 12,6 & 3,3 & 6,5 \\
\hline
\end{tabular}

T2: T1+ valor rateado das atividades pessoais, deslocamento e espera.

Fonte: Dados da pesquisa. São Paulo, 2016 
Tabela 19 - Demonstrativo do tempo despendido pelos nutricionistas clínicos em intervenções de cuidados diretos, com acréscimo dos tempos referentes às atividades associadas e valor proporcional de cuidados indiretos, segundo o nível de atendimento nutricional, $\mathbf{n}$ nas três unidades hospitalares, entre setembro e dezembro de 2014

\begin{tabular}{|c|c|c|c|c|c|c|c|}
\hline \multirow{2}{*}{$\begin{array}{c}\text { Nível de } \\
\text { Atendimento }\end{array}$} & \multirow[b]{2}{*}{ Intervenções de cuidados diretos } & \multirow[b]{2}{*}{$\boldsymbol{F}$} & \multirow[b]{2}{*}{ T3 } & \multirow[b]{2}{*}{ Médio } & \multirow[b]{2}{*}{ DP } & \multicolumn{2}{|c|}{ Intervalo de confiança $95 \%$} \\
\hline & & & & & & Limite inferior & Limite superior \\
\hline \multirow{4}{*}{ Primário } & 02 - Avaliação do estado nutricional & 1 & 4,5 & 4,5 & - & Dados insuficientes & Dados insuficientes \\
\hline & 06 - Ensino: dieta prescrita & 1 & 2,0 & 2,0 & - & Dados insuficientes & Dados insuficientes \\
\hline & 15 - Triagem nutricional & 21 & 271,8 & 12,9 & 19,0 & 4,8 & 21,1 \\
\hline & Subtotal & 48 & 396,8 & 8,3 & 19,8 & 2,6 & 13,9 \\
\hline \multirow{4}{*}{ Secundário } & 02 - Avaliação do estado nutricional & 23 & 256,5 & 11,2 & 16,0 & 4,6 & 17,7 \\
\hline & 08 - Monitoramento da evolução nutricional & 35 & 531,0 & 15,2 & 29,2 & 5,5 & 24,9 \\
\hline & 09 - Orientação alimentar e nutricional na alta hospitalar & 10 & 236,9 & 23,7 & 25,6 & 7,8 & 39,6 \\
\hline & 15 - Triagem nutricional & 37 & 547,9 & 14,8 & 26,8 & 6,1 & 23,5 \\
\hline \multirow{3}{*}{ Terciário } & Subtotal & 107 & $1.611,7$ & 15,1 & 25,0 & 10,3 & 19,8 \\
\hline & 02 - Avaliação do estado nutricional & 5 & 175,0 & 35,0 & 40,7 & 0,0 & 70,9 \\
\hline & 06 - Ensino: dieta prescrita & 1 & 9,7 & 9,7 & - & Dados insuficientes & Dados insuficientes \\
\hline Total & & 237 & $4.169,6$ & 17,6 & 34,7 & 13,2 & 22,0 \\
\hline
\end{tabular}

F: frequência; DP: desvio padrão;

T3: T2 + valor rateado das atividades associadas e as intervenções de cuidado indireto.

Fonte: Dados da pesquisa. São Paulo, 2016 


\subsection{COMPARAÇÃO DOS PARÂMETROS OBTIDOS NA PESQUISA COM OS PRECONIZADOS PELA RESOLUÇÃO} CFN №. 280/2005 ${ }^{(7)}$.

O Quadro 8 apresenta a comparação dos valores de tempo médio de assistência, encontrados neste estudo, com os da Resolução CFN no. 380/2005. Observa-se que não houve diferença estatisticamente significante entre os tempos.

A aplicação do teste de significância entre os tempos médios de cuidado aos pacientes, segundo o nível de atendimento de nutrição, recomendados pelo CFN e os tempos de cuidado aos pacientes calculados na pesquisa, indica que os valores da pesquisa são significativamente superiores aos valores recomendados pelo CFN, ao nível de 95\% (Quadro 8).

Quadro 8 - Comparação dos tempos médios observados com os tempos médios preconizados pela Resolução CFN no 380 de 2005, segundo o nível de atendimento nutricional, entre setembro e dezembro de 2014

\begin{tabular}{|c|c|c|c|c|c|c|c|c|c|c|c|c|c|c|}
\hline \multirow{3}{*}{$\begin{array}{c}\text { Nível de } \\
\text { atendimento }\end{array}$} & \multirow{2}{*}{\multicolumn{2}{|c|}{$\begin{array}{l}\text { Pacientes } \\
\text { atendidos }\end{array}$}} & \multirow{2}{*}{\multicolumn{2}{|c|}{$\begin{array}{l}\text { Duração média } \\
\text { do turno (min) }\end{array}$}} & \multirow{3}{*}{$\begin{array}{c}\text { Tempo das } \\
\text { intervenções } \\
\text { (min) }\end{array}$} & \multirow{2}{*}{\multicolumn{2}{|c|}{$\begin{array}{c}\text { Tempo de } \\
\text { cuidado por } \\
\text { paciente (turno } \\
\text { de } 360 \mathrm{~min} \text { ) }\end{array}$}} & \multirow{3}{*}{$\begin{array}{l}\text { Desvio } \\
\text { Padrão }\end{array}$} & \multirow{3}{*}{$\begin{array}{c}\text { Diferença } \\
\text { das médias } \\
\text { (min) }\end{array}$} & \multicolumn{5}{|c|}{ TESTE $\mathrm{T}$} \\
\hline & & & & & & & & & & \multicolumn{2}{|c|}{ t (Student 95\%) } & \multicolumn{2}{|c|}{ Comparação } & \multirow[t]{2}{*}{ valor-p } \\
\hline & CFN & Pesq & CFN & Pesq & & CFN & Pesq & & & tobs & tcrit & tobs $x$ tcrit & $\begin{array}{l}\text { tcfn } x \\
\text { tpesq }\end{array}$ & \\
\hline Primário & 60 & 47 & 360 & 400 & 396,8 & 6,0 & 7,6 & 2,41 & 1,6 & 4,5 & 2,0 & $4,5>2,0$ & $26,6 \%$ & 0,000 \\
\hline secundário & 30 & 90 & 360 & 400 & $1.611,7$ & 12,0 & 16,1 & 2,06 & 4,1 & 19,0 & 2,0 & $19,0>2,0$ & $34,3 \%$ & 0,000 \\
\hline terciário & 15 & 68 & 360 & 400 & $2.161,1$ & 24,0 & 28,6 & 5,10 & 4,6 & 7,4 & 2,0 & $7,4>2,0$ & $19,2 \%$ & 0,000 \\
\hline
\end{tabular}

Tempo de cuidado por paciente (turno 360 min.) = razão entre tempo das intervenções e o n..$^{\text {de }}$ pacientes atendidos na pesquisa.

$\mathrm{t}_{\mathrm{obs}}=$ observado; $\mathrm{t}_{\text {crit }}=$ crítico.

Fonte: Arquivo da pesquisadora. São Paulo, 2016 
Para melhor visualização dos resultados, os valores dos tempos médios de cuidado aos pacientes, obtidos com os dados da pesquisa, são apresentados no Quadro 9, como uma relação da quantidade de nutricionista por pacientes internados, por turno de trabalho de 360 minutos, como apresentado na Resolução CFN №. 380 de $2005^{(9)}$.

Quadro 9 - Comparação entre o tempo requerido por paciente e o quantitativo de pacientes por nutricionista, conforme o nível de atendimento de nutrição, obtido na pesquisa e o preconizado pela resolução CFN n‥ 380/2005

\begin{tabular}{|l|c|c|c|c|c|}
\hline \multirow{2}{*}{$\begin{array}{c}\text { Nível de } \\
\text { atendimento } \\
\text { de nutrição }\end{array}$} & \multirow{2}{*}{$\begin{array}{c}\text { Duração do } \\
\text { turno (min.) }\end{array}$} & \multicolumn{2}{|c|}{$\begin{array}{c}\text { Tempo de cuidado por } \\
\text { paciente (min.) }\end{array}$} & \multicolumn{2}{|c|}{$\begin{array}{c}\text { Pacientes por } \\
\text { nutricionista }\end{array}$} \\
\cline { 3 - 6 } & & CFN & Pesquisa & CFN & PESQUISA \\
\hline Primário & 360 & 6,0 & 7,6 & $60: 1$ & $48: 1$ \\
\hline Secundário & 360 & 12,0 & 16,1 & $30: 1$ & $22: 1$ \\
\hline Terciário & 360 & 24,0 & 28,6 & $15: 1$ & $13: 1$ \\
\hline
\end{tabular}

Fonte: Arquivo da pesquisadora e parâmetros numéricos da Resolução CFN n.ำ 380/2005. São Paulo, 2016 


\section{DISCUSSÃO}

Poucos estudos têm investigado as práticas de trabalho do nutricionista clínico, especialmente acerca do tempo requerido por estes profissionais na prestação do cuidado aos pacientes internados ${ }^{(84,115,117,119,120,121-123)}$.

Esses estudos, de modo geral, ainda incipientes no que se à investigação da carga de trabalho dos nutricionistas clínicos, estão voltados para a análise da distribuição do tempo e/ou proposição de parâmetros para o dimensionamento destes profissionais. No entanto, pouca ênfase é dada aos procedimentos metodológicos adotados na construção dos instrumentos empregados.

Cabe destacar, também, que não há na literatura científica publicações prévias que evidenciem o uso da taxonomia NIC, em outras disciplinas da saúde, com a finalidade de construir instrumentos de medida da carga de trabalho.

Portanto, a realização desta pesquisa foi importante pela inexistência de publicações voltadas para o desenvolvimento de instrumentos para mensuração da carga de trabalho, na área de nutrição clínica, bem como pelo pioneirismo no uso da NIC como referencial para a construção dessa ferramenta.

Por outro lado, a escassez de estudos relacionados à mensuração da carga de trabalho dos nutricionistas clínicos aliada à inexistência de um sistema para avaliação padronizada, constituem-se limitações para discussão deste estudo.

Considerando essa perspectiva, os resultados serão discutidos e comparados, quando possível, com os achados de autores com publicações correlatas ao tema. 


\subsection{VALIDAÇÃO DAS INTERVENÇÕES E ATIVIDADES}

Na etapa de validação de conteúdo, a interação entre as juízas, possibilitou a adequação das intervenções/atividades, tornando-as mais compreensíveis e adaptadas à realidade do trabalho desenvolvido pelos nutricionistas clínicos (Quadro $5)$.

A opção pelos diferentes perfis de juízes relacionou-se à necessidade de validar uma lista de intervenções/atividades de nutrição clínica que teve como eixo norteador uma taxonomia internacional específica do campo da enfermagem.

A esse respeito, convêm destacar que a história tem apontado para 0 importante papel da enfermagem no surgimento da profissão de nutricionista e, sobretudo, na área de Nutrição Clínica ${ }^{(124,125)}$.

Desse modo, o uso de uma taxonomia internacionalmente reconhecida no campo da enfermagem e da técnica de mapeamento cruzado das intervenções de nutrição clínica aliadas à oficina de trabalho, contribuiu para abreviar o tempo e simplificar o processo de desenvolvimento do instrumento de medida da carga de trabalho dos nutricionistas clínicos.

Cabe notar que foram sugeridas alterações no conteúdo relativas à numeração; definição de intervenções; descrição, agrupamento e realocação de atividades; inclusão ou exclusão de domínios, classes, intervenções e atividades (Apêndice G).

Com relação aos domínios, apenas a Família não apresentou correspondência com as intervenções desenvolvidas pelos nutricionistas clínicos, segundo a avaliação das juízas. Por isso, foi também excluída a classe Cuidados ao longo da vida, a intervenção Apoio ao cuidador e todas as atividades relacionadas ao domínio Família (Apêndice G).

Quanto às intervenções, Delegação e Encaminhamento foram excluídas por não representarem a prática hospitalar do nutricionista clínico no Brasil, segundo a avaliação das juízas. Em contrapartida, foram incluídas as intervenções Triagem nutricional e Terapia recreacional (Apêndice G). 
Em geral, a maioria dos itens avaliados durante a oficina de validação foi mantido sem alteração, o que mostra a eficácia das estratégias adotadas na etapa que antecedeu a validação de conteúdo (Apêndice $\mathrm{G}$ ).

A partir dos resultados obtidos durante a etapa de validação das intervenções e atividades, pode-se admitir que o uso NIC contribuiu para a estruturação das intervenções e atividades e ofereceu uma base consistente quanto aos aspectos formais e conceituais, além de abreviar o tempo requerido na elaboração da taxonomia.

É importante ressaltar, também, que o uso da classificação das intervenções de enfermagem não implicou, nem esteve relacionado à violação aos princípios da enfermagem ou aos direitos autorais, visto que, como reconhecem as próprias autoras, a NIC pode ser "[...] utilizada ou adaptada e empregada por outros, caso assim desejem"(103).

\subsection{CONSTRUÇÃO DO INSTRUMENTO}

Uma vez validada as intervenções e atividades, partiu-se para a construção do instrumento. Considerando o extenso quantitativo de atividades contempladas em cada intervenção da taxonomia (Quadro 5), que poderia dificultar a aplicação futura do instrumento, optou-se pela seleção das intervenções.

Assim sendo, o instrumento ficou constituído no total por 34 itens, dos quais 16 itens (47\%) para identificação das intervenções de nutrição clínica; três itens $(8,8 \%)$ para identificação das atividades associadas; nove itens $(26,4 \%)$ foram considerados para as atividades pessoais; quatro itens (12\%) para outras atividades; um item $(2,9 \%)$ para identificar o tempo não observado e outro item $(2,9 \%)$ para inserir prováveis atividades ou intervenções observadas, não contempladas no instrumento (Figuras 3 e 4). 
Para aumentar a abrangência do instrumento, estabeleceu-se um mecanismo capaz de torná-lo flexível e adaptável ao usuário, o qual consiste em possibilitar a inserção de atividades não contempladas na taxonomia, desde que mantida a consistência entre a atividade e a definição da intervenção. No entanto, nesta investigação, não houve necessidade de inserção de atividades.

Portanto, pode-se observar que o presente instrumento foi desenvolvido para se adaptar aos diversos cenários, não estando restrito a uma localidade geográfica ou instituição específica.

$\mathrm{Na}$ literatura, é possível encontrar instrumentos desenvolvidos para verificação da carga de trabalho dos nutricionistas clínicos ${ }^{(119-122)}$, mas há diferenças entre os agrupamentos das intervenções/atividades apresentados em cada uma das publicações.

O sistema de classificação proposto por Shanklin et al. ${ }^{(119)}$ considera seis agrupamentos, dos quais cinco foram utilizados no estudo: atividades relacionadas ao cliente, funções administrativas/gerenciais, atividades profissionais, atividades não profissionais, atrasos e tempo em trânsito.

O agrupamento denominado Atividades relacionadas ao cliente refere-se às intervenções de cuidado direto e indireto, totalizando 19 intervenções. Já agrupamento Funções administrativas/gerenciais inclui uma diversidade de intervenções, tais como: Educação em serviço, Elaboração de documentos/impressos, Padrões de cuidado em nutrição, Organização de reuniões com os funcionários, Prestação de contas, Responsabilidades gerenciais relacionadas à UAN, Preparação e dispensação de suplementos e formulações enterais, Desenvolvimento de cardápios e etc ${ }^{(119)}$.

As atividades profissionais consideradas pelos autores incluem Revisão na literatura, Educação continuada e Outras atividades profissionais. O agrupamento relativo aos Atrasos foi classificado como atraso pessoal ou forçado. Para o agrupamento Tempo em trânsito, não há exemplos, assim como as Atividades não profissionais ${ }^{(119)}$. 
Observou-se algumas semelhanças nos agrupamentos apresentados por Shanklin et al. ${ }^{(119)}$ que corroboram com os achados desta investigação. Revisão da literatura e Educação continuada, por exemplo, foram contempladas na intervenção Desenvolvimento de funcionários. Skanklin et al. ${ }^{(119)}$ também consideraram o Tempo em trânsito e os Atrasos.

Com relação às intervenções de nutrição clínica, os autores ${ }^{(119)}$ agruparam as intervenções de cuidado direto e indireto em uma mesma categoria. Entretanto, observou-se que algumas intervenções, consideradas como cuidado indireto nesta investigação, foram categorizadas como Função administrativa/gerencial por Shanklin et al. ${ }^{(119)}$. No Brasil, essas atividades não fazem parte das atribuições do nutricionista clínico ${ }^{(9)}$.

Towers et al. ${ }^{(120)}$ agruparam as intervenções e atividades desenvolvidas pelos nutricionistas clínicos em oito categorias: cuidado direto ao paciente, atividades de escritório, atividades relacionadas aos estudantes/internos, atividades com a equipe multiprofissional, tempo não trabalhado, desenvolvimento profissional, administração do serviço de alimentação e miscelânea. Para cada grupo foi identificado se a atividade estava relacionada ao atendimento prestado aos pacientes nas unidades de internação e ambulatoriais ou não.

O agrupamento Tempo não trabalhado contemplou as atividades referentes ao Deslocamento, Alimentação, Espera e Pessoais. Porém, no presente estudo, a atividade Espera foi incorporada ao tempo produtivo, visto que, na taxonomia adotada, esta atividade relaciona-se à prestação de cuidado ao paciente.

Com relação à Avaliação sensorial, Verificação do porcionamento das refeições e Reuniões com os funcionários, Towers et al. ${ }^{(120)}$ classificaram como Atividades administrativas. Contudo, nesta investigação, apenas a terceira atividade foi considerada Atividade administrativa, enquanto que as duas primeiras atividades foram agrupadas na intervenção Supervisão da distribuição das refeições nas unidades.

Portanto, embora haja semelhança ou aspectos comuns ente os agrupamentos propostos por Towers et al. ${ }^{(120)}$, nota-se a existência de particularidades que 
diferenciam os instrumentos e inviabilizam a comparação dos resultados obtidos no presente estudo.

Utami (121) considerou quatro agrupamentos (cuidados diretos, cuidados indiretos, atividades pessoais e atividades não produtivas). O estudo teve como objetivo avaliar a carga de trabalho e o desempenho dos nutricionistas clínicos em um hospital na Indonésia. A lista de intervenções/atividades desenvolvidas pelos nutricionistas clínicos foi obtida por meio da daily log technique, que consiste no auto registro das atividades executadas diariamente pelo trabalhador. Os agrupamentos propostos pela autora ${ }^{(121)}$, embora não sejam idênticos, apresentam um alto grau de semelhanças com o presente estudo.

Um estudo piloto realizado na Austrália ${ }^{(122)}$ considerou cinco agrupamentos: Cuidado direto ao paciente, Cuidado indireto, Comunicação, Administração, Ensino/pesquisa e diversas. Vinte e sete intervenções/atividades foram identificadas, das quais 11 (40,7\%) foram distribuídas entre os cuidados diretos e indiretos ao paciente.

Convém observar que o agrupamento Comunicação, utilizado pelos autores $^{(122)}$, equivale à intervenção Troca de informações, proposta no presente estudo, enquanto que as atividades relacionadas à Educação continuada foram contempladas na intervenção Desenvolvimento de funcionários. Do mesmo modo, as Atividades desenvolvidas com os estudantes de nutrição equivalem à intervenção Preceptor estudante.

Uma publicação recente do Journal of the Academy of Nutrition and Dietetics apresentou 23 variáveis e as respectivas definições utilizadas no Clinical Dietitian Staffing and Productivity Benchmarking Study ${ }^{(123)}$. Embora não haja agrupamento das intervenções e atividades, todas foram contempladas na taxonomia proposta nesta investigação.

Ao analisar os agrupamentos apresentados pelos autores ${ }^{(119-122)}$, foi possível perceber que a maioria apresentou equivalência em relação aos propostos nesta pesquisa. Porém, a diversidade de agrupamentos tornam as comparações difíceis. 
Do mesmo modo, não foi encontrada, em outras publicações, a descrição completa dos agrupamentos utilizados pelos autores ${ }^{(119-122)}$. Talvez essa seja a principal justificativa para a existência de vários instrumentos.

Quanto à operacionalização da coleta de dados, verificou-se a viabilidade do uso concomitante do instrumento e do cronômetro, sem prejuízo à qualidade do registro dos dados, além do aprimoramento da logística de coleta de dados, sendo possível garantir a segurança das informações. Contudo, o fato de ter sido aplicado por um único observador, sugere a necessidade de dar continuidade à avaliação do referido instrumento.

Durante o estudo piloto, percebeu-se a necessidade de aperfeiçoamento do instrumento, uma vez que duas intervenções (Avaliação do estado nutricional e Monitoramento da evolução nutricional) abrangiam atividades relacionadas tanto ao cuidado direto quanto ao cuidado indireto.

Desta forma, sempre que a intervenção executada se referiu aos cuidados diretos, a mesma foi identificada pela colocação das letras "D" (direto) ou "I" (indireto) ao lado do código numérico. A distinção do tempo que é utilizado no cuidado direto e indireto do paciente teve como principal objetivo analisar com profundidade o processo de trabalho do nutricionista clínico.

Embora nem todas as intervenções e atividades tenham sido observadas no estudo piloto, foi possível avaliar a pertinência, clareza e abrangência da taxonomia validada pelos juízes, uma vez que $100 \%$ das intervenções e atividades desenvolvidas pelos nutricionistas clínicos estavam contempladas no instrumento.

A ausência de algumas intervenções como, por exemplo, avaliação de produto e estabelecimento de protocolo de cuidado, possivelmente, se deve ao fato de que a frequência com que ocorrem, segue intervalo diferente, podendo variar de acordo com as diretrizes estabelecidas por cada instituição (quinzenal, mensal, semestral ou anual).

Análise dos resultados do estudo piloto, sumarizada na Tabela 2 e Gráfico 1, possibilitou calcular o valor preliminar do tempo médio das intervenções/atividades 
realizadas pelos nutricionistas clínicos $\bar{\delta}_{I}$, cujo valor médio encontrado foi de 3,5 minutos/intervenção, com intervalo de confiança IC 95\% $(1,6 ; 5,5)$.

Além disso, foi possível constatar, pelo confronto dos intervalos de confiança de 95\%, que os tempos médios das intervenções/atividades não apresentaram diferença significativa quando comparados aos resultados dos quatro turnos observados.

\subsection{CARACTERIZAÇÃO DOS PARTICIPANTES}

No presente estudo participaram 19 nutricionistas clínicos. A maioria dos participantes pertencia ao gênero feminino $(94,8 \%)$, com idade entre 20 e 30 anos (63\%), graduada há menos de cinco anos (45\%), em universidades públicas $(75 \%)$. Mais da metade dos participantes possuía título de especialista (67\%) e experiência profissional na área de Nutrição Clínica entre 1 e 5 anos (58\%). Quanto ao regime de trabalho, $100 \%$ cumpriam jornada de 40 horas semanais.

Os resultados da pesquisa de inserção profissional ${ }^{(126)}$, realizada pelo Conselho Federal de Nutricionistas em 2005, revelaram que a maioria dos nutricionistas são mulheres (97,5\%), nas faixas etárias de 20 a 25 anos $(25 \%)$ e tempo de graduação inferior a cinco anos (50,9\%), corroborando com os achados deste estudo.

Com relação à instituição de graduação, a pesquisa revelou um maior quantitativo de profissionais graduados em instituições particulares $(53,6 \%)$ e, também, a maior titulação encontrada foi de especialização $(36,9 \%)$.

Um estudo realizado em duas cidades do estado de São Paulo, Campinas e Ribeirão Preto encontrou que $48,8 \%$ dos nutricionistas que trabalhavam na rede pública hospitalar tinha especialização, dos quais $57,7 \%$ eram na área clínica ${ }^{(18)}$. Esse estudo teve como objetivo caracterizar e comparar o dimensionamento de recursos humanos em hospitais. 
Com relação ao tempo de atuação dos nutricionistas, um estudo que avaliou a prática do nutricionista clínico em hospitais em Florianópolis, Santa Catarina, revelou que $35 \%$ dos nutricionistas tinham entre um e cinco anos de experiência e $60 \%$ atuavam entre 5 e 10 anos no segmento hospitalar.

O único estudo que adotou o método tempo e movimento contínuo para analisar a distribuição do tempo despendido pelos nutricionistas clínicos em unidades de internação hospitalares australianas contou com a participação de nove nutricionistas, todas do gênero feminino, $44,4 \%$ tinha entre oito e doze anos de experiência na área e jornada de trabalho de 40 horas semanais, distribuída em turnos de oito horas.

Com relação à distribuição quantitativa dos participantes, o número de participantes do estudo (19) foi inferior ao total de turnos observados (24) porque o quantitativo de nutricionistas clínicos, alocados nas unidades de internação do HSPB e HSPC, era inferior ao total de turnos observados. Consequentemente, alguns nutricionistas do HSPB e HSPC, que aceitaram participar do estudo, foram observados no mesmo turno, em dois momentos distintos.

\subsection{CARACTERIZAÇÃO DAS UNIDADES}

Considerando os critérios de elegibilidade para participação do estudo, os resultados evidenciaram um perfil homogêneo entre as UAN dos hospitais estudados, conforme era esperado.

Em relação ao quantitativo de pacientes atendidos pelos nutricionistas clínicos, foram atendidos em média nove pacientes por turno trabalhado, nos três hospitais, dos quais $77 \%$ tinham demanda de atendimento para os níveis secundário ou terciário (Tabela 6).

Mas, se for considerada a jornada de trabalho diária de cada hospital estudado, que variou entre seis e oito horas, é possível perceber que o quantitativo de 
atendimentos, em média, foi de: 7,8 pacientes no HSPA, 11,8 pacientes no HSPB e 6,1 pacientes no HSPC.

No estudo realizado por Somers e Mulroney ${ }^{(84)}$, em 1983, foram atendidos 265 pacientes por cinco nutricionistas ao longo de seis meses, o que perfaz em média 8,8 pacientes por nutricionista com jornada de trabalho diária de oito horas.

Em estudos mais recentes, Milosavljecic et al. ${ }^{(122)}$ e Utami ${ }^{(121)}$ encontraram uma média de 5,5 e 6,0 pacientes atendidos em oito horas de trabalho, respectivamente.

Apesar de os autores ${ }^{(84,121,122)}$ adotarem diferentes métodos de mensuração da carga de trabalho (estudo do tempo e movimento contínuo, amostragem do trabalho e auto-relato), observa-se que o quantitativo de pacientes atendidos por cada nutricionista durante a jornada de trabalho se aproximou nas diversas realidades observadas.

Em relação ao grupo etário dos pacientes atendidos, $91 \%$ eram adultos ou idosos. Procurou-se não incluir os nutricionistas responsáveis pelas unidades pediátricas, considerando um possível viés em relação ao tempo médio padrão.

Mas, devido às características do estudo (descritivo) e particularidades de duas instituições (HSPB e HSPC), nas quais os nutricionistas são alocados em mais de uma unidade, não sendo possível excluir totalmente os atendimentos realizados no grupo etário pediátrico.

\subsection{FREQUÊNCIAS DAS INTERVENÇÕES}

\section{5.1 Cuidado direto}

As 16 intervenções foram agrupadas em 5 (31\%) intervenções de cuidado direto e 11 (69\%) de cuidado indireto, sendo que duas intervenções (avaliação do 
estado nutricional e monitoramento da evolução nutricional) contemplaram atividades relacionadas ao cuidado direto e indireto. $\mathrm{O}$ tempo total consumido nas intervenções foi de $72,8 \%$, dos quais $9,5 \%$ foram de cuidado direto.

Um estudo realizado em um hospital de ensino, localizado na zona urbana dos Estados Unidos, Huyck e McNamara ${ }^{(115)}$ observaram que $22 \%$ do tempo é dedicado ao cuidado direto, dos quais $74 \%$ do tempo de atendimento é realizado pelos nutricionistas. Esse resultado foi obtido através do auto registro de seis nutricionistas clínicos e dois técnicos de nutrição que participaram do estudo.

Um estudo realizado no Canadá ${ }^{(120)}$, em um hospital universitário, o tempo médio despendido nas intervenções de cuidado direto foi de 38,5\%. Participaram desse estudo 16 nutricionistas clínicos e os dados foram coletados em quatro períodos durante $\mathrm{o}$ ano. Os nutricionistas clínicos foram orientados a recordar, a cada 5 minutos, a intervenção ou atividade em execução.

Outro estudo realizado em um hospital no Canadá ${ }^{(84)}$ identificou $44 \%$ do tempo despendido nas intervenções de cuidado direto. Participaram do estudo cinco nutricionistas clínicos que recordaram durante 30 dias o tempo dispensado nas intervenções.

$\mathrm{Na}$ Indonésia ${ }^{(121)}$, o tempo despendido nas intervenções de cuidado direto foi de $35,5 \%$. Participaram do estudo 15 nutricionistas clínicos. Os dados foram coletados durante dois dias consecutivos e a amostragem do trabalho foi a técnica utilizada para mensuração da carga de trabalho.

Na Austrália, Milosavljevic et al. ${ }^{(122)}$, em um estudo piloto que utilizou o método tempo e movimento contínuo, encontraram $18,3 \%$ do tempo consumido em intervenções de cuidado direto. Para Puckett ${ }^{(127)}$, a proporção de tempo recomendada ao atendimento das intervenções de cuidado direto é de $55 \%$.

Ao comparar as publicações ${ }^{(84,115,120,121,122,127)}$, percebe-se que os resultados desses autores foram superiores aos encontrados no presente estudo. Essa variação pode ser atribuída à classificação e definição das atividades e à diversidade em relação à técnica empregada na mensuração da carga de trabalho. 
Verificou-se também que a porcentagem de tempo despendido nas intervenções de cuidado direto tem apresentado uma tendência de redução nas publicações mais recentes ${ }^{(121,122)}$. Isso significa, entre outros motivos, um menor tempo de contato entre os nutricionistas clínicos e os pacientes.

Por outro lado, convém destacar que esse cenário não favorece a criação de vínculo com o nutricionista, que estará sujeito a insucessos decorrentes da não adesão do paciente ao tratamento dietoterápico ${ }^{(128-130)}$, além de haver uma tendência à generalidade, isto é, à superficialidade de ações relacionadas ao cuidado direto.

Porém, o fato de não existirem dados na literatura a respeito do tempo ideal para a execução das intervenções de cuidado direto torna difícil a comparação dos resultados, além de exigir uma análise cuidadosa, especialmente, no que se refere ao procedimento utilizado para avaliar os efeitos da intervenção.

As intervenções de cuidado direto com representatividade superior a $1 \%$ foram: Triagem nutricional (2,6\%), Orientação alimentar e nutricional na alta hospitalar $(1,8 \%)$, Monitoramento da evolução nutricional $(10,9 \%)$ e Avaliação do estado nutricional $(1,5 \%)$, sendo que os percentuais de tempo apresentados nas duas últimas intervenções citadas incluem o tempo despendido na execução de atividades de cuidado indireto.

Contudo, não foram encontrados na literatura estudos análogos de tempo e movimento que descrevessem isoladamente percentuais de tempo relativos a essas intervenções, não sendo possível compará-los com os resultados obtidos no presente estudo.

A intervenção monitoramento da evolução nutricional apresentou a maior representatividade entre as intervenções de cuidado direto. $O$ encontro com os pacientes e familiares durante as visitas de seguimento tem grande valor para 0 nutricionista clínico, que deve estar atendo à aceitação da dieta hospitalar pelo paciente, bem como às intercorrências e alterações capazes de interferir no estado nutricional ${ }^{(131)}$. 
O monitoramento da evolução nutricional se caracteriza pelo acompanhamento sistemático do paciente para prevenir ou minimizar a desnutrição, conforme definição validada pelas juízas e, portanto, favorece a recuperação clínica.

No Brasil, a periodicidade desse monitoramento pode variar de acordo com o nível de atendimento de nutrição (primário, secundário e terciário) e/ou conforme protocolo definido em cada instituição hospitalar, isto porque não está estabelecido na Resolução CFN nํ. 380 de $2005^{(9)}$.

Consciente da necessidade de preencher essa lacuna de informação, a ASBRAN publicou o "Manual Orientativo: Sistematização dos Cuidados de Nutrição" ${ }^{(79)}$, no qual propõe um plano de atendimento para pacientes internados e estabelece ações específicas para cada nível de assistência, inclusive a frequência do atendimento. Para os níveis primário, secundário e terciário, além da visita admissional em 24 horas, o retorno deverá ocorrer em até sete dias, 96 horas ou 72 horas, respectivamente.

A intervenção Monitoramento da evolução nutricional, considerada nesta pesquisa, corresponde ao retorno. Assim, observou-se que no HSPB e HSPC o monitoramento dos pacientes classificados como terciários ocorria diariamente, secundários, duas vezes por semana e primários, uma vez por semana. No HSPA, a frequência do Monitoramento baseava-se apenas na presença risco nutricional ou desnutrição. Pacientes sem risco eram avaliados semanalmente, pacientes com risco nutricional, duas vezes por semana e desnutridos, diariamente.

A maior porcentagem de tempo despendido no Monitoramento da evolução nutricional pode ser explicada pelo maior quantitativo de pacientes ser do nível secundário e terciário. Esse perfil de paciente costuma permanecer mais tempo internado, além de demandar mais tempo na prestação do cuidado alimentar e nutricional, especialmente, no que se refere à avaliação clínico-nutricional, à verificação e análise da prescrição médica e adesão ao tratamento dietoterápico, imprescindíveis para a tomada de decisão focalizada na obtenção de resultados. 
Além disso, cabe destacar que o quantitativo de pacientes atendidos, bem como a porcentagem de tempo consumido em intervenções de cuidado direto se relacionou diretamente com o plano de atendimento das instituições hospitalares estudas, ou seja, à frequência do retorno.

Entretanto, com relação à periodicidade do retorno, é preciso avaliar se as atividades relacionadas às intervenções de cuidado direto/indireto são executadas somente nos dias em que está previsto o retorno ou se, na rotina, há necessidade de envolver os auxiliares de nutrição e/ou a equipe de enfermagem na execução de determinadas ações inerentes ao nutricionista. $O$ envolvimento desses profissionais, nos dias em que não está previsto o retorno do nutricionista, caracteriza uma efetiva ocorrência de delegação de tarefas e responsabilidades, cabendo às chefias das UAN avaliar com cautela se o auxiliar de nutrição é capaz de assumir certas atividades e/ou se isso pode gerar sobrecarga de trabalho à equipe de enfermagem.

A Triagem nutricional foi a segunda intervenção mais representativa. Apesar de não se tratar de uma intervenção exclusiva do nutricionista, ou seja, "qualquer profissional da área de saúde treinado está apto a realizá-la" (132), observa-se na prática a sua incorporação no processo de trabalho do nutricionista brasileiro.

A regulamentação da Portaria ํo. 272 do Ministério da Saúde/Sistema de Vigilância Sanitária de 08 de abril de $1998^{(133)}$ e da Portaria Secretaria de Atenção à Saúde o․ 131 de 08 de março de $2005^{(134)}$, que tornou obrigatória a implantação de protocolos de triagem nutricional como condicionante financeira para a remuneração de terapia nutricional enteral e parenteral pelo Sistema Único de Saúde, provavelmente impulsionou os nutricionistas a incorporarem esta intervenção.

O resultado da triagem nutricional é de extrema importância para o nutricionista porque permite a identificação precoce dos pacientes em situação de risco nutricional e possibilita direcionar com rapidez as atividades de monitoramento e controle de riscos.

De acordo com Posthauer ${ }^{(135)}$, a triagem nutricional deve ser realizada em até 72 horas da admissão hospitalar e repetida na semana seguinte, quando não for identificado o risco. 
Em todas as unidades de internação observadas foi possível observar a realização da Triagem nutricional no momento da admissão dos pacientes, ou seja, nas primeiras 24 horas. Se o resultado da Triagem evidenciasse risco nutricional, o paciente era submetido à avaliação do estado nutricional imediatamente ou no dia subsequente à visita. Porém, se o paciente não apresentasse risco nutricional, a Triagem era repetida após sete dias da internação.

Em sequência, a intervenção Orientação alimentar e nutricional na alta hospitalar foi a terceira intervenção que os nutricionistas mais despendem tempo. Destaca-se que nas três unidades, somente os pacientes classificados nos níveis secundário e terciário foram orientados pelo nutricionista clínico na alta hospitalar, seguindo a proposta de sistematização de cuidado da ASBRAN ${ }^{(79)}$.

De acordo com Isosaki e Nakasato ${ }^{(136)}$, o planejamento de orientação nutricional é realizado ao longo da internação, de maneira individualizada, visando atender as necessidades de cada paciente. $O$ uso de material impresso relacionado aos cuidados com a alimentação e nutrição é altamente indicado para essa intervenção e tem como objetivo reforçar as instruções verbais.

É importante aqui ressaltar que o tempo despendido na orientação alimentar e nutricional correspondeu ao período dedicado às orientações verbais, com ou para o paciente. O tempo consumido na elaboração do impresso correspondeu à documentação.

A Avaliação do estado nutricional foi a quarta intervenção mais representativa entre as intervenções de cuidado direto. Trata-se de uma atribuição privativa do nutricionista que possui grande importância na prática clínica, além de ser a primeira etapa para a prevenção e tratamento da malnutrição.

Os pacientes identificados em situação de risco nutricional, por meio da triagem, devem ser submetidos à avaliação do estado nutricional, sendo esta uma condição para o reembolso da terapia nutricional pelo SUS ${ }^{(133)}$.

Quanto às atividades que compõem a Avaliação do estado nutricional, destacase a convergência entre as atividades contempladas na intervenção Monitoramento da evolução nutricional. Isto se deve ao fato de que a maioria das atividades 
relacionadas à Avaliação do estado nutricional coincide com as atividades de Monitoramento ao longo da internação.

Assim, com o intuito de referendar preocupações das juízas com relação às diferenças entre essas duas intervenções convêm destacar que a Avaliação do estado nutricional foi considerada a abordagem inicial, subsequente à Triagem nutricional.

Ao analisar os resultados apresentados na Tabela 13, percebe-se que a maioria do tempo despendido na Avaliação do estado nutricional foi dedicado aos pacientes classificados como nível secundário e terciário. Do total de 48 pacientes primários atendidos pelos nutricionistas, apenas um foi submetido à Avaliação do estado nutricional. Esse modo de proceder revela o uso racional do tempo frente às exigências dos pacientes.

Com relação ao percentual de tempo consumido na Avaliação do estado nutricional, convém destacar que o elenco de ações que envolvem a coleta e interpretação de indicadores nutricionais objetivos e subjetivos ${ }^{(79),}$ que abrangem os cuidados direto e indireto, respectivamente, apresenta relação de interdependência e, portanto, merecem ser discutidos conjuntamente.

A diferença observada nos tempos despendidos no cuidado, com maior proporção consumida em ações de cuidado indireto, era esperada, devido à necessidade de comparar os indicadores nutricionais com os padrões de normalidade, específicos para cada grupo etário e condição clínica.

A mesma explicação se aplica às proporções de tempo verificadas no Monitoramento da evolução nutricional, visto que a necessidade de comparação dos indicadores nutricionais com os padrões de normalidade e a verificação dos resultados obtidos após as intervenções tendem a requerer maior tempo para sua execução e, consequentemente, para a tomada de decisões.

Verificou-se, em todas as instituições investigadas, a utilização de sistemas de informação como suporte para a tomada de decisões em nutrição. Porém, os módulos não se apresentavam integrados ao prontuário eletrônico/sistema de cadastro do paciente, o que de certa forma não contribuía para reduzir o tempo de 
execução das ações indiretas previstas nas intervenções Avaliação do estado nutricional e Monitoramento da evolução nutricional.

Todavia, não foi objetivo deste estudo avaliar se o tempo de execução da Avaliação do estado nutricional encontrava-se adequado à prestação do cuidado, de acordo com o nível de complexidade dos pacientes.

\subsubsection{Cuidado indireto}

Este estudo mostrou que os nutricionistas despendem $63,3 \%$ do tempo total em intervenções de cuidado indireto. Todavia, dois estudos análogos de tempo e movimento encontraram proporções inferiores com $39 \%{ }^{(122)}$ e $40,5 \%{ }^{(121)}$.

As intervenções de cuidado indireto com representatividade superior da $1 \%$ foram: Documentação $(31,5 \%)$, Troca de informações sobre os cuidados de saúde $(15,1 \%)$, Monitoramento da evolução nutricional (7,1\%), Preceptor: estudante $(3,9 \%)$, Desenvolvimento de funcionários $(1,1 \%)$, Supervisão da distribuição das refeições nas unidades $(1,1 \%)$ e Reunião para avaliação do cuidado multidisciplinar.

Não foram encontrados na literatura estudos de tempo e movimento que descrevessem isoladamente percentuais de tempo de todas as intervenções de cuidado indireto listadas na presente pesquisa. Porém, foi possível comparar os resultados obtidos em quatro intervenções: Preceptor-estudante, Reunião para avaliação do cuidado multiprofissional, Desenvolvimento profissional e Troca de informações sobre os cuidados de saúde.

Neste estudo, a intervenção Documentação foi a que consumiu a maior parte do tempo dos nutricionistas entre as intervenções de cuidado indireto. Segundo Wills ${ }^{(137)}$, documentação é o método pelo qual os outros profissionais de saúde estão cientes de abordagens específicas para problemas e resultados dos pacientes e inclui os registros realizados no prontuário do paciente. 
Contudo, no processo de trabalho do nutricionista clínico, a Documentação não se limita ao prontuário do paciente. Ou seja, uma parcela do tempo é consumida na etapa de integração do fluxo operacional do atendimento clínico-nutricional e o da produção de refeições ${ }^{(135)}$.

No HSPA, a Documentação realizada no prontuário do paciente e aquela relacionada à produção de refeições era eletrônica. Porém, é importante destacar que o modo como era feito 0 registro dos cuidados prestados ao paciente não 0 diferenciava do modo manual.

No HSPB e HSPC, o sistema de informação hospitalar não era totalmente eletrônico. A Documentação dos cuidados prestados ao paciente, por exemplo, era feita em prontuário físico, assim como o registro de informações relacionadas às dietas dos pacientes, que serviam de orientação para os auxiliares de nutrição, no momento da distribuição das refeições.

A documentação acurada dos serviços de nutrição prestados aos pacientes é essencial para a gestão de sistemas hospitalares, utilização, controle de qualidade, avaliação e reembolso ${ }^{(127)}$. Do mesmo modo, a implantação de sistemas informatizados tem proporcionado ganhos significativos no tempo despendido por atividades nas UAN hospitalares ${ }^{(136)}$.

Os resultados obtidos neste estudo, referentes ao tempo despendido na Documentação, apontam para a necessidade de se analisar com profundidade os processos e fluxos de trabalho, para que seja possível identificar falhas e/ou variáveis potencialmente modificáveis com foco na racionalização e qualidade.

No presente estudo, a Troca de informações sobre os cuidado de saúde foi a segunda a apresentar maior representatividade no grupamento das intervenções de cuidado indireto.

Os achados obtidos por Milosavljecic et al. ${ }^{(122)}$ mostraram que o nutricionista despende $4,2 \%$ do tempo para comunicar-se com os outros profissionais (médicos, enfermeiros, outros profissionais de saúde e o pessoal da UAN) e 1,6\% do tempo na comunicação através de telefone/dispositivos móveis, totalizando 5,8\%. Assim, 
observa-se que os nutricionistas brasileiros despendem, aproximadamente, 5 vezes mais tempo do que os nutricionistas australianos.

Em seu artigo, Relações interpessoais na equipe do Programa de Saúde da Família, Cardoso ${ }^{(138)},(2004$, p. 4), destaca a importância da comunicação ao afirmar que:

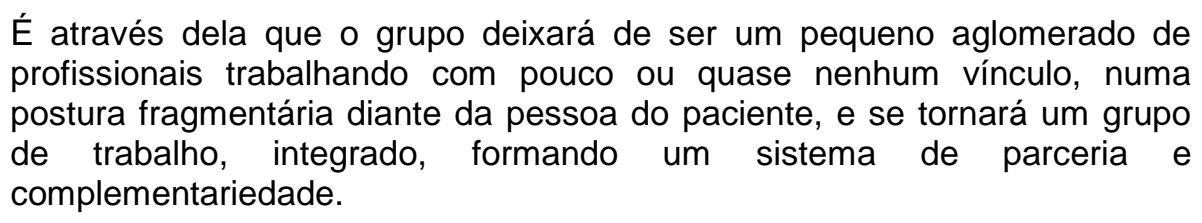

Com relação à intervenção Preceptor:estudante, o resultado encontrado por Milosevic et al. $(1,7 \%)^{(122)}$ foi inferior ao encontrado no presente estudo. Somers e Mulroney ${ }^{(84)}$ e Towers et al. ${ }^{(120)}$ encontraram resultados superiores ao avaliar esta mesma intervenção, sendo 6,0\% e 6,5\%, respectivamente.

Porém, é preciso ter cautela ao comparar esses resultados. O primeiro motivo se deve ao fato de que apenas Milosavljecic et al. ${ }^{(122)}$ utilizou a técnica de tempos e movimentos. Além disso, o estudo não foi realizado em hospitais de ensino.

O segundo motivo diz respeito ao fato de que embora Somers e Mulroney ${ }^{(84)} \mathrm{e}$ Tower et al. ${ }^{(120)}$ tenham conduzido seus estudos em hospitais de ensino, o método utilizado baseou-se no auto relato, o qual é alvo de criticas por diversos autores, enquanto que a técnica de tempo e movimento é considerada mais adequada para a mensuração da carga de trabalho.

De modo geral, a proporção de tempo despendido na intervenção Desenvolvimento de funcionários encontrada neste estudo $(1,1 \%)$ foi inferior aos achados na maioria dos estudos. As porcentagens de tempo encontradas por Shanklin ${ }^{(119)}$, Milosavljecic et al. ${ }^{(122)}$, Somers e Mulroney ${ }^{(84)}$ e Towers et al. ${ }^{(120)}$, foram $1,0 \%, 2,8 \%, 3,0 \%$ e $7,0 \%$, respectivamente.

Ao comparar esses resultados, é importante destacar, mais uma vez, que apenas Milosavljecic et al. ${ }^{(122)}$ empregou a técnica de tempo e movimento, enquanto que os demais autores se basearam no auto relato dos profissionais. 
A Supervisão da distribuição das refeições nas unidades consumiu, em média, $1,1 \%$ do tempo referente às intervenções de cuidado direto. No entanto, não foram encontrados na literatura estudos análogos que avaliaram esta intervenção, o que impossibilita a comparação com outros estudos.

Ao comparar a porcentagem de tempo despendido na intervenção Reunião para avaliação do cuidado multidisciplinar encontrada neste estudo $(1,1 \%)$ com os estudos realizados por Milosavljecic et al. $(6,8 \%)^{(122)}$ e Huyck et al. $(2,9 \%)^{(115)}$, podese perceber que os resultados desta investigação foram inferiores.

A importância do trabalho em equipe e das reuniões multiprofissionais tem sido reportada por diversos autores ${ }^{(139-141)}$, sendo esta abordagem a que mais se aproxima da complexidade que caracteriza o cuidado em saúde.

\subsubsection{Atividades associadas ao trabalho}

Nesta investigação, os nutricionistas clínicos dos hospitais estudados despenderam 0,6\% do tempo em atividades associadas ao trabalho, sendo inferior ao encontrado por Shanklin et al. $(5,1 \%)^{(119)}$.

Contudo, não foi possível comprar os resultados com os outros estudos devido às dificuldades encontradas para identificar nas publicações quais as atividades foram classificadas como associadas ao trabalho, ou seja, atividades que não são específicas para os nutricionistas clínicos.

Embora a literatura não ofereça dados referentes a essa categorização, podese verificar que, no presente estudo, as atividades associadas não contribuíram para aumentar a carga de trabalho, visto que sua representatividade foi inferior a $1 \%$.

Pode-se dizer, então, que esse resultado era esperado, já que o estudo foi realizado em instituições estruturadas que promovem as boas práticas na saúde. 


\subsubsection{Atividades pessoais}

A proporção de tempo despendido pelos nutricionistas clínicos em atividades pessoais foi de $9,1 \%$, enquanto que Utami ${ }^{(121)}$ encontrou $22,5 \%$. Entretanto, cabe ressaltar que a autora utilizou o método de amostragem do trabalho, diferentemente deste estudo, em que foi aplicada a técnica de tempo e movimento contínuo.

Embora não haja outros estudos descritos na literatura indicando a porcentagem de tempo ideal para as atividades pessoais, sabe-se que o tempo consumido nas atividades pessoais é contabilizado nas horas trabalhadas, por ser indissociável do trabalho, qualquer que seja ele.

Segundo Grandjean e Kromer ${ }^{(142)}$, a adoção de pausas tem a finalidade de prevenir doenças ocupacionais, permitir a alimentação e possibilitar contatos sociais. Portanto, o tempo despendido nas atividades pessoais não deve ser visto como ameaça à produtividade nem gerar inquietações por parte dos gestores e empregadores, desde que não seja efetuado em detrimento da assistência ao paciente ${ }^{(143)}$.

\subsubsection{Outras atividades: Espera, Ausência, Deslocamento e Participação em reunião administrativa}

As proporções de tempo despendido pelos nutricionistas nas atividades relacionadas à Espera (2,6\%), Ausência (0,6\%), Deslocamento (11,8\%) e Participação em reunião administrativa $(0,6 \%)$ encontradas nesta investigação enquanto categorias de análise foram reportadas em dois estudos ${ }^{(115,119)}$.

Shanklin et al. ${ }^{(119)}$ verificaram que $19,5 \%$ do tempo foi consumido nos deslocamentos e 3,5\% referente ao tempo de espera. Já Huyck e McNamara ${ }^{(115)}$ encontraram que $3,8 \%$ do tempo foi gasto em reuniões com os profissionais da 
UAN. Não foram encontrados estudos que avaliassem, separadamente, a categoria ausência.

Com relação ao tempo gasto durante os deslocamentos, Shanklin et al ${ }^{(119)}$, consideraram a localização sala dos nutricionistas e as dimensões físicas hospitalares influenciaram o tempo de deslocamento.

Sobre a dimensão tempo-deslocamento para o atendimento das necessidades dos pacientes, o conhecimento do processo de trabalho é imprescindível, como também a avaliação do impacto financeiro das perdas da produtividade laboral e eficiência.

A falta de informações sobre o tempo despendido no deslocamento aliada às dificuldades encontradas pelas chefias das UAN em transformar esta variável em dados financeiros pode prejudicar a tomada de decisão no que se refere à justificativa para ampliação do quadro de nutricionistas clínicos. Porém, a interdisciplinaridade dos estudos de economia e saúde vem contribuindo para reduzir esses obstáculos.

Com relação ao tempo de espera, os resultados encontrados neste estudo corroboram com os achados de Shanklin et al. ${ }^{(119)}$, que consideraram como atividades desta categoria, o tempo aguardando informações médicas, esperando o elevador, a equipe multidisciplinar ou os familiares. Porém, é preciso ter cautela ao comprar esses resultados.

O primeiro motivo se deve ao fato de que o método utilizado para mensuração do tempo despendido pelos nutricionistas clínicos se baseou no auto relato dos profissionais. O segundo motivo está relacionado ao tempo esperando o elevador, que foi considerado, nesta investigação, como deslocamento.

A proporção de tempo despendido em reuniões administrativas encontrada neste estudo não contribuiu para o aumento do tempo requerido nas atividades não relacionadas ao paciente, visto que foi inferior a $1 \%$ do tempo total, diferente do resultado encontrado por Huych e McNamara ${ }^{(115)}$. 


\subsection{DISTRIBUIÇÃO DAS INTERVENÇÕES}

Os resultados deste estudo evidenciaram que a maior parte do tempo dos nutricionistas clínicos das unidades avaliadas é despendida nas intervenções de cuidado direto e indireto.

No que diz respeito à distribuição do tempo de trabalho do nutricionista clínico, $72,5 \%$ estão voltadas para as intervenções de cuidado direto e indireto, $0,6 \%$ em atividades associadas, 9,0\% em atividades pessoais, 0,6\% em ausências, 12,1\% em deslocamento, $2,6 \%$ em espera, $0,6 \%$ em reuniões administrativa e em $1,9 \%$ do tempo não foi registrado.

Poucos estudos mensuraram o tempo despendido pelos nutricionistas clínicos na assistência hospitalar. Estes estudos utilizaram a técnica de tempo e movimento contínuo e a amostragem do trabalho. Porém, a inexistência de um modelo de referência para análise da carga de trabalho do nutricionista clínico e das proporções de tempo recomendadas para 0 atendimento às necessidades dos pacientes, dificultou a comparação e avaliação dos valores encontrados neste estudo.

\subsection{PRODUTIVIDADE, TEMPO EFETIVO DE TRABALHO E CARGA DE TRABALHO}

A gestão da produtividade tem sido tema recorrente nas organizações de saúde que, diante das necessidades da população, buscam viabilizar o melhor aproveitamento dos recursos disponíveis.

Quanto ao uso do termo produtividade, diferentes abordagens dão origem a vários conceitos. De acordo com Maximiano, "a produtividade é definida como a relação entre os recursos utilizados e os resultados obtidos, ou produção" (144). 
Mello e Barros ${ }^{(145)}$ entendem que "o conceito de produtividade está na redução do tempo gasto para executar um serviço, ou o aumento da qualidade de produtos elaborados, com a manutenção dos níveis de qualidade, sem o acréscimo de mão de obra ou aumento dos recursos necessários".

Segundo Biesemeier ${ }^{(20)}$, na prática, o termo produtividade é usado para indicar como os profissionais usam seu tempo para realizar o trabalho que necessita ser feito.

Para fins de comparação dos resultados obtidos nesta investigação com um maior número de estudos, tendo em vista a insuficiência de publicações sobre essa temática nos serviços de nutrição clínica, considerou-se produtividade a porcentagem de tempo dedicado às intervenções de cuidado direto e indireto, conforme taxonomia adotada no presente estudo.

No estudo conduzido nos Estados Unidos, em um hospital com 460 leitos e taxa de ocupação de $76 \%$, McManners e Barina ${ }^{(117)}$ encontraram nível de produtividade de $86 \%$. Cada nutricionista era responsável, em média, por 80 a 90 pacientes por dia. Para quantificar a porcentagem de tempo despendido pelos nutricionistas clínicos, as autoras se basearam em sete critérios estabelecidos pela JCAH.

O estudo realizado por McManners e Barina ${ }^{(117)}$ teve duração de 12 meses e os dados foram obtidos por meio do auto relato de quatro nutricionistas clínicos que faziam parte do Serviço de Nutrição Clínica. É importante ressaltar também que a categorização das intervenções de cuidado adotada pelas autoras se baseou em quatro níveis: produção do cardápio, cuidado básico, dietoterapia e suporte metabólico.

Os resultados obtidos por Utami ${ }^{(121)}$ relevaram que $74,5 \%$ do tempo de trabalho dos nutricionistas são consumidos em intervenções de cuidado direto e indireto. O estudo conduzido pela autora ocorreu em um único hospital, por meio da técnica de amostragem do trabalho, e contou com a participação de 13 nutricionistas clínicos, na Indonésia. 
Os estudos realizados por Somers e Mulroney ${ }^{(84)}$, no Canadá, e Shanklin et al ${ }^{(119)}$, nos Estados Unidos, encontraram $64 \%$ e $50,7 \%$ de produtividade, enquanto que Milosavljevic et al. ${ }^{(122)}$, na Austrália, encontraram $58,8 \%$.

Mas é preciso analisar com cautela esses resultados porque diferentes há diferenças quanto às classificações, terminologias, definições e métodos empregados por esses autores ${ }^{(84,119,122)}$.

Quanto à técnica empregada para a medida da distribuição do tempo de trabalho dos nutricionistas, apenas Milosavljevic et al. ${ }^{(122)}$ utilizou o estudo de tempo e movimento. Os demais autores obtiveram os dados por meio do auto relato dos nutricionistas clínicos.

Com relação à categorização, diferente deste estudo, os autores ${ }^{(84,119 \text { e 122) não }}$ consideraram como intervenções de cuidado indireto aquelas relativas à comunicação entre os profissionais, educação continuada, preceptoria, elaboração de projetos e pesquisa como parte das intervenções de cuidado indireto.

No presente estudo, a proporção de tempo dedicada às intervenções de cuidado direto e indireto foi de $72,8 \%$, considerado satisfatório de acordo com os critérios de avaliação da produtividade preconizados por Biseng ${ }^{(146)}$. Entretanto, se comparado aos níveis de produtividade estabelecidos por O'Brien-Pallas ${ }^{(147)}$, entre 80 e $90 \%$, o valor médio encontrado está abaixo do recomendado.

Contudo, é preciso refletir sobre a expressividade de algumas atividades, como por exemplo, o tempo de deslocamento e espera. Apesar dessas atividades não se constituírem parte do tempo produtivo, não se pode desconsiderar o contexto em que ocorre a prática.

Nesta investigação, por exemplo, verificou-se que o tempo consumido no deslocamento e na espera esteve intrinsecamente relacionado ao desenvolvimento das intervenções de cuidado direto e indireto, pela própria definição estabelecida.

Outra informação que não pode ser desconsiderada é que a maioria dos nutricionistas observados é responsável por mais de uma unidade de internação, o que exige maior tempo para o deslocamento. 
Além disso, a transmissão de informações que ocorre entre as unidades de internação e a copa de distribuição (área para recepção, inspeção, despesa e distribuição das refeições e utensílios situada em cada unidade de internação) faz com que o fluxo de trabalho do nutricionista clínico seja caracterizado por frequentes deslocamentos.

Partindo dessas considerações, pode-se dizer que se não fosse a expressividade das atividades deslocamento $(11,8 \%)$ e espera $(2,6 \%)$, o nível médio de produtividade poderia ter alcançado $87,2 \%$ (somatório das porcentagens médias referentes às intervenções de cuidado direto, deslocamento e espera), isto é, o potencial máximo de produtividade.

Considerando a importância da produtividade do trabalho para a sustentabilidade das organizações/instituições, Bomfim ${ }^{(110)}$, em seu estudo sobre o planejamento da força de trabalho de enfermagem na Estratégia de Saúde da Família, propôs diferenciar a produtividade em "real" e "potencial".

De acordo com Bonfim ${ }^{(110)}$, a "produtividade real" representa a proporção de tempo despendido na execução de tarefas relacionadas exclusivamente ao trabalho, que incluem as intervenções de cuidado direto e indireto e as atividades associadas, enquanto que a "produtividade potencial" refere-se ao pico de produtividade que poderia ser alcançado e, portanto, inclui também a proporção de tempo consumido em atividades não relacionadas ao trabalho, tais como Espera e Ausência.

Assim, os resultados da produtividade real $(73,4 \%)$ e potencial $(87,8 \%)$ obtidos no presente estudo, Tabela 16, sugerem a necessidade de se estudar com profundidade o processo de trabalho dos nutricionistas clínicos dessas unidades hospitalares, a fim de torná-lo mais eficiente, com vistas ao alcance dos objetivos e metas das instituições hospitalares.

O tempo efetivo de trabalho é outra variável importante para o dimensionamento e corresponde à produtividade dos profissionais, expresso pelo produto entre a produtividade e a jornada de trabalho ${ }^{(95)}$. No presente estudo, o tempo efetivo de trabalho encontrado, considerando jornada média de trabalho de 6,66 horas (400 minutos) e produtividade real média de $72,8 \%$, foi 4,84 horas. 
Os dados obtidos, por meio da cronometragem do tempo, permitiram, também, calcular o tempo médio das intervenções de cuidado direto realizadas pelos nutricionistas clínicos (Tabela 17).

Considerando a classificação quanto ao nível de atendimento de nutrição, preconizada pela Resolução CFN nํ. 380/2005 ${ }^{(9)}$, o tempo médio requerido por paciente para cada nível foi: 1,8 minutos para o nível primário, 3,7 minutos para o nível secundário e 5,2 minutos para o nível terciário.

Uma vez determinados os tempos médios despendidos nas intervenções de cuidado direto, segundo o nível de atendimento, procedeu-se o rateio (acréscimo proporcional) dos tempos referentes às Atividades pessoais, Deslocamento e Espera (Tabela 18), seguido do rateio dos tempos referentes às Atividades associadas e às Intervenções de cuidado indireto (Tabela 19).

Assim, os parâmetros de tempo de cuidado requeridos para um paciente, de acordo com os níveis primário, secundário e terciário de atendimento de nutrição, corresponderam a 8,3 minutos, 15,1 minutos e 26,4 minutos por paciente, respectivamente (Tabela 19$)$.

Para o cálculo dos parâmetros de tempo, tomou-se como base o número de atendimentos realizados pelos nutricionistas para os níveis primário, secundário e terciário; o tempo de duração do turno; e o tempo gasto em intervenções/atividades obtido após o rateio. Em virtude das diferenças de duração dos turnos das instituições estudadas, tomou-se como referência o valor médio de 400 minutos (Quadro 8).

É importante destacar que o método de análise empregado na obtenção dos parâmetros para o atendimento de nutrição nos níveis primário, secundário e terciário baseou-se na impossibilidade de medir os tempos referentes à maioria das intervenções de cuidado indireto, sem que houvesse interferência do observador, e pela necessidade de se propor parâmetros que incluíssem os tempos consumidos no Deslocamento, na Espera, em Reuniões administrativas e Atividades pessoais, por entender que eles são intrínsecos ao contexto do trabalho. 
Diante disso, pode-se afirmar que os parâmetros de tempo de cuidado encontrados nesta pesquisa correspondem à carga média de trabalho das unidades de internação investigadas (17,6 minutos por paciente), para 6,66 horas (400 minutos), obtida por meio da razão entre o tempo de assistência de nutrição clínica utilizada (4.169,6 minutos) e a quantidade de pacientes assistidos (237).

Considerando que este é o primeiro estudo empírico brasileiro a propor padrões de tempo de trabalho dos nutricionistas assistenciais, com base na cronometragem contínua do tempo, e cuja análise partiu de um sistema de classificação de atendimento de nutrição específico deste país, não foi possível comprar os tempos médios encontrados neste estudo com outros autores ${ }^{(117,119)}$.

\subsection{COMPARAÇÃO COM OS PARÂMETROS NUMÉRICOS ESTABELECIDOS PELA RESOLUÇÃO CFN N ${ }^{\circ} .380$ DE $2005^{(9)}$}

Por se tratar de uma pesquisa empírica pioneira no Brasil e considerando os parâmetros numéricos estabelecidos pela Resolução CFN ํo. 380/2005 ${ }^{(9)}$ procedeuse à comparação dos resultados.

Para tanto, foi necessário ajustar o tempo de duração do turno encontrado neste estudo para 360 minutos antes de comparar os resultados. Além disso, foi necessário converter a proporção de pacientes por nutricionista em tempo de cuidado (minutos) por paciente (Quadro 8).

Para verificar se existiram diferenças estatísticas entre os parâmetros encontrados neste estudo com aqueles estabelecidos pela Resolução CFN №. $380 / 2005^{(9)}$ aplicou-se o teste $t$ - Student, ao nível de significância de $5 \%$, e assumiuse um valor crítico de 2,0 . 
Como o tempo observado $t_{\text {obs }}$ foi maior do que o tempo crítico $t_{\text {crit, }}$, em todos os níveis de atendimento de nutrição, constatou-se existir diferença entre as médias dos parâmetros numéricos propostos quando comparados aos estabelecidos pela Resolução CFN no. 380/2005 ${ }^{(9)}$ (Quadro 9).

Ao comparar os tempos médios requeridos por paciente, verificou-se que os resultados encontrados nesta pesquisa foram superiores aos preconizados. Esse resultado era esperado devido ao acréscimo dos tempos relacionados às atividades pessoais, espera e deslocamento, que provavelmente não estão contemplados na Resolução CFN n.ํ이 de $2005^{(9)}$.

Por outro lado, os resultados referentes à proporção de pacientes por nutricionista mostraram-se inferiores aos preconizados. Isto se deve ao quantitativo de tempo consumido pelos pacientes, segundo o nível de atendimento de nutrição, que foi superior àquela estabelecida na Resolução CFN n. ${ }^{\circ} 380$ de $2005^{(9)}$.

Com relação às diferenças encontradas entre os tempos médios preconizados e aqueles obtidos nos três níveis de atendimento de nutrição, verificou-se que os níveis primário $(26,6 \%)$ e secundário $(34,3 \%)$ apresentaram as maiores diferenças (Quadro 8).

Cabe destacar que a presente pesquisa não foi exaustiva e o método utilizado não objetivou avaliar as necessidades de cuidado alimentar e nutricional dos pacientes assistidos, mas sim verificar o tempo consumido por eles, o que não garante que as demandas dos pacientes foram completamente atendidas.

É importante ainda ressaltar que os resultados nesta investigação refletem a dinâmica do trabalho do nutricionista clínico nas unidades de internação durante um período específico, não sendo possível avaliar a ocorrência das intervenções não observadas. Entretanto, Towers et al. ${ }^{(120)}$, em estudo realizado durante os meses de janeiro, abril, junho e setembro em um hospital no Canadá, não observou variações expressivas na distribuição do tempo despendido pelos nutricionistas clínicos. 
176 


\section{CONSIDERAÇÕES FINAIS}

\subsection{PERSPECTIVAS E LIMITES DA PESQUISA}

Este estudo apresentou limitações relacionadas ao objeto, ao investigador e aos participantes que devem ser consideradas. Além disso, são apresentadas reflexões e recomendações para outros estudos.

No que diz respeito à validade externa do instrumento, deve-se considerar que a sua aplicabilidade foi testada em três unidades hospitalares localizadas na cidade de São Paulo. Por isso, para eliminar o viés relacionado à validade do constructo e fidedigndade da taxonomia, recomenda-se aos pesquisadores e nutricionistas verificar a aplicabilidade do instrumento na unidade hospitalar a ser estuada antes da sua utilização.

Quanto ao método empregado, embora a técnica de tempo e movimento contínuo seja considerada a mais indicada para a realidade estudada, está descrito na literatura o "efeito Hawthorne", que consiste em uma mudança positiva do comportamento dos trabalhadores observados.

Para minimizar o viés da presença do observador junto ao profissional, foi oportunizado aos participantes das três unidades hospitalares um contato prévio com a pesquisadora (observadora), que apresentou detalhadamente os objetivos e os instrumentos utilizados da pesquisa, sendo um momento aberto às perguntas $e$ dúvidas.

Além disso, outros cuidados foram adotados pelo observador durante a coleta de dados, tais como: identificação, distância mínima em relação ao profissional, cordialidade, discrição, verbalização restrita às necessidades, atenção voltada às intervenções/atividades executadas pelo nutricionista (sem fixar o olhar nos pacientes e/ou profissionais) e tempo de deslocamento compatível com o ritmo do trabalhador observado. 
Cabe destacar, também, que o viés decorrente da presença do observador, durante a coleta de dados, pode ter sido contornado pela observação de múltiplos profissionais, permitindo que as diferenças, por ventura existente no trabalho de cada um desses profissionais, fossem incluídas na própria variância dos dados coletados.

Com relação às unidades de internação e aos profissionais observados, podese afirmar que a escolha não seguiu distribuição aleatória, visto que as unidades foram selecionadas pelos coordenadores do setor de nutrição clínica de cada instituição participante, de acordo com os critérios definidos pelo estudo e mediante a assinatura do termo de consentimento dos nutricionistas alocados.

Considerando a possibilidade de variações relacionadas ao comportamento dos pacientes e dos profissionais em função do turno de trabalho e da instituição, os dados foram coletados em diferentes turnos. Verificou-se pela aplicação do teste estatísitico que não houve diferença significativa entre os turnos e entre os hospitais. Por isso, não houve necessidade de ampliar o número de instituições participantes.

Outra limitação do estudo se deve ao fato de ter sido realizado no período de setembro a dezembro, não sendo possível avaliar a ocorrência de intervenções que poderiam estar concentradas em outros períodos do ano.

Quanto à participação do mesmo observador (a pesquisadora) na etapa de campo, é preciso considerar que, se por um lado foi importante porque contribuiu para aumentar a confiabilidade dos dados, por outro lado impossibilitou avaliar a validade e confiabilidade do instrumento (intra e inter-observador) quanto comparado ao padrão ouro (a pesquisadora).

Outro possível viés está relacionado à classificação quanto ao nível de atedimento de nutrição, obtido a partir de dados secundários. Embora os pacientes tenham sido classificados pela pesquisadora, os dados referentes à triagem ou diagnóstico nutricional e à prescrição dietética foram fornecidos pelos nutricionistas clínicos.

Devido à diversidade de ferramentas de triagem nutricional aliada ao fato de que o diagnóstico nutricional depende dos indicadores utilizados para avaliar 0 
estado nutricional, não se pode desconsiderar a possibilidade de variação na classificação do nível de atendimento de nutrição, de acordo com a instituição e o profissional.

Sendo este estudo pioneiro no Brasil, os resultados apresentados podem servir de marco referencial para estudos mais amplos que reflitam melhor o planejamento da força de trabalho na área da Nutrição Clínica.

Nesse sentido, para elucidar as limitações acima referidas, destaca-se a necessidade de pesquisas de caráter longitudinal, que permitam conhecer as reais necessidades de cuidado de nutrição do paciente internado.

Quanto aos três níveis de atendimento de nutrição, é importante avaliar se a classificação estabelecida pela Resolução CFN n‥ 380/2005 ${ }^{(9)}$ é suficiente para identificar o tempo de cuidado requeirdo pelo paciente. Para tanto, é imprescindível verificar se existem diferenças em relação ao tempo de atendimento entre pacientes classificados no mesmo nível de atendimento, nas diversas especialidades médicas e cirúrgicas.

Considerando que a padronização do cuidado é essencial para o planejamento, avaliação e comparação dos resultados, é imperativo que se busque estabelecer uma aproximação com a abordagem internacional proposta pela $A N D$.

Ao analisar a proporção de tempo destinada às intervenções e atividades executadas pelo nutricionista clínico, é preciso refletir sobre as proporções de tempo encontradas e confrontá-las com as reais necessidades dos pacientes.

Considerando a ênfase atual dada à segurança do paciente e humanização do cuidado, pode-se inferir que algumas intervenções/atividades podem ter o seu tempo reduzido (Documentação, Deslocamento e Espera) e outras aumentado (todas as intervenções de cuidado de direto, Reunião para avaliação do cuidado multidisciplinar e Supervisão da distribuição das refeições nas unidades).

A discussão em torno do papel do técnico de nutrição e dietética nas unidades de internação merece ser analisada pelas chefias dos setores de nutrição clínica, visto que algumas intervenções poderiam ser executadas por este profissional, tais como: realizar pesagem, mensuração e outras técnicas definidas pelo nutricionista 
para concretização da avaliação nutricional e de consumo alimentar; coletar dados estatísticos ou informações por meio da aplicação de entrevistas, questionários; e preenchimento de formulários conforme protocolo definido pelo nutricionista ${ }^{(148)}$.

Contudo, Hilovsky et al. ${ }^{(149)}$ recomendam a realização estudos preliminares para avaliar as características de nutricionistas clínicos, em matéria de delegação de responsabilidades aos técnicos, que afetam o papel atribuído aos técnicos de nutrição na prática clínica das unidades de internação.

Acredita-se que os parâmetros propostos neste estudo tem potencialidade de aplicação nas instituições hospitalares brasileiras, mas se faz necessário replicá-lo em contextos locais, municipais, regionais e nacionais. 


\section{CONCLUSÃO}

Os resultados obtidos neste estudo, inédito no Brasil, permitiram as seguintes conclusões:

1) $O$ instrumento utilizado na coleta de dados, para mensuração da carga de trabalho dos nutricionistas clínicos, apresenta 100\% das intervenções e atividades desenvolvidas pelos nutricionistas das três unidades hospitalares estudadas;

2) O número de observações realizadas em cada hospital superou o cálculo do tamanho da amostra nas três instituições e a análise estatística demonstrou não haver diferença significativa entre os hospitais. Portanto, o quantitativo de observações realizadas e de instituições hospitalares avaliadas está adequado à técnica empregada (tempo e movimento contínuo);

3) Os nutricionistas clinicos despenderam 72,8\% em intervenções, sendo 9,5\% em cuidado direto e $63,3 \%$ em cuidado indireto; $0,6 \%$ em atividades associadas; 9,1\% em atividades pessoais; $0,6 \%$ em ausências; $12,1 \%$ em deslocamento; $2,6 \%$ em espera; $0,6 \%$ em reuniões administrativas e em $1,9 \%$ do tempo não foi registrado;

4) As intervenções mais expressivas, ou seja, que consumiram a maior proporção de tempo dos nutricionistas, foram: Documentação (31,5\%), Troca de informações sobre cuidados de saúde $(15,1 \%)$, Monitoramento da evolução nutricional $(10,9 \%)$, Preceptor-estudante $(3,9 \%)$, Triagem nutricional $(2,6 \%)$, Orientação alimentar e nutricional na alta hospitalar (1,8\%), Avaliação do estado nutricional (1,5\%), Desenvolvimento de funcionários $(1,1 \%)$ e Supervisão da distribuição das refeições nas unidades de internação $(1,1 \%)$;

5) A produtividade real dos nutricionistas clínicos acompanhados foi de $72,8 \%$, mas poderia ser ampliada até $87,2 \%$, se fossem reduzidos os tempos despendidos no Deslocamento e Espera; 
6) Os resultados forneceram uma visão ampliada das intervenções e atividades que fazem parte do cotidiano de trabalho dos nutricionistas clínicos, podendo servir de apoio à gestão da UAN, com vistas à melhor eficiência da força de trabalho, isto é, atendimento das necessidades prioritárias dos pacientes internados (individuais e coletivas) e das metas estabelecidas pela instituição, além da segurança e bem estar deste profissional;

7) A análise estatística dos resultados obtidos nesta investigação mostrou haver diferença significativa entre os parâmetros encontrados quando comparados aos parâmetros propostos pela Resolução CFN n. 380/2005;

8) A carga média de trabalho dos nutricionistas clínicos, nas seis horas (360 minutos), correspondeu a 7,6 minutos para o nível primário, 16,1 minutos para 0 nível secundário e 28,6 minutos para o nível terciário. A carga média de trabalho correspondeu a 17,4 minutos.

9) Os parâmetros propostos para os três níveis de atendimento, considerando a proporção de pacientes por nutricionista e uma jornada de trabalho com duração de 360 minutos foram, 48:1 para o nível primário de atendimento de nutrição, 22:1 para o nível secundário e 13:1 para o nível terciário, sendo inferiores aos estabelecidos pela Resolução CFN n. 380/2005. 


\section{REFERÊNCIAS}

1. Cecílio LCO, Merhy EE. Integralidade do cuidado como eixo da gestão hospitalar. Disponível em: http://www.hc.ufmg.br/gids/Integralidade.pdf

2. Brasil. Presidência da República. Ministério da Saúde. Portaria MS/GM no 3.390, de 30 de dezembro de 2013. Institui a Política Nacional de Atenção Hospitalar (PNHOSP) no âmbito do Sistema Único de Saúde (SUS), estabelecendo-se as diretrizes para a organiação do componente hospitalar da Rede de Atenção à Saúde (RAS). Diário Oficial da União, Poder Executivo, Brasília, DF 2013a, 31 dez; seção 1.

3. Kaiser Family Foundation. Health Care Costs: A Primer Key Information on Health Care Costs and their Impact. 2012. Available in: http://kff.org/healthcosts/issue-brief/health-care-costs-a-primer/

4. Beulke R, Berto DJ. Gestão de custos e resultado na saúde: hospitais, clínicas, laboratórios e congêneres. 3. ed. ver. ampl. São Paulo: Saraiva; 2005.

5. Batista-Filho M, Rissin A. A transição nutricional no Brasil: tendências regionais e temporais. Cadernos de Saúde Pública. 2003; 19 (1): 181-91.

6. Duarte EC, Barreto SM. Transição demográfica e epidemiológica: a Epidemiologia e Serviços de Saúde revisita e atualiza o tema. Epidemiol. Serv. Saúde. 2012; 21 (4): 529-32.

7. Pinheiro ARO, Freitas SFT, Corso ACT. Uma abordagem epidemiológica da obesidade. Rev. Nutr. 2004; 17 (4): 523-33.

8. Gao J, Moran E, Almenoff PL, Render ML, Campbell J, Jha AK. Variations in efficiency and the relationship to quality of care in the veterans health system. Health Affairs (Millwood). 2011;30(4):655-663.

9. Conselho Federal de Nutricionistas, Resolução CFN ํㅜ. 380 de 9 de dezembro de 2005. Dispõe sobre a definição das áreas de atuação do nutricionista e suas atribuições, estabelece parâmetros numéricos de referência, por área de atuação, e dá outras providências. [acessado 2011 mai 11].Disponível em: http://www.crn5.org.br/data/site/uploads/arquivos/380\%20$\% 20$ Areas\%20de\%20atuacao,\%20atribuicoes\%20e\%20parametros\%20nume ricos.pdf

10.Bachuinas D. A unidade de nutrição e dietética, o seu papel como atividadefim na organização hospitalar e sua terceirização. Mundo saúde. 2002; 26 (2): 321-31. 
11.Souza AA. A interação entre a terapia nutricional e a produção de refeições: repensando a função da alimentação hospitalar. Nutrição em Pauta. 2002; 53 : $17-21$.

12.Carmo MGT, Holzinger M, Rosa MC, Benvenutti JCLM, Viteritte P. Prática do nutricionista de clínica nos hospitais da Grande Florianópolis-SC. Rev Cienc Saúde. 1994; 13 (1/2): 70-81.

13.Boog MCF, Rodrigues KRM, Silva SMF. Situação profissional dos nutricionistas egressos da PUCCAMP. Rev Nutr. 1989; 2 (1): 55-87.

14.De Seta MH, O'Dwyer G, Henriques P, Sales GL. Cuidado nutricional em hospitais públicos de quatro estados brasileiros: contribuições da avaliação em saúde à vigilância sanitária de serviços. Ciênc saúde coletiva. 2010; 15 (3): 3413-22.

15.Prado SD, Abreu MSD. Nutricionista: onde trabalha? Quais suas condições de trabalho? Rev Nutr. 1991; 4 (1/2): 65-91.

16.Bosi MLM. Profissionalização e conhecimento: a nutrição em questão. São Paulo: Hucitec; 1996.

17. Almeida VLM, Junqueira A, Maltoni LA, Bruno LC. Dimensionamento da força de trabalho necessária às Unidades Hospitalares do Instituto Nacional de Câncer/MS. Revista Brasileira de Cancerologia. 2007; 53(1): 71-78.

18.Santos RCL, Diez-Garcia RW. Dimensionamento de recursos humanos em serviços de alimentação e nutrição de hospitais públicos e privados. Revista de Administração Pública. 2011; 45 (6): 1805-19.

19. Biessemeier CK. Achieving Excelence: Clinical Staffing for Today and Tomorrow. American Dietetic Association; 2004.

20.Diez-Garcia RW, Japur CC, Medeiros MAT. Food and nutritional care quality indicators in hospital. Journal of Hospital Administration. 2013; 2 (3):132-41.

21. Najmi M, Vahdat Shariatpanahi Z, Tolouei M, Amiri Z. Effect of oral olive oil on healing of $10-20 \%$ total body surface area burn wounds in hospitalized patients. Burns. 2015; 41 (3): 493-6.

22.Sakr Y, Maia VP, Santos C, Stracke J, Zeidan M, Bayer O, Reinhart K. Adjuvant selenium supplementation in the form of sodium selenite in postoperative critically ill patients with severe sepsis. Crit Care. 2014;18 (2): R68.

23. Bellomo $\mathrm{R}$ et al. Calorie intake and patient outcomes in severe acute kidney injury: findings from The Randomized Evaluation of Normal vs. Augmented Level of Replacement Therapy (RENAL) study trial. Crit Care. 2014; 18 (2): R45.

24.Locatelli F, Del Vecchio L, Violo L, D Pontoriero. Phosphate binders for the treatment of hyperphosphatemia in chronic kidney disease patients on dialysis: a comparison of safety profiles. Expert Opinion on Drug Safety. 2014; 13 (5): 51-61. 
25. Charles EJ et al. Hypocaloric compared with eucaloric nutritional support and its effect on infection rates in a surgical intensive care unit: a randomized controlled trial. Am J Clin Nutr. 2014; 100 (5): 1337-43.

26. Bellomo $\mathrm{R}$ et al. Daily protein intake and patient outcomes in severe acute kidney injury: findings of the randomized evaluation of normal versus augmented level of replacement therapy (RENAL) trial. Blood Purif. 2014; 37(4): 325-34.

27.Kiss CM, Byham-Gray L, Denmark R, Loetscher R, Brody RA. The impact of implementation of a nutrition support algorithm on nutrition care outcomes in an intensive care unit. Nutr Clin Pract. 2012; 27(6): 793-801.

28. Guida B. Dietary phosphate restriction in dialysis patients: A new approach for the treatment of hyperphosphataemia. Nutr Metab Cardiovasc Dis. 2011; 21(11): 879-84.

29. Pontes-Arruda A et al. Enteral nutrition with eicosapentaenoic acid, Y-linolenic acid and antioxidants in the early treatment of sepsis: results from a multicenter, prospective, randomized, double-blinded, controlled study: the INTERSEPT study. Crit Care. 2011; 15(3): R144.

30.Sahade V; Montera VSP. Tratamento nutricional em pacientes com insuficiência cardíaca. Rev Nutr. 2009; 22(3): 399-408.

31. Edington J, Boorman J, Durrant ER, Perkins A, Giffin CV, James R, et al. Prevalence of malnutrition on admission to four hospitals in England. The malnutrition prevalence group. Clin Nutr. 2000; 19 (3):191-5.

32. Wyszynski DF, Perman M, Crivelli A. Prevalence of hospital malnutrition in Argentina: preliminary results of a population-based study. Nutrition. 2003; 19:115-19.

33.Diez-Garcia RV, Leandro-Merhi VA, Pereira AM. Estado nutricional e sua evolução em pacientes internados em clínica médica. Rev Bras Nutr Clin. 2004; 19 (2): 59-63.

34. Waitzberg D, Caiffa WT, Correia MITD. Hospital Malnutrition: The Brazilian National Survey (IBRANUTRI): A study of 4000 patients. Nutrition. 2001; 17(78):573-80.

35. Byham-Gray LD. Departmental Performance Improvement Plan 1999. Shore Memorial Hospital, Department of Nutrition Services. Somers Point, NJ: unpublished work, 1999.

36. Correia MITD, Campos AC. Prevalence of hospital malnutrition in Latin America: the multicenter ELAN study. Nutrition. 2003; 9(10):823-5.

37. Coates KG, Morgan SL, Bartolucci AA, and Weinsier RL. Hospital-associated malnutrition: A reevaluation 12 years later. J Am Diet Assoc. 1993; 93(1): 2733. 
38. Kondrup J, Johansen N, Plum LM, Bak L, Larsen IH, Martinsen A, et al. Incidence of nutritional risk and causes of inadequate nutritional care in hospitals. Clin Nutr. 2002; 21(6): 461-8.

39. Hiesmayr M, Schindler K, Pernick E, Schuh C, Schoeniger-Hekel A, Bauer P et al. Decrease food intake is a risk factor for mortality in hospitalized patients: The NutritionDay survey 2006. Clin Nutr. 2009; 28: 484-91.

40.Elia M. Detection and management of under-nutrition in the community. A report by The Malnutrition Advisory Group. A standing committee of The British Association for Parenteraland Enteral Nutrition. 2000. Maidenhead, BAPEN.

41. Stratton RJ, Green CJ, Elia M. Disease-related malnutrition: an evidencebased approach to treatment. Oxon, UK: CABI Publishing; 2003; p. 3.

42. Pirlich M, Schutz T, Norman K, et al. The German hospital malnutrition study. Clin Nutr 2006; 25: 563-572.

43. Soeters PB, Reijven PL, van der Schueren MA VB-d, Schols JM, Halfens RJ, Meijers JM,van Gemert WG (2008) A rational approach to nutritional assessment. Clin Nutr 27(5):706-716.

44. Jackson AA. Severe malnutrition. In: Warrell DA, Cox TM, Firth JD, Benz EJ (eds). Oxford textbook of medicine, 4th edn, vol 1. Oxford: Oxford University Press, 2003:1054-61.

45. Butterworth CE Jr. The skeleton in the hospital closed. Nutr Today. 1974;9:48.

46. Merhi VAL, Corrêa B, Fogaça KP, Oliveira MRM. Acompanhamento dietoterápico durante a internação em pacientes hospitalizados. Cad saúde colet.2008; 16(4): 803-14.

47. Barker J. The high incidence of malnutrition in our hospitals. J Hum Nutr Diet. 2006; 19(16): 453-4.

48. Anderson CF, Moxness K, Meister J, Burrit MF. The sensitivity and specificity of nutrition-related variables in relationship to the duration of hospital stay and the rate of complications. Mayo Clin Proc. 1984; 59(7): 477-83.

49. Beisel WR: Magnitude of the host nutritional responses to infection. Am J Clin Nutr. 1977; 30(8):1236-47.

50.50.Brugler L, DiPrinzio MJ, Bernstein L: The five-year evolution of a malnutrition treatment program in a community hospital. Practice Guidelines. J Quality Improv. 1999; 25 (4):191-206.

51. Correia MITD, Waitzber DL. The impact of malnutrition on morbity, mortality, length of hospital stay and costs evaluated through a multivariate model analysis. Clin Nutr. 2003; 22(3): 235-9. 
52. Naber THJ, Schermer T, Bree A.de, Nusteling K, Eggink L, Kruimel JW, et al. Prevalence of malnutrition in nonsurgical hospitalized patients and its association with disease complications. Am J Clin Nutr. 1997; 66(5): 1232-9.

53. Weinsier RI, Hunker EM, Krumdieck CL, Butterworth Jr CE. Hospital malnutrition. A prospective evaluation of general medical patients during the course of hospitalization. Am J Clin Nutr. 1979; 32(8): 418-26.

54. Bubzy GP, Mullen JL, Matthews DC, Hobbs CL, Rosato EF. Prognostic nutritional index in gastrointestinal surgery. Am J Surg. 1980;139(1):160-7.

55. Hill GL, Blackett RL, Pickford I, Burkinshaw L, Young GA, Warren JV, et al. Malnutrition in surgical patients: an unrecognized problem. Lancet. 1977;26(1):689-92.

56. Amaral TF, Matos LC, Tavares MM, Subtil A, Martins R, Nazare M. The economic impact of disease-related malnutrition at hospital admission. Clin Nutr. 2007; 26 (6): 778-84.

57. Chima CS, Barco K, Dewitt MLA, Maeda M, Teran JC, Mullen KD. Relationship of nutrition status to length of stay, hospital costs and discharge status of patients hospitalized in the medicine service. Journ Amer Diet Assoc. 1997; 97(9): 975-8.

58. Reilly MKS, Hull SF, Albert N, Waller A, Bringardener S. Economic impact of malnutrition: a model system for hospitalized patients. J Parent Enteral Nutr. $1988 ; 12(4): 371-6$.

59. Sichieri R, Nascimento S, Coutinho W. The burden of hospitalization due to overweight and obesity in Brazil. Cad Saúde Pública. 2007; 23(7):1721-7.

60. Brylinski C. Processo de cuidado nutricional. In: Mahan LK, Escot-Stump S. Alimentos, nutrição e dietoterapia. 10. ed. São Paulo: Roca, 2002. 416-466p.

61. Parisenti J, Copetti CF, Espínola CG. Avaliação de Sobras de Alimentos em Unidade Produtora de Refeições Hospitalares e Efeitos da Implantação do Sistema de Hotelaria. Alim. Nutr. 2008; 19(2): 191-94.

62. Pedroso CGT, Sousa AA, Salles RK. Cuidado nutricional hospitalar: percepção de nutricionistas para atendimento humanizado. Ciênc Saúde Coletiva. 2011;16 (Supl 1):1155-62.

63. Merhy EE. Saúde: a cartografia do trabalho vivo. $2^{a}$ ed. São Paulo: Hucitec; 2005.

64. Garcia TR, Nóbrega MML, Carvalho EC. Processo de enfermagem: aplicação à prática profissional. Brazilian Journal of Nursing. 2004; 3(2): [aprox.8 telas] Disponível em: http:// www.uff.br/nepae/objn302garciaetal.htm.

65. World Confederation for Physical Therapy. Policy statement: Standards of physical therapist practice. London, UK: WCPT; 2011. Disponível em: www.wcpt.org/policy/ps-standards. 
66. Roley et al. Occupational therapy practice framework: domain \& practice, 2nd edition. Am J Occup Ther. 2008; 62(6):625-83.

67. Nutrition Care Process/Standarized Language Committee. Nutrition Care Process Part II: Using the International Dietetics and Nutrition to Document the Nutrition Care Process. J Am Diet Assoc. 2008;108 (8):1287-93.

68. American Dietetic Association. Identifying patients at risk: ADA's definitions for nutrition screening and nutritional assessment. J Am Diet Assoc. 1994; 94(8):838-9.

69. Lacey K, Pritchett E. Nutrition process and model: ADA adopts road map to quality care and outcomes management. J Am Diet Assoc. 2003; 103:106171.

70. American Dietetic Association. Nutrition care process and model part II: using the International Dietetics and Nutrition Terminology to document the nutrition care process. J Am Diet Assoc. 2008; 108 (8):1287-93.

71. Van Heukelom H, Fraser V, Koh JC, McQueen K, Vogt K, Johnson F. Implementing nutrition diagnosis at a multisite health care organization. Can $\mathrm{J}$ Diet Pract Res. 2011;72:178-80.

72. Atkins M, Basualdo-Hammond C, Hotson B; Dietitians of Canada. Canadian perspectives on the nutrition care process and international dietetics and nutrition terminology. Can J Diet Pract Res. 2010;71:18-20.

73. Gardner-Cardani J, Yonkoski D, Kerestes J. Nutrition care process implementation: a change management perspective. $\mathrm{J}$ Am Diet Assoc. 2007; 107:1429-33.

74. EM, Baek HJ. A survey on the status of nutrition care process implementation in Korean Hospitals. Clin Nutr Res. 2013;2:143-8.

75. Papoutsakis C, Orrevall Y. EFAD Professional Practice Committee, The use of standardized language among dietitians in Europe. Dietistaktuellt. 2012. $\mathrm{XXI}(1)$ : 32-3.

76. Porter JM, Devine A, O'sullivan. Evaluation of a nutrition care process implementation package in hospital dietetic departments. Nutrition \& Dietetics. 2015; 72 (3): 213-21.

77. Lövestam E, Orrevall Y, Koochek A, Karlström B, Andersson A. Evaluation of a nutrition care process-based audit instrument, the diet-NCP-audit, for documentation of dietetic care in medical records. Scand $\mathrm{J}$ Caring Sci. 2014;28(2):390-7.

78. Duchini L; Jordão AA; Brito TT; Diez-Garcia RW. Avaliação e monitoramento do estado nutricional de pacientes hospitalizados: uma proposta apoiada na opinião da comunidade científica. Rev. Nutr. 2010; 23(4):513-22.

79. Associação Brasileira de Nutrição. Manual Orientativo: Sistematização do Cuidado de Nutrição/ [Organizado pela Associação Brasileira de Nutrição; organizadora Marcia Samia Pinheiro Fidelix. - São Paulo - Associação 
Brasileira de Nutrição 66p. Disponível em: http://www.asbran.org.br/arquivos/PRONUTRI-SICNUT-VD.pdf.

80. International Confederation of Dietetic Associations (ICDA). International Definition of Dietitian. 2004. Disponível em http://www.internationaldietetics.org/International-Standards/InternationalDefinition-of-Dietitian.aspx..

81. Lipscomb M. Early days of hospital dietetics. J Am Diet Assoc. 1966; 49(2):103-9.

82. Conselho Federal de Nutricionistas. Inserção profissional dos nutricionistas no Brasil. Brasília: CFN; 2006. Disponível em: www.cfn.org.br/novosite/pdf/pesquisa.pdf.

83. Organización Mundial de la Salud (OMS): 10.a Asamblea Mundial de la Salud 1974; 29.a Asamblea Mundial de la Salud 1976, resolución WHA29.72; 35 Asamblea Mundial de la Salud 1982, resolución WHA35.25. 1982. Disponível em:

http://whqlibdoc.who.int/wha_eb_handbooks/9243652060_Vol2_(part3).pdf.

84. Somers JP, Mulroney RA. Workload measurement study to develop staffing guidelines for the clinical inpatient dietitian. J Can Diet Assoc. 1983; 44(3): 246-50.

85. Ministerio de la Salud. Presidencia de la Nacion. Argentina. Normas de organización y funcinamento de las areas de alimentación y dietoterapia de los estabelecimientos asistenciales. Resolución 168. Disponível em: http://www.msal.gov.ar/pngcam/resoluciones/msres168_1997.pdf.

86. Simmons ML, Vaughan LA. Patient nutrition acuity as a predictor of the time required to perform medial nutrition therapy. J Am Diet Assoc. 1999; 99(11):1367-72.

87. Kopple JD. National kidney foundation K/DOQI clinical practice guidelines for nutrition in chronic renal failure. Am J Kidney Dis. 2001;37(1 Suppl 2):S66-70.

88. British Renal Society. The Renal Team A Multi-Professional Renal Workforce Plan For Adults and Children with Renal Disease. Recommendations of the National Renal Workforce Planning Group 2002. Disponível em: http://www.britishrenal.org/getattachment/workforce-

planning/WFP_Renal_Book1.pdf.aspx

89. The Intensive Care Society Standars Committee. Allied Health Professionals (AHP) and Healthcare Scientistis (HCS) Critical Care Staffing Guidance. A Guideline for AHP and HCS Staffing levels A Guideline for AHP and HCS Staffing levels. 2003. Disponível em www.ukcpa.org.uk/ukcpadocuments/2.pdf.

90. The All Wales Critical Care Development GroupQuality. Requirements for Adult Critical Care in Wales. 2006. http://www.wales.nhs.uk/sites3/Documents/768/Quality\%20requirements\%20f or\%20critical\%20care.pdf 
91. British Association of Perinatal Medicine. Service Standards for Hospitals Providing Neonatal Care. $2010 . \quad$ Disponível em: http://www.bapm.org/publications/documents/guidelines/hosp_standards.pdf.

92. End stage renal dialysus facilities licesing rules Texas Department of State Health Services. Health Facility Program Rules. End Stage Renal Disease Facilities Licensing Rules. Texas Department of State Health Services. 2010. Disponível em: http://www.dshs.state.tx.us/HFP/rules.shtm.

93. Australasian Faculty of Rehabilitation Medicine. The Royal Australasian College of Physicians. Standards for the provision of inpatient adult rehabilitation Medicine Services in Public and Private Hospitals Standards for the provision of Inpatient Adult Rehabilitation Medicine Services in Public and. Private Hospitals. 2011. Disponível em: www.racp.edu.au/

94. Federación Latinoamericana de Terapia Nutricional, Nutrición Clínica Y Metabolismo. FELANPE. Documento de Consenso. Funciones y competencias del nutricionista clinico http://www.slan.org.ve/publicaciones/concensos/Consenso de Funciones de I Nutricionista Clinico 2012.pdf

95. Fugulin FMT, Gaidzinski RR, Castilho V . Dimensionamento de pessoal de enfermagem em instituições de saúde. In: Paulina Kurcgant. (Org.). Gerenciamento em Enfermagem. 1ed.Rio de Janeiro: Guanabara Koogan; 2010. p. 121-135.

96. Slack N, Chambers S, Harland C, Harrison A, Johnston R. Administração da produção. São Paulo: Atlas, 1997.728p.

97. Lopetegui M, Po-Yin Yen AL, Jeffries J, Embi P, Payne P. Time motion studies in healthcare: What we are talking aboout? Journal of Biomedical Informatics. 2014; 49: 292-9.

98. Pelletier D, Duffield C. Work sampling: valuable methodology to define nursing practice to the study of nursing personnel. Nurs Health Sci. 2003;5(1):31-8.

99. Abdellah FG. Levine E. Work sampling applied to the study of nursing personnel. Nurs Res.1954;3(1):11-6.

100. Urden L, Roode J. Working sampling: A decision-making tool for determining resources and work redesign. J Nurs Adm. 1997;27(9):34-41.

101. Moresi E. Metodologia da Pesquisa [internet]. Brasília - DF; 2003.p. 106. [cited 2015 Jul 10]. Disponível em: http:// http://www.inf.ufes.br/ falbo/files/MetodologiaPesquisa-Moresi2003.pdf

102. Gil, AC. Métodos e técnicas de pesquisa social. São Paulo: Atlas, 1999.

103. Barros, AJP; Lehfeld NAS. Projeto de pesquisa: propostas metodológicas. Petrópolis: Vozes; 1999.

104. Dochtherman J, Butcher HK, Bulechek GM. Classificação das Intervenções de Enfermagem. Rio de Janeiro: Elsevier; 2010. 
105. Lucena AF, Barros ALBL. Mapeamento cruzado: uma alternativa para a análise de dados em enfermagem. Acta Paul Enfermagem. 2005; 18 (1): 82-8.

106. Bonfim D. Identificação das intervenções de enfermagem na atenção básica à saúde como parâmetro para o dimensionamento de trabalhadores [Internet]. São Paulo: Escola de Enfermagem, Universidade de São Paulo; 2009 [citado 2015 mai. 4]. Disponível em:www.teses.usp.br/teses/disponiveis/7/7140/tde.../ME_DaianaBonfim.pdf

107. Cruz CWM. Construção de instrumento de medida do tempo de trabalho da enfermagem em centro de diagnóstico por imagem [Internet]. São Paulo: Escola de Enfermagem, Universidade de São Paulo; 2012 [citado 2015 mai. 4]. Disponível em: www.teses.usp.br/teses/disponiveis/7/.../ME_Carla_Weidel_Marques.pdf

108. Martin LGR. Carga de trabalho de enfermagem em ambulatório de oncologia e hematologia [Internet]. São Paulo: Escola de Enfermagem, Universidade de São Paulo; 2013 [citado 2015 mai. 4]. Disponível em: www.teses.usp.br/teses/.../Lelia_Goncalves_Rocha_Martin_Corrigida.pdf

109. LoBiondo-Wood G, Haber J. Pesquisa em Enfermagem. Métodos, avaliação crítica e utilização. Rio de Janeiro: Guanabara; 2001.

110. Bonfim D. Planejamento da força de trabalho de enfermagem na Estratégia de Saúde da Família: indicadores de carga de trabalho [Internet]. São Paulo: Escola de Enfermagem, Universidade de São Paulo; 2014 [citado 2015 mai. 4]. Disponível em: www.teses.usp.br/teses/disponiveis/7/7140/tde-16092014$105517 /$

111. Brasil. Lei Orgânica de Saúde no. 8.080, de 19 de setembro de 1990. Dispõe sobre as condições para a promoção, proteção e recuperação de saúde, a organização e o funcionamento dos serviços correspondentes e da outras providencias. Diário Oficial da União 1990; 20 set. Disponível em: www.planalto.gov.br/ccivil_03/Leis/L8080.htm

112. Bromaghin JF. Sample Size Determination for Interval Estimation of Multinominal Probabilities. The American Statistician. 1993; 47(3): 203-6.

113. Dellefield ME, Harrington C, Kelly A. Observing how RNs use clinical time in nursing home: a pilot study. Geriatr Nurs. 2012; 33 (4):256-63.

114. Conselho Federal de Nutricionistas, Resolução CFN Nº 417/2008. Dispõe sobre procedimentos nutricionais para atuação dos nutricionistas e dá outras providências.

Disponível

em:

http://www.asbran.org.br/sitenovo/arquivos/resolucao417.pdf

115. Huyck SA, McNamara PM. Monitoring accountability of a clinical nutrition service. J Am Diet Assoc. 1987; 87(5):620-3.

116. Lutton SE, Baker MM, Billman RV. Levels of patient nutrition care for use in clinical decision making. J Am Diet Assoc. 1985; 85(7):849-51. 
117. McManners MH, Barina SA. Productivity in clinical dietetics. J Am Diet Assoc. 1984; 84(9):1035-8.

118. No authors listed. Identification of clinical dietetic practitioner's time use for the provision of nutrition care. J Am Diet Assoc. 1981; 79(6):708-15.

119. Shanklin CW, Hernandez HN, Gould RM, Gorman MA. Documentation of time expenditures of clinical dietitians: Results of a statewide time study in Texas. J Am Diet Assoc. 1988; 88(1):38-43.

120. Towers D ML, Coskumer H, Brunet K, Kack M. A System of Workload Measurement for Clinical Dietitians. J Can Diet Assoc. 1987; 48(4):243-6.

121. Utami NG. Analysis of workload and performance of dietitian in performing nutrition care process at inpatient unit of Hasan Sadikin Hospital Bandung. Thesis Summary. Faculty of Medicine Gadjah Mada University Yogyakarta. 2011. Disponível em:http://webcache.googleusercontent.com/search?q=cache:QQYoSS9PSIoJ :https://www.yumpu.com/en/document/view/25277231/1-analysis-of-workloadand-performance-of-dietitian-in-performing-+\&cd=1\&hl=pt-BR\&ct=clnk\&gl=br

122. Milosavljevic M, Williams P, Perez G, Dalla T. The results of a pilot time-andmotion study in three Australian hospitals: Where do we spend our time? Nutrition \& Dietetics. 2011; 68: 185-8.

123. Hand RK, Jordan B, DeHoog S, Pavlinac J, Abram JK, Parrott JS. Inpatient staffing needs for registered dietitian nutritionistas in 21 st century acute care facilities. J Acad Nutr Diet. 2015; 115 (6):985-1000.

124. Sousa APGG, Barreira IA. Nexos entre Enfermagem, Nutrição e Serviço Social, profissões femininas pioneiras na área da Saúde. Rev. esc. enferm. USP. 2008; 42 (3): 474-82.

125. Nightingale F. Notas sobre enfermagem: o que é e o que não é. São Paulo (SP): Cortez; 1989.

126. Conselho Federal de Nutricionistas. Inserção profissional dos nutricionistas no Brasil. Brasília: CFN; 2006 [acesso 2015 jul.02]. Disponível em: www.cfn.org.br/novosite/pdf/pesquisa.pdf

127. Puckett RP. Food servisse manual for health care instituitions / Byers BA, Shanklin CW, and Hooever LC. 1994.

128. Santos GF, Dammero DRR, Vaz JS. Barreira de adesão à dieta em paciente com diabete melito do tipo 2: uma narrativa. Rev.Interd. 2015; 8 (4): 199-200.

129. Calixto AATF. Adesão ao tratamento: estudo entre portadores de hipertensão arterial internados em um hospital privado do interior paulista [dissertação de mestrado] Ribeirão Preto: Escola de Enfermagem de Ribeirão Preto da Universidade de São Paulo; 2010. 
130. Reiners AAO, Azevedo RCS, Vieira MA, Arruda ALG. Produção bibliográfica sobre adesão/não-adesão de pessoas ao tratamento de saúde. Ciênc Saúde Coletiva. 2008;13(Suppl. 2):2299-306.

131. Nozaki VT, Gravena AAF, Carvalho IZC, Bennemann RM, Reis NT. Atendimento nutricional de pacientes hospitalizados. Editora Rubio. 2013; 236p.

132. Sociedade Brasileira de Nutrição Parenteral e Enteral; Associação Brasileira de Nutrologia. Triagem e Avaliação do Estado Nutricional. Projeto Diretrizes, Associação Médica Brasileira e Conselho Federal de Medicina, 16p. 8 set. 2011. Disponível em: http://www.projetodiretrizes.org.br/9_volume/triagem_e_avaliacao_do_estado _nutricional.pdf

133. Brasil. Ministério da Saúde. Secretaria de Vigilância Sanitária. Portaria 272 MS/SVS de 08 de abril de 1999. Aprova o Regulamento Técnico para fixar os requisitos mínimos para a Terapia de Nutrição Parenteral. Diário Oficial da União; 23 abr.

134. Brasil. Ministério da Saúde. Agência Nacional de Vigilância Sanitária. Resolução da Diretoria Colegiada - RCD n 63, de 6 de julho de 2000. Regulamento Técnico para terapia de nutrição enteral. Diário Oficial da União, 7 de junho de 2000. Brasília: Ministério da Saúde; 2000. Disponível em: http://portal.anvisa.gov.br/wps/wcm/connect/61e1d380474597399f7bdf3fbc4c 6735/RCD+N\%C2\%B0+63-2000.pdf?MOD=AJPERES

135. Posthauer ME. The value of nutritional screening and assessment. Adv Skin Wound Care 2006;19:388-90.

136. Isosaki M, Nakasato M. Gestão de serviço de nutrição hospitalar. Rio de Janeiro: Elsevier; 2009.

137. Wills BB. Documentation: The missing link in evaluation. J Am Diet Assoc. 1985; 85 (2): 225-7.

138. Cardoso LC. Relações interpessoais na equipe do Programa de Saúde da Família. 2004. Revista APS; 7 (1): 47-50.

139. Peduzzi M. Equipe multiprofissional de saúde: a interface entre trabalho e interação. Tese. de Doutorado, Campinas: Faculdade de Ciências Médicas, Universidade de Campinas, 1998.

140. Schraiber LB, Peduzzi M, Sala A, Nemes MIB, Castanhera ERL, Kon R. Planejamento, gestão e avaliação em saúde: identificando problemas. Ciênc. saúde coletiva. 1999; 4 (2) 221-42.

141. Cardoso CG, Hennington EA. Trabalho em equipe e reuniões multiprofissionais de saúde: uma construção à espera pelos sujeitos da mudança. Trab. educ. saúd. 2011; 9 (1): 85-112. 
142. Grandjean E, Kromer, KHE. Manual de ergonomia: adaptando o trabalho ao homem. $5^{\mathrm{a}}$ ed. Porto Alegre: Bookman; 2005.

143. Lee DS. The morning tea break ritual: a case study. Int J Nurs Pract. 2001; 7 (2): 69-73.

144. Maximiano ACA. Fundamentos da Administração. 3. ed. Rio de Janeiro: Livros Técnicos e Científicos Editora Ltda., 2014. v. 1. 312 p.

145. Mello ERC, Barros CDC. Cartilha da Qualidade e Produtividade 1997. Disponível em: <www.acttive.com.br>.

146. Biseng W. Administração financeira em engenharia clínica [Workshop]. São Paulo; 1996.

147. O'Brien-Pallas $L$ et al. Evidence-based standard for measuring nurse staffing and performance. Nursing Health Services Research Unit. 2004; 208p. Disponível em: <http://fhs.mcmaster.ca/nru/documents/_VTI_CNF/Evidence\%20Based\%20St andards\%20for\%20Measuring\%20Nurse\%20Staffing\%20and\%20Performanc e.pdf>.

148. Brasil. Conselho Federal de Nutricionistas, Resolução CFN No 312/2003. Altera a Resolução CFN №227, de 1999, que trata do registro e focalização profissional de Técnicos e dá outra providências. [acessado 2015 mai 11].Disponível em: www.cfn.org.br/novosite/pdf/res/2000_2004/res312.pd

149. Hilovsky CS, Zolber KK, Abbey DE, Bertrum CC, Burke KI. Utilization of the clinical dietetic technician. Am J Diet Assoc. 1986; 86 (8): 1028-32. 


\section{APÊNDICE A - INSTRUMENTO DE CARACTERIZAÇÃO DOS JUÍZES}

\section{Identificação}

* Idade em anos:

* Sexo: ( ) Feminino ( ) Masculino

* Escola em que se graduou:

* Ano de graduação:

\section{Formação}

Especialização: ( ) sim ( ) não Quantas?

Área:

Local:

Ano:

Mestrado: ( ) sim ( ) não

Área:

Local:

Ano:

Doutorado: ( ) sim ( ) não

Área:

Local:

Ano:

3. Assinale os itens que descrevem o seu perfil.

Ter no mínimo quatro anos de experiência na assistência nutricional hospitalar.

Ter produção científica na área de Nutrição Clínica.

Ter experiência como tutor ou supervisor de estagiários, residentes ou aprimorandos em Nutrição Clínica.

Ter experiência como docente na área de Nutrição Clínica 
204 
APÊNDICE B - LISTA DE INTERVENÇÕES DE NUTRIÇÃO CLÍNICA E ATIVIDADES, SEGUNDO A CLASSIFICAÇÃO DA NIC

\begin{tabular}{|c|c|}
\hline DOMÍNIO 1 \\
Fisiológico Básico - Cuidados que dão suporte ao funcionamento físico (NIC, 2010) \\
\hline CLASSE D \\
Suporte nutricional - Conjunto de procedimentos terapêuticos para manutenção e/ou recuperação do estado nutricional (adaptado da NIC, 2010 e \\
RDC n ${ }^{\circ} .63$ de 2000). \\
\hline INTERVENÇÕES
\end{tabular}




\begin{tabular}{|l|l|l|}
\hline $\begin{array}{l}\text { Avaliação do Estado Nutricional - Obtenção e análise de } \\
\text { indicadores diretos (clínicos, bioquímicos e antropométricos) }\end{array}$ & $\begin{array}{l}\text { evisar o prontuário do paciente para obter dados básicos tais como a } \\
\text { indiretos (consumo alimentar, renda, disponibilidade de alimentos, } \\
\text { entre outros) que tem como conclusão o diagnóstico nutricional na } \\
\text { admissão (Resolução CFN nóstico, dieta prescrita, idade, sexo, peso e estatura, } \\
\text { medicamentos em uso, história médica, prognóstico e exames } \\
\text { laboratoriais alterados. } \\
\text { Realizar anamnese completa: preferências e aversões, intolerâncias, } \\
\text { alergias, apetite, problemas alimentares, mudança de peso recente, } \\
\text { ingestão alimentar habitual, frequência alimentar, medicamentos, } \\
\text { vitaminas e minerais, habilidade para ler e escrever, nível de atividade } \\
\text { física, condição socioeconômica e conhecimento prévio acerca das } \\
\text { restrições alimentares. } \\
\text { Avaliar e analisar o gasto energético por calorimetria indireta. } \\
\text { Avaliar e analisar a composição corporal por bioimpedância e/ou medidas } \\
\text { antropométricas. } \\
\text { (JADA, v. 79, 1981, p. 708-715; JADA, v. 84, n. 9, 1984; JADA, v. 85, } \\
\text { n. 7, 1985; Resolução CFN no. 417/2008, Journal of Hospital } \\
\text { Administration, v. 2, n. 3, 2013) }\end{array}$ \\
\hline
\end{tabular}




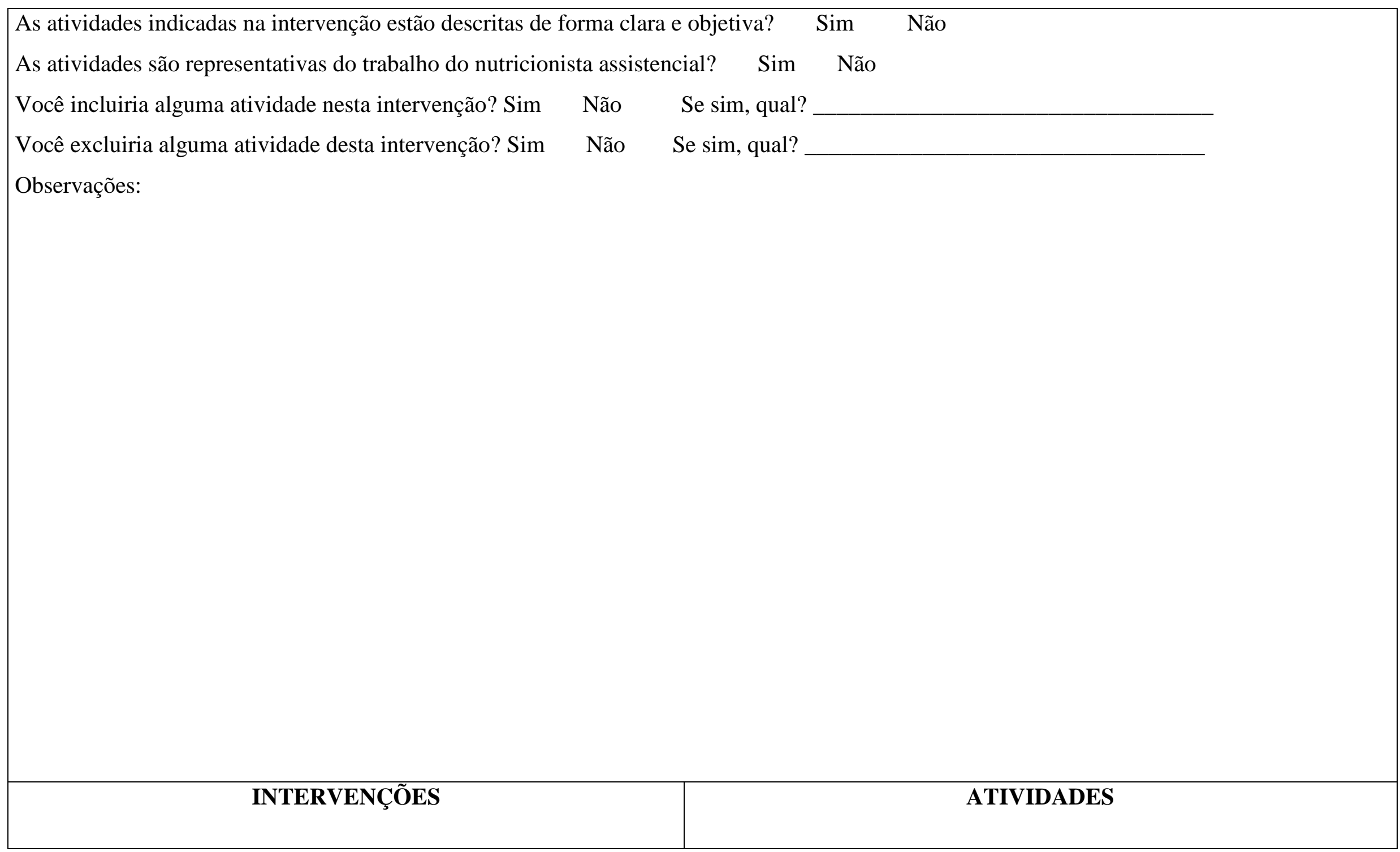




\begin{tabular}{|c|c|}
\hline $\begin{array}{l}\text { Monitoramento da Evolução Nutricional - } 1160 \text { - p. } 551 \text { - Coleta e } \\
\text { análise de dados do paciente para prevenir ou minimizar desnutrição } \\
\text { (NIC, 2010). Indica o acompanhamento da evolução nutricional } \\
\text { (Journal of Hospital Administration, v. 2, n. 3, 2013). }\end{array}$ & $\begin{array}{l}\text { Monitorar a ingestão calórica e de nutrientes, os dados dos exames } \\
\text { laboratoriais, medicações em uso, medidas antropométricas e/ou } \\
\text { composição corporal. } \\
\text { Observar a ocorrência de mudanças importantes no comportamento } \\
\text { alimentar ou no estado nutricional durante a visita de acompanhamento, } \\
\text { conforme apropriado. } \\
\text { Escolher os indicadores nutricionais adequados ao paciente para } \\
\text { monitoramento contínuo com base na condição do paciente. } \\
\text { Estabelecer frequência da coleta e interpretação dos dados conforme } \\
\text { protocolo. } \\
\text { Comparar o estado nutricional atual com o anterior para detectar } \\
\text { melhorias e pioras na condição do paciente. } \\
\text { Instituir o tratamento adequado, usando protocolos válidos. } \\
\text { Identificar os fatores fisiológicos capazes de afetar os valores } \\
\text { laboratoriais. } \\
\text { Reconhecer o efeito dos medicamentos sobre os valores laboratoriais. } \\
\text { Consultar a bibliografia adequada em busca de implicação clínica. } \\
\text { (JADA, v. 79, 1981, p. 708-715; JADA, v. 84, n. 9, 1984; JADA, v. 85, } \\
\text { n. 7, 1985; JADA, v. 88, n. 1, 1988; Resolução CFN no } 417 / 2008, \text { NIC, } \\
\text { 2010, Journal of Hospital Administration, v. 2, n. 3, 2013) }\end{array}$ \\
\hline
\end{tabular}




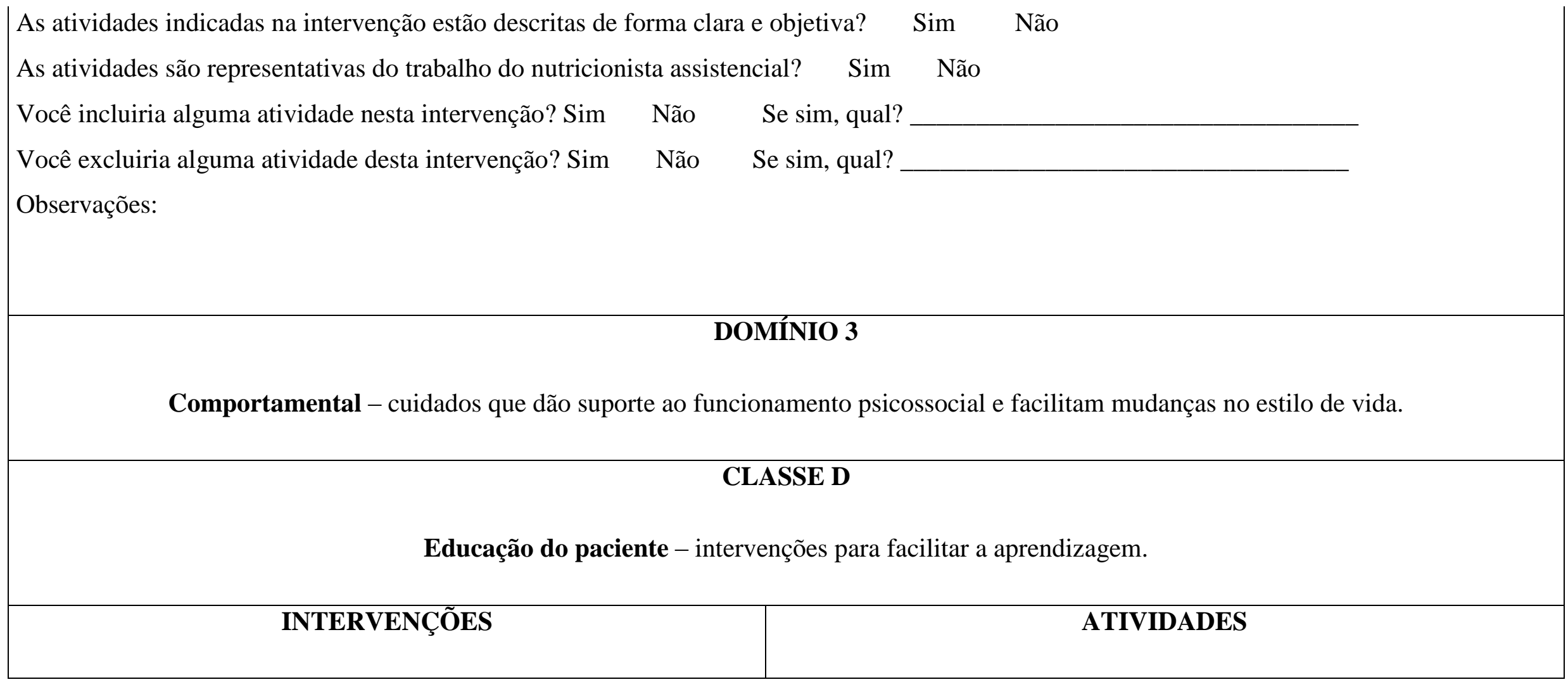




\begin{tabular}{|c|c|}
\hline $\begin{array}{l}\text { Ensino: dieta prescrita - 5614- p.339 - Preparação do paciente para } \\
\text { seguir a dieta prescrita (NIC, 2010). }\end{array}$ & $\begin{array}{l}\text { Avaliar o nível atual de conhecimentos do paciente sobre a dieta } \\
\text { prescrita. } \\
\text { Explicar a finalidade da dieta e/ou esclarecer dúvidas relacionadas à dieta } \\
\text { ou ao tratamento nutricional. } \\
\text { Informar o paciente sobre possíveis interações de fármacos e alimentos, } \\
\text { conforme apropriado. } \\
\text { Reforçar informações oferecidas por outros membros da equipe de saúde, } \\
\text { conforme apropriado. } \\
\text { Incluir a família/pessoas importantes, conforme apropriado. } \\
\text { Orientar o paciente/família/pessoas importantes sobre a dieta prescrita. } \\
\text { (JADA, v. 79, 1981, p. 708-715; JCDA, v. 44, n. 3, 1983; JADA, v. 84, n. } \\
\text { 9, 1984; JADA, v. 85, n. 7, 1985; JADA, v. 48, n. 4, 1987; JADA, v. 88, } \\
\text { n. 1, 1988; Resolução CFN n }{ }^{\circ} \text {. 417/2008, NIC, 2010) }\end{array}$ \\
\hline \multicolumn{2}{|c|}{$\begin{array}{l}\text { As atividades indicadas na intervenção estão descritas de forma clara e objetiva? } \\
\text { As atividades são representativas do trabalho do nutricionista assistencial? }\end{array}$} \\
\hline Segurança: Cuidados que dão Supor & rte à Proteção Contra Danos (NIC, 2010) \\
\hline
\end{tabular}




\section{CLASSE V}

Controle de risco - Intervenções para iniciar atividades de redução de risco e manter o monitoramento de risco durante certo tempo (NIC, 2010)

\begin{tabular}{|l|l|}
\hline \multicolumn{1}{|c|}{ INTERVENÇÕES } & \multicolumn{1}{|c|}{ ATIVIDADES } \\
\hline $\begin{array}{l}\text { Controle de infecção - 6540- p.468 - Minimizar a aquisição e a } \\
\text { transmissão de agentes infecciosos (NIC, 2010). }\end{array}$ & $\begin{array}{l}\text { Lavar as mãos } \\
\text { Descartar roupa de precaução de contato } \\
\text { Paramentar-se } \\
\text { Higienizar as mãos com álcool gel } \\
\text { Desprezar materiais descartáveis } \\
\text { Realizar desinfecção de materiais e equipamentos } \\
\text { (NIC, 2010) }\end{array}$ \\
\hline
\end{tabular}




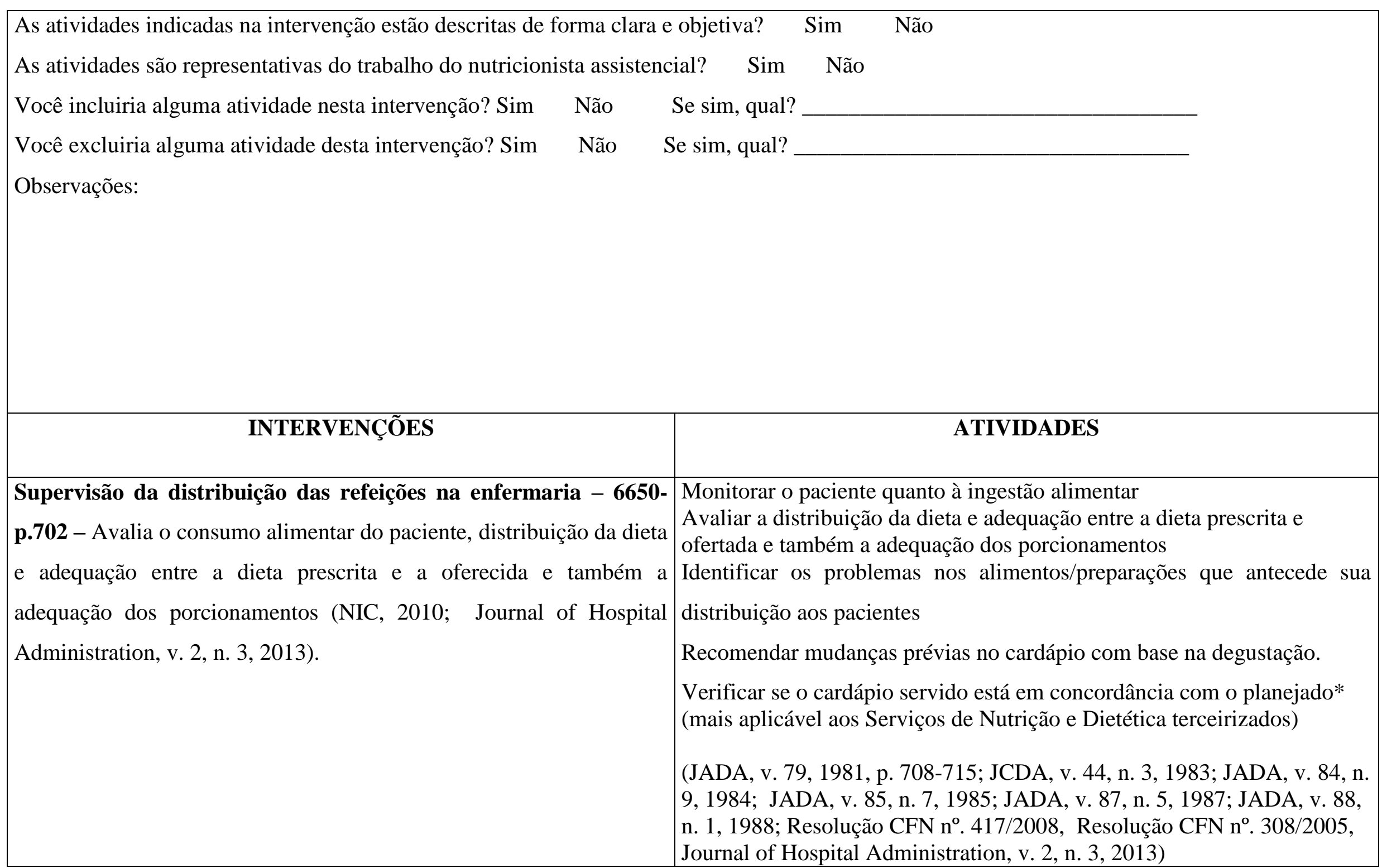




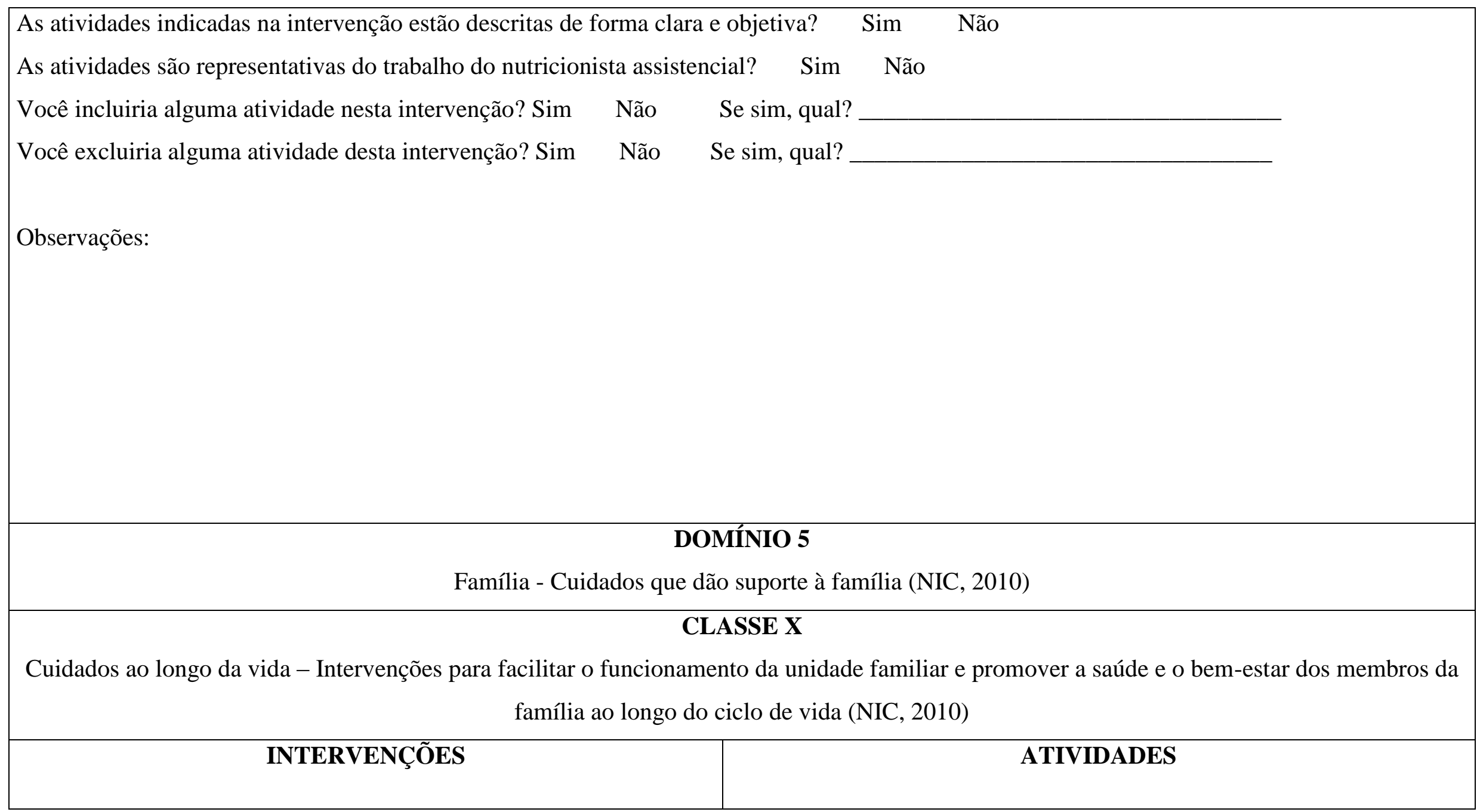


Apoio ao cuidador - 7040 - p.255 - Oferecimento das informações Admitir a dependência que o paciente tem do cuidador, conforme necessárias, defesa e apoio para facilitar o cuidado primário ao apropriado.

paciente por pessoa que não seja um profissional de saúde (NIC, Encorajar o cuidador a assumir responsabilidades, conforme apropriado. 2010).

(NIC, 2010)

As atividades indicadas na intervenção estão descritas de forma clara e objetiva? $\quad$ Sim Não

As atividades são representativas do trabalho do nutricionista assistencial? Sim Não

Você incluiria alguma atividade nesta intervenção? Sim Não Se sim, qual?

Você excluiria alguma atividade desta intervenção? Sim Não Se sim, qual?

Observações:

\section{DOMÍNIO 6}

Sistema de Saúde - Cuidados que dão suporte ao uso eficaz do sistema de atendimento à saúde (NIC, 2010) 


\section{CLASSE Y}

Mediação do sistema de saúde - Intervenções para facilitar a interface entre paciente /família e o sistema de atendimento de saúde (NIC, 2010)

INTERVENÇÕES

Cuidados na admissão - 7310- p.121 - Facilitar a admissão de um paciente na instituição de prestação de cuidados de saúde 2010).

\section{ATIVIDADES}

Apresentar-se e informar seu papel na prestação dos cuidados.

Realizar o exame físico da admissão, conforme apropriado.

Realizar anamnese nutricional básica (preferências e aversões, intolerâncias, alergias, apetite, problemas alimentares, mudança de peso recente).

Realizar triagem nutricional.

Classificar o nível de assistência nutricional.

(JADA, v. 79, 1981, p. 708-715; JCDA, v. 44, n. 3, 1983; JADA, v. 84, n. 9, 1984; JADA, v. 85, n. 7, 1985; JADA, v. 87, n. 5, 1987; JADA, v. 88,

n. 1, 1988; Resolução CFN nº. 417/2008; NIC, 2010) 
As atividades indicadas na intervenção estão descritas de forma clara e objetiva? Sim Não

As atividades são representativas do trabalho do nutricionista assistencial? Sim Não

Você incluiria alguma atividade nesta intervenção? Sim Não Se sim, qual?

Você excluiria alguma atividade desta intervenção? Sim Não Se sim, qual?

Observações:

\section{INTERVENÇÕES}

\section{Orientação Alimentar e Nutricional na Alta Hospitalar -} orientação para segmento domiciliar ao paciente/família/responsável, relativa a sua alimentação e nutrição (Resolução CFN nº.417/2008).

\author{
em domicílio.
}

(Resolução CFN n . 417/2008).

(JADA, v. 79, 1981, p. 708-715; JCDA, v. 44, n. 3, 1983; JADA, v. 84, n. 9, 1984; JADA, v. 85, n. 7, 1985;JADA, v. 88, n. 1, 1988; Resolução CFN nº. 417/2008, Resolução CFN nº. 308/2005, Journal of Hospital Administration, v. 2, n. 3, 2013) 


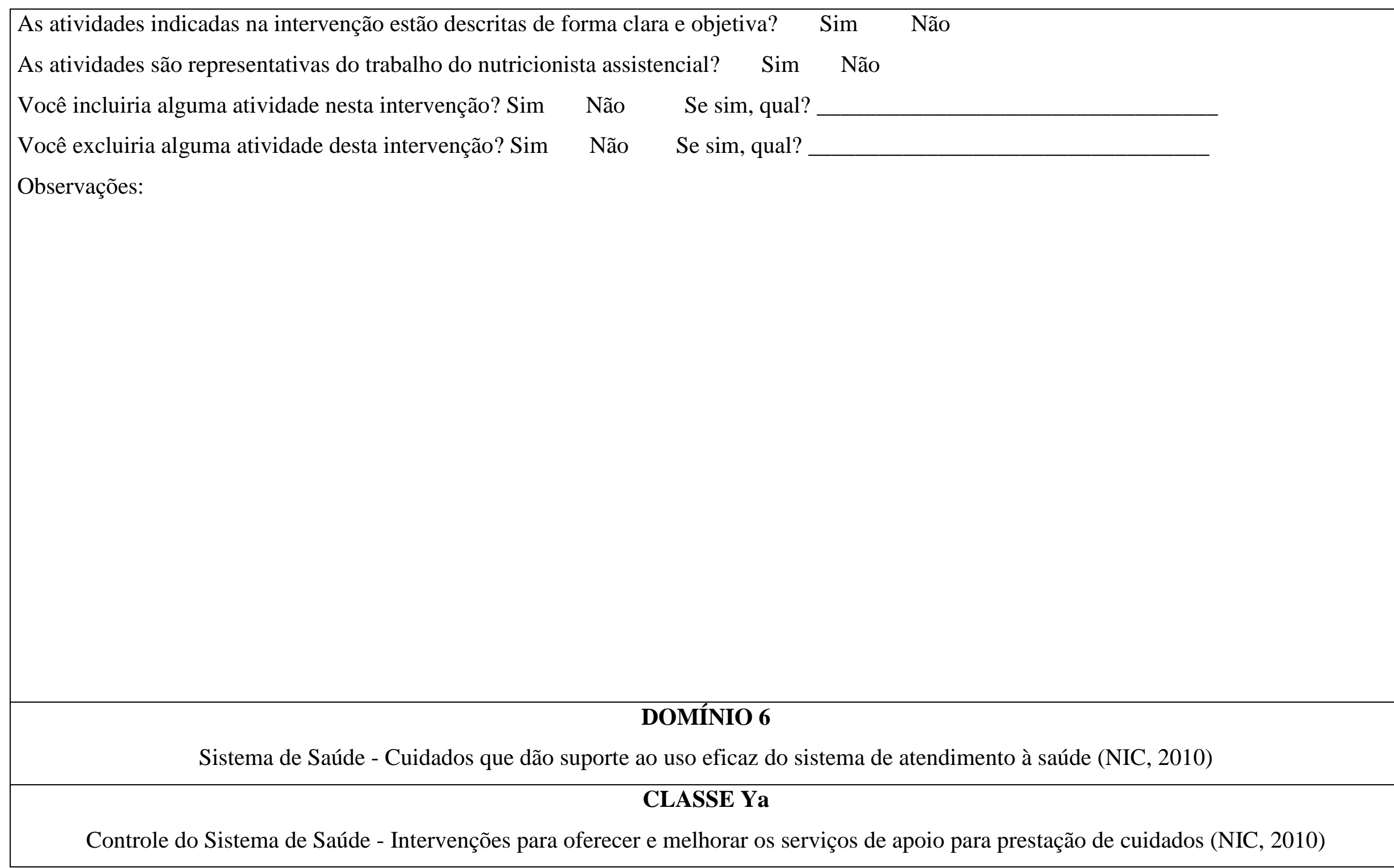


Delegação - 7650- p.265 - Transferência de responsabilidade pela Explicar a tarefa à equipe de enfermagem ou à família (exemplo: registrar realização dos cuidados do paciente, ao mesmo tempo em que o consumo alimentar do paciente nas 24 horas em formulário específico mantém a responsabilidade pelos resultados (NIC, 2010). da Nutrição).

(JCDA, v. 48, n. 4, 1987) 


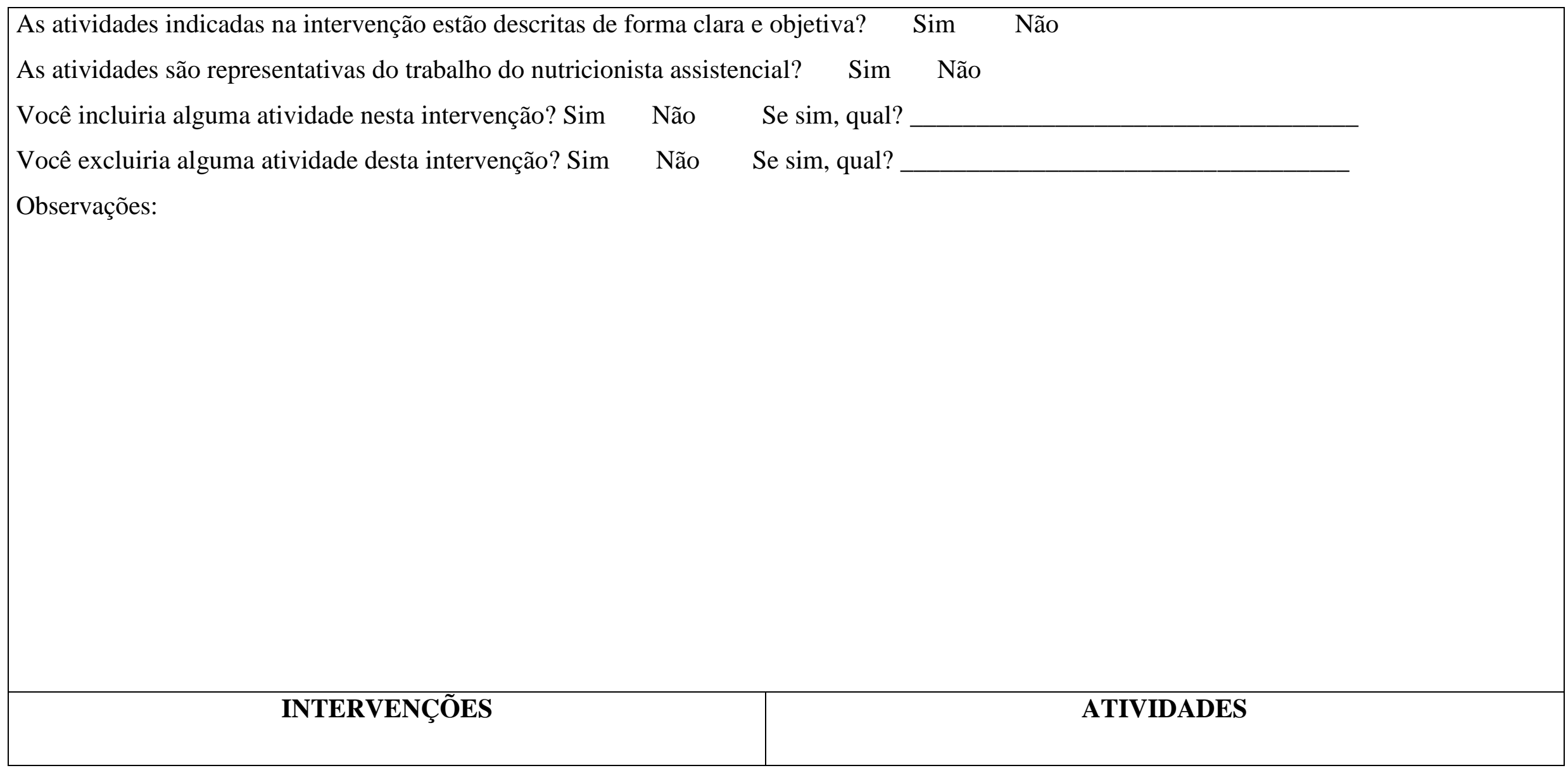




\begin{tabular}{|c|c|}
\hline $\begin{array}{l}\text { Preceptor: estudante }-\mathbf{7 7 2 6} \text { - p. } 602 \text { - Assistência e apoio a } \\
\text { experiência de aprendizagem de um estudante (NIC, 2010). }\end{array}$ & $\begin{array}{l}\text { Facilitar a aceitação dos estudantes como cuidadores pelo paciente. } \\
\text { Apresentar os alunos aos membros da equipe e aos pacientes. } \\
\text { Acompanhar estagiário de nutrição em procedimento. } \\
\text { Orientação aos internos e residentes. } \\
\text { Avaliar evoluções e prescrições de nutrição realizadas por estagiários. } \\
\text { Tirar dúvidas de estagiários de nutrição. } \\
\text { Discutir o plano de cuidados nutricionais com os estudantes. } \\
\text { Envolver os estudantes em atividades de pesquisa, conforme apropriado. } \\
\text { ((Resolução CFN n }{ }^{\circ} .308 / 2005 \text {, NIC, 2010). }\end{array}$ \\
\hline
\end{tabular}




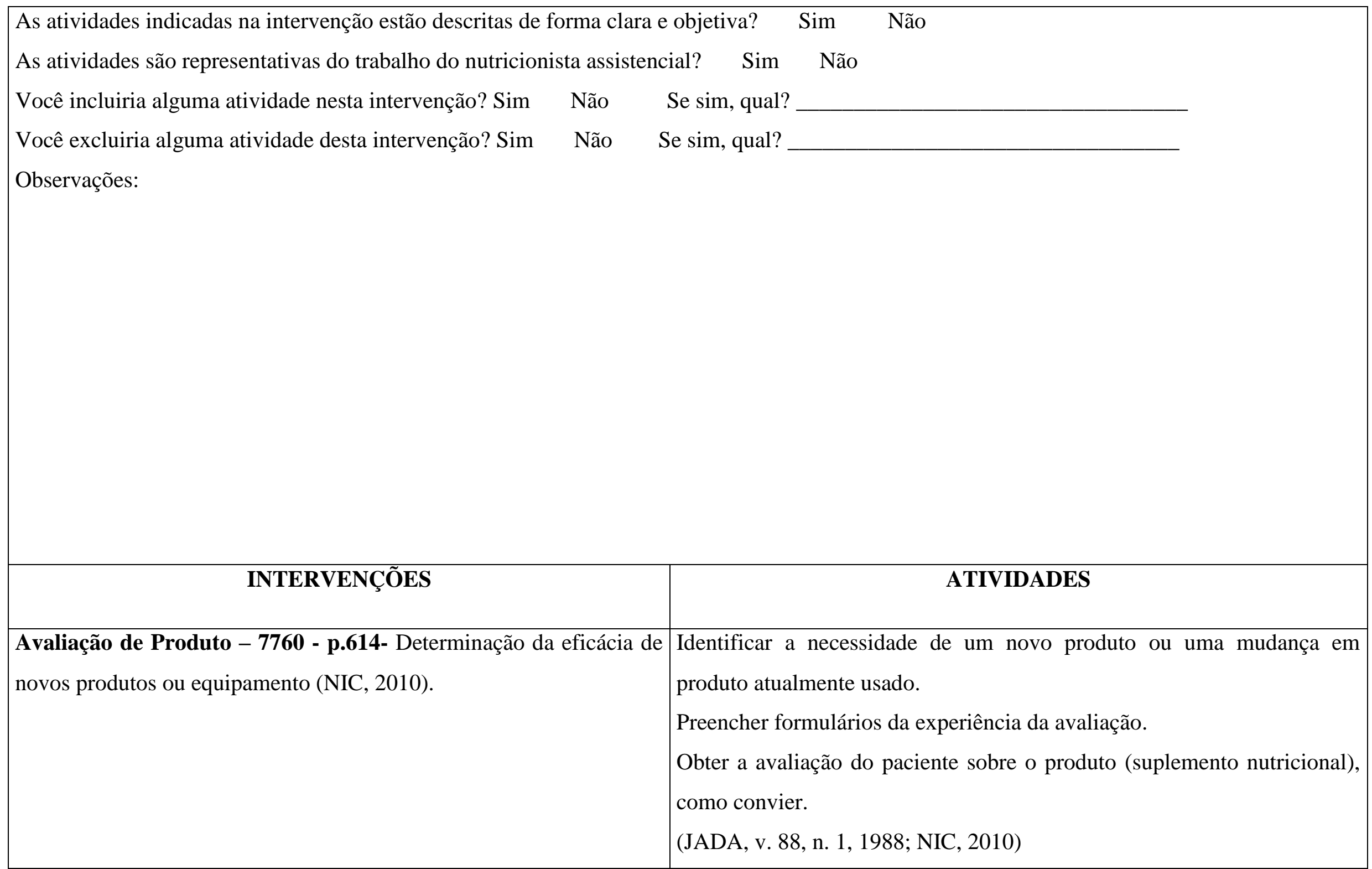


As atividades indicadas na intervenção estão descritas de forma clara e objetiva? Sim Não

As atividades são representativas do trabalho do nutricionista assistencial? Sim Não

Você incluiria alguma atividade nesta intervenção? Sim Não Se sim, qual?

Você excluiria alguma atividade desta intervenção? Sim Não Se sim, qual?

Observações: 


\begin{tabular}{|l|l|}
\hline $\begin{array}{l}\text { Desenvolvimento de Funcionários - } \mathbf{7 8 5 0}-\mathbf{p . ~ 4 1 6 - 4 1 7 -}- \\
\text { Desenvolvimento, manutenção e monitoração da competência de } \\
\text { funcionários (NIC, 2010). }\end{array}$ & $\begin{array}{l}\text { Elaborar o plano de trabalho anual, contemplando os procedimentos } \\
\text { adotados para o desenvolvimento das atribuições. } \\
\text { Encorajar a participação em atividades fora do Serviço de Nutrição e } \\
\text { Dietética (organizaçóes profissionais, eventos científicos e etc). } \\
\text { Providenciar assistência financeira e tempo livre para a participação em } \\
\text { programas educacionais, conforme exigências do trabalho (ex.: preparar } \\
\text { e/ou apresentar palestras, jornais, informativos e etc). } \\
\text { (JCDA, v. 47, n. 4, 1987; Resolução CFN nº 38/2005; NIC, 2010; } \\
\text { Journal of Hospital Administration, v. 2, n. 3, 2013). }\end{array}$ \\
\hline
\end{tabular}




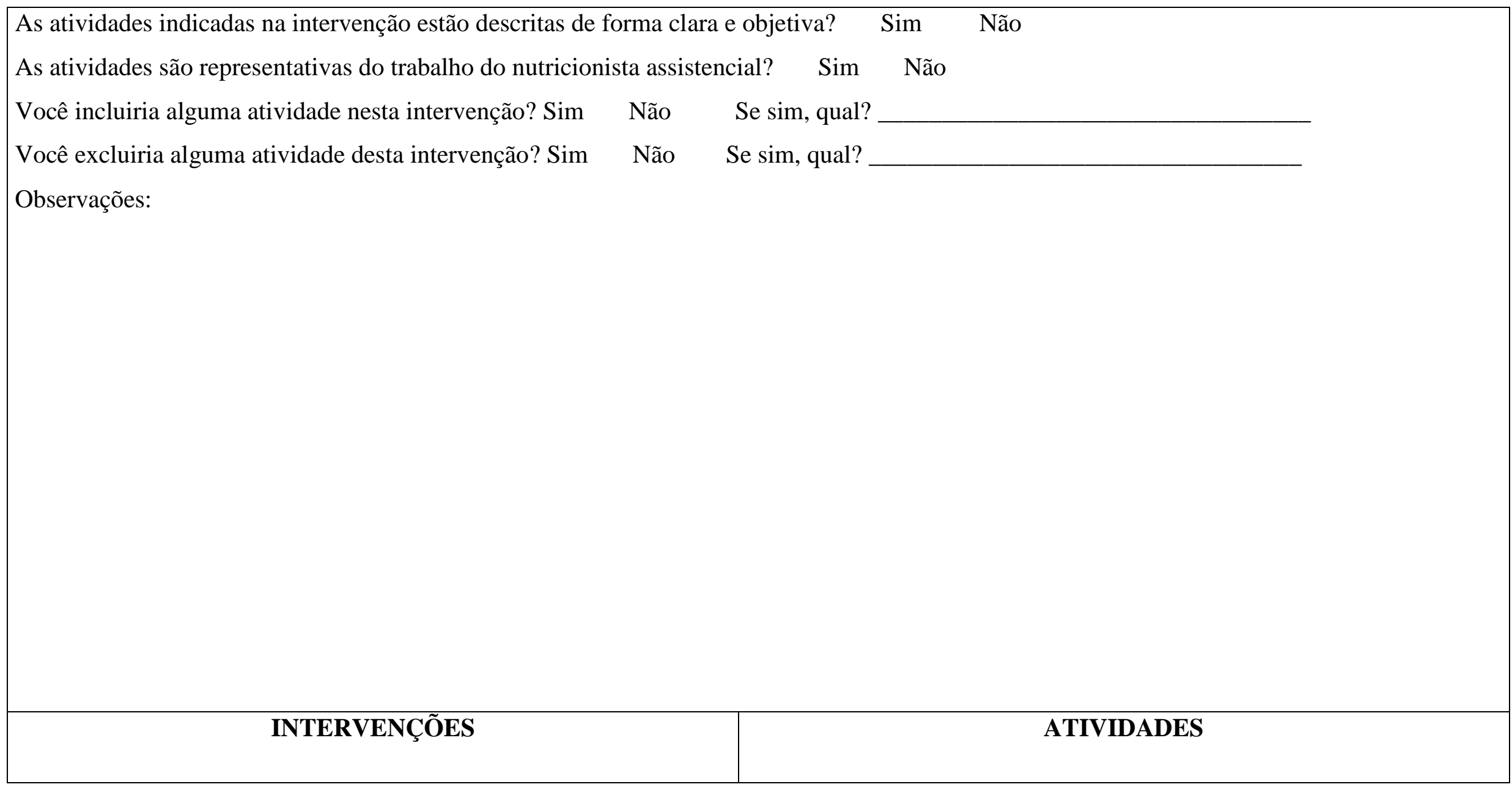


Desenvolvimento de Protocolos de Cuidado - 7640 - p.617- Revisar os padrões atuais de prática relacionados à população de Elaboração e uso de uma sequência programada de atividades de pacientes.

cuidado para melhorar os resultados desejados para o paciente a um Revisar os protocolos de cuidados nutricionais, conforme apropriado. custo-efetivo (NIC, 2010). Elaborar/revisar impressos próprios para o atendimento nutricional.

Colaborar com outros profissionais de saúde para elaborar protocolos de cuidado.

(JADA, v. 88, n. 1, 1988; Resolução CFN nº. 308/2005, Resolução CFN $n^{\circ}$. 417/2008; NIC, 2010, Journal of Hospital Administration, v. 2, n. 3, 2013) 


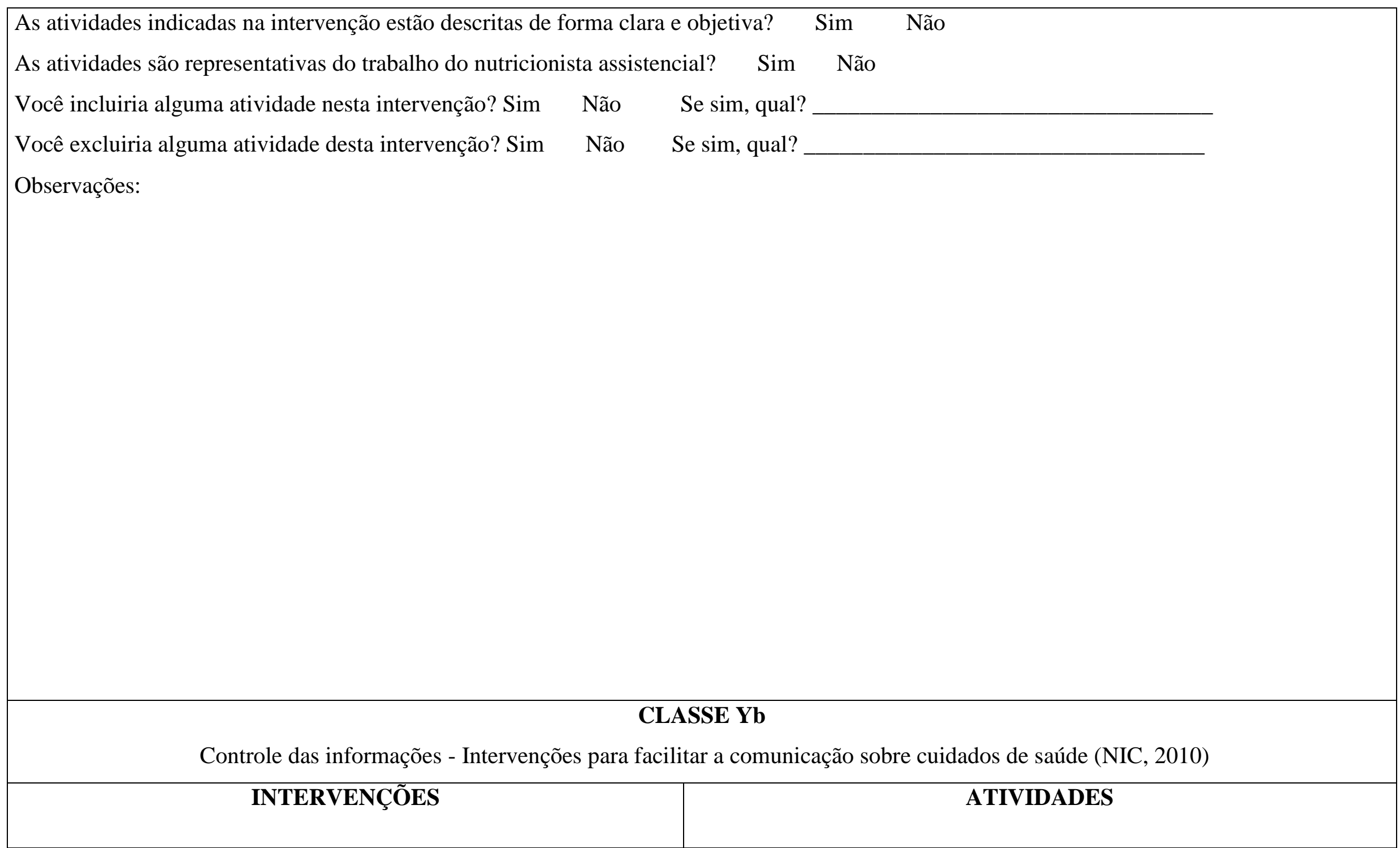




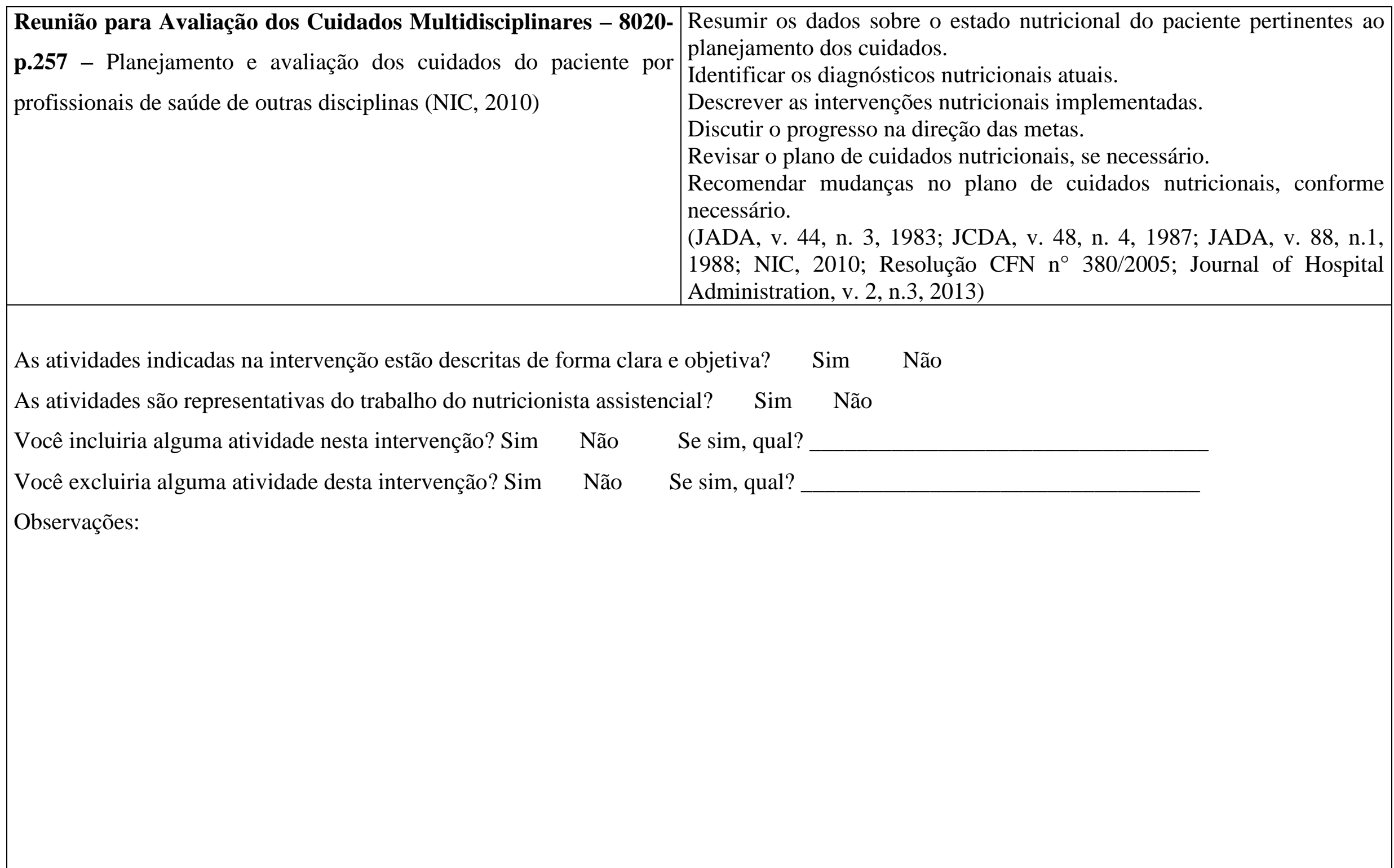




\begin{tabular}{|c|c|}
\hline INTERVENÇÕES & ATIVIDADES \\
\hline
\end{tabular}




\begin{tabular}{|c|c|}
\hline \multicolumn{2}{|c|}{\begin{tabular}{|lll} 
As atividades indicadas na intervenção estão descritas de forma clara e objetiva? & Sim $\quad$ Não
\end{tabular}} \\
\hline \multirow{2}{*}{\multicolumn{2}{|c|}{$\begin{array}{l}\text { As atividades são representativas do trabalho do nutricionista assistencial? } \quad \text { Sim } \quad \text { Não } \\
\text { Você incluiria alguma atividade nesta intervenção? Sim } \quad \text { Não } \quad \text { Se sim, qual? }\end{array}$}} \\
\hline & \\
\hline \multicolumn{2}{|l|}{ Observações: } \\
\hline INTERVENÇÕES & ATIVIDADES \\
\hline $\begin{array}{l}\text { Encaminhamento - 8100- p.329 - Oferecimento de informações de } \\
\text { cuidados do paciente a outros profissionais da saúde (NIC, 2010). }\end{array}$ & $\begin{array}{l}\text { Fazer um monitoramento contínuo para determinar a necessidade do } \\
\text { encaminhamento. } \\
\text { Fazer encaminhamento escrito adequado (p.ex., psicologia, } \\
\text { fonoaudiologia e etc). } \\
\text { (JADA, v. 84, n. 9, 1984; JADA, v. 85, n. 7, 1985; JADA, v. 85, n. 5, } \\
\text { 1987; NIC, 2010; Resolução CFN n }{ }^{\circ} \text { 380/2005) }\end{array}$ \\
\hline
\end{tabular}




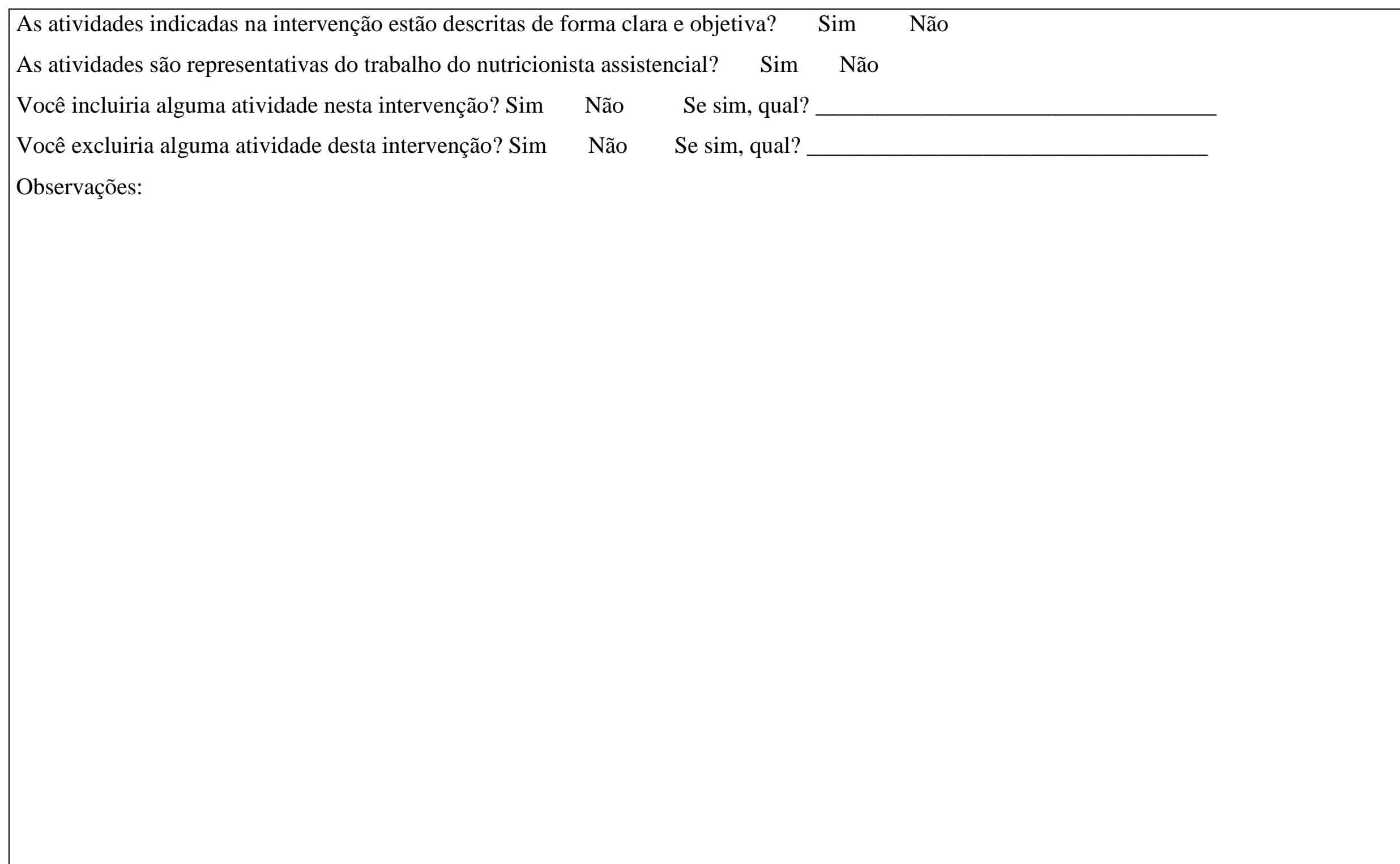




\section{ATIVIDADES}

\begin{tabular}{|c|c|}
\hline $\begin{array}{l}\text { Troca de informações sobre cuidados de saúde - 7960- p.678 - } \\
\text { Oferecimento de informações de cuidados do paciente a outros } \\
\text { profissionais da saúde (NIC, 2010). }\end{array}$ & $\begin{array}{l}\text { Acessar e-mail institucional. } \\
\text { Atender telefone relacionado à atividade do Serviço de Nutrição e } \\
\text { Dietética. } \\
\text { Atender telefone relacionado aos cuidados do paciente (p.ex., demandas } \\
\text { dos profissionais de saúde relacionadas ao paciente). } \\
\text { Fornecer informações sobre evolução do estado nutricional do paciente } \\
\text { para profissionais da equipe multidisciplinar. } \\
\text { Comunicar troca de leito do paciente ao Serviço de Nutrição e Dietética. } \\
\text { Fornecer ao Serviço de Nutrição e Dietética as informações referentes à } \\
\text { dieta prescrita para o paciente. } \\
\text { Discutir as preocupações com os cuidados ao paciente, ou assuntos } \\
\text { relativos à prática, diretamente com os profissionais envolvidos. } \\
\text { Discutir os recursos financeiros quando houver necessidade de } \\
\text { providências de cuidados nutricionais após a alta. } \\
\text { Auxiliar o paciente a manifestar preocupações ao médico. } \\
\text { (JADA, v. 79, 1981; JADA, v. 84, n. 9, 1984; JADA, v. 85, n. 5, 1987; } \\
\text { JCDA, v. 48, n. 4, 1987; JADA, v. 88, n.1, 1988; NIC, 2010; Resolução } \\
\text { CFN n 380/2005) }\end{array}$ \\
\hline
\end{tabular}




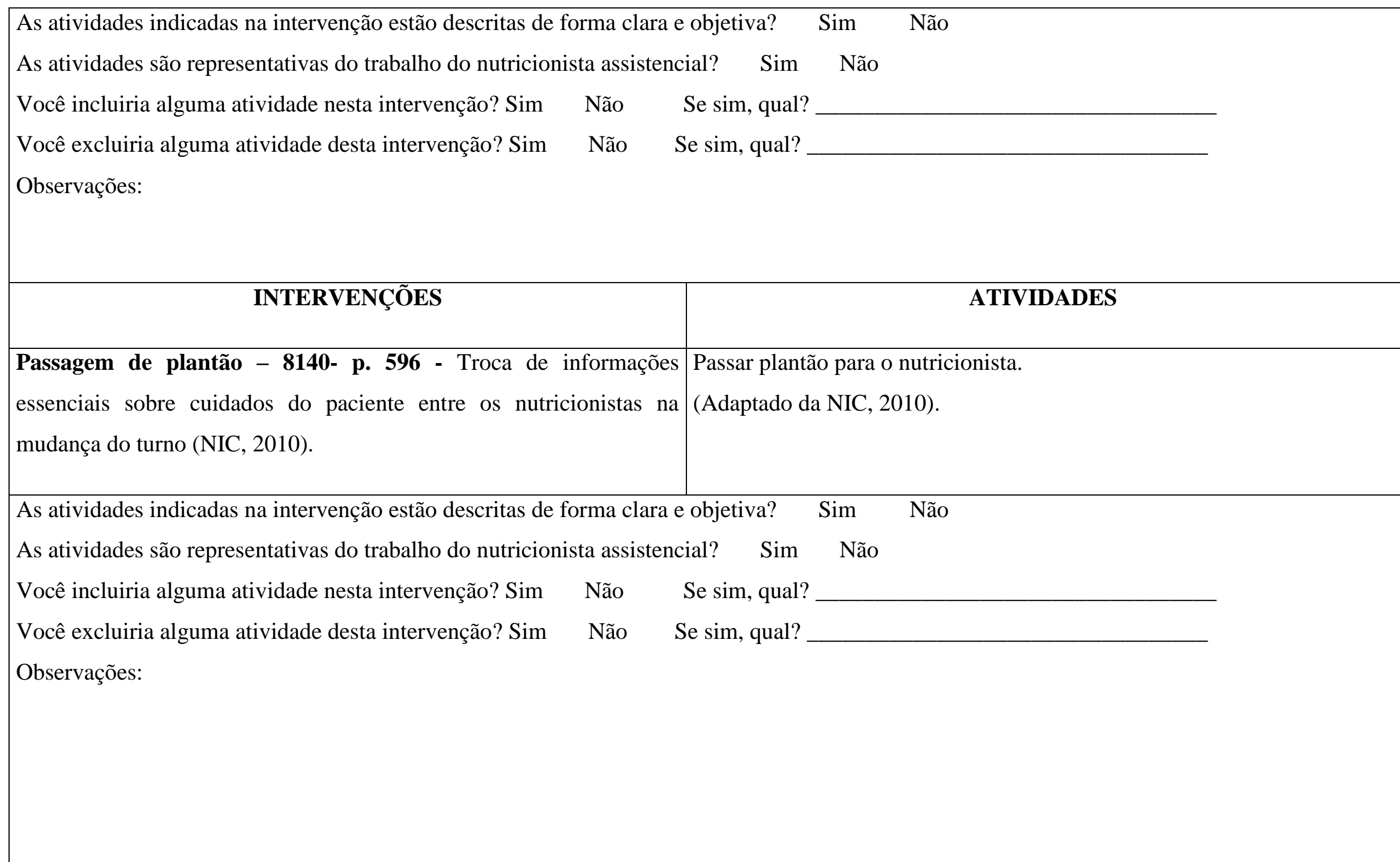


ATIVIDADES PESSOAIS

Acessar computador

Checar caixa de e-mail pessoal

Guardar refeição na geladeira

Hidratar-se

Ler

Descansar

Socializar com acompanhantes

Socializar com equipe multidisciplinar

Usar telefone

Usar toalete

Alimentar-se

Tomar medicamentos 


\section{ATIVIDADES ASSOCIADAS}

Cadastrar acompanhante do paciente no sistema de pacientes

Procurar kardex/mapa

Revisar as etiquetas de identificação da refeição do paciente

Organizar mesa dos computadores

Organizar pranchetas

Procurar anotações/evoluções nutricionais anteriores que já não estão mais na prancheta

Retirar documentos da prancheta para arquivar em prontuário

Separar etiquetas de identificação da refeição do paciente

Guardar e conferir materiais/equipamentos para avaliação nutricional

Procurar prontuário

\section{OUTRAS}

Ausente

Esperar o paciente

Deslocar-se até o paciente e/ou Serviço de Nutrição e Dietética

Participar de reunião administrativa

\section{Referências:}

Brasil. Conselho Federal de Nutricionistas, Resolução CFN Nº 380 de 9 de dezembro de 2005. Dispõe sobre a definição das áreas de atuação do nutricionista e suas atribuições, estabelece parâmetros numéricos de referência, por área de atuação, e dá outras providências. [acessado 2011 mai 
11].Disponível em: http://www.crn5.org.br/data/site/uploads/arquivos/380\%20-

$\% 20$ Areas $\% 20 \mathrm{de} \% 20$ atuacao, $\% 20$ atribuicoes $\% 20 \mathrm{e} \% 20$ parametros $\% 20$ numericos.pdf

Brasil. Conselho Federal de Nutricionistas, Resolução CFN N 417/2008. Dispõe sobre procedimentos nutricionais para atuação dos nutricionistas e dá outras providências. [acessado 2014 jan 11].Disponível em: http://www.asbran.org.br/sitenovo/arquivos/resolucao417.pdf

Diez-Garcia RW, Japur CC, Medeiros MAT. Food and nutritional care quality indicators in hospital. Journal of Hospital Administration. 2013; 2 (3):132-41.

Dochtherman J, Butcher HK, Bulechek GM. Classificação das Intervenções de Enfermagem. Rio de Janeiro: Elsevier, 2010.

Huyck SA, McNamara PM. Monitoring accountability of a clinical nutrition service. J Am Diet Assoc. 1987; 87(5):620-3.

Lutton SE, Baker MM, Billman RV. Levels of patient nutrition care for use in clinical decision making. J Am Diet Assoc. 1985; 85(7):849-51.

McManners MH, Barina SA. Productivity in clinical dietetics. J Am Diet Assoc. 1984; 84(9):1035-8.

No authors listed. Identification of clinical dietetic practitioner's time use for the provision of nutrition care. J Am Diet Assoc. 1981; $79(6): 708-15$.

Shanklin CW, Hernandez HN, Gould RM, Gorman MA. Documentation of time expenditures of clinical dietitians: Results of a statewide time study in Texas. J Am Diet Assoc. 1988; 88(1):38-43.

Somers JP, Mulroney RA. Workload measurement study to develop staffing guidelines for the clinical inpatient dietitian. J Can Diet Assoc. 1983; 44(3): 246-50. 
Towers D ML, Coskumer H, Brunet K, Kack M. A System of Workload Measurement for Clinical Dietitians. J Can Diet Assoc. 1987; 48(4):243-6. 


\section{APÊNDICE C - CARTA AOS JUÍZES PARA ORIENTAR A AVALIAÇÃO DAS ATIVIDADES NA OFICINA DE VALIDAÇÃO}

Caro Juiz,

Agradeço sua participação na construção desta oficina, como parte do projeto de pesquisa intitulado "Dimensionamento de Recursos Humanos em Assistência Nutricional Hospitalar", que tem como objetivo geral, propor parâmetros para o dimensionamento de pessoal de nutrição clínica no âmbito hospitalar.

Solicito que você avalie as atividades que foram observadas ou descritas na literatura e classificadas em atividades/intervenções de nutrição clínica. Cada atividade/intervenção apresentada deve ser avaliada quanto à pertinência.

Para isso, encaminho o Termo de Consentimento Livre e Esclarecido e o instrumento com a listagem das intervenções/atividades e solicito que analise previamente, para que a oficina seja mais proveitosa.

Providenciarei as impressões, para que você tenha todo o material em mãos no dia da oficina.

Desde já agradeço sua disposição em contribuir e conto com sua valorosa presença no dia ________ no Departamento de Orientação Profissional ENO, da Escola de Enfermagem da Universidade de São Paulo, sala 160. 


\section{APÊNDICE D - INSTRUMENTO DE CARACTERIZAÇÃO DOS NUTRICIONISTAS CLÍNICOS}

Código de identificação da Instituição _-
1. Identificação
Idade em anos:
Sexo: ( ) Feminino ( ) Masculino
Escola em que se graduou:
Ano de graduação:
2. Qualificação
Maior titulação:
$\quad$ ( ) Bacharel em nutrição
$\quad$ ( ) Doutor
3. Experiência profissional Especialista
a) Você já trabalhou em outros hospitais? ( ) sim ( ) Mestre
Se sim, por quanto tempo (anos ou meses)?
b) Há quanto tempo (anos ou meses) você trabalha nesta Instituição:
c) Há quanto tempo (anos ou meses) você trabalha nesta Unidade:
d) Você já trabalhou em outras Unidades nesta Instituição? ( ) sim ( ) não.
Se sim, qual (ais) e por quanto tempo (anos ou meses)?




\section{APÊNDICE E - INSTRUMENTO DE CARACTERIZAÇÃO DOS HOSPITAIS}

\section{Código de identificação da Instituição: \\ Caracterização do Serviço de Nutrição e Dietética}

Tipo de Serviço de Nutrição e Dietética: ( ) próprio ( ) terceirizado

O Serviço de Nutrição e Dietética é informatizado? ( ) sim ( ) não

O Serviço disponibiliza alguma ferramenta (software de nutrição) para avaliação nutricional e monitoramento dos pacientes internados? ( ) $\operatorname{sim}($ ) não

\section{Caracterização da Instituição}

Qual o quantitativo de nutricionistas clínicos?

Qual o quantitativo de nutricionistas clínicos por dia?

Qual o quantitativo de nutricionistas membros da Equipe Multiprofissional de Terapia Nutricional?

Qual o quantitativo de nutricionistas membros da Equipe Multiprofissional de Terapia Nutricional por dia?

O quantitativo de profissionais de nutrição clínica e nutricionistas membros EMTN é mantido durante todos os dias a semana, inclusive finais de semana e feriados?

( ) $\operatorname{sim}()$ não

Quais os equipamentos abaixo são disponibilizados para a realização da avaliação nutricional e monitoramento dos pacientes internados:

- Balança mecânica tipo plataforma com estadiômetro: ( ) sim ( ) não

- Balança portátil: ( ) sim ( ) não

- Balança integrada ao leito: ( ) sim ( ) não

- Cadeira balança: ( ) sim ( ) não

- Estadiômetro portátil: ( ) sim ( ) não

- Fita inelástica antropométrica: ( ) sim ( ) não

- Régua antropométrica (para aferição da altura do joelho): ( ) sim ( ) não

- Bioimpedância: ( ) sim ( ) não 
- Calorímetro: ( ) sim ( ) não

- Adipômetro: ( ) sim ( ) não

- Outro (s):

Quais os exames laboratoriais são disponibilizados para a avaliação nutricional e/ou monitoramento dos pacientes internados:

- Hemograma: ( ) sim ( ) não

- Albumina: ( ) sim ( ) não

- Pré-albumina: ( ) sim ( ) não

- Outro (s): 


\section{APÊNDICE F - TERMO DE CONSENTIMENTO LIVRE E ESCLARECIDO \\ DIMENSIONAMENTO DE RECURSOS HUMANOS EM ASSISTÊNCIA NUTRICIONAL HOSPITALAR}

Eu, Clotilde Assis Oliveira, aluna de pós-graduação da Escola de Enfermagem da Universidade de São Paulo (USP), convido você para participar como voluntário de uma pesquisa que pretendo realizar cujo objetivo é propor parâmetros para o dimensionamento de nutricionistas assistenciais no âmbito hospitalar. Para atingir este objetivo, será elaborado um instrumento para medir a carga de trabalho pautado nas atividades realizadas pelos nutricionistas assistenciais, que estão contidas nas intervenções de nutrição clínica. Para isso, preciso observá-lo durante a execução de suas atividades diárias no setor que você trabalha.

A realização desta pesquisa está contextualizada no estudo de temas sobre planejamento de recursos humanos, dimensionamento de pessoal e carga de trabalho na área de Nutrição Clínica, o qual se identificou grandes dificuldades na obtenção de subsídios para administradores de saúde, diretores de departamentos de nutrição, gerentes de nutrição clínica e o próprio pessoal de nutrição clínica nas instituições hospitalares.

Desta forma, acredito que ela seja importante porque os resultados obtidos no presente estudo poderão contribuir para instrumentalizar as chefias dos Serviços de Nutrição e Dietética Hospitalares para o gerenciamento dos recursos humanos, com respaldo científico que fundamente e fortaleça seu argumento no que se refere à manutenção de padrões de pessoal adequados à clientela.

Antes de iniciar a pesquisa serão apresentados a você os instrumentos utilizados durante a avaliação que constará de um formulário para caracterização dos participantes, contendo os dados demográficos (sexo e idade), formação e experiência profissional, além de uma lista de atividades realizadas pelo nutricionista assistencial que comporão um instrumento de medida da distribuição do tempo de trabalho dos nutricionistas assistenciais nas unidades.

Será assegurado e respeitado o sigilo e anonimato, além da garantia de que os resultados desta pesquisa serão utilizados e divulgados com a finalidade única de 
contribuir para os conhecimentos científicos e que a pesquisadora responsável poderá ser contatada pelo telefone: (11) 9 59741-803 e no e-mail: clotildeassis@usp.br. Em relação à parte ética, poderá contatar o Comitê de Ética em Pesquisa da Escola de Enfermagem da Universidade de São Paulo, órgão responsável pela aprovação deste projeto, pelo telefone: (11) 3061-7548 ou pelo email: edipesq@usp.br.

$\mathrm{Eu}$ fui esclarecido (a) sobre a pesquisa e estou ciente de seus objetivos, finalidades e preenchimento deste termo em duas vias, ficando uma comigo e outra com o pesquisador.

Concordo em participar voluntariamente, sem qualquer benefício ou prejuízo financeiro, consentindo que a pesquisadora me observe durante a execução de minhas atividades diárias. Esta observação não ocasionará alteração na condução de minhas atividades diárias e será realizada no momento em que eu desejar.

Tenho a garantia da pesquisadora de que poderei solicitar a interrupção da observação a qualquer momento, além de desistir de participar da pesquisa, não havendo qualquer prejuízo para minha pessoa.

Além disso, caso você não queira responder alguma pergunta e/ou se sinta constrangido durante o preenchimento do formulário de caracterização dos sujeitos da pesquisa, sua participação poderá ser interrompida a qualquer momento sem qualquer prejuízo.

Participante do estudo

Local e data:

Pesquisadora Assistente

Local e data: 
Endereços e meios de contato:

Pesquisadora

responsável:

Clotilde

Assis

Oliveira

R. Frei Inácio da Conceição, 629, apt. 04. Butantã/SP. CEP 05362-040

Tefefone: (0**11) 9 5974-1803

E-mail: clotildeassis@usp.br

\section{Orientadora:}

$\begin{array}{llll}\text { Profa. } & \text { Dra. } & \text { Raquel } & \text { Rapode }\end{array}$ Av. Enéas de Carvalho Aguiar, 419 - 1․․ Andar. Cerqueira César. São Paulo/SP. CEP 05403-000.

Telefone:

E-mail: raqui@usp.br

\section{Comitê de Ética em Pesquisa EEUSP}

Av. Enéas de Carvalho Aguiar, $419-2^{\circ}$. Andar. Cerqueira César. São Paulo/SP. CEP 05403-000.

Fone: $3061-7548$

E-mail: edipesq@usp.br 


\section{APÊNDICE G - QUADRO COMPARATIVO DA TAXONOMIA}

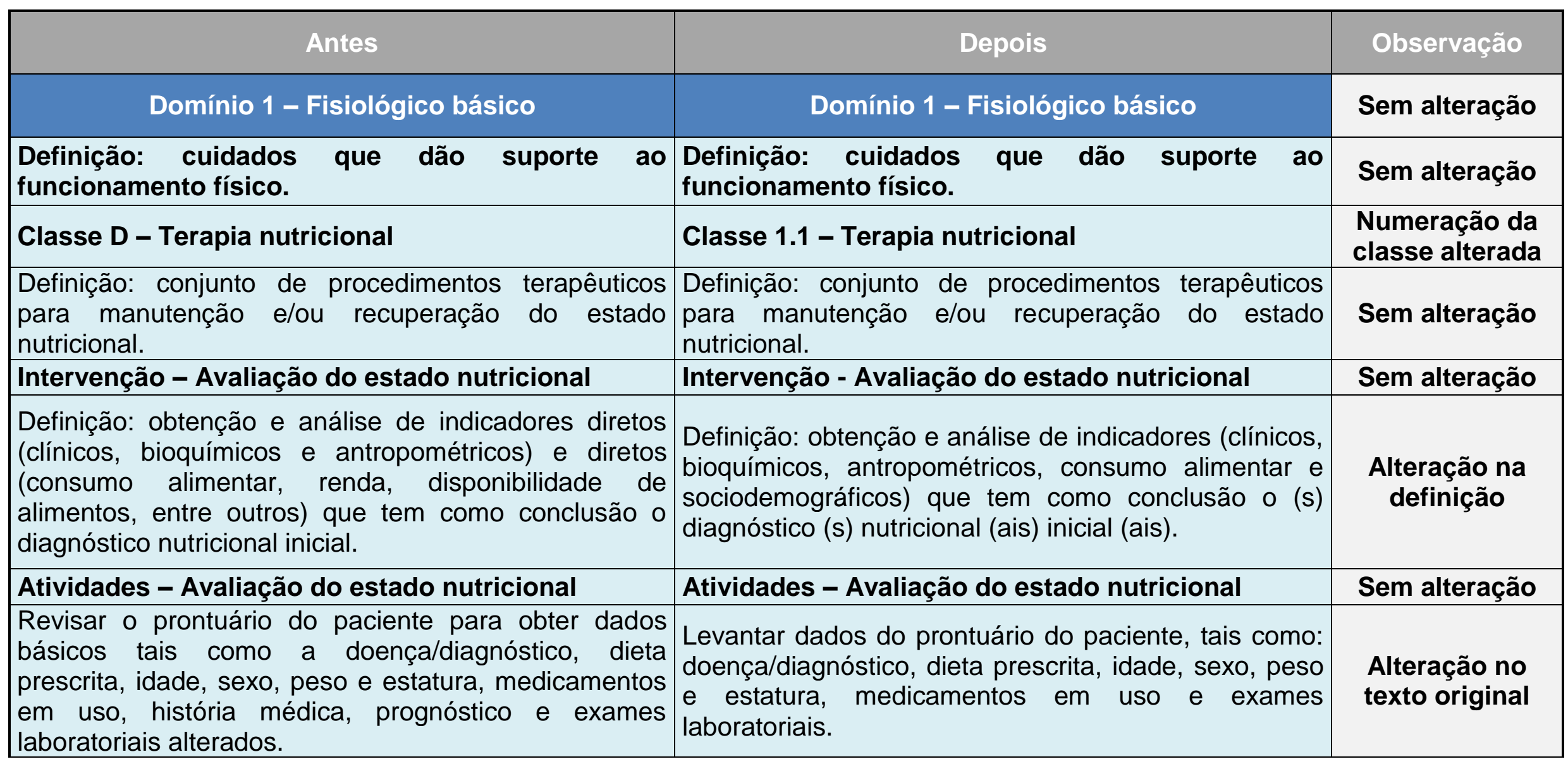


Realizar anamnese completa: preferências e aversões,| Realizar anamnese: preferências e aversões, intolerâncias, alergias, apetite, problemas alimentares, intolerâncias, alergias, apetite, problemas alimentares, mudança de peso recente, ingestão alimentar habitual, mudança de peso recente, ingestão alimentar frequência alimentar, medicamentos, vitaminas e habitual, frequência alimentar, medicamentos, minerais, habilidade para ler e escrever, nível de suplementos nutricionais, habilidade para ler e atividade física, condição socioeconômica e escrever, nível de atividade física, condição conhecimento prévio acerca das restrições socioeconômica e conhecimento prévio acerca das alimentares. restrições alimentares.

Avaliar e analisar o gasto energético por calorimetria Avaliar a composição corporal através de medidas indireta. antropométricas, bioimpedância ou calorimetria.

Avaliar e analisar a composição corporal por Analisar a composição corporal através de medidas bioimpedância e/ou medidas antropométricas. antropométricas, bioimpedância ou calorimetria.

Alteração no texto original

(----------------------------

Cálculo do gasto energético basal e das necessidades energéticas e nutricionais.

Alteração no texto original

Alteração no texto original Retirar/devolver materiais/equipamentos para Atividade proposta

\begin{tabular}{|l|l|}
\hline & \\
& \\
Intervenção - Monitoramento da evolução
\end{tabular}
avaliação do estado nutricional.

Atividade proposta

\begin{tabular}{|c|c|c|}
\hline 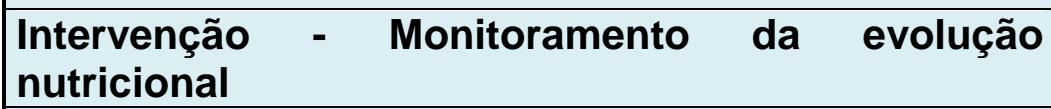 & $\begin{array}{llll}\begin{array}{l}\text { Intervenção } \\
\text { nutricional }\end{array} & \text { Monitoramento da evoluç } \\
\end{array}$ & $\mathrm{Se}$ \\
\hline $\begin{array}{l}\text { efinição: coleta e análise de da } \\
\text { evenir ou minimizar desı } \\
\text { companhamento da evolução nu }\end{array}$ & $\begin{array}{l}\text { Defir } \\
\text { para } \\
\text { recul }\end{array}$ & \\
\hline - Monitoramento da evolução & \begin{tabular}{|llll}
$\begin{array}{l}\text { Atividades } \\
\text { nutricional }\end{array}$ & - Monitoramento da evolução \\
\end{tabular} & \\
\hline $\begin{array}{l}\text { lonitorar a ingestão calórica e } \\
\text { os exames laboratoriais, } \\
\text { ledidas antropométricas e/ou }\end{array}$ & $\begin{array}{l}\text { rar a ingestão } \\
\text { dos exames labo } \\
\text { s antropométrica }\end{array}$ & \\
\hline $\begin{array}{l}\text { bservar a ocorrência de mudanças importantes } \\
\text { omportamento alimentar ou no estado nutricior } \\
\text { urante a visita de acompanhamento, conforn } \\
\text { propriado. }\end{array}$ & $\begin{array}{l}\text { Observar a ocorrência de mudanças importante } \\
\text { estado nutricional e iniciar tratamentos, conf } \\
\text { apropriado. }\end{array}$ & \\
\hline
\end{tabular}




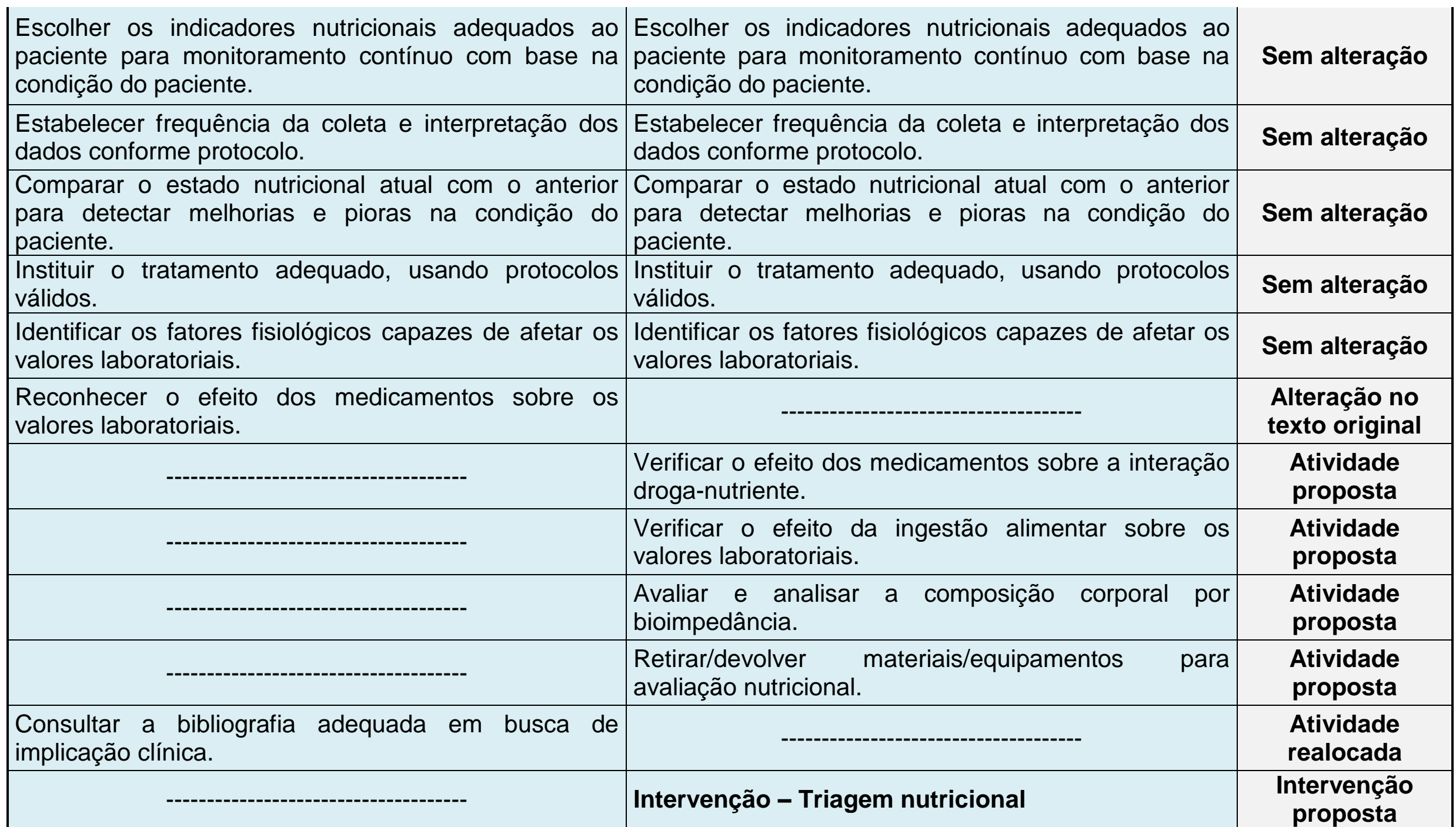




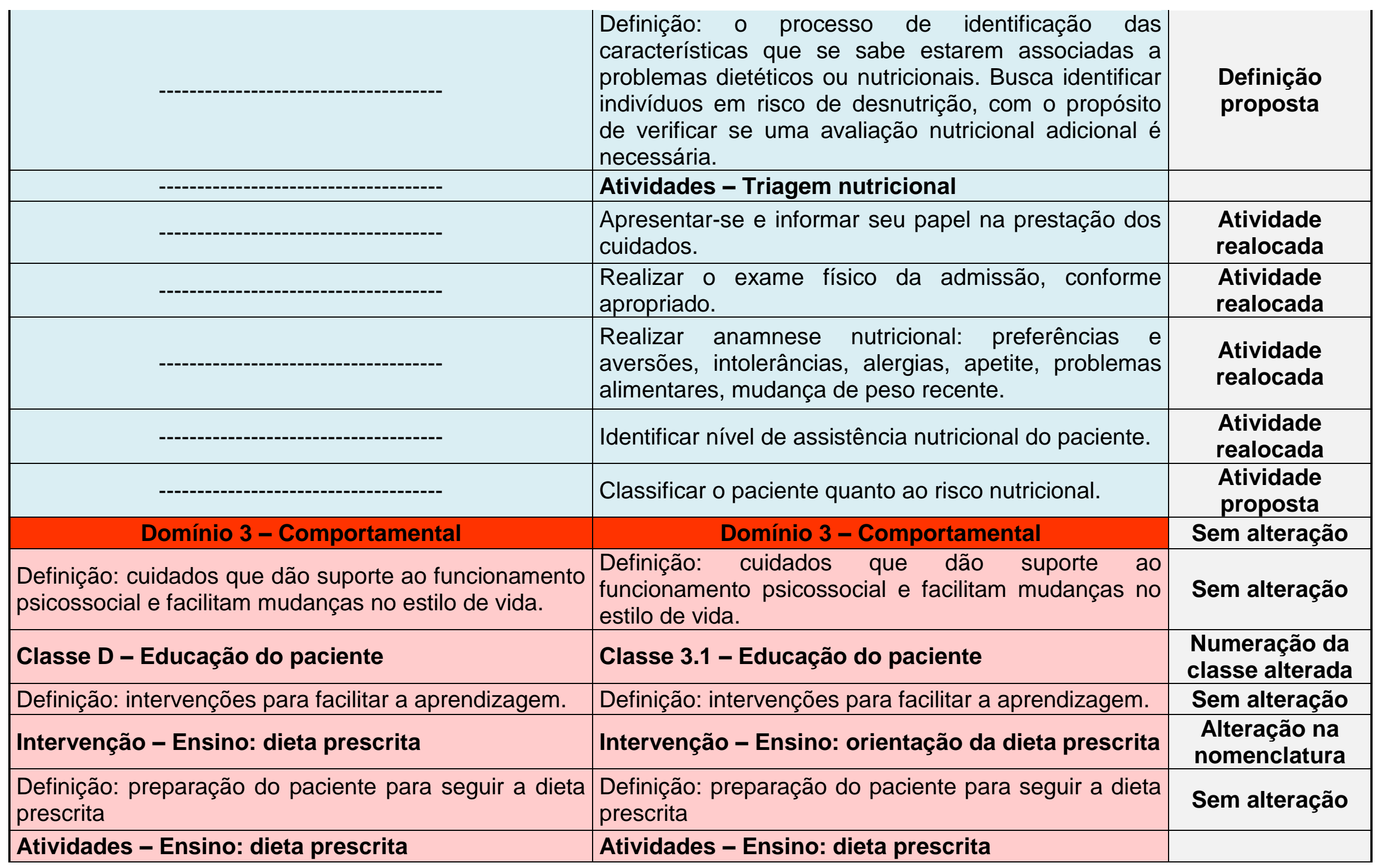




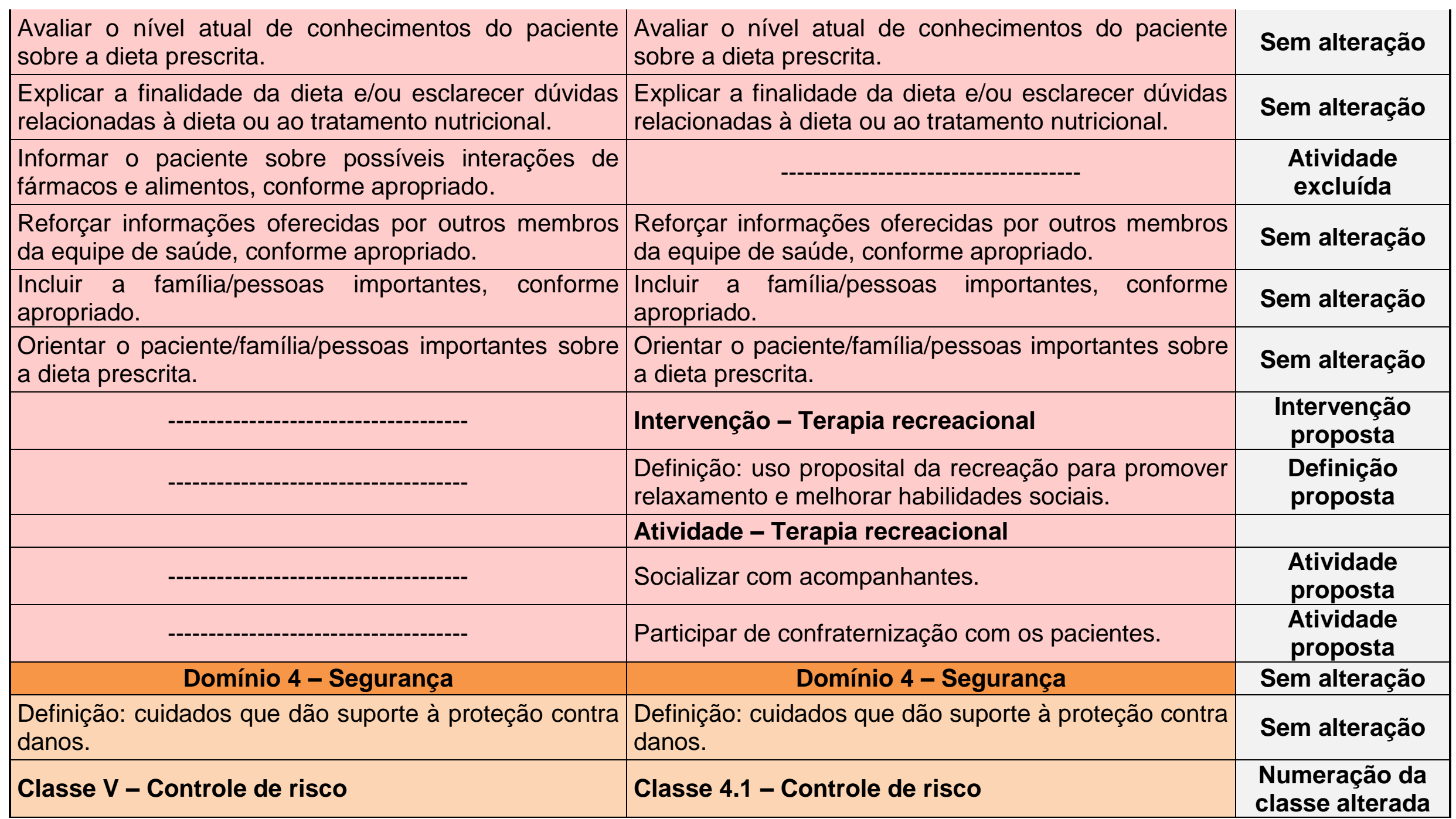


Definição: intervenções para iniciar atividades de Definição: intervenções para iniciar atividades de redução de risco e manter o monitoramento de risco redução de risco e manter o monitoramento de risco durante certo tempo Intervenções para iniciar durante certo tempo Intervenções para iniciar atividades de redução de risco e manter o atividades de redução de risco e manter o monitoramento de risco durante certo tempo.

\section{Intervenção - Controle de infecção}

Definição: minimizar a aquisição e a transmissão de agentes infecciosos.

\begin{tabular}{|l|l|}
\hline Atividades - Controle de infecção & Lavar as mãos. \\
\hline Descartar roupa de precaução de contato. & \\
\hline Paramentar-se. & \\
\hline Higienizar as mãos com álcool gel. & \\
\hline Desprezar materiais descartáveis. & \\
\hline Realizar desinfecção de materiais e equipamentos. \\
\hline $\begin{array}{l}\text { Intervenção - Supervisão da distribuição das } \\
\text { refeições na enfermaria }\end{array}$ \\
\hline
\end{tabular}
monitoramento de risco durante certo tempo. Intervenção - Controle de infecção

Definição: minimizar a aquisição e a transmissão de agentes infecciosos.

\section{Atividades - Controle de infecção}

Lavar as mãos.

Descartar roupa de precaução de contato.

Paramentar-se.

Higienizar as mãos com álcool gel.

Desprezar materiais descartáveis.

Realizar desinfecção de materiais e equipamentos.

\section{Sem alteração}

Sem alteração

Sem alteração Intervenção - Supervisão da distribuição das refeições na enfermaria

Definição: avalia o consumo alimentar do paciente, Definição: avalia o consumo alimentar do paciente, distribuição da dieta e adequação entre a dieta distribuição da dieta e adequação entre a dieta prescrita e a oferecida e também a adequação dos prescrita e a oferecida e também a adequação dos porcionamentos. porcionamentos.

Atividades - Supervisão da distribuição das Atividades - Supervisão da distribuição das refeições na enfermaria refeições na enfermaria

Monitorar o paciente quanto à ingestão alimentar.

-------------------------------------

Avaliar a distribuição da dieta e adequação entre a Avaliar a distribuição da dieta e adequação entre a dieta prescrita e ofertada e também a adequação dos dieta prescrita e ofertada e também a adequação dos porcionamentos.

\section{Sem alteração \\ Sem alteração \\ Sem alteração \\ Sem alteração \\ Sem alteração \\ Sem alteração \\ Sem alteração}

Sem alteração

Atividade excluída

Sem alteração 
Identificar os problemas nos alimentos/preparações que antecede sua distribuição aos pacientes.

Recomendar mudanças prévias no cardápio com base na degustação.

Verificar se o cardápio servido está em concordância com o planejado.

\section{Domínio 5 - Família}

Definição: cuidados que dão suporte à família.

\section{Classe $\mathbf{X}$ - Cuidados ao longo da vida}

Definição: intervenções para facilitar o funcionamento da unidade familiar e promover a saúde e o bem-estar dos membros da família ao longo do ciclo de vida.

\section{Intervenção - Apoio ao cuidador}

Definição: oferecimento das informações necessárias, defesa e apoio para facilitar o cuidado primário ao paciente por pessoa que não seja um profissional de saúde.

\section{Atividades - Apoio ao cuidador}

Admitir a dependência que o paciente tem do cuidador, conforme apropriado.

Encorajar o cuidador a assumir responsabilidades, conforme apropriado.

$$
\text { Domínio } 6 \text { - Sistema de saúde }
$$

Definição: cuidados que dão suporte ao uso eficaz do Definição: cuidados que dão suporte ao uso eficaz do sistema de atendimento à saúde.
Domínio 6 - Sistema de saúde

Identificar os problemas nos alimentos/preparações que antecede sua distribuição aos pacientes, tais como temperatura e apresentação.

Realizar degustação das preparações.

Verificar se o cardápio servido está em concordância com o planejado.

-
Classe excluída

\begin{tabular}{|c} 
Domínio 6 - Sistema de saúde \\
\hline Definição: cuidados que dão suporte ao uso eficaz do \\
\hline \\
sistema de atendimento à saúde.
\end{tabular}

Domínio excluído Definição excluída Definição excluída

Intervenção excluída

Definição excluída

Alteração no

Alteração no texto original

Sem alteração

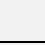

Atividade excluída

Atividade excluída

Sem alteração 


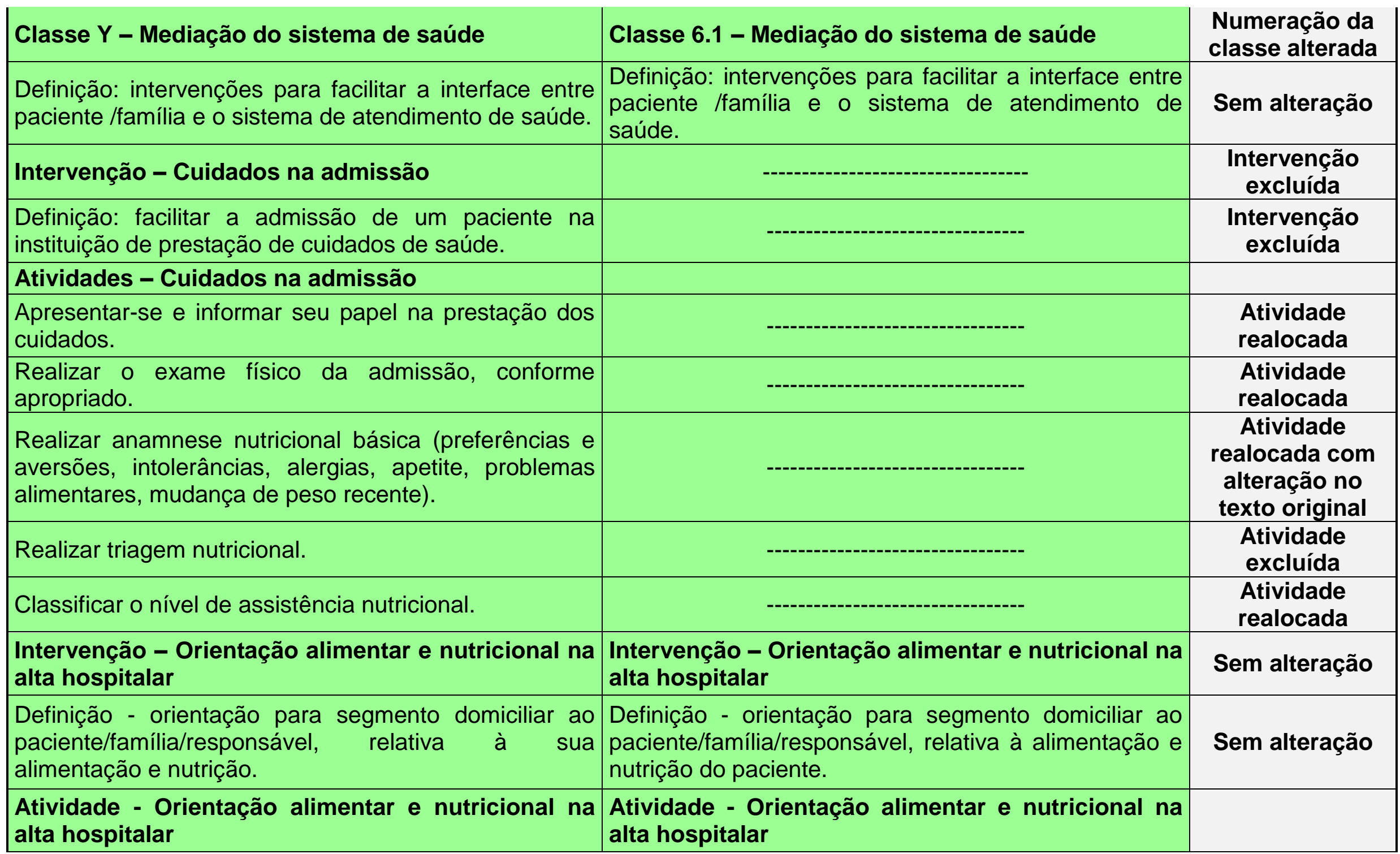




\begin{tabular}{|c|c|c|}
\hline $\begin{array}{l}\text { Orientar o paciente/família/responsável quanto aos } \\
\text { cuidados nutricionais em domicílio. }\end{array}$ & $\begin{array}{l}\text { Orientar o paciente/família/responsável quanto aos } \\
\text { cuidados nutricionais em domicílio. }\end{array}$ & Sem alteração \\
\hline & $\begin{array}{l}\text { Realizar grupos educativos com pacientes no pós-alta } \\
\text { hospitalar. }\end{array}$ & $\begin{array}{l}\text { Atividade } \\
\text { incluída }\end{array}$ \\
\hline $\begin{array}{l}\text { Definição: Intervenções para oferecer e melhorar os } \\
\text { serviços de apoio para prestação de cuidados. }\end{array}$ & $\begin{array}{l}\text { Definição: Intervenções para oferecer e melhorar os } \\
\text { serviços de apoio para prestação de cuidados. }\end{array}$ & Sem alteração \\
\hline $\begin{array}{l}\text { Definição: transferência de responsabilidade pela } \\
\text { realização dos cuidados do paciente, ao mesmo tempo } \\
\text { em que mantém a responsabilidade pelos resultados. }\end{array}$ & & $\begin{array}{l}\text { Intervenção } \\
\text { excluída }\end{array}$ \\
\hline \multicolumn{3}{|l|}{ Atividade - Delegação } \\
\hline $\begin{array}{l}\text { Explicar a tarefa à equipe de enfermagem ou à família } \\
\text { (exemplo: registrar o consumo alimentar do paciente } \\
\text { nas } 24 \text { horas em formulário específico da Nutrição). }\end{array}$ & & $\begin{array}{l}\text { Atividade } \\
\text { excluída }\end{array}$ \\
\hline $\begin{array}{l}\text { Definição: assistência e apoio a experiência de } \\
\text { aprendizagem de um estudante. }\end{array}$ & $\begin{array}{l}\text { Definição: assistência e apoio a experiência de } \\
\text { aprendizagem de um estudante. }\end{array}$ & Sem alteração \\
\hline Atividades - Preceptor: estudante & Atividades - Preceptor: estudante & \\
\hline $\begin{array}{l}\text { Facilitar a aceitação dos estudantes como cuidadores } \\
\text { pelo paciente. }\end{array}$ & Facilitar a interação entre estudantes e pacientes. & $\begin{array}{l}\text { Alteração no } \\
\text { texto original }\end{array}$ \\
\hline $\begin{array}{l}\text { Apresentar os alunos aos membros da equipe e aos } \\
\text { pacientes. }\end{array}$ & $\begin{array}{l}\text { Apresentar os alunos aos membros da equipe e aos } \\
\text { pacientes. }\end{array}$ & Sem alteração \\
\hline Acompanhar estagiário de nutrição em procedimento. & $\begin{array}{l}\text { Acompanhar estagiário de nutrição na realização das } \\
\text { atividades. }\end{array}$ & Sem alteração \\
\hline Orientação aos internos e residentes. & Orientação aos internos e residentes. & Sem alteração \\
\hline
\end{tabular}




\begin{tabular}{|c|c|c|}
\hline $\begin{array}{l}\text { Avaliar evoluções e prescrições de nutrição realizadas } \\
\text { por estagiários. }\end{array}$ & $\begin{array}{l}\text { Avaliar evoluções e prescrições de nutrição realizadas } \\
\text { por estagiários. }\end{array}$ & Sem alteração \\
\hline $\begin{array}{l}\text { Discutir o plano de cuidados nutricionais com os } \\
\text { estudantes. }\end{array}$ & $\begin{array}{l}\text { Discutir o plano de cuidados nutricionais com os } \\
\text { estudantes. }\end{array}$ & Sem alteração \\
\hline $\begin{array}{l}\text { Envolver os estudantes em atividades de pesquisa, } \\
\text { conforme apropriado. }\end{array}$ & $\begin{array}{l}\text { Envolver os estudantes em atividades de pesquisa, } \\
\text { conforme apropriado. }\end{array}$ & Sem alteração \\
\hline--- & Participar em apresentação de estudantes. & $\begin{array}{l}\text { Atividade } \\
\text { incluída }\end{array}$ \\
\hline Intervenção - Avaliação de produto & Intervenção - Avaliação de produto & Sem alteração \\
\hline $\begin{array}{l}\text { Definição: determinação da eficácia de novos produtos } \\
\text { ou equipamento. }\end{array}$ & $\begin{array}{l}\text { Definição: determinação da eficácia de novos } \\
\text { produtos ou equipamento. }\end{array}$ & Sem alteração \\
\hline Atividades - Avaliação de produto & Atividades - Avaliação de produto & \\
\hline $\begin{array}{l}\text { Identificar a necessidade de um novo produto ou uma } \\
\text { mudança em produto atualmente usado. }\end{array}$ & $\begin{array}{l}\text { Identificar a necessidade de um novo produto ou uma } \\
\text { mudança de produto atualmente usado. }\end{array}$ & Sem alteração \\
\hline & Assistir a apresentação de representante de produto. & $\begin{array}{l}\text { Atividade } \\
\text { incluída }\end{array}$ \\
\hline Intervenção - Desenvolvimento de funcionários & Intervenção - Desenvolvimento de funcionários & Sem alteração \\
\hline $\begin{array}{l}\text { Definição: desenvolvimento, manutenção } \\
\text { monitoração da competência de funcionários. }\end{array}$ & $\begin{array}{l}\text { Definição: desenvolvimento, manutenção } \\
\text { monitoração da competência de funcionários. }\end{array}$ & Sem alteração \\
\hline Atividades - Desenvolvimento de funcionários & Atividades - Desenvolvimento de funcionários & \\
\hline $\begin{array}{l}\text { Elaborar o plano de trabalho anual, contemplando os } \\
\text { procedimentos adotados para o desenvolvimento das } \\
\text { atribuições. }\end{array}$ & & $\begin{array}{l}\text { Atividade } \\
\text { excluída }\end{array}$ \\
\hline
\end{tabular}




\begin{tabular}{|c|c|c|}
\hline $\begin{array}{l}\text { Encorajar a participação em atividades fora do Serviço } \\
\text { de Nutrição e Dietética (organizações profissionais, } \\
\text { eventos científicos e etc). }\end{array}$ & $\begin{array}{l}\text { Encorajar a participação em atividades dentro e fora } \\
\text { do Serviço de Nutrição e Dietética (organizações } \\
\text { profissionais, eventos científicos). }\end{array}$ & $\begin{array}{l}\text { Atividade } \\
\text { incluída }\end{array}$ \\
\hline $\begin{array}{l}\text { Providenciar assistência financeira e tempo livre para a } \\
\text { participação em programas educacionais, conforme } \\
\text { exigências do trabalho (ex.: preparar e/ou apresentar } \\
\text { palestras, jornais, informativos e etc). }\end{array}$ & & $\begin{array}{l}\text { Atividade } \\
\text { excluída }\end{array}$ \\
\hline & $\begin{array}{l}\text { Consultar bibliografia adequada em busca de } \\
\text { implicação clínica. }\end{array}$ & $\begin{array}{l}\text { Atividade } \\
\text { realocada }\end{array}$ \\
\hline $\begin{array}{l}\text { Intervenção - Desenvolvimento de protocolos de } \\
\text { cuidado }\end{array}$ & $\begin{array}{l}\text { Intervenção - Desenvolvimento de protocolos de } \\
\text { cuidado }\end{array}$ & Sem alteração \\
\hline $\begin{array}{l}\text { Definição: elaboração e uso de uma sequência } \\
\text { programada de atividades de cuidado para melhorar os } \\
\text { resultados desejados para o paciente a um custo- } \\
\text { efetivo. }\end{array}$ & $\begin{array}{l}\text { Definição: elaboração e uso de uma sequência } \\
\text { programada de atividades de cuidado para melhorar } \\
\text { os resultados desejados para o paciente a um custo- } \\
\text { efetivo. }\end{array}$ & Sem alteração \\
\hline $\begin{array}{l}\text { Revisar os padrões atuais de prática relacionados à } \\
\text { população de pacientes. }\end{array}$ & Elaborar/revisar os padrões atuais de prática & Agrupamento de \\
\hline $\begin{array}{l}\text { Revisar os protocolos de cuidados nutricionais, } \\
\text { conforme apropriado. }\end{array}$ & & \\
\hline $\begin{array}{l}\text { Elaborar/revisar impressos próprios para } 0 \\
\text { atendimento nutricional. }\end{array}$ & $\begin{array}{l}\text { Elaborar/revisar impressos próprios para } 0 \\
\text { atendimento nutricional. }\end{array}$ & Sem alteração \\
\hline $\begin{array}{l}\text { Colaborar com outros profissionais de saúde para } \\
\text { elaborar protocolos de cuidado. }\end{array}$ & $\begin{array}{l}\text { Colaborar com outros profissionais de saúde para } \\
\text { elaborar protocolos de cuidado multidisciplinar. }\end{array}$ & $\begin{array}{l}\text { Alteração no } \\
\text { texto original }\end{array}$ \\
\hline Classe Yb - Controle das informações & Classe 6.3 - Controle das informações & $\begin{array}{l}\text { Numeração da } \\
\text { classe alterada }\end{array}$ \\
\hline
\end{tabular}




\begin{tabular}{|c|c|c|}
\hline $\begin{array}{l}\text { Definição: intervenções para facilitar a comunicação } \\
\text { sobre cuidados de saúde. }\end{array}$ & $\begin{array}{l}\text { Definição: intervenções para facilitar a comunicação } \\
\text { sobre cuidados de saúde. }\end{array}$ & Sem alteração \\
\hline $\begin{array}{l}\text { Resumir os dados sobre o estado nutricional do } \\
\text { paciente pertinentes ao planejamento dos cuidados. }\end{array}$ & $\begin{array}{l}\text { Resumir os dados sobre o estado nutricional do } \\
\text { paciente pertinentes ao planejamento dos cuidados. }\end{array}$ & Sem alteração \\
\hline Identificar os diagnósticos nutricionais atuais. & Identificar os diagnósticos nutricionais. & Sem alteração \\
\hline $\begin{array}{lll}\text { Descrever as } & \text { intervenções } & \text { nutricionais } \\
\text { implementadas.. }\end{array}$ & $\begin{array}{l}\text { Descrever as intervenções } \\
\text { implementadas. }\end{array}$ & Sem alteração \\
\hline $\begin{array}{l}\text { Recomendar mudanças no plano de cuidados } \\
\text { nutricionais, conforme necessário. }\end{array}$ & $\begin{array}{l}\text { Recomendar mudanças no plano de cuidados } \\
\text { nutricionais, conforme necessário. }\end{array}$ & Sem alteração \\
\hline Intervenção - Documentação & Intervenção - Documentação & Sem alteração \\
\hline $\begin{array}{l}\text { Definição: registro de dados pertinentes do paciente } \\
\text { em prontuário clínico ou registros específicos do } \\
\text { Serviço de Nutrição e Dietética. }\end{array}$ & $\begin{array}{l}\text { Definição: registro de dados pertinentes ao paciente } \\
\text { em prontuário clínico ou formulários específicos do } \\
\text { Serviço de Nutrição e Dietética. }\end{array}$ & Alteração textual \\
\hline Atividades - Documentação & Atividades - Documentação & \\
\hline $\begin{array}{l}\text { Elaborar/alterar prescrição de nutrição que está em } \\
\text { vigor. }\end{array}$ & $\begin{array}{l}\text { Redigir ou digitar ou ticar dados relacionados ao } \\
\text { cuidado nutricional do paciente. }\end{array}$ & $\begin{array}{l}\text { Agrupamento de } \\
\text { atividades }\end{array}$ \\
\hline
\end{tabular}




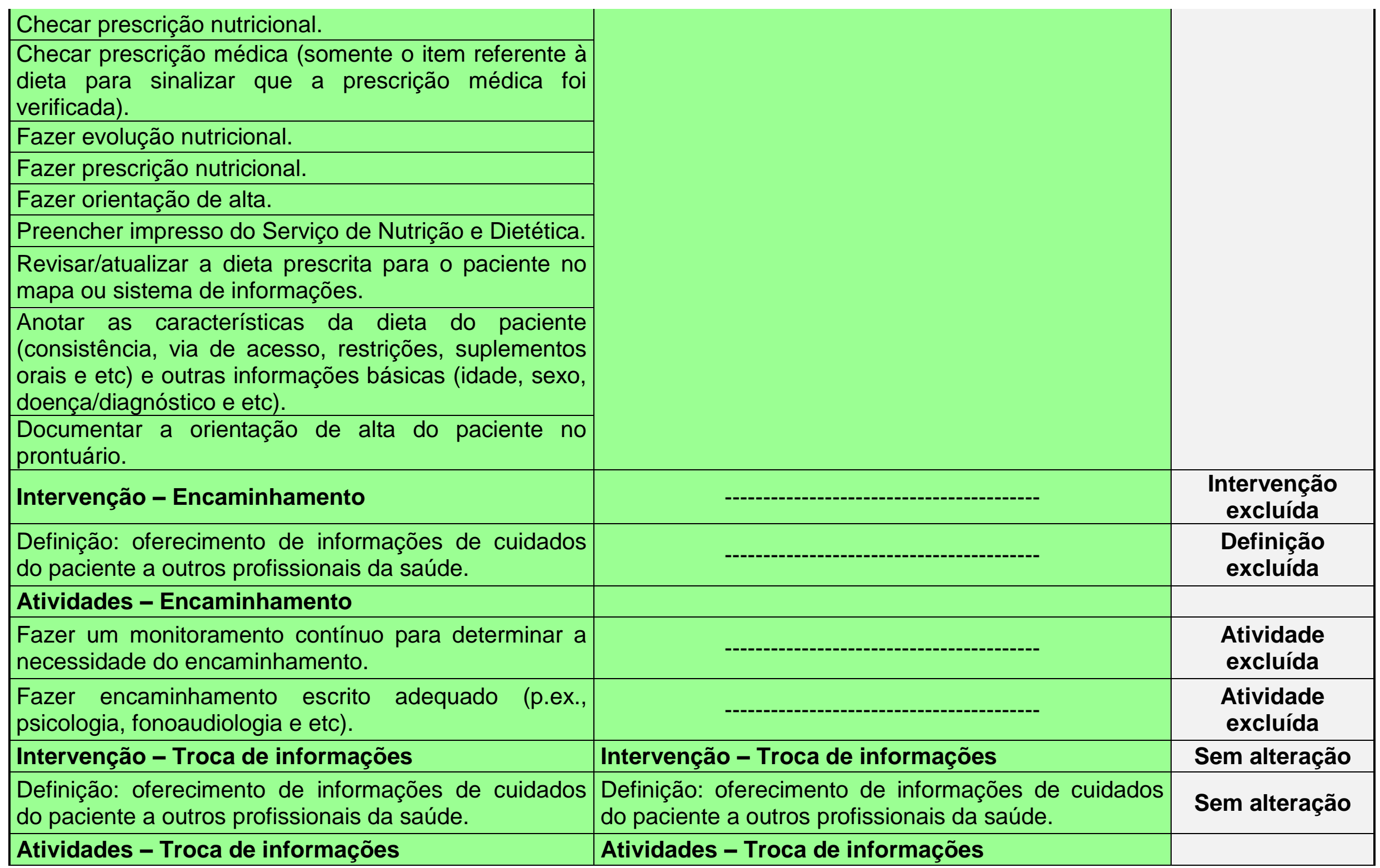




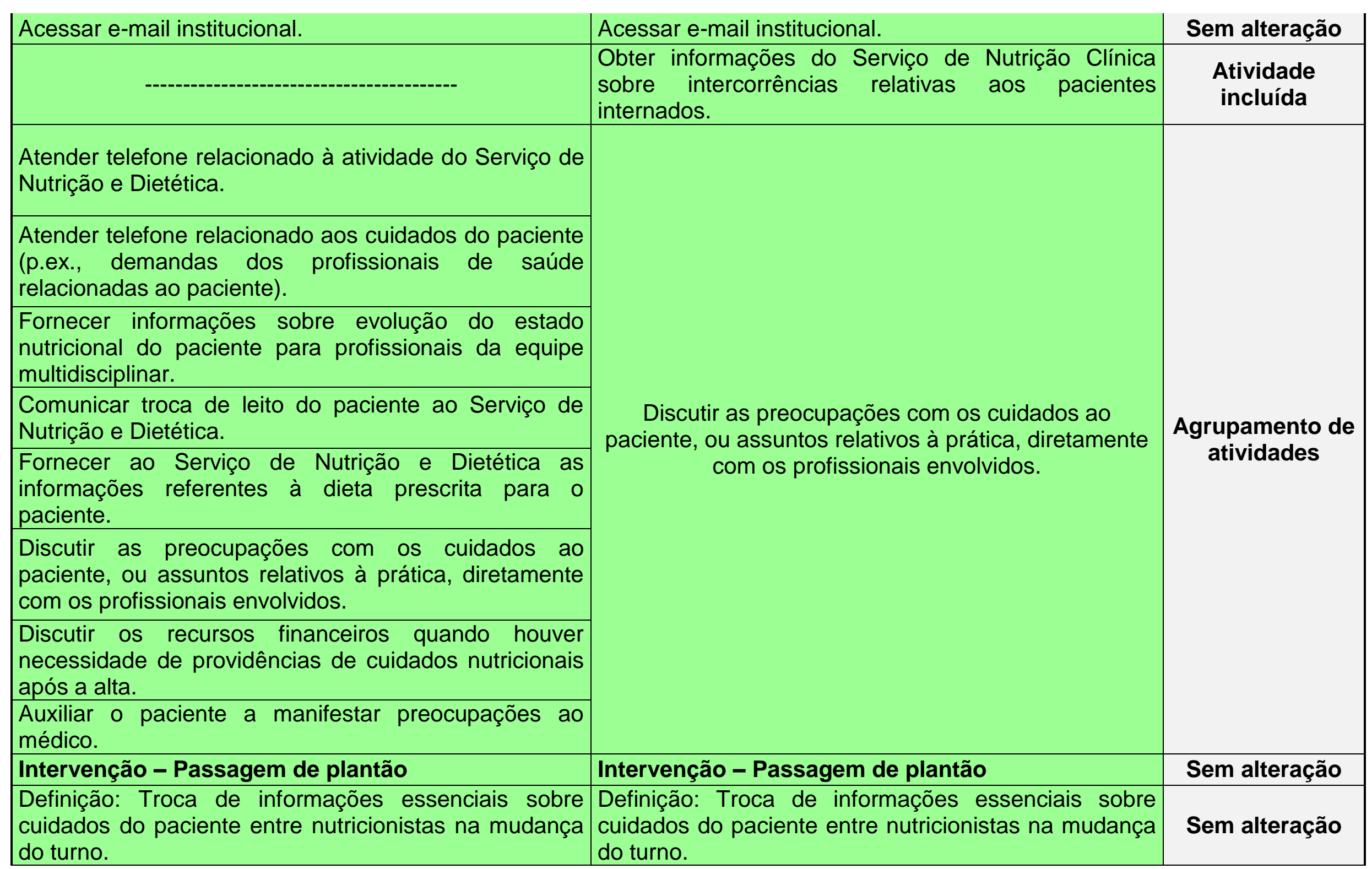




\begin{tabular}{|c|c|c|}
\hline Atividade - Passagem de plantão & Atividade - Passagem de plantão & \\
\hline Passar plantão para o nutricionista. & Passar plantão para o nutricionista. & Sem alteração \\
\hline Acessar computador & \multirow{2}{*}{$\begin{array}{l}\text { Acessar computador ou dispositivos móveis para uso } \\
\text { pessoal }\end{array}$} & \multirow{2}{*}{$\begin{array}{l}\text { Agrupamento de } \\
\text { atividades }\end{array}$} \\
\hline Checar caixa de e-mail pessoal & & \\
\hline Guardar refeição na geladeira & Retirar ou guardar objetos de uso pessoal & $\begin{array}{c}\text { Alteração na } \\
\text { descrição da } \\
\text { atividade }\end{array}$ \\
\hline Hidratar-se & Hidratar-se & Sem alteração \\
\hline Ler & Ler & Sem alteração \\
\hline Descansar & Descansar & Sem alteração \\
\hline Socializar com acompanhantes & 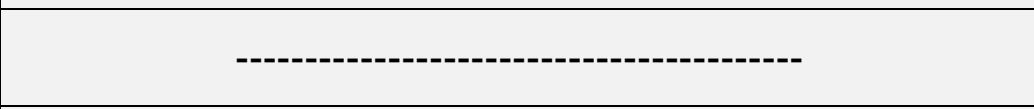 & $\begin{array}{l}\text { Atividade } \\
\text { realocada }\end{array}$ \\
\hline Alimentar-se & Alimentar-se & Sem alteração \\
\hline Tomar medicamentos & 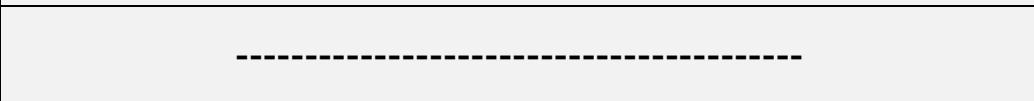 & $\begin{array}{l}\text { Atividade } \\
\text { excluída }\end{array}$ \\
\hline Atividades associadas & Atividades associadas & \\
\hline $\begin{array}{l}\text { Cadastrar acompanhante do paciente no sistema de } \\
\text { pacientes }\end{array}$ & Cadastrar acompanhante do paciente no sistema & $\begin{array}{c}\text { Alteração na } \\
\text { descrição da } \\
\text { atividade }\end{array}$ \\
\hline Procurar kardex/mapa & 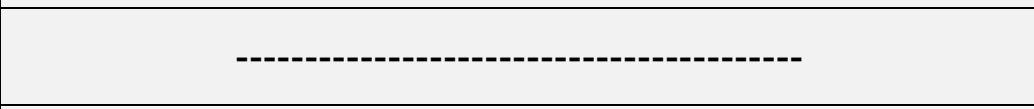 & $\begin{array}{l}\text { Atividade } \\
\text { excluída }\end{array}$ \\
\hline $\begin{array}{l}\text { Revisar as etiquetas de identificação da refeição do } \\
\text { paciente }\end{array}$ & $\begin{array}{l}\text { Revisar as etiquetas de identificação da refeição do } \\
\text { paciente }\end{array}$ & Sem alteração \\
\hline
\end{tabular}




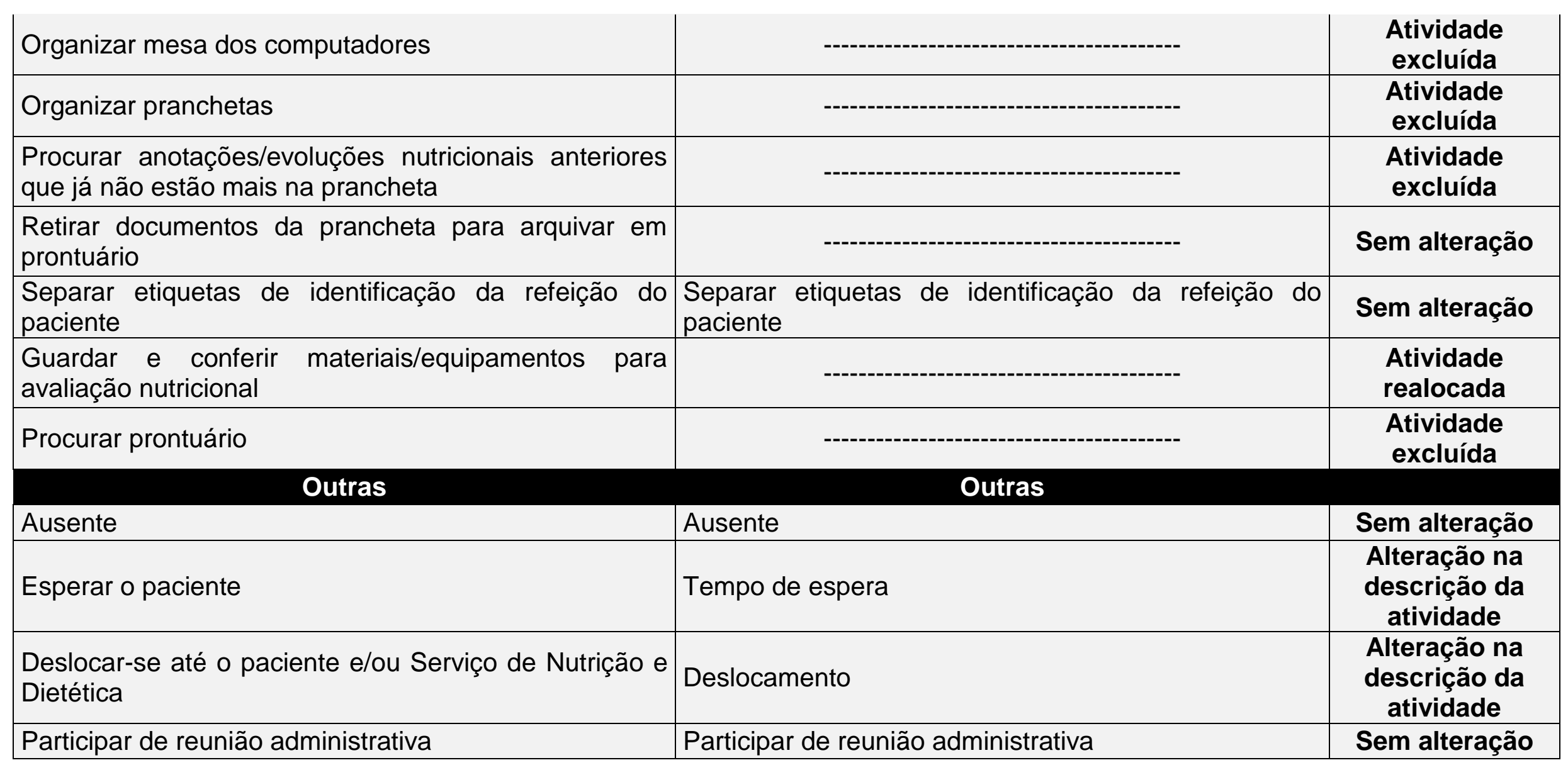

Fonte: arquivos da pesquisadora. São Paulo, 2016 


\section{APÊNDICE H - INSTRUÇÃO PARA O USO DO CRONÔMETRO}

O aplicativo cronômetro é composto por dois relógios. Para iniciar a mensuração do tempo, o usuário deve acionar o botão verde, no lado esquerdo da tela (Figura 6).

Figura 6 - Tela inicial do aplicativo cronômetro

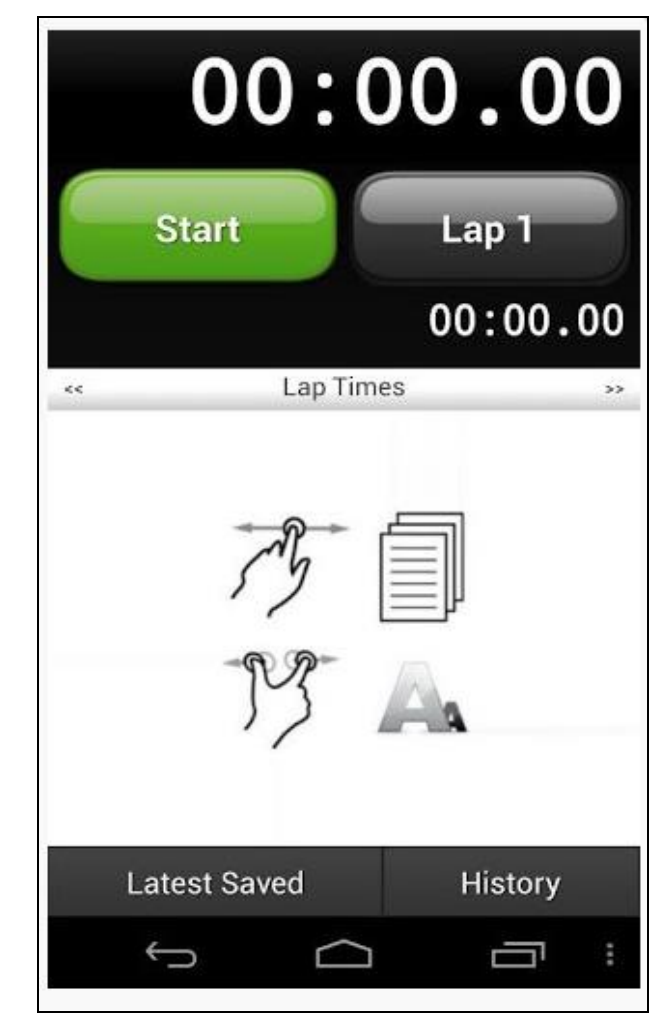

Fonte: Stopwatch Pro ${ }^{\circledR}$. São Paulo, 2016

A interface simples e objetiva do cronômetro mostra o progresso do tempo despendido em cada intervenção ou atividade executada, segundo a ordem em que elas acontecem. O botão "lap", que significa volta, é usado para finalizar uma intervenção/atividade e iniciar outra. Portanto, enquanto o primeiro relógio (em tamanho maior) mostra o tempo total mensurado, o segundo relógio (em tamanho menor) exibe a duração da intervenção atual (Figura 7). 
Figura 7 - Processo de Mensuração do tempo

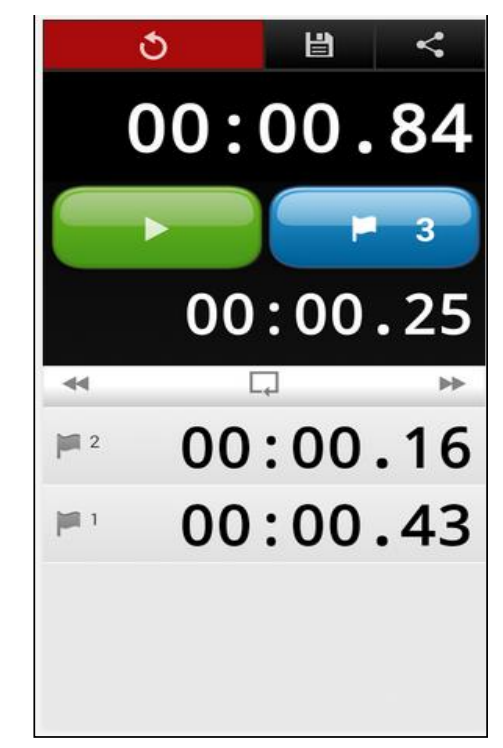

Fonte: Stopwatch Pro ${ }^{\circledR}$. São Paulo, 2016

Cada vez que uma intervenção/atividade era iniciada, o botão azul, no lado direito da tela, era acionado e o observador anotava, na folha de registro, o código referente à intervenção ou atividade verificada. Desta forma, foi possível registrar o tempo de duração de cada intervenção/atividade, no momento em que ela ocorria. 
Na Figura 8 é demonstrado um exemplo do processo de preenchimento dos dados. Com o cronômetro ao lado da folha de registro e apoiado na prancheta, o observador inicia a mensuração do tempo. Assim, é possível garantir o preenchimento dos campos "paciente", "leito" e "intervenção" (destacados em vermelho), no instante da leitura do cronômetro.

Figura 8 - Processo de anotação da folha de registro (frente)
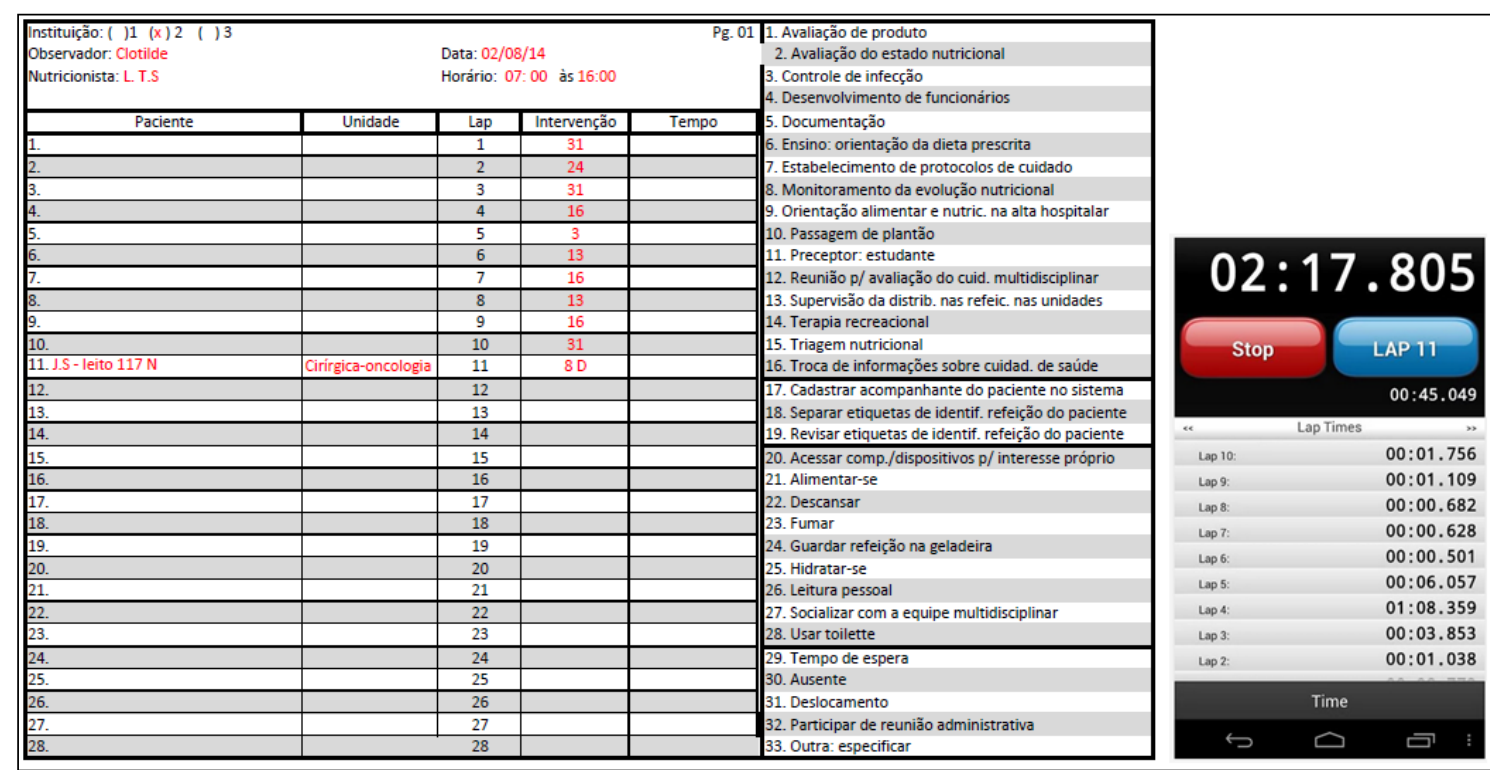

Fonte: Arquivo da pesquisadora e Stopwatch Pro ${ }^{\circledR}$. São Paulo, 2016

Os dados referentes ao tempo requerido para a realização de cada intervenção ou atividade, lido e armazenado no cronômetro segundo a ordem em que foram observados, eram exportados para o e-mail e anotados na folha de registro. 
O processo de transmissão de dados, com todos os tempos dispostos na sequência em que foram observados, foi obtido ao final da jornada de trabalho, quando o cronômetro era paralisado (Figura 9). O histórico além de ser gravado no aplicativo, era enviado para o e-mail, impresso e depois anotado na folha de registro.

Figura 9 - Processo de transmissão dos dados

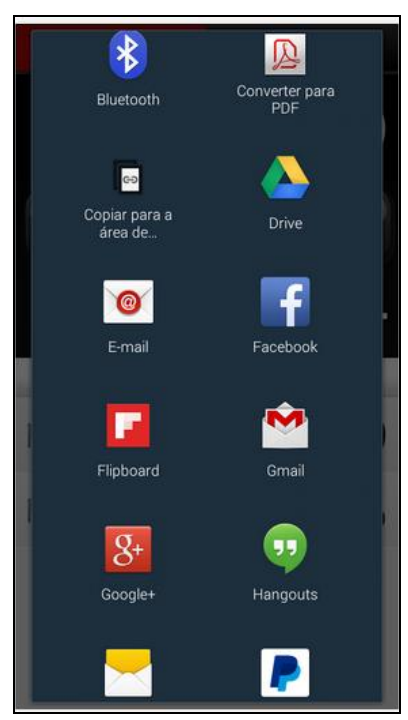

Fonte: Stopwatch Pro ${ }^{\circledR}$. 
A Figura 10 apresenta dados complementares do processo de anotação, no verso da folha de registro. As informações presentes no verso eram disponibilizadas pelo nutricionista ao final da jornada de trabalho.

Figura 10 - Processo de anotação da folha de registro (verso)

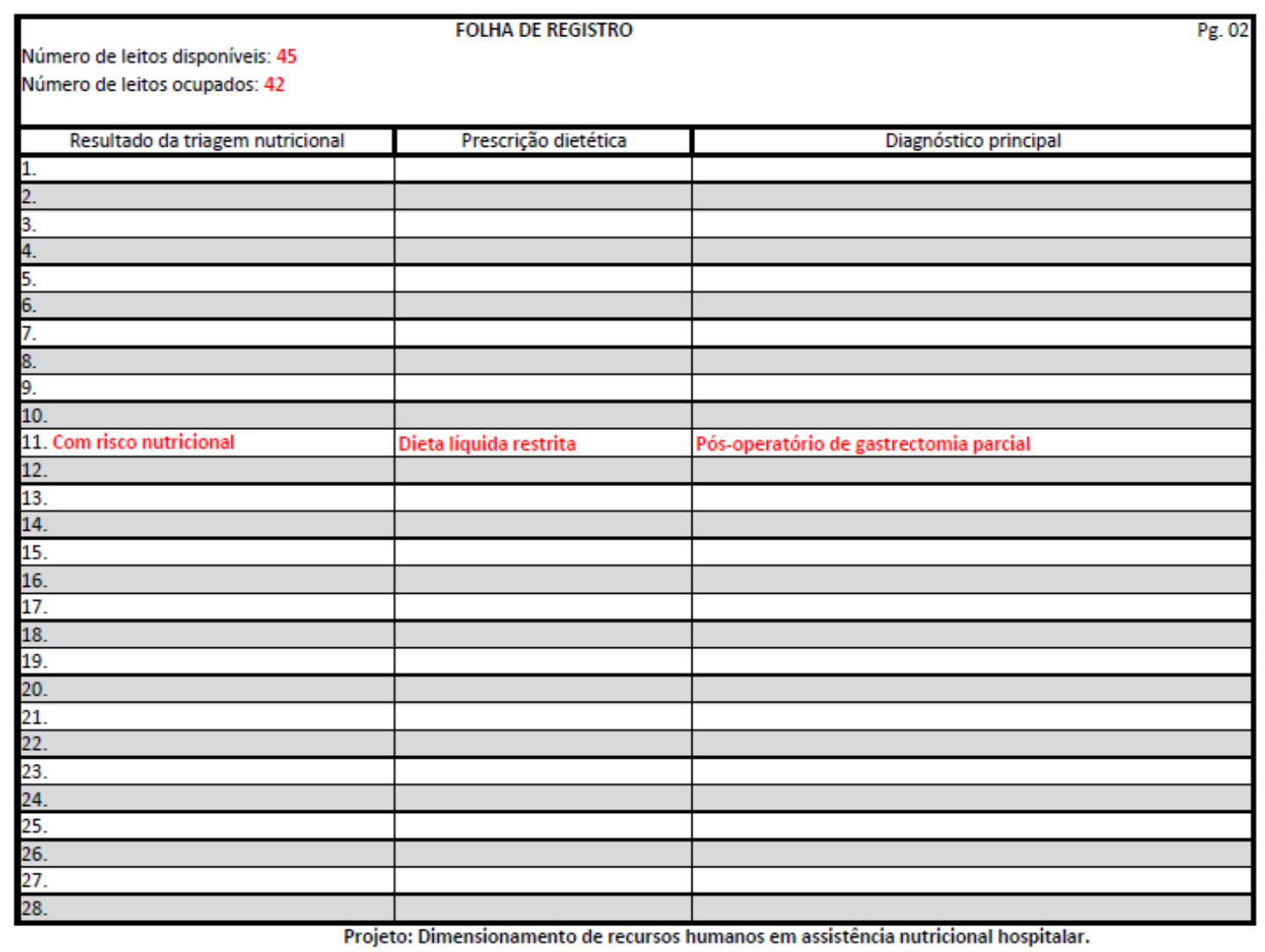

Fonte: Arquivo da pesquisadora. São Paulo 


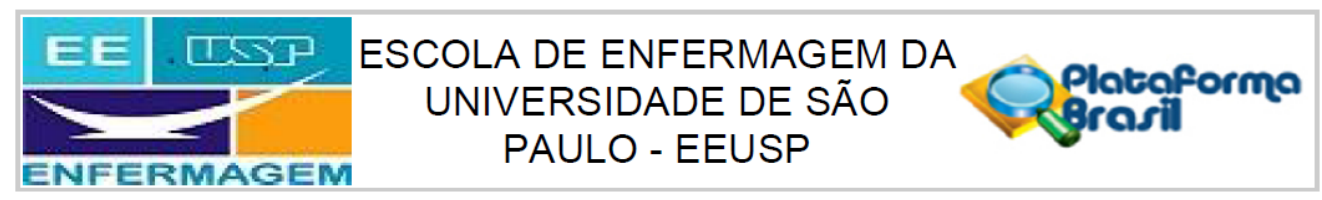

\section{PARECER CONSUBSTANCIADO DO CEP}

\section{DADOS DO PROJETO DE PESQUISA}

Título da Pesquisa: DIMENSIONAMENTO DE RECURSOS HUMANOS EM ASSISTÊNCIA NUTRICIONAL HOSPITALAR

Pesquisador: Raquel Rapone Gaidzinski

Área Temática:

Versão: 1

CAAE: 26889914.9 .0000 .5392

Instituição Proponente: Escola de Enfermagem da Universidade de São Paulo - EEUSP

Patrocinador Principal: Financiamento Próprio

\section{DADOS DO PARECER}

Número do Parecer: 561.818

Data da Relatoria: $18 / 03 / 2014$

\section{Apresentação do Projeto:}

Trata-se de um estudo de desenvolvimento metodológico com foco na elaboração de parâmetros para o dimensionamento de pessoal de Nutrição Clínica no âmbito hospitalar.Para mensurar a distribuição do tempo despendido pelas profissionais será utilizada a técnica de amostragem do trabalho, proposta por LoBiondo-Wood e Haber. Esta técnica consiste em fazer observações intermitentes, em um período consideravelmente maior do que em geral utilizado no estudo de cronometragem. As atividades realizadas pelos profissionais de nutrição serão observadas e registradas, periodicamente, em intervalos de 10 minutos. Os dias de observação escolhidos serão aqueles que representarem o cotidiano do trabalho nas instituições;As atividades realizadas pelos profissionais de nutrição clínica serão observadas e registradas, periodicamente, em intervalos de 10 minutos, em cada unidade, por turno (matutino e vespertino), dos hospitais selecionados.

O campo escolhido será constituído de três hospitais públicos, considerados de boas práticas de nutrição, em todos os turnos de funcionamento, localizados na cidade de São Paulo. O critério de escolha será baseado no papel que a organização representa no conjunto do sistema de saúde, não só no estado de São Paulo como também no âmbito nacional, na tradição em prestação de assistência de alta qualidade, no desenvolvimento de atividades de ensino e pesquisa e como referência de tecnologia de alta complexidade no sistema de saúde brasileiro e emitir termo de

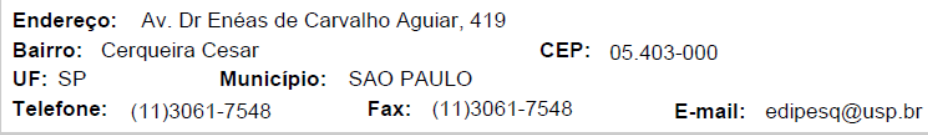

\section{ANEXO 1 - PARECER DO CÔMITE DE ÉTICA EM PESQUISA}




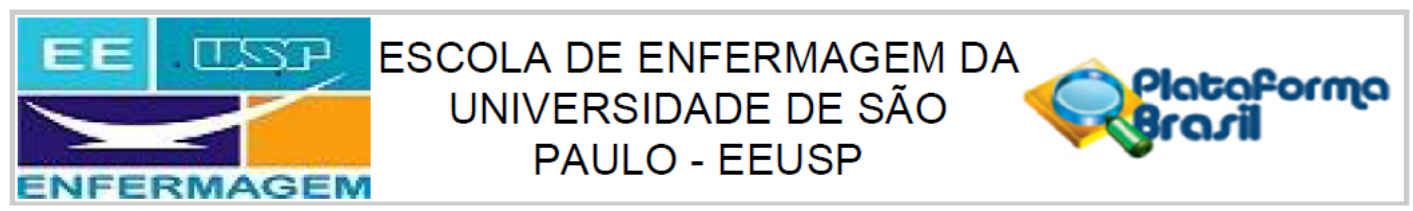

Continuação do Parecer: 561.818

anuência para participação no estudo.

À partir do conhecimento da carga média de trabalho será possível dimensionar o quadro de pessoal de Nutrição Clínica adequado para atender as unidades de internação hospitalares.

Este estudo será realizado em três instituições e a amostra será de 15 indivíduos observados em cada hospital.

Serão utilizados juízes que irão avaliar as atividades que serão observadas ou descritas na literatura e classificadas em atividades/intervenções de nutrição clínica, conforme os Indicadores de Qualidade do Cuidado Nutricional proposto por Díez-Garcia et al.

Para a coleta de dados serão utilizados dados primários e secundários, organizados conforme as etapas:

1 primeira etapa: identificação das atividades desenvolvidas pelos nutricionistas assistenciais (revisão de literatura)

2 Segunda etapa: classificação das atividades desenvolvidas pelos nutricionistas assistenciais segundo os Indicadores de Qualidade do Cuidado Nutricional, propostos por Diez-Garcia et al57;

3 Terceira etapa: validação das atividades desenvolvidas pelos nutricionistas assistenciais. $O$ processo de validação do conteúdo do instrumento será realizado por meio de oficina, tendo como base os seguintes critérios para seleção dos juízes: ser nutricionista, possuir experiência e conhecimento na área de Nutrição Clínica Hospitalar de no mínimo quatro anos e consentir em participar da oficina, por meio da assinatura do Termo de Consentimento Livre e Esclarecido.

4 Quarta etapa: construção do instrumento para medida da distribuição da carga de trabalho dos nutricionistas assistenciais.

5 Quinta etapa: teste piloto do instrumento de medida da distribuição do tempo dos desenvolvidas pelos nutricionistas assistenciais. $O$ instrumento construído será aplicado, inicialmente, em um teste piloto, durante a sua jornada de trabalho, durante uma semana, em cada tipo unidade estudada, em um hospital a ser selecionado para este fim, com o objetivo de verificar se as

Endereço: Av. Dr Enéas de Carvalho Aguiar, 419

Bairro: Cerqueira Cesar

UF: SP Município: SAO PAULO

Telefone: (11)3061-7548 Fax: (11)3061-7548 E-mail: edipesq@usp.br 


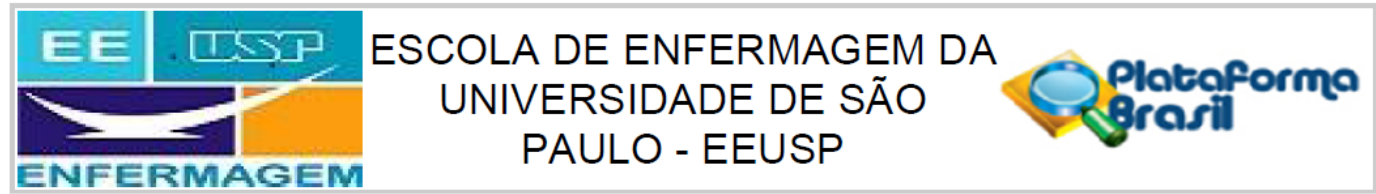

Continuação do Parecer: 561.818

atividades elencadas refletem o trabalho das nutricionistas e possibilitam mensurar o tempo despendido na sua realização. As atividades realizadas pelos profissionais de nutrição serão observadas e registradas, periodicamente, em intervalos de 10 minutos; os dias de observação escolhidos serão aqueles que representarem o cotidiano do trabalho nas instituições; e a distribuição quantitativa de pacientes por nutricionista seguirá a classificação do nível de assistência estabelecido pelo CFN na Resolução $\mathrm{n}^{\circ}$ $380 / 2005$.

6 Sexta etapa: mensuração do tempo despendido nas intervenções/atividades desenvolvidas pelos nutricionistas assistenciais. Após o teste piloto, o instrumento será aplicado para mensurar a distribuição tempo despendido pelos profissionais de nutrição clínica em atividades diretas, indiretas e atividades associadas e pessoais pela técnica de amostragem do trabalho.

7 Sétima etapa: obtenção de informações junto aos Serviços de Nutrição e Dietética que caracterizem as Instituições e as unidades;

8 Oitava etapa: identificação dos parâmetros para o cálculo de nutricionistas assistenciais.

\section{Objetivo da Pesquisa:}

Esta pesquisa tem como objetivo propor parâmetros para o dimensionamento de pessoal de nutrição clínica no âmbito hospitalar e comparar os resultados encontrados, referentes ao dimensionamento de nutricionistas assistenciais, com o preconizado pela Resolução Conselho Federal de Nutricionistas (CFN) $n^{\circ}$ 380/20054.

Avaliação dos Riscos e Benefícios:

Riscos:

O estudo não apresenta riscos aos participantes.

Benefícios:

Instrumentalizar gerentes para a contratação de número adequado de trabalhadores.

Comentários e Considerações sobre a Pesquisa:

O trabalho Dimensionamento de Recursos Humanos em Assistência Nutricional Hospitalar, que tem como objetivo geral, propor parâmetros para o dimensionamento de pessoal de nutrição clínica no âmbito hospitalar, é relevante para a área de nutrição e dietética, visto que são escassos os estudos referentes ao dimensionamento de pessoal nesta área.

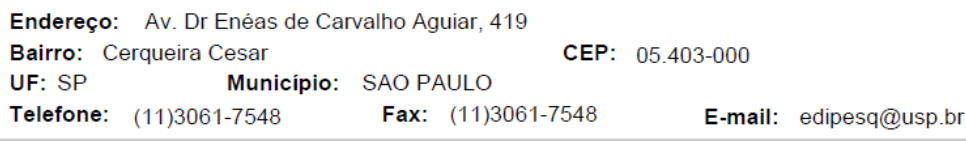




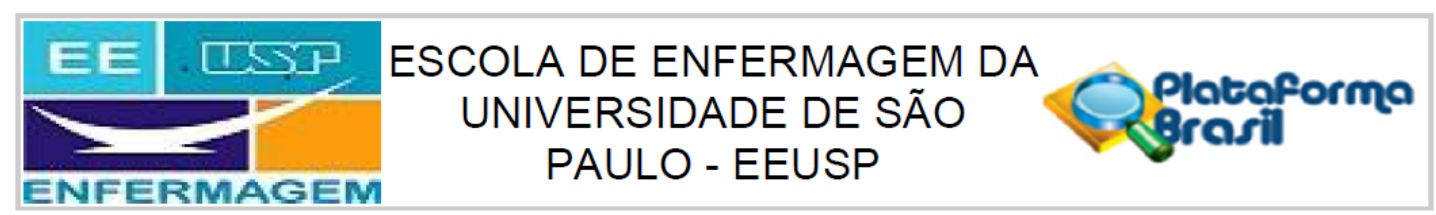

Continuação do Parecer: 561.818

Considerações sobre os Termos de apresentação obrigatória:

TCLE 1 : se aplica ao sujeito da pesquisa está de acordo com o estabelecido.

TCLE 2 : será aplicado aos juízes do estudo. Inserir o tempo estimado da oficina.

Os Instrumentos que serão realizados para a obtenção dos dados das instituições participantes e tb o instrumento referente a caracterização dos participantes estão em conformidade.

A Carta que será enviada aos juízes para orientar a avaliação das atividades na oficina de validação, apresenta linguagem clara e está bem objetiva.

\section{Recomendações:}

Inserir o tempo estimado da oficina no TCLE dos juízes. O TCLE aos juízes não constitui apresentação obrigatória. O tempo estimado pode ser informado na carta convite.

Conclusões ou Pendências e Lista de Inadequações:

O estudo não apresenta óbices éticos.

Situação do Parecer:

Aprovado

Necessita Apreciação da CONEP:

Não

Considerações Finais a critério do CEP:

A aprovação do Comitê de Ética em Pesquisa da EEUSP não substitui a autorização da instituição coparceira para o início da pesquisa.

Reitera-se a necessidade de registro dos relatórios, parcial e final, na Plataforma Brasil.

SAO PAULO, 19 de Março de 2014

Assinador por:

Ruth Natalia Teresa Turrini

(Coordenador)

Endereço: Av. Dr Enéas de Carvalho Aguiar, 419

Bairro: Cerqueira Cesar CEP: $05.403-000$

UF: SP Município: SAO PAULO

Telefone: (11)3061-7548 Fax: (11)3061-7548 E-mail: edipesq@usp.br 


\begin{tabular}{|c|c|c|}
\hline$\equiv \equiv$ & ISSP & $\begin{array}{c}\text { ESCOLA DE ENFERMAGEM DA } \\
\text { UNIVERSIDADE DE SÃO } \\
\text { PAULO - EEUSP }\end{array}$ \\
\hline
\end{tabular}

Continuação do Parecer: 561.818

Endereço: Av. Dr Enéas de Carvalho Aguiar, 419 